\title{
Formal and informal patient payments for public health care services in Bulgaria
}

Citation for published version (APA):

Atanasova, E. (2014). Formal and informal patient payments for public health care services in Bulgaria. [Doctoral Thesis, Maastricht University]. Maastricht University. https://doi.org/10.26481/dis.20140904ea

Document status and date:

Published: 01/01/2014

DOI:

10.26481/dis.20140904ea

Document Version:

Publisher's PDF, also known as Version of record

\section{Please check the document version of this publication:}

- A submitted manuscript is the version of the article upon submission and before peer-review. There can be important differences between the submitted version and the official published version of record.

People interested in the research are advised to contact the author for the final version of the publication, or visit the DOI to the publisher's website.

- The final author version and the galley proof are versions of the publication after peer review.

- The final published version features the final layout of the paper including the volume, issue and page numbers.

Link to publication

\footnotetext{
General rights rights.

- You may freely distribute the URL identifying the publication in the public portal. please follow below link for the End User Agreement:

www.umlib.nl/taverne-license

Take down policy

If you believe that this document breaches copyright please contact us at:

repository@maastrichtuniversity.nl

providing details and we will investigate your claim.
}

Copyright and moral rights for the publications made accessible in the public portal are retained by the authors and/or other copyright owners and it is a condition of accessing publications that users recognise and abide by the legal requirements associated with these

- Users may download and print one copy of any publication from the public portal for the purpose of private study or research.

- You may not further distribute the material or use it for any profit-making activity or commercial gain

If the publication is distributed under the terms of Article $25 \mathrm{fa}$ of the Dutch Copyright Act, indicated by the "Taverne" license above, 


\section{FORMAL AND INFORMAL PATIENT PAYMENTS FOR PUBLIC HEALTH CARE SERVICES IN BULGARIA}

Elka Atanasova 
Formal and informal patient payments for public health care services in Bulgaria

(C) Elka Atanasova, 2014

All rights reserved. No part of this publication may be reproduced, stored in a retrieval system, or transmitted in any form or by any means, electronic, mechanical, photocopying, recording or otherwise, without written permission from the author.

ISBN: 978-90-821059-2-6

Printed by STENO Publishing House - Varna, Bulgaria 


\title{
FORMAL AND INFORMAL PATIENT PAYMENTS FOR PUBLIC HEALTH CARE SERVICES IN BULGARIA
}

\author{
Dissertation \\ to obtain the degree of Doctor at Maastricht University, \\ on the authority of the Rector Magnificus, Prof. dr. L. L. G. Soete \\ in accordance with the decision of the Board of the Deans, \\ to be defended in public \\ on Thursday 4 September 2014, at 10.00 hours
}

by

Elka Atanasova 
Supervisor:

Prof. Dr. W. Groot

Co-supervisors:

Dr. M. Pavlova

Dr. E. Moutafova (Medical University - Varna, Bulgaria)

Assessment Committee:

Prof. Dr. H. Maassen van den Brink (chair)

Prof. Dr. H. Brand

Dr. A. Kerekovska (Medical University - Varna, Bulgaria)

Prof. Dr. S. Koeva (Medical University - Varna, Bulgaria)

Prof. Dr. J.A.M. Maarse

Acknowledgement of funding:

The study is financed by the European Commission under the 7th Framework Program, Theme 8 Socio-economic Sciences and Humanities, Project ASSPRO CEE 2007 (Grant Agreement no. 217431). The views expressed in this dissertation are the sole responsibility of the authors and do not necessarily reflect the views of the European Commission or its services. 


\section{CONTENTS}

\section{Chapter 1}

GENERAL INTRODUCTION $\ldots \ldots \ldots \ldots \ldots \ldots \ldots \ldots \ldots \ldots \ldots$

\section{Chapter 2}

WHAT HAVE 10 YEARS OF HEALTH INSURANCE REFORMS

BROUGHT ABOUT IN BULGARIA? RE-APPRAISING THE HEALTH

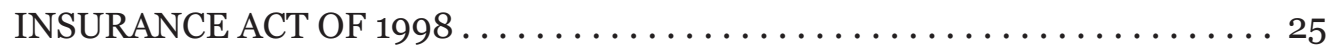

\section{Chapter 3}

OUT-OF-POCKET PAYMENTS FOR HEALTH CARE SERVICES IN

BULGARIA: FINANCIAL BURDEN AND BARRIER TO ACCESS .41

\section{Chapter 4}

INFORMAL PAYMENTS FOR HEALTH CARE SERVICES:

THE EXPERIENCE OF BULGARIA AFTER 10 YEARS OF

FORMAL CO-PAYMENTS. . . . . . . . . . . . . . . . . . . 57

\section{Chapter 5}

PATIENT CHARGES FOR HEALTH CARE SERVICES: THE OPINIONS

OF HEALTH CARE STAKEHOLDERS IN BULGARIA $\ldots \ldots \ldots \ldots \ldots \ldots \ldots 71$

\section{Chapter 6}

MODELING OUT-OF-POCKET PATIENT PAYMENTS AND

WILLINGNESS TO PAY FOR PHYSICIAN AND HOSPITAL SERVICES:

AN APPLICATION FOR BULGARIA $\ldots \ldots \ldots \ldots \ldots \ldots \ldots \ldots \ldots \ldots$

\section{Chapter 7}

GENERAL DISCUSSION, CONCLUDING REMARKS

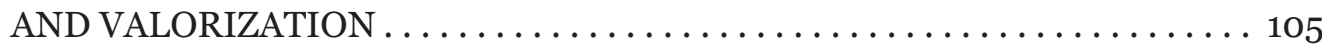

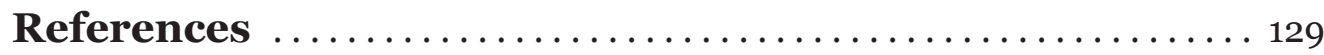

\section{Appendix A}

DESCRIPTION OF THE QUANTITATIVE DATA COLLECTION ........ 143

\section{Appendix B}

ENGLISH WORDING OF THE SURVEY QUESTIONNAIRE

\section{Appendix C}




\section{Appendix D}

ENGLISH WORDING OF THE STAKEHOLDER QUESTIONNAIRE. . . . . . 159

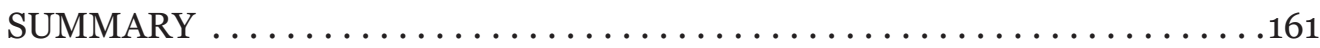

THANK YOU WORDS $\ldots \ldots \ldots \ldots \ldots \ldots \ldots \ldots \ldots \ldots \ldots \ldots \ldots \ldots \ldots \ldots$

CURRICULUM VITAE $\ldots \ldots \ldots \ldots \ldots \ldots \ldots \ldots \ldots \ldots \ldots \ldots \ldots \ldots$

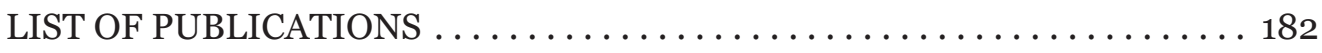


Chapter 1 GENERAL INTRODUCTION 


\subsection{The scope and motivation of the dissertation}

During the past two decades of transition from a state-planned to market economy, the Bulgarian health care sector experienced radical reforms. In particular, the development of a private health care sector was accompanied by the introduction of social health insurance in 2000, which brought about important changes in the organization and funding of the Bulgarian health care system (Pavlova et al., 2000; Dimova et al., 2007; Vekov, 2009). Among other issues, the reform included the introduction of formal patient charges for public health care services. These charges take the form of co-payments and apply to all levels of medical services, except for emergency care. The formal co-payment are collected and retained by the providers and their official objective is to improve the efficiency of public health care provision (Ministry of Health, 1998). However, these charges were implemented in a situation of informal patient payments, which have continued to exist irrespective of the formal charges (OSI, 2008). The question is whether Bulgaria patients are able to cope with the double payments for health care. The dissertation at hand addresses this social and policy issue by focusing on the financial burden of formal and informal patient payments in the Bulgarian public health care sector.

The study in this dissertation originates from the observation that many patients in Bulgaria struggle to meet the formal and informal payments for health care, but the study is also inspired by previous research on out-of-pocket patient payments in Bulgaria (Delcheva, 1999; Pavlova et al., 2002, Balabanova \& McKee, 2004) conducted before and after the introduction of social health insurance (and the introduction of formal co-payments related to it). However, previous research appears limited in scope since it primarily analyses different aspects of informal payments in Bulgaria (Delcheva et al., 1997, Balabanova \& McKee M, 2002a). Only few studies have examined the potential of formal co-payments and their acceptability to the population (Pavlova et al., 2003; Pavlova et al., 2004). None of these previous studies however, has addressed the co-existence of formal and informal patient payments. Thus, in contrast to previous research, this dissertation offers an integrated analysis of both formal and informal patient payments, as well as of the attitudes of health care stakeholders towards these payments. Besides, the dissertation provides up-to-date evidence on out-of-pocket health care expenditure in Bulgaria, which allows making a comparison with earlier studies and outlining overall trends in formal and informal patient payments in Bulgaria.

The dissertation also focuses on the stated willingness to pay for public health care services (as an indicator of public acceptance of formal co-payments for health care service) and on its comparison to actual out-of-pocket payments. The latter problem 
has not been addressed in previous studies in Bulgaria, and has received little attention in international research on patient payment policies (Danyliv, 2014). One of the reasons for this is the specific character of the stated willingness-to-pay techniques, socalledstated-preferencemethods.Althoughstated-preferencemethods are broadly applied within the framework of cost-benefit analysis, they are relatively new compared to revealed-preference methods, i.e. actual payment behavior. The predictive validity of stated-preference methods is still uncertain (Danyliv, 2014). This diminishes their application in policy analysis. The comparison of statedpreference data with revealed-preference data offered in this dissertation is expected to contribute to our knowledge on the validity of stated-preference methods.

\subsection{Brief overview of the financial health care reform in Bulgaria}

The social and economic reform began in Bulgaria when the new Constitution was adopted in 1991. The period up to 1989 marked the development of the Bulgarian health care system within an environment of centralized management and financing based entirely on general taxes. Medical services were provided by the state or municipality public health care establishments (private medical practice was prohibited before 1989). These establishments were allocated an earmarked budget, the size of which was mainly determined on a historical basis. The key factors that were considered in allocating funds were the number of staff and beds. Large staff and a high number of beds were rewarded, and a high level of patient admissions and long hospital stays were common. The reimbursement of health care professionals was in the form of a salary based on employment contracts.

With the political changes in 1989, many elements of the Bulgarian health care model were discredited. A number of problems with the health and demographic status of the population became visible. The failure to cope with the inefficiencies in the health care sector, as well as the poor management and suboptimal use of health care system resources, gradually became more evident. The reform of the health care system was put on the government agenda, aiming to restructure health care financing, strengthening primary care and rationalizing the network of outpatient and inpatient facilities. The preparation for the introduction of the health insurance system was accompanied by the adoption of legislative acts that formed the basis for the health care reforms. The Act on Medicines and Pharmacies in Human Medicine was adopted in 1995 and outlined the terms and procedures for the licensing and control of the manufacturing, clinical trial testing, wholesale and retailing of drugs intended for use in human medicine in Bulgaria. In 1998, the Act on Professional Organizations was adopted, which defined the legal status and rights of physician 
and dentist organizations. The professional organizations became responsible for the licensing of physicians and dentists, managing continuing education and representing health professionals during the negotiations with the National Health Insurance Fund (NHIF). The Health Care Establishments Act was adopted in 1999, which regulated the organization of medical (outpatient and inpatient) and dental care. The existing public and private health care establishments were reorganized according to this act. Health care providers became autonomous organizations registered as trade companies or corporations. Their governing bodies are regulated by the Trade Law or Corporations Law and depend on their legal status. In some cases, ownership of the capital was acquired by the state and the rights were exercised by the Minister of Health. In other cases, capital was acquired by a given municipality and the rights were exercised by its municipal council.

The discussion on the need to restructure the centralized tax-based health care system into a social health insurance system started in the 1990's and was conducted parallel with the transformation of the country's economy from a centrally planned economy to a market-based economy (Dimova et al., 2012a). However, the health care system was transformed into a social health insurance system only in 2000 after the Bulgarian Parliament adopted the Health Insurance Act of 1998 (Pavlova et al, 2000). The reform introduced market principles, decentralization, as well as pluralism in the ownership of the health institutions and the provision of health care services.

In order to fully understand the latest trends in the performance of the health care system and the financial health care reform, its structure and participants are briefly outlined. The regulatory changes created three major players in the system: (1) patients as consumers, (2) outpatient and hospital establishments as providers, and (3) public and private health insurance organizations as third-party payers. The Act of 1998 established the NHIF and defined the relationship between the NHIF, health care consumers and providers. In addition to the NHIF, the other main government institutions which regulate the performance of the health care system at present are the National Assembly, the Ministry of Health, and the Supreme Medical Council. The National Assembly has an important role in the development of national health policy. The reforms in the early 2000's included the establishment of a Parliamentary Commission on Health. This Committee possesses legislative authority and reviews pressing health-related issues. The Ministry of Health develops and implements comprehensive national health policy. The Minister of Health is the primary administrator of the health care budget and has competences in managing the national health care system. The Minister presents the annual National Health Report as well as the report on the implementation of the National 
Health Strategy to the National Assembly. The NHIF is the only compulsory health insurance fund in the Bulgarian public health care sector. Its budget is determined each year by the National Assembly. The Supreme Medical Council is an advisory body to the Ministry of Health. It gives advice on the national health strategy, drafts budgets as well as the annual report of the Minister.

The relationships between the NHIF and health care providers are based on the National Framework Contract. Based on this contract model, providers sign individual contracts with the district branches of the NHIF, namely the 28 Regional Health Insurance Funds (RHIF). The NHIF interacts with all kinds of providers. The general practitioner (GP) is the central figure in primary care who acts as a gatekeeper for specialized ambulatory and hospital care. Ambulatory care is provided by specialized outpatient facilities, including individual and group practices, medical and medico-dental centers, diagnostic-consultative centers and medico-technical laboratories. Hospital care is provided by public and private health establishments divided into multi-profile and specialized hospitals.

Bulgaria currently has a mixed system of health care financing. Health care is financed from compulsory and voluntary health insurance contributions, taxes, out-of-pocket payments, donations and external funding. The revenue from the general taxation decreased gradually as the compulsory health insurance revenue increased from 1999 to 2003 (Georgieva et al., 2007). However, the diminishing state role in the financing of the health care system led to a significant increase in out-of-pocket payments, which became the predominant revenue source in 2000 (Dimova et al., 2012a). This trend has continued and at present the main source of revenue for the health care system is out-of-pocket payments. The second largest source of revenue is the social health insurance contributions which constitute $8 \%$ of the individual monthly income. These contributions are shared between the employee and employer at a ratio of 40:60, or are paid individually by the self-employed or unemployed. The third main source of revenue is the general taxation allocated to the Ministry of Health budget from the central budget. The municipalities also receive revenues from the state budget. In addition to this transfer, the municipalities can use local tax revenues to finance health activities.

\subsection{Trends in health care expenditure in Bulgaria}

Broadly speaking, the overall development of the health care expenditure in Bulgaria can be divided into two periods. In the first period, 1990-1998, the data for health care expenditure as a percentage of Gross Domestic Product (GDP) were 
provided by national sources only. This period was preparatory for the adoption and implementation of the social health insurance system. In the second period, since 1999, the trends in health care expenditure in Bulgaria have been provided by the World Health Organization (WHO) based on national data. Previous studies have already underlined the implications of the differences between these two types of sources (Bulgarian Academy of Sciences, 2013; Delcheva, 2011). Delcheva (2011) however makes an additional comment that the information on Bulgaria in the WHO databases should be regarded with caution because it can be incomplete (as data on some indicators are not being submitted to WHO), subjective (due to the lack of official statistics, WHO experts make assessments on many indicators), and outdated.

Between 1991 and 1998, health care expenditure in Bulgaria as a percentage of GDP fluctuated significantly: dropping from as high as 5.4\% in 1991 to only 3.3\% in 1996 and rising slightly to $3.8 \%$ in 1998 (Table 1.1). At the same time, per capita health care expenditure (in \$PPP) dropped from \$ 291 in 1995 to \$ 241 in 1996, and raised to $\$ 286$ in 1998 . These numbers include public health care expenditure only, as no official data on private expenditure are available for that period. The overall decrease in health care expenditure reflects both the economic difficulties of the 1990's and the relatively low priority attached by the central and municipal governments to spending on health care (Koulaksazov et al., 2003).

Table 1.1 Trends in health care expenditure in Bulgaria before the implementation of social health insurance system

\begin{tabular}{lcccccccc}
\hline & 1991 & 1992 & 1993 & 1994 & 1995 & 1996 & 1997 & 1998 \\
\hline Total health care expenditure (\% of GDP) & 5.4 & 5.3 & 4.8 & 3.9 & 3.7 & 3.3 & 3.5 & 3.8 \\
\hline
\end{tabular}

Source: Dimova et al., 2007; Koulaksazov et al., 2003.

In the period since 1999, Bulgaria's total health care expenditure (comprising both public and private health care expenditure) as a percentage of GDP has been moderate, amounting to $7.6 \%$ of GDP in 2010, compared to the European Union (EU) average of 9.0\% (WHO, 2014). This indicator increased in the period 1999 - 2003 from $6.0 \%$ to $7.6 \%$ of GDP. Then it slightly decreased and has remained relatively stable since 2006 (Table 1.2). As can be seen in Table 1.2, there has been an overall increase in spending on health care in absolute values. In 2010, per capita health care expenditure (in \$PPP) tripled (\$1057) compared to 1999 (\$338). Though, this is still far below the EU average ( $\$ 3216$ in 2010). The increasing trend 
in health care spending reflects the increasing health care needs and demand of the Bulgarian population but also improvements in the country's economy due to the restructuring, increased wages, decreased unemployment and policy efforts to obtain the EU membership (Georgieva et al., 2007). It is also linked to the enlargement of the private medical sector and the introduction of the social health insurance system.

Public health care expenditure as a share of total health care expenditure however has gradually decreased during the entire transition period. Since 2006, this share has been stable with some variations over the years (55-60\%) reflecting the relative increase of private health care expenditure (Dimova et al., 2012a; OECD, 2012). Overall, there is a continuously growing shortage of public resources for health care. The economic crises have also affected the mix of public and private health financing as public spending has been contained or cut by the government on many occasions to cope with the reduced public budgets.

Table 1.2 Trends in health care expenditure in Bulgaria after the implementation of social health insurance system

\begin{tabular}{lcccccccccccc}
\hline & 1999 & 2000 & 2001 & 2002 & 2003 & 2004 & 2005 & 2006 & 2007 & 2008 & 2009 & 2010 \\
\hline $\begin{array}{l}\text { Total health care expenditure } \\
\text { (\% of GDP) }\end{array}$ & 5.9 & 6.2 & 7.4 & 7.6 & 7.6 & 7.3 & 7.3 & 6.9 & 6.8 & 6.9 & 7.2 & 7.6 \\
\hline $\begin{array}{l}\text { Total health care expenditure } \\
\text { (PPP \$ per capita) }\end{array}$ & 338.4 & 385.1 & 505.1 & 574.7 & 624.1 & 650.4 & 718.7 & 763.9 & 842.6 & 970.5 & 991.4 & 1075.1 \\
\hline $\begin{array}{l}\text { Public health care expenditure } \\
\text { (\% of total health care } \\
\text { expenditure) }\end{array}$ & 66.3 & 60.9 & 58.4 & 61.3 & 62.1 & 60.7 & 60.9 & 57.0 & 58.2 & 58.5 & 55.4 & 55.7 \\
\hline
\end{tabular}

Source: WHO Regional Office for Europe, 2014.

In 2009, most of the activities paid from the Ministry of Health budget, were redirected to be paid by the NHIF budget. Prevention and health promotion of the population are a responsibility of the state represented by the Ministry of Health. The trend to decrease funds intended for health promotion and disease prevention shows that the state continues to withdraw from important health policy areas and transfers responsibilities to the NHIF. As a result, the public expenditure on health promotion and prevention is reduced at the expense of funds allocated by the citizens and households (Bulgarian Academy of Sciences, 2013).

Insight in the changes in health care expenditure in Bulgaria can also be obtained by analyzing its dynamics. As depicted in Figure 1.1, until 2001, the growth of health care expenditure outstripped the growth of GDP. Since 2002, the trend has been 


\section{Chapter 1}

reversed, i.e. health care expenditure has been growing less fast than GDP, and this difference in growth rates has gradually increased. A difference in the growth of public and private health care expenditure is also observed (Figure 1.2). Throughout the entire period, the growth rates of private health care expenditure significantly outstripped the growth rate of public health care expenditure.

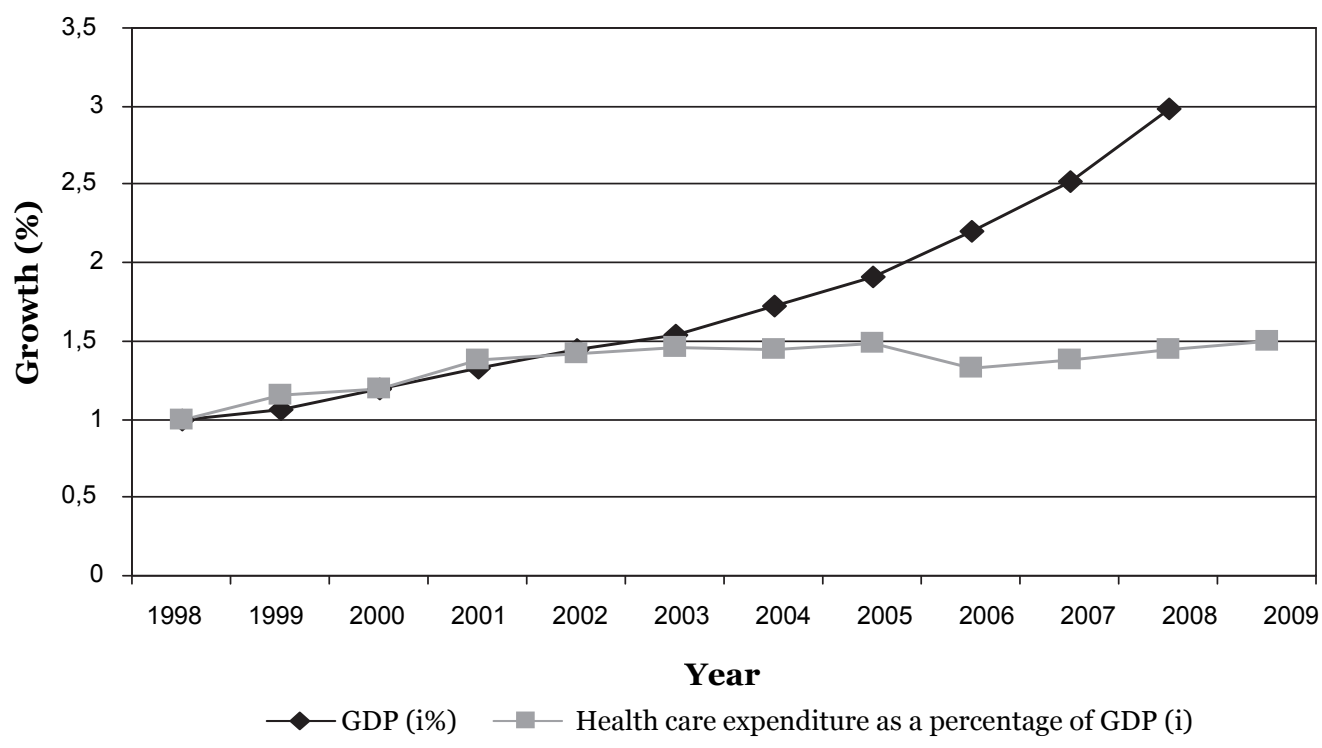

Figure 1.1. Growth of GDP and health care expenditure as a percentage of GDP

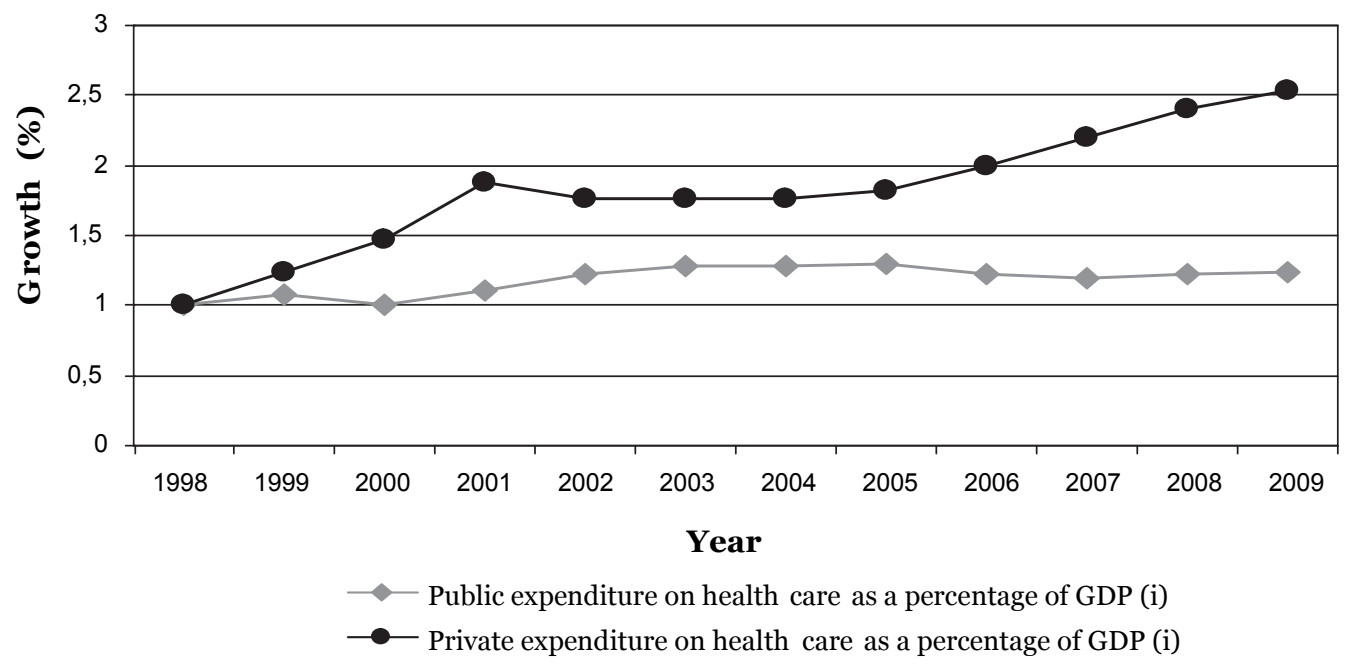

Figure 1.2 Growth of public and private health care expenditure as a percentage of GDP 
Also, the share of out-of-pocket payments has substantially increased in Bulgaria during the transition period. This reflects a common trend in Europe. For example, the share of out-of-pocket payments spending has increased over the past decade in about half of the EU member states (Szalay et al., 2011). In Bulgaria, this increase is due to a rise in co-payments, higher spending by households on non-prescribed pharmaceuticals, increased use of private providers and informal payments to public providers. The balance between public and private expenditure on health care has been violated in recent years. In 2008, out-of-pocket payments in Bulgaria formed $40 \%$ of total expenditure on health, compared to $16 \%$ in EU. In 2009, this ratio was $43.4 \%$ and in 2010, it was $44.2 \%$. The projection for Bulgaria is that this trend will continue and the share of out-of-pocket payments on health care is expected to reach as high as $48-49 \%$ of total health care expenditures in the coming years (Bulgarian Academy of Sciences, 2013). Thus, the role of patient payments becomes even more important. According to the National Statistical Institute (NSI) in Bulgaria, there are no official statistics about the size of each form of out-of-pocket payments. There are only data for total health care expenditure of households.

\subsection{Trends in household expenditure on health care in Bulgaria}

The discussion of the financial burden of the formal and informal patient payments requires a brief review of the underlying structure and changes in the household's budgets in Bulgaria. The structure of these budgets reflects the patterns of household's income and spending. Total household income includes monetary income (derived from wages, self-employment, property, pensions, social benefits, regular transfers from other households, etc.). The main source of income for households in Bulgaria comprises wages. In 2010, the relative share of wages in the total gross household income was 50.9\%, and in 2009, it was 52.2\%. However, there was a reduction in the household income from wages in nominal terms: from 1928 BGN1 per person in 2009 to 1857 BGN in 2010. In 2010 and 2011, deteriorating macroeconomic indicators of unemployment and employment caused a reduction in the disposable household income and thus, also a reduction in the funds flowing into the insurance pool. Moreover, the reduced households' purchasing power negatively affected the households' living standard as well as the ability to maintain the health status. The changes in the structure of the household consumption show a relatively large share of health care costs compared to other types of expenditure (Table 1.3).

Bulgarian leva (BGN), $1 \mathrm{BGN} \approx 0.5$ EUR 
Within total household expenditure, expenditure on food is relatively high. Though, a gradual decrease in this share has started since 2001, from $44.9 \%$ in 2001 to $36.5 \%$ in 2009. In 2010, it again increased to $37.2 \%$ and in 2011 again decreased to $36.2 \%$.

The only item whose share in the households' budgets has been growing steadily is that of health care. When we compare the share of health expenditure to total household spending for the period from the beginning of health care reform up to 2011, we observe a growth in health care spending by more than $90 \%$ at the expense of the slightly modified total household expenditure and a reduction in other types of costs. As can be seen in Table 1.3, expenditure on health care increased almost fivefold and its relative share in the household spending rose from $3.4 \%$ in 1999 to $6.7 \%$ in 2011. During the economic crisis in the country in 2009, a rapid increase in household health care expenditure could be observed. This expenditure is mainly influenced by the constantly rising prices of pharmaceuticals. This can be explained by the low price-elasticity of demand of pharmaceuticals and health care services. Overall, it can be concluded that contrary to the contraction of the household spending and impoverishment of the population brought about by the financial and economic crisis, consumer spending on health care has been growing continuously.

Table 1.3 Total income and expenditure of households in Bulgaria, 1999-2012

(selected expenditure groups)

19992000200120022003200420052006200720082009201020112012

\begin{tabular}{lllllllllllllll}
\hline $\begin{array}{l}\text { Total annual } \\
\text { household } \\
\text { income (BGN) }\end{array}$ & 4179 & 4360 & 4307 & 5289 & 5584 & 5925 & 6158 & 6657 & 7818 & 8686 & 9122 & 9023 & 9251 & 10244 \\
\hline $\begin{array}{l}\text { Total annual } \\
\text { household } \\
\text { expenditure (BGN) }\end{array}$ & 3095 & 3254 & 3315 & 3744 & 3970 & 4285 & 4612 & 5123 & 6121 & 6896 & 7057 & 6952 & 7177 & 8020
\end{tabular}

Food and non-alcoholic

beverages expenditure 15951691172718361854197220632239269629603004301630953209 $(\mathrm{BGN})^{\mathrm{a}}$

\begin{tabular}{lcccccccccccccc}
\hline $\begin{array}{l}\text { Communication } \\
\text { expenditure (BGN) }\end{array}$ & 75 & 98 & 128 & 182 & 214 & 243 & 272 & 289 & 335 & 360 & 371 & 378 & 397 & 423 \\
\hline $\begin{array}{l}\text { Recreation, culture and } \\
\text { education expenditure } \\
(\mathrm{BGN})^{\mathrm{a}}\end{array}$ & 119 & 124 & 124 & 141 & 162 & 174 & 193 & 210 & 259 & 298 & 318 & 282 & 295 & 396 \\
$\begin{array}{l}\text { Health care expenditure } \\
(\mathrm{BGN})^{\mathrm{a}}\end{array}$ & 104 & 139 & 150 & 176 & 199 & 226 & 253 & 273 & 338 & 385 & 438 & 447 & 479 & 501 \\
$\begin{array}{l}\text { Health expenditure } \\
(\% \text { of total household } \\
\text { expenditure })\end{array}$ & $3.4 \%$ & $4.3 \%$ & $4.5 \%$ & $4.7 \%$ & $5.0 \%$ & $5.3 \%$ & $5.5 \%$ & $5.3 \%$ & $5.5 \%$ & $5.6 \%$ & $6.2 \%$ & $6.4 \%$ & $6.7 \%$ & $6.2 \%$ \\
\hline
\end{tabular}

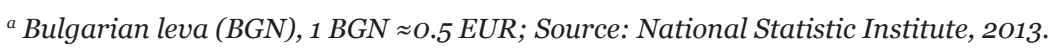


The growth rate of household income and expenditure and the growth rate of household health care expenditure are depicted in Figure 3.1. Overall, the household income and expenditure increased steadily in the period 1999-2009. Only in 2002 and 2003, the growth rate of income exceeded the growth of household expenditure. Since 2004, household expenditure has been growing faster than income. Differences in these growth rates have gradually increased and the largest difference was in 2009 - 0.21 points. In the structure of household expenditure, the share of health care expenditures rose from $2.9 \%$ (1999) to $5.3 \%$ (2009). Health care expenditure was shifted from the ninth place in 1999 to fourth place in total household expenditure in 2009.

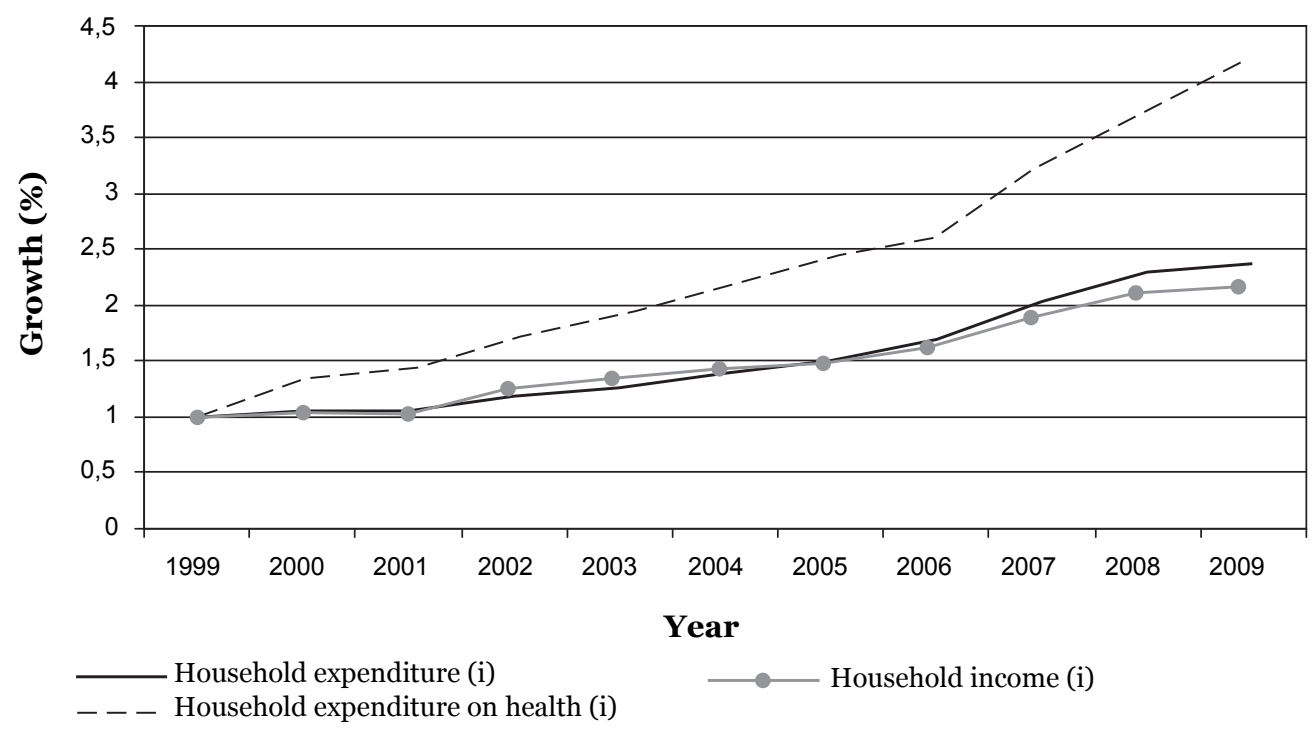

Figure 1.3 Growth of household income and household expenditure

The trends depicted in Figure 1.3. raise concerns about the ability of Bulgarian households to cope with the increasing burden of the out-of-pocket payments for health care. In order to delineate the negative effects of these payments, up-todate evidence on the combined formal and informal out-of-pocket payments by household members is needed. Such evidence can help policy makers to reevaluate the existing patient payment mechanism in Bulgarian and to outline strategies to target vulnerable patient and population groups. 


\subsection{Central research aim}

The high share of out-of-pocket payments for health care makes patient payments an important topic of analysis. The lack of an integrated analysis of both formal and informal patient payments and the sensitivity of the topic of out-of-pocket payments for health care services in Bulgaria makes this issue particularly challenging. Based on the research motivation and the scope of the study outlined above, the central aim of this dissertation is to analyze the propensity, magnitude and affordability of both formal and informal patient payments for public health care services in Bulgaria, as well as the attitudes of health care stakeholders towards these payments.

Given the central aim, the following research questions are addressed:

1. What have been the main outcomes of the financial reforms in the Bulgarian public health care sector?

This research question focuses on the prior expectations and concerns about the social health insurance reforms. The objective is to analyze these aspects based on a systematic review of empirical data related to the outcomes of this reform. In particular, the study focuses on financial sustainability, efficiency, equity, and quality effects brought about after the implementation of social health insurance in 2000 in Bulgaria. Previous studies have addressed these problems isolated from each other. Thus, our goal is to analyze them as a whole and to give a broader perspective on these effects, which has not been done in previous research.

2. What is the scale of out-of-pocket payments for public health care services in Bulgaria and to what extent are these payments affordable for Bulgarian patients?

This research question requires the evaluation of the scale of out-of pocket payments for public health care services. As suggested by previous research, outof-pocket payments contribute to a regressive income distribution in Western Europe (van Doorslaer et al., 1999). Therefore, given the general lack of studies on out-of-pocket spending in Bulgaria, the objective is to explore the scale of out-of-pocket payments and whether official charges, combined with informal payments are affordable for the population. The awareness of Bulgarian health care consumers about the size of official user fees for health care services is also in the focus of this dissertation.

3. How widespread are informal patient payments in the Bulgarian public health care system and what are the public attitudes towards these payments? Although the Bulgarian health care sector has experienced radical reforms during the last 20 years, a lot of problems continue to exist. The reform included 
the introduction of formal patient charges for health care services. However, these charges have been accompanied by informal patient payments. Taking into account the previous empirical research on informal payments in Bulgaria (Delcheva et al., 1997; Balabanova \& McKee, 2002a; Open Society Institute, 2008), this third research question is addressed by examining the current scale and types of informal payments, as well as public attitudes and perceptions. Regarding the perceptions to informal payment behavior, the objective is to explore why these payments are still widespread.

4. What are the views of health care stakeholders about the existence of official patient charges for public health care services?

The rise in co-payments is one of the reasons for the increase in out-of-pocket spending in Bulgaria. In this dissertation, attention is paid to official patient charges introduced in 2000. This fourth research question has the objective to provide a qualitative perspective on the issue of patient charges in Bulgaria, which has not been done in previous research in Bulgaria, and also rarely in other countries (Baji et al., 2011). In particular, the focus is on the attitudes of different health care players toward these charges. When analyzing the opinions of stakeholders in terms of meaningful units, we examine whether official charges have received equal support among health care consumers, health care providers, policy-makers and health care insurers.

5. To what extent are Bulgarian consumers willing to pay official charges for public health care services and how does stated willingness to pay compare to actual payments?

This research question puts the issue of consumer willingness to pay formally for health care services in the focus of the dissertation. The objective is to compare hypothetical consumer behavior (stated willingness to pay) with actual behavior regarding the past payments for health care services given the co-existence of formal and informal payments. Our empirical findings complement previous research (Foreit and Foreit, 2002; Bhatia and Fox-Rushby, 2003) with similar results obtained of the two approaches applied (revealed- and stated-preference approaches). Thus, the analysis of stated willingness to pay data cannot substitute demand analysis based on revealed preferences but it can complement it and can be useful for policy making in periods preceding the actual price changes. 


\subsection{Methodology}

The study combines three research methods: systematic literature review (desk research), quantitative data analysis (survey method) and a qualitative study (focus group discussions and semi-structured interviews). The first method (systematic literature review) is applied when addressing research question 1 to review the main directions of the financial reforms in Bulgaria, the trends in health care expenditure and evidence on the outcomes of the health insurance reform. The results of the application of this method provide a basis to analyze prior expectations and concerns in terms of the implementation of social health insurance reform.

The second method (quantitative data analysis) is used to address research questions 2, 3 and 5. The method uses data from representative national surveys among 1003 respondents in 2010 and 817 respondents in 2011. The data are collected in face-to-face interviews at respondents' homes using a standardized questionnaire (with identical questions on health care use and expenditure in both years). The questionnaire is validated in discussions with external experts and pre-tested to decide on the amount of questions and to improve the wording of the questions. To draw the sample, a multi-stage random probability method is used. In the first stage, the residence places are distributed proportionally to the regional characteristics of the population. In the second stage, addresses and households are selected using the random route method (selecting every fourth address on the left-hand side of the street or every fourth inhabitable house on both sides of the interviewer's route). The third stage includes the selection of an adult respondent within the household, using the "last-birthday" principle (Oldendick et al., 1988; Gaziano, 2005). Only one individual per household is interviewed. If the respondent determined at stage 3 refuses or is unavailable to take part in the interview, stages two and three are repeated to identify a replacement. In line with Bulgarian legislation, there is no need for the study to be approved by an ethics committee. However, informed consent is obtained from each respondent prior to the interview. The data collected in the survey allow for analyzing the propensity, magnitude and affordability of formal and informal patient payments for public health care services in Bulgaria, as well as the consumer's willingness to pay for public health care services. The attitudes of Bulgarian health care consumers towards informal patient payments are also studied using these survey data. Appendix A provides technical information about the data collection process.

To address research question 4, a qualitative study is carried out in Bulgaria in MayJune 2009. The qualitative study includes 12 focus group discussions: 6 groups with consumers and 6 groups with health care providers. These focus groups are 
supplemented by 10 in-depth interviews: 5 with policy-makers and 5 with health insurance representatives. The data collected in the focus-groups discussions and semi-structured interviews are analyzed to compare the opinion and attitudes of the different health care stakeholders toward formal patient payments. Appendix D provides technical information about the qualitative study.

\subsection{Outline of the dissertation}

This dissertation contains a set of research articles presenting the analyses for each research objective listed above. Chapter 2 presents the results of the systematic literature review related to research question 1. Chapter 3 reports empirical evidence on the scale of out-of-pocket payments for public health care services in Bulgaria as well as evidence on the affordability of these payments for Bulgarian patients, which is related to research objective 2. In addition to this, Chapter 4 presents empirical evidence on the scale of informal patient payments, as well as public attitudes and perceived behavior related to these payments. The chapter provides the input for research question 3. In Chapter 5, qualitative data on the opinion and attitudes of Bulgarian health care stakeholders (health care consumers, providers, insurers and policy-makers) toward formal patient charges are analyzed to answer the fourth research question. Chapter 6 presents empirical evidence on the willingness of Bulgarian consumers to pay official charges for public health care services (stated-preference data). The stated willingness to pay is compared to actual out-of-pocket payment for health care as defined in research question 5 . After the five research articles, the dissertation includes a general discussion of the key findings of the dissertation presented in Chapter 7. The discussion focuses on the interpretation of the dissertation findings to better understand the processes in the Bulgarian health care sector and to facilitate the development of an adequate patient payment policy in Bulgaria. 

Chapter 2

WHAT HAVE 10 YEARS OF HEALTH INSURANCE REFORMS BROUGHT ABOUT IN BULGARIA? RE-APPRAISING THE HEALTH INSURANCE ACT OF 1998

Published as:

Atanasova E, Pavlova M, Velickovski R, Nikov B, Moutafova E, Groot W. (2011).

What have 10 years of health insurance reforms brought about in Bulgaria?

Re-appraising the Health Insurance Act of 1998. Health Policy, 102 (2-3): 263- 269. 


\section{Abstract}

This chapter analyzes the financial reforms in the Bulgarian public health care sector. Since 1998, when the Bulgarian parliament passed the Health Insurance Act, compulsory contributions for social health insurance have become the main source of public health care financing. They replaced the previous tax-based health care funding mechanism. The chapter reviews empirical evidence and macro indicators to analyze to what extent the expectations of this reform are achieved. Two groups of sources are reviewed: (1) publications prior to the implementation of the social health insurance in Bulgaria, that discuss its potential impact; (2) publications after the insurance implementation, that investigate the actual impact of this reform. The results suggest that social health insurance in Bulgaria brought about certain efficiency improvements in the public health care sector. However, the overall social benefit of the reform is less than expected. The main reasons for this are related to the ineffective organization of the Bulgarian public health care sector, as well as to the overall lack of financial resources for health care in the country. Also, our analysis raises a major concern about the deterioration of equity in the public health care sector after the introduction of social health insurance in Bulgaria. Fundamental equity principles (e.g. solidarity, equality, accessibility) were violated as a result of the insurance implementation and this requires the urgent attention of policy-makers. 


\subsection{Introduction}

Since the start of the transition process in 1989, the Bulgarian health sector has experienced radical reforms, such as the establishment of a private health care sector and the decentralization of the public health care system (see Chapter 1, Section 1.2). However, the tax-based mechanism of public health care finance inherited from the communist period, remained largely unchanged during the first decade after the transition. This resulted in a deterioration of the public health care provision, including pressing sustainability, efficiency, equity and quality problems (Borisov \& Rathwell, 1996; Datzova, 2003; Ministry of Health, 2000; Pavlova et al., 2000), as well as in widespread informal payments, either in cash or gifts in kind (Delcheva et al., 1997; Delcheva, 1999).

It was only in 2000 when the Bulgarian government actually took the political risk and started the financial reform in the public health care sector (based on the Health Insurance Act of 1998). Following the common trend in Central and Eastern European (CEE) countries (Rechel \& McKee, 2009), the tax-based funding of the public health care sector was radically changed and a previously non-existing social health insurance body (NHIF) was established. The implementation of social health insurance was largely accepted in the country because it was seen as a movement away from the legacy of the communist regime and a movement towards a Western European type of health care system (Preker, 2002). It was expected that this reform could help to improve health care provision in Bulgaria, even though the first experiences of other CEE countries indicated that such reforms have limited effect on their own (Pavlova et al., 2000; Balabanova \& McKee, 2004).

The aim of this chapter is to review the evidence on the outcomes of the health insurance reform in Bulgaria from the perspective of expectations and concerns at the start of the reform. Apart from some studies that analyze the separate effects of this reform, or of the Bulgarian health care reforms in general (Datzova, 2003; Balabanova \& McKee, 2002b; Datzova, 2006; Markova, 2006; Pashev, 2006; Hadjiev et al., 2007), a review of studies that focus on the reform outcomes, is lacking. Such review could facilitate a systematic evidence based evaluation of the Bulgarian health insurance, which emphasizes the relevance of our study. The chapter first presents the process of the reform implementation followed by an overview of currently observed consequences and effects. This provides a base for policy recommendations at the end of the chapter. 


\subsection{The implementation of the social health insurance in Bulgaria}

The establishment of social health insurance and NHIF in Bulgaria was legislated by the Health Insurance Act passed by the Bulgarian Parliament in 1998. The design of the social health insurance mechanism is briefly discussed in Chapter 1 and in detail elsewhere (Pavlova et al., 2000, Dimova et al., 2012a). In general, the insurance contributions are compulsory. The self-employed pay the full contribution, whereas the contributions of the employed are divided between employees and their employers (see Table 2.1). The employed and self-employed pay contributions for their dependent family members. State funds cover the contributions of pensioners and persons with social assistance, as well as service provision to children (National Assembly, 1998; National Health Insurance Fund, 2010).

Table 2.1 Changes in the payments for health insurance by employers and employees

\begin{tabular}{lcccc}
\hline Period & $\begin{array}{c}\text { Minimum monthly salary } \\
\text { determined by the government } \\
(\mathrm{BGN})^{\text {a }}\end{array}$ & $\begin{array}{c}\text { Average } \\
\text { monthly salary } \\
(\mathrm{BGN})^{\mathrm{a}}\end{array}$ & $\begin{array}{c}\text { Size of monthly health } \\
\text { insurance contributions } \\
(\% \text { monthly income })\end{array}$ & $\begin{array}{c}\text { Payment ratio } \\
\text { employer: } \\
\text { employee }\end{array}$ \\
\hline 2000 & 75 & 217 & $6 \%$ & $80: 20$ \\
\hline 2001 & 87 & 243 & $6 \%$ & $80: 20$ \\
\hline 2002 & 100 & 260 & $6 \%$ & $75: 25$ \\
\hline 2003 & 110 & 281 & $6 \%$ & $75: 25$ \\
\hline 2004 & 120 & 309 & $6 \%$ & $75: 25$ \\
\hline 2005 & 150 & 332 & $6 \%$ & $70: 30$ \\
\hline 2006 & 160 & 355 & $6 \%$ & $65: 35$ \\
\hline 2008 & 180 & 398 & $6 \%$ & $60: 40$ \\
\hline 2009 & 220 & 501 & $6 \%$ & $60: 40$ \\
\hline
\end{tabular}

${ }^{a}$ Bulgarian leva $(B G N), 1 B G N \approx 0.5 E U R$

Source: National Social Security Institute, 2010.

The implementation of the insurance took place between 2000 and 2002 following a step-wise process (National Health Insurance Fund, 2008b; Rangelova \& Sariiski, 2007) due to a lack of prior experience and financial resources, and due to the need of developing a reliable information system, building the infrastructure and training the staff (Balabanova \& McKee, 2004). At the same time, the economic recession put limits on the collection of the necessary resources (Exadaktylos, 2005). This made the implementation process difficult and slow. 
The system is now fully operational but its functioning relies on supplementary regulations, including the National Framework Contract, which are negotiated annually between the health insurance representatives and providers (National Assembly, 1998). Apart from the basic health insurance package and management regulations, the National Framework Contract also determines the method of payment to health care providers. This includes at present capitation payment for GPs, fee-for-service for medical specialists outside hospitals, and clinical pathways for hospital services (Exadaktylos, 2005). The objective is to establish a diagnosticrelated groups (DRGs) system for hospital funding in the near future but there is still no concrete starting date for this reform.

Within the first four years of the implementation of social health insurance in Bulgaria, the number of non-regular payers of insurance contributions was about 24\% (National Health Insurance Fund, 2003 -2008a). This resulted in lower revenues than expected. The NHIF could not exclude the non-regular payers from the use of services since there was no mechanism to check the insurance status of patients (National Statistic Institute, 2005a). Other reasons included the lack of political will to tackle the problem of non-regular payers (Delcheva, 2006a).

The financial capacity of the NHIF was further limited due to the lack of transparency about the real income of employees in the private sector and selfemployed persons. Since insurance contributions are related to individual income, inaccurate declaration of income to avoid tax payments affects the collection of insurance premiums (Datzova, 2006). Therefore, in 2003, a minimum insurance contribution per professional group was implemented for self-employed persons (such as farmers, freelancers) independent of their registered income. To a certain extent, this makes it possible to secure a minimum level of contributions by this group of insured (National Health Insurance Fund, 2010).

In 2004-2005, various amendments to the health insurance regulations were made: (1) to make it easier for non-regular payers to start paying insurance contributions (e.g. giving the possibility to request an extension), and (2) to define population groups (e.g. individuals living abroad) who are not obliged to have health insurance. Thus, the number of non-regular payers decreased to about 11\% (National Health Insurance Fund, 2003 -2008a). In addition, a computerized system containing data about the insurance status of citizens was created, which makes it easier to identify patients without social health insurance. These patients have the option to use private health care services. Penalties for employers who do not pay insurance contributions for their employees were also introduced. Nevertheless, these measures had no significant effect on insurance revenues since only about 
2.9 million working people pay contributions while the number of insured is about 7.7 million (Datzova, 2006; National Health Insurance Fund, 2003 -2008a). The remaining contributions are covered by state funds.

At present, the social health insurance mechanism in Bulgaria is again the focus of policy discussions. The major concern refers to the high number of non-regular payers, the improvement of quality of health care services and the informal patient payments in the country (Open Society Institute, 2009; Vekov, 2008).

\subsection{Materials and methods}

To review the evidence on the outcomes of the health insurance reform in Bulgaria, we have conducted a desk research. The objective is to identify publications that either discuss the Bulgarian health insurance reform prior to its implementation, or present empirical data related to the outcomes of this reform. For this purpose, the databases PubMed, ScienceDirect, and Google Scholar are searched using the following keywords: Bulgaria and health and insurance. Bulgarian peer-reviewed journals are searched separately since they are not included in the databases mentioned above. Given the objective of our desk search, we exclude publications that provide only general discussions of the effect of the insurance reform without presenting relevant empirical data, as well as publications prior to the insurance implementations that do not discuss its design or potential effects. The reference list of each article is reviewed to check for other relevant publications. In addition to this, we also include official reports published by the Ministry of Health in Bulgaria, the Bulgarian NHIF and international organizations (namely WHO, European Observatory, OECD and EU) for macro indicators related to health and health care in Bulgaria. Materials in the Bulgarian press are omitted since we focus on empirical evidence and official macro data.

Publications before the insurance implementation (Borisov \& Rathwell, 1996; Pavlova et al., 2000; Cichon \& Normand, 1994; Kanavos \& McKee, 1998; Vienonen \& Wlodarczyk, 1993; Vodenitcharov \& Borissov, 1995) are taken into account to outline the prior expectations and concerns related to the implementation of social health insurance in Bulgaria. These expectations and concerns are summarized in Table 2.2 in the form of hypotheses. The hypotheses are divided into four major groups and refer to financial sustainability (macro-level), efficiency (micro-level), equity, and quality effects. 
Table 2.2 Prior expectations and concerns about the social health insurance in Bulgaria

\begin{tabular}{|c|c|c|}
\hline Criteria & Prior positive expectations of the reform & Prior concerns about negative effects \\
\hline 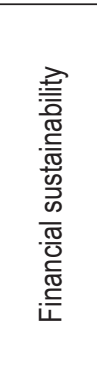 & $\begin{array}{l}\text { 1. Social health insurance contributions would be } \\
\text { only for the health care sector. } \\
\text { 2. Funding of health care would be more } \\
\text { transparent. } \\
\text { 3. Social health insurance could maintain a } \\
\text { degree of independence from government. }\end{array}$ & $\begin{array}{l}\text { 4. Low earnings in Bulgaria would negatively } \\
\text { affect the amount collected for social health } \\
\text { insurance. } \\
\text { 5. The new insurance mechanism would not } \\
\text { create new money in the economy for health } \\
\text { care. } \\
\text { 6. Social health insurance would still need } \\
\text { external funding by the state. } \\
\text { 7. There would be high administrative costs for } \\
\text { establishing a new health insurance body. }\end{array}$ \\
\hline 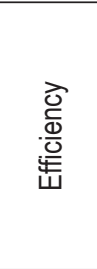 & $\begin{array}{l}\text { 8. Social health insurance could be associated } \\
\text { with efficient allocation of health care resources } \\
\text { if competition can be created. } \\
\text { 9. Social health insurance could stimulate the use } \\
\text { of primary health care. } \\
\text { 10. Social health insurance could reduce } \\
\text { unnecessary hospital stay. }\end{array}$ & $\begin{array}{l}\text { 11. Efficiency would depend on the contract } \\
\text { relation between insurer and providers. }\end{array}$ \\
\hline 訔 & 12. Principle of solidarity would be preserved. & $\begin{array}{l}\text { 13. There might be problems with defining the } \\
\text { basic health care package due to unclear } \\
\text { legislation. } \\
\text { 14. There might be geographic barriers to access } \\
\text { to adequate medical services. } \\
\text { 15. There might be unequal consumer rights, i.e. } \\
\text { limit access for uninsured population. }\end{array}$ \\
\hline 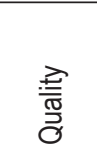 & $\begin{array}{l}\text { 16. There would be opportunity for free choice of } \\
\text { GP's and specialists. } \\
\text { 17. There would be opportunity for creating } \\
\text { competition based on quality. }\end{array}$ & $\begin{array}{l}\text { 18. Quality would depend on the contract relation } \\
\text { between insurer and providers. } \\
\text { 19. There might be low patient satisfaction from the } \\
\text { used services, especially for uninsured. }\end{array}$ \\
\hline
\end{tabular}

Sources: Borisov \& Rathwell, 1996; Pavlova et al., 200o; OSI, 2009; Cichon \& Normand, 1994; Kanavos \& McKee, 1998; Vienonen \& Wlodarczyk, 1993.

Publications issued after the actual implementation of social health insurance in Bulgaria are reviewed to analyze to what extent prior expectations and concerns (i.e. hypotheses) are realized. The results of this analysis and their discussion are presented in the subsequent sections. These sections are structured following the hypotheses in Table 2.2. 


\subsection{Results and discussion}

\subsubsection{Did social health insurance strengthen the financial sustainability of the system?}

As expected (point 1 and 2 in Table 2.2), the implementation of the social health insurance mechanism in Bulgaria helped to improve the transparency in the funding of the public health care sector through the introduction of earmarked social health insurance contributions (National Health Insurance Fund, 2007). In principle, it is not possible to divert resources for health care to finance other public sector activities. However, this did not help to achieve a more important objective, namely to generate additional financial resources for the public health care sector. This is because earning levels in Bulgaria are still rather low, which means that insurance contributions also remain low in absolute terms (Exadaktylos, 2005). This confirms prior concerns (point 4 in Table 2.2).

Expenditures on public health care services during the last years have varied between 3.0\% and 4.8\% of GDP (Datzova, 2003; Pashev, 2006; Delcheva, 2006a; Gladilov \& Delcheva, 2000). In 2007, it was 2194.87 million BGN (National Statistical Institute, 2010), i.e. about $57 \%$ of total expenditure on health care in the country (WHO, 2010). Thus, expenditures on public health care remain one of the lowest in the EU in both relative and absolute terms (Rangelova \& Sariiski, 2007; WHO, 2005; WHO, 2010). This outcome shows that similar to prior concerns (point 5 in Table 2.2), the implementation of social health insurance 'does not create new money in the economy for health care' (Kanavos \& McKee, 1998) and cannot guaranty by itself a sufficient health care budget (Vienonen \& Wlodarczyk, 1993). No matter how funds are collected, if there is no economic growth in a country, the health care budget cannot be increased significantly (Rechel \& McKee, 2009; D'Intignano, 1992).

Thus, consistent with prior concerns (point 6 in Table 2.2), social health insurance in Bulgaria still depends on funding by the state and on the political will to provide state funding (Delcheva, 2006a). At the same time, government spending on health care was reduced from 818 million BGN in 2003 to 629 million BGN in 2007 (National Statistical Institute, 2010). The government also often delays paying the insurance contributions for pensioners and persons with social assistance, which further reduces the financial capacity of the NHIF (Komitov \& Genev, 2009). Thus, in contrast to prior expectations (point 3 in Table 2.2), an independence from government interference is not completely achieved (Rechel \& McKee, 2009). 
To establish the new health insurance body, a huge amount of financial resources was spent (Dimova et al., 2007), which confirms prior concerns (point 7 in Table 2.2). High administrative costs were persuasive in the next year, whereas the basic social health insurance package was continuously being reduced due to insufficient insurance funds (Vekov, 2009b; Vekov, 2009c). Moreover, the funds collected from the insurance contributions are not invested properly (Exadaktylos, 2005). There is a lack of efficient health care financing corresponding to patients preferences (Georgieva et al., 2007; Pavlova et al., 2004; Koulaksazov et al., 2003; Petkov, 2007; Komitov \& Genev, 2006), and an effective system for collecting and managing the scarce health resource (Datzova, 2003; Markova, 2006; Pashev, 2006; Avdeeva, 2007; Schneider, 2007). For instance, in 2007, ca. 1 million citizens did not pay insurance contributions even though these were obligatory.

\subsubsection{Were there any efficiency improvements in service provision?}

The implementation of social health insurance in Bulgaria brought some positive outcomes related to efficiency due to the split between health care funding and provision, and due to the establishment of a contract-based relationship between insurer and providers. As a result, financial resources for health care collected by the NHIF, are allocated to the health care providers based on performance. As expected (point 8 in Table 2.2) the contract-based resource allocation creates a form of competition between heath care providers, which stimulates efficiency (Exadaktylos, 2005).

As already mentioned, the Health Insurance Act defines co-payments for the use of physician and hospital services, which primarily objective is an efficient service use (Pavlova et al., 2000). The act also defines numerous exemptions from co-payments for vulnerable groups. Although the exemptions are governed by equity objectives, they also stimulate the service use by these groups at an early stage.

As expected (point 9 in Table 2.2), efficiency improvements are observed with regard to the use of preventive and primary care services. Priority is given by the NHIF to the development of care, prophylactic and treatment services for mothers, children and chronically sick patients. In particular, access of children to pediatric services, of pregnant women to gynecology/obstetric services and of chronic patients to hospital care is improved (National Health Insurance Fund 2005a-2007; National Health Insurance Fund, 2005b). This way, unnecessary delay in health care provision for these priority groups is to a certain extent avoided. 
Despite these improvements, life expectancy at birth remains one of the lowest in the EU (73 years in 2009) (National Statistical Institute, 2010). The low life expectancy is often attributed to an unhealthy life-style since cardio-vascular diseases are a leading cause of death: $62 \%$ and $71 \%$ of all deaths for men and women respectively (both the highest in the EU) (Allender et al., 2008).

Moreover, patients' trust in primary health care is still low and GPs are often bypassed even though patients have to pay higher co-payments when they have no referral from a GP (Balabanova \& McKee, 2002b; Exadaktylos, 2005). Although outpatient departments of Bulgarian hospitals are less "crowded" compared to hospitals in neighboring countries with no referral system (Exadaktylos, 2005), this does not apply to the emergency departments. Bulgarian patients face no payment obligations for the use of emergency care, which results in unnecessarily overuse of these services (Rechel et al., 2009b).

With regard to hospital services, evidence shows that as expected (point 10 in Table 2.2), hospital use decreased from $19.6 \%$ in 1990 to $14.4 \%$ per 100 inhabitants in 2000 (Ministry of Health, 2000) right after the insurance introduction. This initial reduction could be attributed to the fact that prior to 1990, a high number of hospital beds were filled with patients whose treatment did not really require hospitalization (so called 'social beds') with the purpose to retain hospital capacity and preserve the size of the annual hospital budget (Ministry of Health, 2000). The existence of 'social beds' was no longer beneficial for hospitals after the introduction of clinical pathways under the insurance system.

Table 2.3 Hospitalizations in health care facilities

\begin{tabular}{lcc}
\hline Year & Total number of hospitalizations & Hospitalizations per 100000 population \\
\hline 2000 & 1181097 & 14456 \\
\hline 2001 & 1185927 & 14987 \\
\hline 2002 & 1256557 & 15969 \\
\hline 2003 & 1333698 & 17047 \\
\hline 2004 & 1473631 & 18938 \\
\hline 2005 & 1614313 & 20857 \\
\hline 2006 & 1653264 & 21474 \\
\hline 2007 & 1735341 & 22655 \\
\hline 2008 & 1825488 & 23946 \\
\hline 2009 & 1958897 & 25826 \\
\hline
\end{tabular}

Source: National Centre of Health Information, 2007; National Centre of Health Informatics, 2010. 
In recent years however, the hospitalization rate has increased substantially (see Table 2.3) (National Centre of Health Information, 2007; National Centre of Health Informatics, 2010). The reasons for this could be the low effectiveness of hospital treatment that causes re-hospitalizations (representing 30\% of all hospitalizations). However, unnecessary re-hospitalizations, including re-hospitalizations within the same hospital, also result from strategic hospital behavior induced by the casemix hospital funding (i.e. the clinical pathways) (Rangelova \& Sariiski, 2007; Exadaktylos 2005; Habicht et al., 2007). Moreover, the potential of the system of clinical pathways for hospital management is overlooked (Vekov et al., 2009; Georgieva et al., 2007). This corresponds to the prior concern (point 11 in Table 2.2) that the efficiency under the insurance system would actually depend on the exact insurer-providers relation.

Problems with delivering pharmaceuticals are noticeable as well. Lists of registered pharmaceuticals paid by the NHIF (totally or partly) are developed, which keeps the expenditure of the NHIF on pharmaceuticals relatively constant (around 260 million BGN per year in the period 2003-2007) (National Statistical Institute, 2010). Nevertheless, the number of patients who purchase pharmaceuticals funded by the NHIF is decreasing: (1) due to the exclusion of some frequently used pharmaceutical from the NHIF lists (e.g. for cardio-vascular diseases) and (2) due to preferred suppliers, which limits the brands covered by the NHIF. As a result, household expenditures on pharmaceuticals outside the NHIF have increased substantially from 747 million BGN in 2003 to 1203 million BGN in 2007 (National Statistical Institute, 2010). In addition to this, to obtain pharmaceuticals under the NHIF, the patient should visit the GP, pay the fee for this visit, and perhaps also partly cover the cost of the pharmaceutical. This makes the procedure rather time consuming and expensive for the patient. Therefore, it is not surprising that an increased tendency for self-treatment and alternative medicine is observed (Delcheva , 2006a).

\subsubsection{Was equity affected by the introduction of social health insurance?}

Although the policy of the NHIF has as its goal to decrease the price and non-price barriers for access to more and diverse health care services by insured individuals, some important inequities in health care provision remain or have emerged (Balabanova \& McKee, 2002b; Datzova, 2006; Markova, 2006; National Statistical Institute, 2005b), which is in contrast to prior expectations (point 12 in Table 2.2).

First and foremost, the content of the health insurance package is not clearly specified, which confirms prior concerns (point 13 in Table 2.2). In fact, the Health Insurance Act allows redefining the basic insurance package according to the 
economic circumstances in the country, which in practice results in its reduction. According to a study conducted at the beginning of the reform (Dimova et al., 2002), only about $13.6 \%$ of GPs defined the basic insurance package as meeting the population health needs. Now, this package is further reduced, which makes its adequacy questionable.

In accordance with prior concerns (point 14 in Table 2.2), the geographic limitation for access to GPs, dentists and specialists, which was a major equity problem during the communist government, continues to exist. In particular, the differences between regions with regard to primary, dentistry and specialist services are considerable (National Statistical Institute, 2005b). Yet, an indisputable success of the insurance reform was the fact that the NHIF succeeded to make it more attractive for GPs to work in small villages. This was attained through an additional financial stimulus. In 2004, the NHIF gave additional payments to 1567 GPs who worked in places defined as unfavorable (National Health Insurance Fund, 2005b). This improved equity and access to GP services in these regions.

Another group of inequities in the Bulgarian public health care sector refers to inequity in health care financing. The lack of financial resources to cover treatment and travelling costs is often an important reason for low-income population groups, disabled and rural residents not to seek hospital treatment (Balabanova \& McKee, 2002b; Markova, 2006). There is a tendency to decrease the non-price barriers (e.g. waiting time) to adequate medical service. Nevertheless, a study carried out at the start of the reform shows that 50\% of households admit that they face constant difficulties with payments for medical services (National Statistical Institute, 2000). Comparative analyses also show that the disposable income of employees was substantially reduced due to social security and health insurance contributions (Haralampieva, 1999). Later studies also provide evidence on increasing out-ofpocket payments and widely spread informal patient payments (Datzova, 2006; Markova, 2006; Balabanova \& McKee, 2002a). The informal payments amount to about $3.6 \%$ of the total public health care expenditures (Open Society Institute, 2008). They present a major challenge to policy-makers (Rangelova \& Sariiski, 2007; Exadaktylos, 2005; Balabanova \& McKee, 2002a; Pashev, 2007).

The group of uninsured people also raises equity concerns (Markova, 2006), in accordance to point 15 in Table 2.2. Since 2004, uninsured people (mostly lowincome individuals who cannot afford to pay the contributions and the Roma population) have been excluded from the use of service funded by the NHIF, and have shifted to the private health care sector (Datzova, 2006; Delcheva, 2006b). This led to a considerable reduction of health care use among the uninsured (especially 
among the Roma minorities) (Rechel \& McKee, 2009; Hadjiev et al., 2007). Almost three quarters of the uninsured patients experience a price barrier to necessary health care (Delcheva, 2006a). The groups of poor, Roma, ethnic minority children, elderly and those living in towns and villages are reported as most vulnerable (Hadjiev et al., 2007; Rechel et al., 2009a; Rechel et al., 2009b).

\subsubsection{What was the impact of social health insurance on quality of health care delivery?}

The implementation of social health insurance in Bulgaria resulted in free patients' choice of a GP and medical specialists, which was seen as one of the key features that can create competition and improve quality (Avdeeva \& Georgieva, 2008). However, patient free choice is not always feasible, especially in rural areas. This indicates that there is limited opportunity to achieve the expectation of quality improvement through patients' choice and competition (point 16 and 17 in Table 2.2). In some rural areas, there is often only one GP available, while specialized health care is frequently completely lacking. Due to the limited access to physician services, patients in these regions have no opportunity to search for services with better quality (Vekov, 2009b; Zlatanova et al., 2008).

Moreover, corresponding to prior concerns (point 18 in Table 2.2), the contractbased relation between the NHIF and health care providers, as well as the providers' reimbursement specified in these contracts, still do not provide real incentives for rewarding high quality care under the new social health insurance system (Datzova, 2003; Vekov, 2009b; Pavlova et al., 2004; Vekov et al., 2009; Georgieva et al., 2007; Avdeeva \& Georgieva, 2008). There is no link between the accreditation of health care organizations and the funding that these organizations receive from the NHIF. Such link would be essential because it could stimulate hospitals to provide better medical quality and to invest in service improvement. There is also a lack of a system for continuous improvement of knowledge and skills of physicians and other medical staff (Georgieva et al., 2007). Most of the GPs have never received training in general medicine since the system of GPs was introduced in Bulgaria in 2000 together with the social health insurance. In particular, quality problems (such as errors in diagnostics and delayed referrals) are reported for primary care for children (Genev \& Kalaikov, 2003).

Overall, there is a lack of evidence on the impact of social health insurance on quality. A study carried out by the National Statistical Institute in 2003 (National Statistic Institute, 2005a) provides some insight in patient satisfaction with quality. As suggested by this study, 33\% of the insured indicate that the quality of services 
they use is low and medical supplies are insufficient (National Statistic Institute, 2005). Another study conducted in 2004 (Petkov, 2004) also confirms the lack of satisfaction with service quality (51.7\% of respondents). However, it is unclear whether this low quality can be attributed to the health insurance itself (point 19 in Table 2.2) or more generally to the low funding of the health care sector in Bulgaria.

\subsection{Conclusions and policy recommendations}

As indicated by our analysis, most of the prior expectations about the positive effects of the implementation of social health insurance in Bulgaria (see Table 2.2) are realized but two key expectations (namely independence of health care system funding from government interference and preserving equity in health care delivery) have not been achieved. Moreover, the prior concerns about the possible negative effects of the reforms (see Table 2.2) have also been realized. We recognize that these are only general conclusions interwoven with a certain degree of uncertainty due to the lack of data. During our desk research, we did not find any systematic evidence-based analyses of the effects of the insurance reforms. Nevertheless, our analysis indicates some relevant policy conclusions.

In particular, as suggested in the results section, the replacement of the tax-based system funding by social health insurance led to a certain transparency in health care system funding but this did not completely achieve financial sustainability of the system. Thus, the financial status of the system is still weak due to the reliance on government funds and the poor economic situation in the country (namely low earnings), which limits the size of the insurance contributions. This means that the Bulgarian government still has the responsibility to secure sufficient funding and stimulate cost-effective provision of public health care services, as well as a costeffective administration of the NHIF to avoid waste of health insurance resources.

Although some efficiency improvements have been made, in many respects, the system is still rather inefficient especially regarding the provision and funding of hospital care and pharmaceuticals (as discussed above). Moreover, the promotion of a healthy life-style as well as the prevention of cardio-vascular and other chronic disease should become a priority in the health care sector in general, but also for the NHIF in particular. There is also a need to implement quality improvement strategies (including staff training and adequate investments in equipment).

Our analysis raises a major concern about the deterioration of equity in the public health care sector after the introduction of social health insurance in Bulgaria. It appears that some fundamental equity principles (e.g. solidarity, equality, 
accessibility) were violated as a result of the insurance implementation (including the lack of access to public health care services for people without social health insurance, usually low-income groups, as well as the lack of choice of physician in remote rural areas). These accessibility problems require the urgent attention of policy-makers. The existence of informal patient payments even after the introduction of official co-payments also requires immediate policy actions.

The Ministry of Health has started reforms to improve the collection of insurance contributions and dealing with informal patient payments, which indicates that changes in the health insurance system are of national importance. Nevertheless, the availability of new empirical evidence on the impact of the Bulgarian health insurance reform (especially on cost-effectiveness, equity and quality of public health care provision) could facilitate more rational policy choices for these changes. 

Chapter 3

\section{OUT-OF-POCKET PAYMENTS FOR HEALTH CARE SERVICES IN BULGARIA: FINANCIAL BURDEN AND BARRIER TO ACCESS}

Published as:

Atanasova E, Pavlova M, Moutafova E, Rechel B, Groot W. (2013). Out-of-pocket payments for health care services in Bulgaria: financial burden and barrier to access. European Journal of Public Health , 23(6): 916-922 


\section{Chapter 3}

\section{Abstract}

Bulgaria increasingly relies on out-of-pocket payments as one of the main sources of health care financing. However, it is largely unknown whether the official patient charges, combined with informal payments, are affordable for the population. This chapter explores the scale of out-of-pocket payments for health care services as well as their affordability. Data are collected in two nationally representative surveys, conducted in Bulgaria in 2010 and 2011, using face-to-face interviews based on a standardized questionnaire. To select respondents, a multi-stage random probability method is used. The questionnaire includes questions on the out-of-pocket payments for health care services used by the respondent during the preceding 12 months. In total, $75.7 \%$ (2010) and $84.0 \%$ (2011) of outpatient service users report to have paid out-of-pocket, with $12.6 \%$ (2010) and 9.7\% (2011) of users reporting informal payments. Of those who have used inpatient services, 66.5\% (2010) and 63.1\% (2011) report to have made out-of-pocket payments, with $31.8 \%$ (2010) and $18.3 \%$ (2011) reporting to have paid informally. We find a large inability to pay indicated by the need to borrow money and/or to forego services. The results of the regression analysis show that the inability to pay is especially pronounced among those with poor health status and chronic diseases, and those with low household income. The high level of both formal and informal out-of-pocket payments for health care services in Bulgaria poses a considerable burden for households and undermines access to health services for poorer parts of the population. 


\subsection{Introduction}

Patient charges are not a new phenomenon in Bulgaria. Even during the communist period, when the provision of health services was entirely public, patients had to pay officially for medical appliances and outpatient pharmaceuticals. During the transition period, new official patient charges emerged in connection with the development of a private health care sector. The implementation of social health insurance in 2000 further extended patient payment obligations by introducing user fees for services covered by the insurance fund. An analysis of the financial reform in the Bulgarian health care system can be found in Chapter 2.

At present, Bulgarian patients face a complex system of patient charges when using public or private health care services. As already outlined in Chapter 1, the user fees within the social health insurance system take the form of co-payments paid to health care providers, and apply to all levels of medical services, except for emergency care (Atanasova et al., 2011; Atanasova et al., 2010). The co-payment size is linked to the minimum monthly salary in the country, as set by the government: $1 \%$ of the minimum monthly salary for each outpatient visit to a GP and medical specialist after referral (1.3 EUR in 2011; a higher fee in case of no referral), and $2 \%$ of the minimum monthly salary (about 2.7 EUR in 2011) per day for the first 10 days of hospital stay (paid once a year). Although there is a wide range of exemptions (e.g. children under 18 years, certain occupational groups and war veterans), frequent users (such as people with chronic illnesses) are not always exempted (Atanasova et al., 2011).

In 2006, a Ministry of Health ordinance was passed, which allowed patients to choose a physician or treatment team at prices set by the health care establishments (in hospitals only). This turned into another way for health care providers to raise funds. Patients are often not aware of the fact that they could avoid these payments, if they decided to forego the free choice of physicians. Sometimes, patients are even urged by health care providers to make such a choice, without being informed that they will have to pay for this (Velkov, 2011; Moutafova et al., 2011).

Outside the services covered by social health insurance, patients have the opportunity to use the private sector, where prices are set by providers. Health care services in the private sector are also the only option for patients who are uninsured. In 2011, about 1.9 million citizens out of a total population of 7.5 million, i.e. 25\% of the population, were uninsured (Bulgarian Medical Association, 2011). The population groups with the greatest risk of falling outside the health insurance system are unemployed persons, persons with informal employment and the Roma population (Bulgarian Medical Association, 2011; Rechel et al., 2009a; Rechel et al., 2009b) 
As in other countries in CEE (Stepurko et al., 2010), there are also widespread informal (under-the-counter) payments. The size of informal payments was estimated to be equal to $3.6 \%$ of public expenditure on health $(47.1 \%$ of all out-ofpocket payments) (Open Society Institute, 2008). These payments undermine the efficiency and equity of health care provision. Policy-makers were hoping that formal patient charges could help to "formalize" and eradicate informal contributions (Atanasova et al., 2010). However, recent evidence suggests that informal payments to physicians, nurses and hospital attendants continue to exist (Colombini et al., 2011; Rechel et al., 2011).

Out-of-pocket payments have become a major source of health financing in Bulgaria as already outlined in Chapter 1. However, up-to-date evidence on the distribution of these payments across socio-demographic groups is lacking. It is largely unknown whether official charges, combined with informal payments, are affordable for the population. This chapter aims to explore these issues.

Previous research has shown that out-of-pocket payments are characterized by a regressive distribution across income groups in Western Europe (van Doorslaer et al., 1999). However, in transitional countries, where out-of-pocket payments fill gaps in public health care funding, (Aarva et al., 2009; Balabanova et al., 2004; Bonilla-Chacin et al., 2005; Gaal et al., 2006a; Gotsadze et al., 2005; Sari et al., 2000) this is not always the case (Habibov, 2011). In some of these countries (low-income countries), out-of-pocket payments are equally distributed across income groups (Gotsadze et al., 2005; Habibov, 2011) although in others (high-income countries), their distribution is regressive (Gaal et al., 2006a). These figures may be biased as people who refrain from using health care because of out-of-pocket payments are usually not accounted for. Since Bulgaria is an upper-middle-income country in transition, we expect a moderate association between out-of-pocket payments and income. Given the general lack of studies on out-of-pocket expenditure in Bulgaria and other middle-income countries, our analysis contributes to the literature by shedding light on this issue. In addition to income, we also take into account other factors (such as socio-demographic factors, health status and insurance coverage) that are found to be related to out-of-pocket expenditure (Ruger \& Kim, 2007; Skarbinski et al., 2002; Walters \& Suhrcke, 2005).

\subsection{Methods}

In this chapter, we use data from two nationally representative cross-sectional surveys in Bulgaria, in July 2010 and July 2011, using face-to-face interviews based on a standardized questionnaire (with identical questions on health care use and 
expenditure in both years). The respondents are identified based on a multi-staged random probability method (see Section 1.6 Methodology and Appendix A).

The questionnaire includes questions on the total out-of-pocket payments for health care services (outpatient physician visits and hospitalizations) used by respondents during the preceding 12 months. Out-of-pocket payments are defined as direct payments for health care services, excluding monthly health insurance contributions and payments that the patient received back from the state or a health insurer. The respondents are asked to make a distinction between formal payments, for which one usually receives a receipt or other document, and informal payments, such as cash payments (including gratitude and under-the-table payments) and gifts in kind for receiving health care services.

We analyze the propensity and the number of outpatient visits and hospitalizations, the propensity and magnitude of total out-of-pocket payments, and informal payments for outpatient visits and hospitalizations, as well as difficulties in paying for health care (the need to take a loan or to forego services because of patient payments) and awareness of the exact fee size. We also examine the association between these (dependent) variables and a set of explanatory variables (sociodemographic characteristics, health and insurance characteristics, income per household member). For this purpose, we use regression analysis (logistic regression for binary dependent variables, and linear regression for continuous dependent variables) after pooling the data for both years. A year indicator is added.

\subsection{Results}

In total, 1003 respondents participated in the 2010 survey (response rate 67\%) and 817 in 2011 (response rate 61\%). The socio-demographic characteristics across the two years are pretty similar (see Appendix C). They are also broadly in line with those of the general population, as established by the 2011 national census.

Descriptive statistics on the use of and payments for health care services during the previous 12 months, as well as on the difficulties in paying for health care services, are presented in Table 3.1. As shown in the table, more than $70 \%$ of respondents in both years have visited a physician in the preceding 12 months, with the median number of visits being 3. More than $75 \%$ of users of physician services paid outof-pocket in 2010 and $84 \%$ paid in 2011. Of those who paid, 13\% paid informally in 2010 (about 10\% in 2011) and about 6\% borrowed money to pay for services (in both years). In total, $32 \%$ of the sample reported in 2010 foregoing physician visits due to high payments (median number of visits foregone $=2$ ). In 2011, this share is 
lower (26\%). Only about half of the respondents report that they are familiar with the fee size for outpatient services (in both years).

Table 3.1 Use of and payments for services during the preceding 12 months, 2010 and 2011 survey

\begin{tabular}{|c|c|c|c|c|c|}
\hline \multirow{2}{*}{ Variables } & & \multicolumn{2}{|c|}{ Outpatient physician visits } & \multicolumn{2}{|c|}{ Hospitalizations } \\
\hline & & 2010 & 2011 & 2010 & 2011 \\
\hline \multirow{2}{*}{$\begin{array}{l}\text { Used services during the } \\
\text { preceding } 12 \text { months (sample) }\end{array}$} & $0=$ No & $239(24.5 \%)$ & $226(27.7 \%)$ & $831(82.9 \%)$ & $689(84.3 \%)$ \\
\hline & $1=$ Yes & $736(75.5 \%)$ & $589(72.3 \%)$ & $171(17.1 \%)$ & $128(15.7 \%)$ \\
\hline \multirow{2}{*}{$\begin{array}{l}\text { Number of services per person } \\
\text { per year (users) }\end{array}$} & Mean (SD) & $5.9(7.3)$ & $5.5(5.7)$ & $2.3(7.7)$ & $1.5(1.0)$ \\
\hline & Median & 3.0 & 3.0 & 1.0 & 1.0 \\
\hline \multirow{2}{*}{$\begin{array}{l}\text { Paid out-of-pocket for services } \\
\text { used (users) }\end{array}$} & $0=$ No & $173(24.3 \%)$ & $92(16.0 \%)$ & $53(33.5 \%)$ & $45(36.9 \%)$ \\
\hline & $1=$ Yes & $540(75.7 \%)$ & $483(84.0 \%)$ & $105(66.5 \%)$ & $77(63.1 \%)$ \\
\hline \multirow{2}{*}{$\begin{array}{l}\text { Annual out-of-pocket } \\
\text { payments per person (payers) }\end{array}$} & Mean (SD) & $58.0(193.7)$ & $36.6(98.8)$ & $200.3(374.2)$ & $197.9(379.1)$ \\
\hline & Median & 12.0 & 10.0 & 50.0 & 48.0 \\
\hline \multirow{2}{*}{$\begin{array}{l}\text { Paid informally for } \\
\text { services used (payers) }\end{array}$} & $0=$ No & $491(87.4 \%)$ & $447(90.3 \%)$ & $73(68.2 \%)$ & $67(81.7 \%)$ \\
\hline & $1=$ Yes & $71(12.6 \%)$ & $48(9.7 \%)$ & $34(31.8 \%)$ & $15(18.3 \%)$ \\
\hline \multirow{2}{*}{$\begin{array}{l}\text { Annual informal payments } \\
\text { per person (informal payers) }\end{array}$} & Mean (SD) & $91.3(298.3)$ & $45.7(69.0)$ & $192.6(368.8)$ & $217.3(453.7)$ \\
\hline & Median & 30.0 & 20.0 & 20.0 & 60.0 \\
\hline \multirow{2}{*}{$\begin{array}{l}\text { Borrowed money to pay for } \\
\text { services used (payers) }\end{array}$} & $0=$ No & $545(94.3 \%)$ & $469(94.4 \%)$ & $94(81.0 \%)$ & $74(89.2 \%)$ \\
\hline & $1=$ Yes & $33(5.7 \%)$ & $28(5.6 \%)$ & $22(19.0 \%)$ & $9(10.8 \%)$ \\
\hline \multirow{2}{*}{$\begin{array}{l}\text { Amount borrowed per person } \\
\text { per year a (borrowed) }\end{array}$} & Mean (SD) & $323.2(441.3)$ & $115.8(145.6)$ & $440.5(386.9)$ & $511.2(487.7)$ \\
\hline & Median & 112.0 & 62.5 & 280.0 & 300.0 \\
\hline \multirow{2}{*}{$\begin{array}{l}\text { Forewent services due to } \\
\text { payments (sample) }\end{array}$} & $0=$ No & $651(68.0 \%)$ & $594(73.9 \%)$ & $925(93.9 \%)$ & $778(95.9 \%)$ \\
\hline & $1=Y e s$ & $307(32.0 \%)$ & $210(26.1 \%)$ & $60(6.1 \%)$ & $33(4.1 \%)$ \\
\hline \multirow{2}{*}{$\begin{array}{l}\text { Number of services foregone } \\
\text { due to payments (forewent) }\end{array}$} & Mean (SD) & $2.8(2.2)$ & $3.2(4.8)$ & $1.6(1.3)$ & $2.1(2.1)$ \\
\hline & Median & 2.0 & 2.0 & 1.0 & 1.0 \\
\hline \multirow{2}{*}{$\begin{array}{l}\text { Always knew the fee size } \\
\text { for services (sample) }\end{array}$} & $0=$ No & $542(54.1 \%)$ & $461(56.4 \%)$ & $772(77.0 \%)$ & $662(81.0 \%)$ \\
\hline & $1=Y e s$ & $460(45.9 \%)$ & $356(43.6 \%)$ & $230(23.0 \%)$ & $155(19.0 \%)$ \\
\hline
\end{tabular}

${ }^{a}$ Bulgarian leva $(B G N), 1 B G N \approx 0.5$ EUR

The average probability of hospitalizations is $17 \%$ in 2010 and $16 \%$ in 2011. In both years, over $60 \%$ of users report having made out-of-pocket payments for hospitalizations. Of those who paid, nearly two times more report to have paid informally in 2010 (32\%) than in 2011 (18\%). More than $10 \%$ of the users borrowed money to pay for services (in both years). About 6\% of the sample in 2010 and $4 \%$ of the sample in 2011 report foregoing hospitalizations due to high payments 
(median number of hospitalizations foregone $=1$ ). In both years, more than $70 \%$ of respondents are poorly informed about the exact size of formal user charges for hospital care.

It should be noted that for both types of services, the mean and median values of annual informal payments tend to exceed the mean and median values of annual out-of-pocket payments (formal and informal payments combined), since most payments are small formal payments.

Table 3.2 and 3.3 present the results of the regression analysis (the data for 2010 and 2011 are combined). Below we only describe the strong statistically significant differences $(\mathrm{p}<0.05)$. With regard to the use of outpatient services (Table 3.2), we find differences in terms of gender, self-reported health status, presence of a chronic disease, and social health insurance status. The use of outpatient physician services is more frequent among females, people with poor self-reported health, and those with chronic diseases, as well as among those with social health insurance. The annual number of visits is considerably higher for people with poor self-reported health and those with chronic diseases. Out-of-pocket payments are lower for those with private health insurance. The annual amounts paid are higher for those with a higher number of physician visits (see above), but also for younger individuals. With regard to informal payments for outpatient visits, these are more common among service payers with a chronic condition, but there are no statistically significant differences for the total amount of informal payments. Service payers who are younger, less healthy, have a chronic illness, or dispose of a low monthly household income, indicate a greater need to borrow money. The amounts borrowed are higher for those with social health insurance. Nearly all explanatory variables show statistical significance for visits foregone due to patient payments. In particular, younger, female, less healthy and chronically sick respondents, and those with low income and no social health insurance more often reported foregoing physician services than other groups.

Hospitalizations (Table 3.3) are more often reported by younger, less healthy and chronically sick respondents, and by those with social health insurance and lower income. The number of hospitalizations is higher among respondents with poor self-reported health and those with no social health insurance. Individuals with higher levels of education pay more out-of-pocket for hospitalizations. We do not observe strong statistically significant differences for total out-of-pocket payments, and total informal payments, except for younger individuals who made lower informal payments compared to older individuals. Individuals in large cities more often reported borrowing money to pay for hospital care than those in rural areas. 


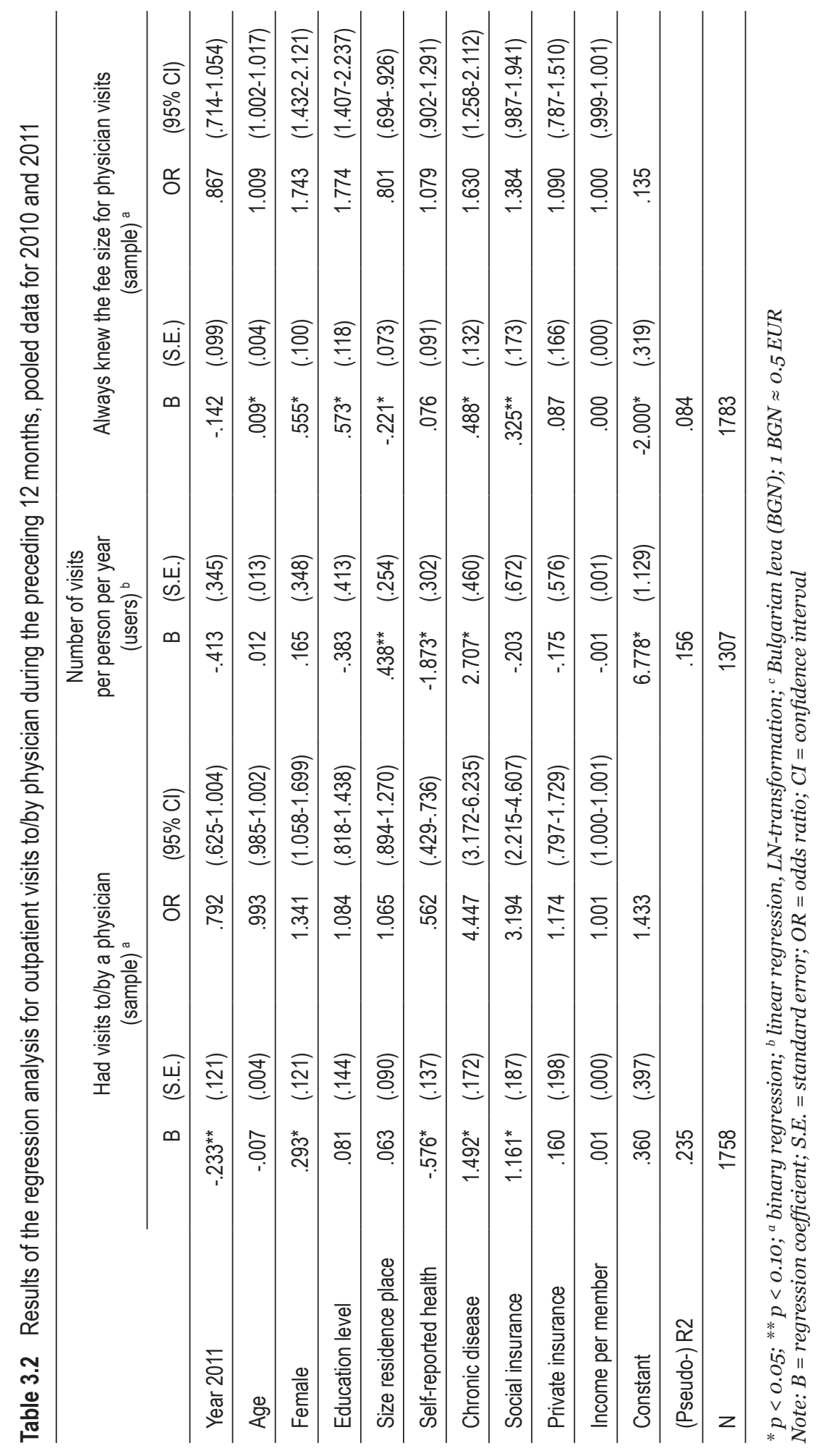




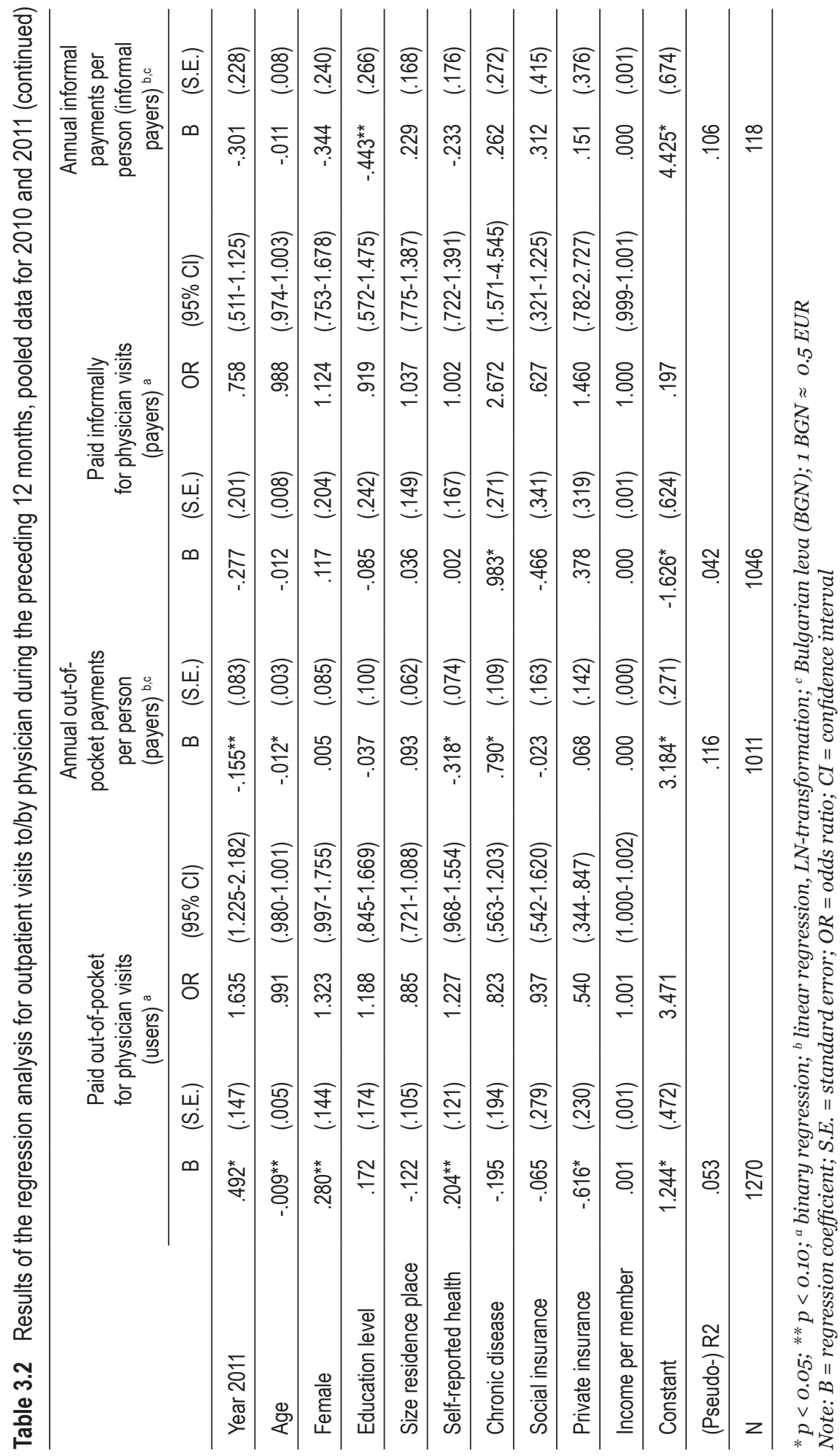




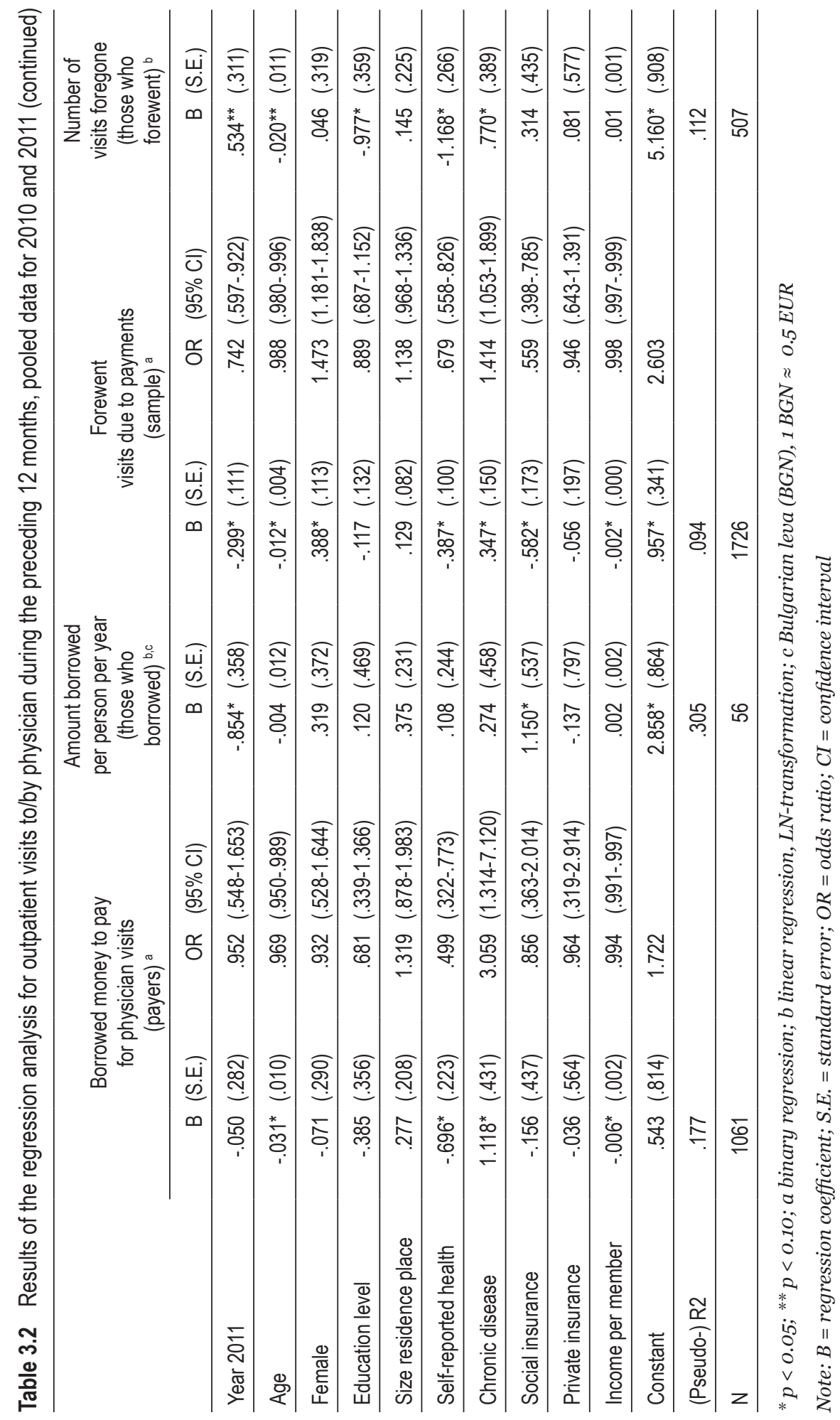




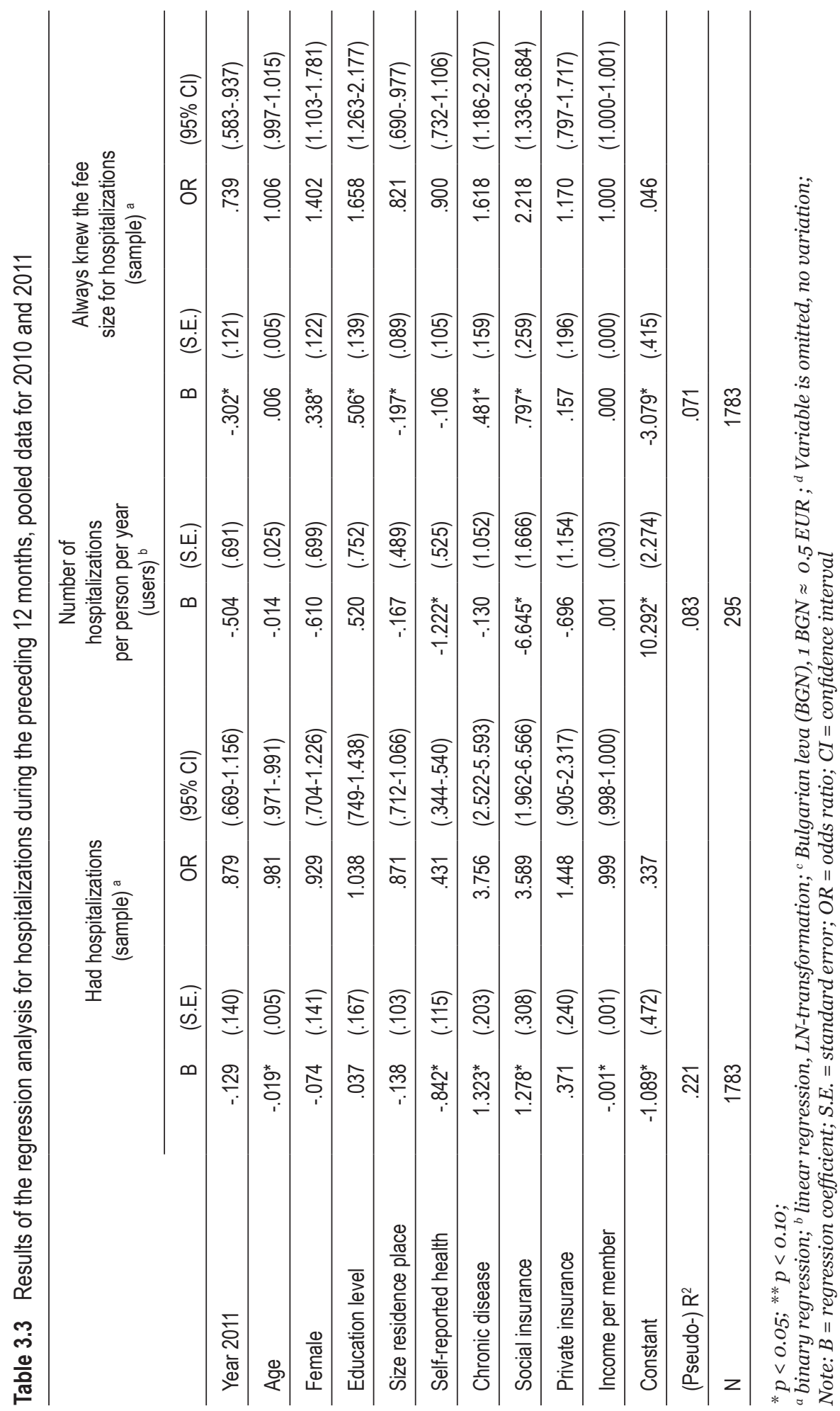




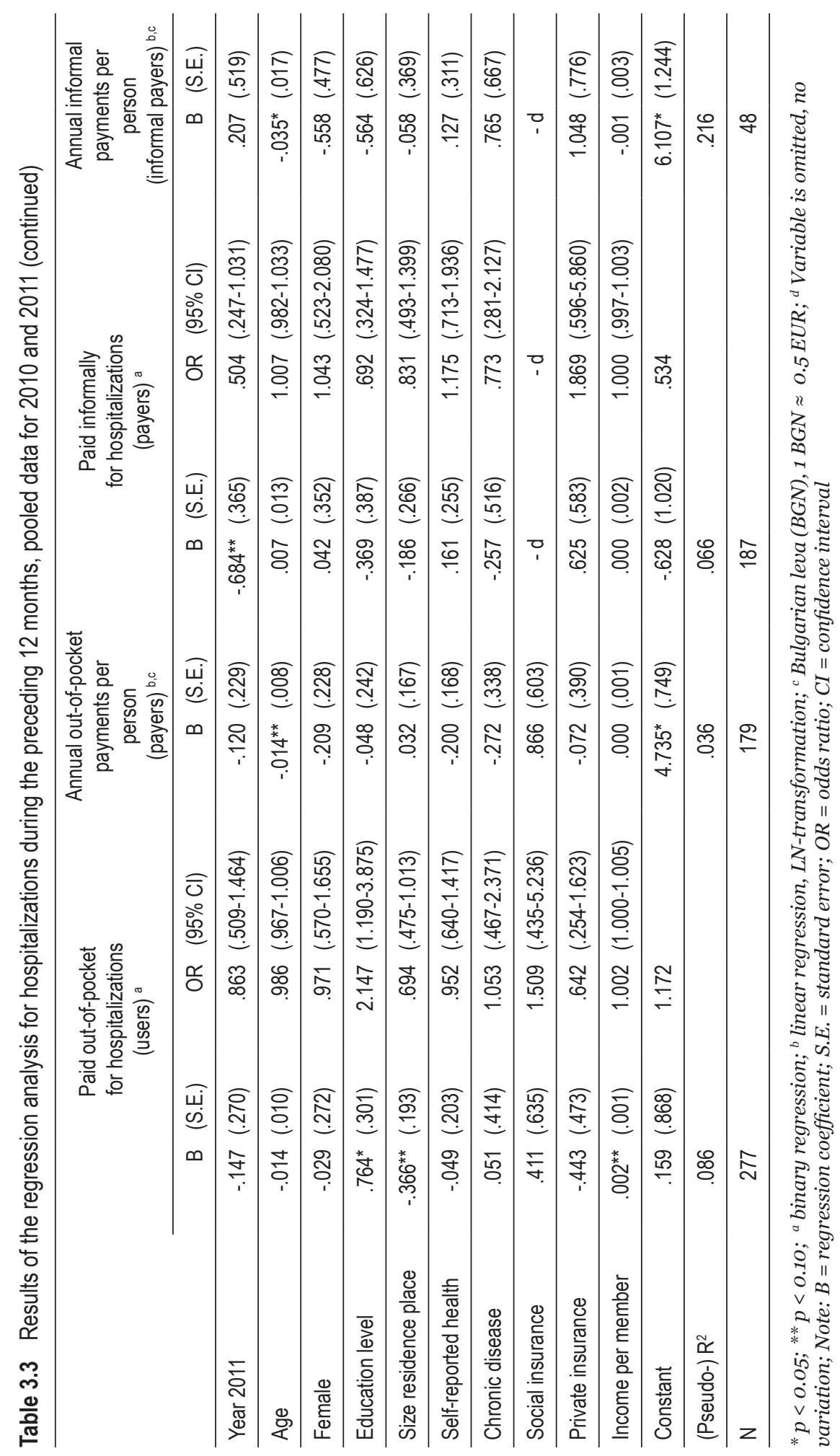




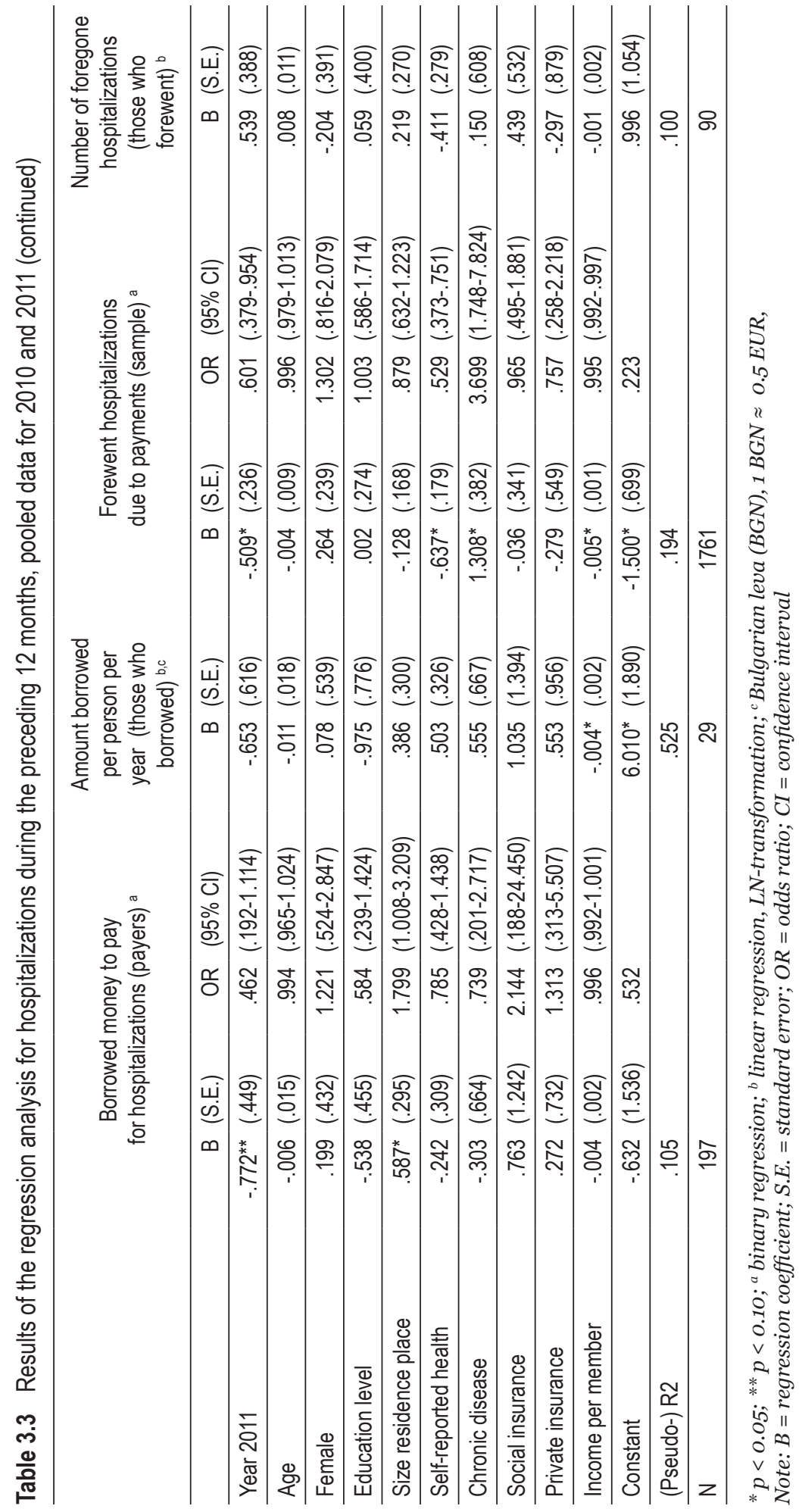


The amount borrowed is larger for low-income groups. The same groups who are more often hospitalized (except for those with social health insurance) also more often forewent hospitalizations.

Finally, Table 3.2 and 3.3 show that various groups, such as older people, women, those with higher levels of education, chronic illnesses, and poor self-reported health are better informed about the size of official user fees than other groups.

\subsection{Discussion}

This chapter has presented evidence of the out-of-pocket payments in Bulgaria and their distribution among the different population groups. Our study is not without limitations. These are mostly related to the short time period covered (only 2 subsequent years), a potential recall bias (a 12 month-recall period), and the cross-sectional design of the survey, with a low number of respondents in some categories.

Despite these limitations, our results provide important new evidence on the existence of a high financial burden of out-of-pocket payments for patients in Bulgaria, which is partly due to informal payments. Compared to previous studies, we observe similarities for outpatient care and differences for inpatient care. A survey carried out in 2006 in Bulgaria (Open Society Institute, 2008) found that the average amount of total patient payments (both formal and informal) for GP visits, specialist visits and hospital services was 11.29 BGN, 7.04 BGN and 5.76 BGN per person respectively. Our surveys suggest a similar average level of out-of-pocket payments for outpatient services (10-12 BGN for visits to GPs or specialists), but a much higher rate for inpatient care (48-50 BGN for hospitalizations). The similarity for outpatient care is to be expected because there have not been any major changes in the patient payment system for these services since 2006. The difference for inpatient services can partly be explained by the increased costs of hospital care, as well as with the lack of funds to adequately compensate physicians for the inpatient services they provide. These issues need to be addressed adequately in future health care reforms in Bulgaria.

Two earlier surveys conducted in Bulgaria in 1996 and 1997 (Ivanov et al., 1996; Balabanova \& McKee, 2002a) indicated a scale of informal payments for outpatient care similar to the one found in our surveys. However, the level of informal payments for inpatient services in our study is twice lower than in the studies mentioned above. This could be due to legislative changes adopted during recent years, such 
as the special ordinance adopted in 2006 (Official Gazette, 2006). It seems possible that part of the informal payments for hospital care is indeed transformed into official charges. However, the existence of informal patient payments for health care services clearly remains a major challenge in Bulgaria, although admittedly they are reported by only a small percentage of patients who paid for services.

The government's attempt to formalize informal payments is undermined by the general lack of awareness of the precise levels of official user fees, as strongly indicated by our results, as well as by earlier qualitative research (Rechel et al., 2011). Among the respondents of our survey, several groups of the population are more likely to know the levels of formal user charges prior to service use. This applied to older people, women, those with higher levels of education, chronic illnesses, and poor self-reported health status. A major part of our sample (more than $50 \%$ with regard to outpatient services and more than $75 \%$ with regard to hospital services), however, state that they do not always know the fee size prior to service use. This presents an important policy challenge, in particular as underdeveloped patient rights and lacking involvement of the population in health reforms have been identified as major impediments to improve the Bulgarian health care system. Patient rights (namely involving and informing patients) should be made a priority in order to increase transparency and minimize the abuse of the system by health care providers.

Our results confirm that Bulgarian patients experience a high burden of out-ofpocket payments for health care. In line with our expectations, we do not find a strong association between out-of-pocket payments and income. Thus, similar to other transitional countries (Gotsadze et al., 2005; Habibov, 2011) the poor and the rich bear roughly the same financial burden when using health care services. However, we observe in our study that low-income groups more often refrained from using inpatient and outpatient services because of the level of outpatient payments. Thus, out-of-pocket payments induce low-income individuals not to use care at all. More than 30\% of our respondents state the need to either borrow money or forego services due to payments. As in other countries in transition (Walters \& Suhrcke, 2005), this inability to pay is unevenly distributed across socio-demographic groups. It is especially pronounced among those with self-reported poor health status, people with chronic diseases, and those with low household income. Although respondents with social health insurance have better access to medical services, they also need to borrow money more often in order to use health services.

Overall, our findings suggest that there are considerable inequities in accessing health care services in Bulgaria that require the urgent attention of policy-makers. 


\section{Chapter 3}

One policy option is to revise the current system of exemptions, taking into account the family budget, the health status of patients and whether the person is included in any social program (i.e. receives social assistance). Some of the current exemptions (for example the exemption of physicians) seem to be both unfair and ineffective. Furthermore, the current system of user fees pushes individuals (especially those with low-income) to forego services or borrow money to pay for health care. The exclusion of a major part of the population from social health insurance is another obstacle to access health care services that has been recognized by the Ministry of Health as requiring urgent attention (Ministry of Health, 2008).

Although official patient charges have been implemented in Bulgaria from the outset of the social health insurance system, the weaknesses that prevent a more effective functioning of this mechanism remain. In order to achieve more equitable health financing, the system of patient payments would need to take account of the health and socio-economic status of patients. Furthermore, informal payments continue to exist, despite the increased reliance on formal charges for health care services. A number of measures will be necessary to eliminate this type of payments, including a stronger regulatory framework, higher and regularly paid salaries for health workers, more developed patient rights and redress mechanisms, increased public awareness, and social campaigns against informal payments. 
Chapter 4

INFORMAL PAYMENTS FOR HEALTH CARE SERVICES: THE EXPERIENCE OF BULGARIA AFTER 10 YEARS OF FORMAL CO-PAYMENTS

Published as:

Atanasova E, Pavlova M, Moutafova E, Rechel B, Groot W. (2013). Informal payments for health services: the experience of Bulgaria after 10 years of formal co-payments. European Journal of Public Health DOI:10.1093/eurpub/ckt165 


\section{Abstract}

Informal payments have been reported in Bulgaria both before and after the introduction of formal co-payments for services included in the basic benefits package in 2000. The aim of this chapter is to establish the current scale and type of informal payments, as well as public attitudes towards these payments. We use data from a nationally representative survey of 1003 individuals conducted in Bulgaria in July 2010 using face-to-face interviews based on a standardized questionnaire. Respondents are selected through a multi-stage random probability method. The questionnaire includes questions on total informal payments (in cash and in kind) for health care services used by the respondent during the preceding 12 months. About $13 \%$ of users report informal payments for outpatient visits and $33 \%$ of users report to have paid informally for hospitalizations. The average amount paid informally for inpatient services is nearly twice higher than that for outpatient services. More than $50 \%$ of the sample has negative attitudes towards informal payments both cash and in kind, but about $27 \%$ of respondents have a positive attitude towards giving gifts in kind. The results of the regression analysis show that respondents with higher levels of education have more negative attitudes towards informal cash payments. Positive attitudes towards gifts in kind are more often stated by citizens of larger cities. Informal payments continue to exist in Bulgaria irrespective of the formal co-payments introduced in 2000. Although the problem has been recognized in Bulgaria, policies should aim to eliminate the underlying structural reasons for such payments. 


\subsection{Introduction}

During the last 20 years, a growing number of studies have addressed the problem of informal (under-the-counter) payments by patients and demonstrated that these payments cannot solely be explained by the level of economic development (Cohen, 2012; Rechel \& McKee, 2009; Stepurko et al., 2010). Although informal payments are more common in low- and middle-income countries (including the post-communist CEE countries), they also exist in some high-income countries in Europe, such as Greece (Liaropoulos et al., 2008). Informal payments present a challenge for health policy-making, because they adversely affect the efficiency of health care provision and aggravate inequalities in access to health services (Ensor, 2004; Gaal et al., 2006b; Lewis, 2007; Pavlova et al., 2010b). Research on informal payments can therefore inform assessments of health care system performance.

The literature offers various theoretical explanations for the existence of informal payments, including a general culture of gifts, insufficient public resources for health care and weak health care system governance (Cohen, 2012; Gaal \& McKee, 2004; Rechel et al., 2011). Informal transactions can be initiated by consumers with the objective of expressing gratitude or obtaining services of higher quality, or by health workers to extract extra resources and increase their income. However, the semiillicit nature of informal payments does not allow an accurate assessment of their scale and scope (Gaal et al., 2006b; Delcheva et al., 1997; Pavlova et al., 2012).

Bulgaria, as a post-communist country, is no exception to the phenomenon of informal payments (Delcheva et al., 1997; Dimova et al., 2012a; Dimova et al., 2012b; Atanasova et al., 2011; Balabanova \& McKee, 2002). This chapter focuses on informal payments in the Bulgarian health care system and builds on the analysis of total out-of-pocket payments presented in Chapter 3. An interesting perspective in this analysis is the co-existence of formal and informal patient payments in the country. As indicated in Chapter 1, in 2000, formal co-payments have been introduced for services provided under the basic social insurance package. However, estimates suggest that a major part of total out-of-pocket payments (47.1\% in 2006) continue to be comprised of informal payments (OSI, 2008). Before the transition period (i.e. before the 1990s), almost all informal payments were gifts in kind (Dimova et al., 2012a). During the transition period, informal cash payments emerged on a large scale.

Already in 1994, the phenomenon of informal payments became the subject of empirical research in Bulgaria. Researchers (Delcheva et al., 1997) discussed two options to deal with informal payments: the enforcement of sanctions against staff 
accepting them, and the incorporation of these payments into the official financing stream of the health care system. However, the "culture of gifts" that underlies informal payments was rooted in long-standing traditions and could not be easily eradicated in a short period of time.

A study, carried out in 1997, i.e. shortly before the introduction of formal copayments in 2000, estimated the scale and determinants of informal payments, and explored reasons for paying informally, as well as the characteristics and timing of informal payments (Balabanova \& McKee, 2002). The results suggested that informal payments were relatively common in Bulgaria, in particular in the form of gifts given at the end of the treatment. However, informal cash payments to well-known physicians were most often given before or during the treatment. Attitudes towards informal payments ranged from strongly negative to tolerant. A nationally representative survey carried out in 2006 (Open Society Institute, 2008) explored the mechanisms, volume and forms of informal payments in the Bulgarian health care system, as well as related consumer attitudes. The study indicated that informal payments were a manifestation of "small" corruption, as they were activities in conflict with existing regulations and conducted primarily for personal gain. Overall, attitudes towards informal payments were strongly negative and patients were sensitive to any additional out-of-pocket costs (Open Society Institute, 2008).

Taking into account this earlier research, the aim of this chapter is to study the current scale and types of informal payments, as well as public attitudes and perceptions. We define informal payments as unregistered payments for health services included in the basic benefits package, given by patients to health care providers, and including cash payments and in kind gifts.

\subsection{Methods}

We use data from a nationally representative survey carried out in July 2010 in Bulgaria, resulting in 1003 completed questionnaires. The data collection is based on face-to-face interviews at the respondents' homes, using a standardized questionnaire. Respondents are selected through a multi-stage random probability method (see Section 1.6 Methodology and Appendix A). The response rate is $67 \%$. Information on socio-demographic variables is presented in Appendix C. The sociodemographic characteristics of the sample are similar to those established by the 2011 national census for the general population. 
The survey collected data on health care utilization by the respondents during the preceding 12 months, and respondents' out-of-pocket payments for health services (including informal payments). Two types of services are investigated: outpatient visits to physicians and inpatient hospital services. Outpatient visits to physicians are defined as including visits to GPs and medical specialists under the health insurance system, as well as outpatient visits to medical specialists in the private sector. Inpatient services are defined as hospitalizations (planned and emergency stays), as well as day treatments and day surgeries that require partial hospitalizations. Furthermore, the interviewers clarified at the beginning of the interviews that the term "out-of-pocket payments" included official payments, for which one usually receives a receipt or other document, informal cash payments (such as gratitude payments or under-the-table payments), or gifts in kind for receiving medical services. In addition, we collected data on whether respondents have ever given informal payments in cash or in kind, and on their awareness of the size of official user fees.

The survey also collected data on the respondents' attitudes towards informal cash payments and in kind gifts (exploring whether these attitudes are positive, negative or indifferent), whether they have been ever requested to pay informally, and whether they know the official fee for the respective service. The respondents are also asked to state whether given statements (five statements related to informal payment behavior) are applied to them (with the options: "yes", "no", and "somewhat").

Our analysis examines the propensity and magnitude of informal payments for outpatient visits to physicians and inpatient hospital services among health care users, as well as attitudes towards informal payments among all respondents. We examine the extent to which a set of explanatory variables (socio-demographic characteristics, self-declared health status, income per household member, individual perceptions about informal payments, and knowledge about official user fees) are associated with reported informal payments (the dependent variable). For this purpose, we carry out binary regression analysis for binary dependent variables and logarithmic linear regression to examine variations in the amount of informal payments made by users (i.e. we are applied a two part model assuming that decisions to pay informally are not related to payment amounts). A limitation of our analysis is that some linear regression analyses are based on very small groups of respondents. We also carry out ordinal regression analysis, using the same set of independent variables but with attitudes towards informal payments in either cash or in kind as the two dependent variables. We also carry out ordinal regression analysis to examine the association between the five perception statements mentioned above. 


\subsection{Results}

\subsubsection{Descriptive statistics}

Findings on utilization and out-of-pocket payments for outpatient and inpatient services are given in Table 4.1. In total, $74 \%$ of respondents visited a physician during the preceding 12 months. About $76 \%$ of these users of outpatient services report outof-pocket payments and $13 \%$ report informal payments. The average annual amount paid informally for outpatient visits is $92 \mathrm{BGN}$, equivalent to about 46 EUR.

Table 4.1 Descriptive statistics - informal payments, awareness, attitudes and perceptions

\begin{tabular}{|c|c|c|}
\hline Variables & Value range & Frequency N[\%] \\
\hline $\begin{array}{l}\text { Physicians visits during the preceding } \\
12 \text { months (sample) }\end{array}$ & $\begin{array}{l}0=\text { did not visit } \\
1=\text { visited }\end{array}$ & $\begin{array}{l}251(25.8 \%) \\
724(74.2 \%)\end{array}$ \\
\hline $\begin{array}{l}\text { Payment for visits during the preceding } \\
12 \text { months (users) }\end{array}$ & $\begin{array}{l}0=\text { did not pay } \\
1=\text { paid }\end{array}$ & $\begin{array}{l}165(23.7 \%) \\
529(76.3)\end{array}$ \\
\hline $\begin{array}{l}\text { Informal payments for physician visits } \\
\text { during the preceding } 12 \text { months (users) }\end{array}$ & $\begin{array}{l}0=\text { did not pay } \\
1=\text { paid }\end{array}$ & $\begin{array}{l}471(87.2 \%) \\
69(12.8)\end{array}$ \\
\hline $\begin{array}{l}\text { Annual amount paid informally for } \\
\text { physician visits, preceding } 12 \text { months (payers) }\end{array}$ & \multicolumn{2}{|c|}{$\begin{array}{l}\text { from } 2 \text { to } 2500 \text { BGN (median 30.00; } \\
\text { mean } 91.80 ; \text { SD 290.00) }\end{array}$} \\
\hline $\begin{array}{l}\text { Hospitalizations during the preceding } \\
12 \text { months (sample) }\end{array}$ & $\begin{array}{l}0=\text { not hospitalized } \\
1=\text { hospitalized }\end{array}$ & $\begin{array}{l}840(83.8 \%) \\
162(16.2 \%)\end{array}$ \\
\hline $\begin{array}{l}\text { Payment for hospitalizations during the preceding } \\
12 \text { months (users) }\end{array}$ & $\begin{array}{l}0=\text { did not pay } \\
1=\text { paid }\end{array}$ & $\begin{array}{c}50(33.5 \%) \\
100(66.5 \%)\end{array}$ \\
\hline $\begin{array}{l}\text { Informal payments for hospitalization during } \\
\text { the preceding } 12 \text { months (users) }\end{array}$ & $\begin{array}{l}0=\text { did not pay } \\
1=\text { paid }\end{array}$ & $\begin{array}{l}68(67.1 \%) \\
32(32.9 \%)\end{array}$ \\
\hline $\begin{array}{l}\text { Annual amount paid informally for } \\
\text { hospitalizations, preceding } 12 \text { months (payers) }\end{array}$ & \multicolumn{2}{|c|}{$\begin{array}{l}\text { from } 3 \text { to } 1500 \text { BGN (median 20.00; } \\
\text { mean 198.60; SD 375.83) }\end{array}$} \\
\hline $\begin{array}{l}\text { Have you ever personally paid INFORMALLY IN } \\
\text { CASH to personnel in health care facilities? (sample) }\end{array}$ & $\begin{array}{l}0=\text { No } \\
1=\text { Yes }\end{array}$ & $\begin{array}{l}795(80.7 \%) \\
190(19.3 \%)\end{array}$ \\
\hline $\begin{array}{l}\text { Have you ever personally given any GIFT IN KIND to personnel } \\
\text { in health care facilities? (sample) }\end{array}$ & $\begin{array}{l}0=\text { No } \\
1=\text { Yes }\end{array}$ & $\begin{array}{l}544(55.6 \%) \\
435(44.4 \%)\end{array}$ \\
\hline $\begin{array}{l}\text { Have you been ever PERSONALLY ASKED by personnel in } \\
\text { health care facilities to pay informally? (sample) }\end{array}$ & $\begin{array}{l}0=\text { No } \\
1=\text { Yes }\end{array}$ & $\begin{array}{l}808(83.1 \%) \\
164(16.9 \%)\end{array}$ \\
\hline $\begin{array}{l}\text { Do you know where to COMPLAIN if personnel in health care } \\
\text { facilities ask you to pay informally? (sample) }\end{array}$ & $\begin{array}{l}0=\text { No } \\
1=\text { Yes }\end{array}$ & $\begin{array}{l}553(61.3 \%) \\
349(38.7 \%)\end{array}$ \\
\hline
\end{tabular}


Table 4.1 Descriptive statistics - informal payments, awareness, attitudes and perceptions (continued)

Variables

Value range $\quad$ Frequency $\mathrm{N}[\%]$

\begin{tabular}{|c|c|c|}
\hline $\begin{array}{l}\text { Do you know the size of the official fees for medical services of } \\
\text { PHYSICIANS BEFORE you use such services? (sample) }\end{array}$ & $\begin{array}{l}0=\text { never } \\
1=\text { sometimes } \\
2=\text { always }\end{array}$ & $\begin{array}{l}181(18.1 \%) \\
374(37.4 \%) \\
446(44.5 \%)\end{array}$ \\
\hline $\begin{array}{l}\text { Do you know the size of the official fees for HOSPITAL services } \\
\text { related to hospital admissions BEFORE you use such services? } \\
\text { (sample) }\end{array}$ & $\begin{array}{l}0=\text { never } \\
1=\text { sometimes } \\
2=\text { always }\end{array}$ & $\begin{array}{c}368(36.8 \%) \\
414(41.3 \%) \\
220(22 \%)\end{array}$ \\
\hline $\begin{array}{l}\text { What is your attitude towards INFORMAL CASH PAYMENTS to } \\
\text { personnel in health care facilities? } \\
\text { (sample) }\end{array}$ & $\begin{array}{l}0=\text { negative } \\
1=\text { indifferent } \\
2=\text { positive }\end{array}$ & $\begin{array}{c}814(84.3 \%) \\
103(10.6 \%) \\
49(5.0 \%)\end{array}$ \\
\hline $\begin{array}{l}\text { What is your attitude towards GIVING GIFTS IN KIND to } \\
\text { personnel in health care facilities? } \\
\text { (sample) }\end{array}$ & $\begin{array}{l}0=\text { negative } \\
1=\text { indifferent } \\
2=\text { positive }\end{array}$ & $\begin{array}{l}519(54.1 \%) \\
181(18.9 \%) \\
258(27.0 \%)\end{array}$ \\
\hline $\begin{array}{l}\text { I will feel UNCOMFORTABLE if I leave the physician's office } \\
\text { without a gratitude cash payment or gift in kind. } \\
\text { (sample) }\end{array}$ & $\begin{array}{l}0=\text { no } \\
1=\text { somewhat } \\
2=\text { yes }\end{array}$ & $\begin{array}{l}782(78.1 \%) \\
153(15.3 \%) \\
67(6.7 \%)\end{array}$ \\
\hline $\begin{array}{l}\text { I would RECOGNIZE the hint of physicians or medical staff for } \\
\text { an informal cash payment or a gift in kind. } \\
\text { (sample) }\end{array}$ & $\begin{array}{l}0=\text { no } \\
1=\text { somewhat } \\
2=\text { yes }\end{array}$ & $\begin{array}{c}56(5.6 \%) \\
301(30.0 \%) \\
645(64.4 \%)\end{array}$ \\
\hline $\begin{array}{l}\text { I will REFUSE to pay if a physician or medical staff } \\
\text { ask me to pay informally for a medical service. } \\
\text { (sample) }\end{array}$ & $\begin{array}{l}0=\text { no } \\
1=\text { somewhat } \\
2=\text { yes }\end{array}$ & $\begin{array}{l}119(11.9 \%) \\
338(33.7 \%) \\
545(54.4 \%)\end{array}$ \\
\hline $\begin{array}{l}\text { I will PREFER to use private medical services if I have to pay } \\
\text { informally for public medical services. } \\
\text { (sample) }\end{array}$ & $\begin{array}{l}0=\text { no } \\
1=\text { somewhat } \\
2=\text { yes }\end{array}$ & $\begin{array}{l}166(16.6 \%) \\
312(31.2 \%) \\
523(52.3 \%)\end{array}$ \\
\hline $\begin{array}{l}\text { If I have SERIOUS PROBLEMS with my health, I will be ready } \\
\text { to pay as much as I have in order to get better medical services. } \\
\text { (sample) }\end{array}$ & $\begin{array}{l}0=\text { no } \\
1=\text { somewhat } \\
2=\text { yes }\end{array}$ & $\begin{array}{l}151(15.1 \%) \\
411(41.1 \%) \\
439(43.9 \%)\end{array}$ \\
\hline
\end{tabular}

The average probability of hospitalization is $16 \%$. Two-thirds (66.5\%) of the users of inpatient services paid out-of-pocket and one-third (32.9\%) paid informally. The average annual amount paid informally for inpatient services is nearly twice higher (198 BGN, about 100 EUR) than for outpatient services. Respondents who have ever paid informally in cash to physicians, medical staff or other personnel in health care facilities represented $19.3 \%$ of the sample, while $44.4 \%$ have ever personally given any gift in kind. 
Information on how respondents stated their attitudes and how they perceived their behavior towards informal payments is given in Table 4.1. More than 50\% of the sample has a negative attitude towards both informal cash payments (84.3\%) and giving gifts in kind (54.1\%). However, about $27 \%$ of respondents have a positive attitude towards giving gifts in kind. When respondents are asked to state how they perceived their behavior, $78 \%$ of the sample would not feel uncomfortable if they left the physician's office without gratitude cash payment or gift in kind. About 54\% of respondents would refuse to pay informally if a physician or other medical staff asked them to make such payments and 52\% would prefer to use private services to avoid paying informally. Two-thirds of respondents are certain that they would recognize hints of health workers for informal payments. However, only $15 \%$ of respondents would not be ready to pay as much as they have, if they have serious problems with their health.

\subsubsection{Results of the regression analysis}

Table 4.2 shows the results of binary and linear regression carried out on data for informal payments made by users for outpatient and inpatient services, respectively. In the binary regression, the dependent variable is coded with 1 if the user paid informally and with o if the user does not pay informally. In the linear regression, the logarithm of the amount of annual informal payments is used as dependent variable to be able to assume a normal distribution and to control for heteroscedasticity. Socio-demographic characteristics and perception behavior indicators (based on the 5 statements) are used as independent variables.

Informal payments for outpatient visits are more frequent among females and people with chronic diseases. We do not observe any statistically significant differences among socio-demographic variables in terms of informal payments for hospitalization. Although females paid more often for outpatient services than males, the amount they paid informally is lower. People with higher levels of education also paid smaller amounts for outpatient services than those with lower levels of education. When we analyze the perception indicators, we find that individuals who reported to refuse to make informal payments less frequently reported making such payments for both types of services. Equally unsurprisingly, those who feel uncomfortable to leave without cash payment or gift in kind, as well as those who prefer to use private services or who have been asked to pay informally, more often reported making informal payments for physician visits. 
Table 4.2 Results of the binary and linear regression - total informal payments per type of service

\begin{tabular}{|c|c|c|c|c|}
\hline & \multicolumn{2}{|c|}{$\begin{array}{l}\text { Informal payments for } \\
\text { physician visits (users) }\end{array}$} & \multicolumn{2}{|c|}{$\begin{array}{l}\text { Informal payments for hospitalization } \\
\text { (users) }\end{array}$} \\
\hline & $\begin{array}{c}0=\text { did not pay } \\
1=\text { paid }\end{array}$ & $\begin{array}{c}\text { LN (informal } \\
\text { payment amount) a }\end{array}$ & $\begin{array}{c}0=\text { did not pay } \\
1=\text { paid }\end{array}$ & $\begin{array}{c}\text { LN (informal } \\
\text { payment amount) }\end{array}$ \\
\hline & $N=664$ & $N=69$ & $N=157$ & $N=32$ \\
\hline & B (S.E.) & B (S.E.) & B (S.E.) & B (S.E.) \\
\hline Age & $-.017(.012)$ & $.010(.012)$ & $.028(.023)$ & $-.031(.033)$ \\
\hline Gender & $.497^{* *}(.299)$ & $-.747^{\star \star}(.444)$ & $.654(.513)$ & $-.695(.708)$ \\
\hline Place of residence & $-.264(.211)$ & $.252(.273)$ & $-.551(.387)$ & $.196(.462)$ \\
\hline Level of education & $-.249(.236)$ & $-.214(.282)$ & $.211(.428)$ & $-1.216^{* *}(.604)$ \\
\hline Self-reported health & $-.116(.248)$ & $.038(.306)$ & $-.004(.392)$ & $.029(.440)$ \\
\hline Chronically ill & $.873 *(.381)$ & $.038(.437)$ & $-.167(.726)$ & $.847(.776)$ \\
\hline Family size & $-.094(.125)$ & $.180(.163)$ & $.009(.245)$ & $-.396(.289)$ \\
\hline Family income & $.014(.023)$ & $-.014(.039)$ & $.091(.066)$ & $-.034(.072)$ \\
\hline Feels uncomfortable & $.593^{*}(.204)$ & $-.288(.236)$ & $.499(.365)$ & $.656(.464)$ \\
\hline Recognizes the hint & $-.233(.275)$ & $.464(.374)$ & $.165(.501)$ & $-.430(.586)$ \\
\hline Refuses to pay & $-.764^{*}(.204)$ & $.340(.254)$ & $-.977^{*}(.375)$ & $-.455(.534)$ \\
\hline Prefers to use private services & $.641^{*}(.233)$ & $-.565^{\star \star}(.328)$ & $-.417(.362)$ & $-.140(.402)$ \\
\hline Pays in case of serious problems & $-.042(.232)$ & $.279(.271)$ & $.043(.402)$ & $-.272(.567)$ \\
\hline Asked to pay informally & $1.027^{*}(.322)$ & $.378(.391)$ & $.657(.595)$ & $2.197^{\star}(.629)$ \\
\hline Know the size of official fees & $.154(.222)$ & $.345(.273)$ & $-.827^{*}(.382)$ & $1.211^{*}(.488)$ \\
\hline Know where to complain & $-.188(.320)$ & $.310(.446)$ & $.225(.582)$ & $.764(.860)$ \\
\hline Constant & $-1.641(1.169)$ & $1.700(1.188)$ & $-1.923(2.204)$ & $6.114(3.399)$ \\
\hline R Square & .183 & .337 & .321 & .748 \\
\hline
\end{tabular}

${ }^{*} p<0.05 ;{ }^{* *} p<0.10 ;{ }^{a}$ Bulgarian leva $(B G N) ; 1$ BGN $\approx 0.5$ EUR

Table 4.3 presents the regression results on the association of socio-demographic variables, stated behavior and awareness of official user charges with the respondents' attitudes regarding informal cash payments and gifts in kind. There are significant differences in the attitudes towards informal cash payments and gifts in kind by level of education and place of residence. The direction of the regression coefficient indicates the direction of the attitudes. Higher levels of education are associated with more negative attitudes towards informal cash payments. Positive attitudes towards gifts in kind are more often stated by citizens of large cities. 
Table 4.3 Results of the ordered probit regression - attitudes toward informal payments

\begin{tabular}{|c|c|c|c|c|}
\hline & \multirow{2}{*}{\multicolumn{2}{|c|}{$\begin{array}{l}\text { Attitude towards informal } \\
\text { cash payments to personnel in health } \\
\text { care facilities } \\
\text { 0=negative; } 1 \text { =indifferent; } 2=\text { positive }\end{array}$}} & \multirow{2}{*}{\multicolumn{2}{|c|}{$\begin{array}{c}\begin{array}{c}\text { Attitude towards giving gifts } \\
\text { in kind to personnel in health care } \\
\text { facilities }\end{array} \\
0=\text { negative; } 1 \text { =indifferent; } 2=\text { positive }\end{array}$}} \\
\hline & & & & \\
\hline & $B$ & (S.E.) & B & (S.E. ) \\
\hline Age & -.007 & $(.008)$ & -.004 & $(.005)$ \\
\hline Gender & -.199 & $(.207)$ & -.167 & $(.140)$ \\
\hline Place of residence & .191 & $(.159)$ & $.188^{* *}$ & $(.104)$ \\
\hline Level of education & $-.398^{*}$ & $(.177)$ & -.071 & $(.120)$ \\
\hline Self-reported health & .032 & $(.200)$ & .076 & $(.136)$ \\
\hline Chronically ill & .233 & $(.281)$ & .277 & $(.191)$ \\
\hline Family size & .031 & $(.082)$ & -.013 & $(.058)$ \\
\hline Family income & .012 & $(.019)$ & .018 & $(.015)$ \\
\hline Feels uncomfortable & $.860^{*}$ & $(.144)$ & $.748^{*}$ & $(.120)$ \\
\hline Recognizes the hint & $-.321^{* *}$ & $(.166)$ & -.119 & $(.120)$ \\
\hline Refuses to pay & $-.559^{\star}$ & $(.149)$ & $-.195^{\star *}$ & $(.107)$ \\
\hline Prefers to use private services & $-.261^{* *}$ & $(.150)$ & $-.188^{* *}$ & $(.104)$ \\
\hline Pays in case of serious problems & $.302^{* *}$ & $(.169)$ & $.475^{\star}$ & $(.112)$ \\
\hline Asked to pay informally & $-.728^{*}$ & $(.314)$ & $-1.121^{*}$ & $(.214)$ \\
\hline Knows the fees size (outpatient) & -.029 & $(.162)$ & $.208^{\star *}$ & $(.110)$ \\
\hline Knows the fee size (inpatient) & .040 & $(.158)$ & -.119 & $(.106)$ \\
\hline Threshold (0) & .511 & $(.797)$ & .434 & $(.544)$ \\
\hline Threshold (1) & $1.855^{*}$ & $(.805)$ & $1.338^{*}$ & $(.556)$ \\
\hline (Pseudo-) R2 & & & & \\
\hline
\end{tabular}

${ }^{*} p<0.05 ;{ }^{* *} p<0.10$

The results show that all perceived behavior statements have a statistically significant association with both types of attitudes. We observe positive associations for statements that indicate feeling uncomfortable when leaving without a gratitude payment and that indicate a willingness to pay informally in case of serious health problems. The remaining statements show a negative association. The ability to recognize the hint of a physician for an informal payment was associated with more negative attitudes towards informal cash payments. Knowledge of the size of user fees is only associated with the attitude towards gifts in kind with respect to outpatient services.

Table 4.4 presents the results of the ordinal regression. It gives the association between the five statements related to informal payment behavior and the awareness of respondents of official user fees (the dependent variables) and socio-demographic 
characteristics, supplemented by the number of physician visits and hospitalizations (the explanatory variables). Most of the explanatory variables have a statistically significant positive association with payment in case of a serious health problem. However, being younger and higher educated, as well as belonging to a household with a higher income and fewer family members, increased the probability of reporting to prefer to use private services instead of paying informally for public medical services.

We find a statistically significant positive association between the level of education and the ability to recognize a hint for an informal payment. We also observe that being a user (for both types of services), living in large cities and having a chronic disease increased the probability of reporting having ever paid informally. The size of official user fees for physician services tended to be known by older people, women, those living in rural areas, families with more members, and users of physician services in the preceding 12 months. People with higher levels of education, living in rural areas, having a chronic disease, and having been hospitalized in the preceding 12 months are more likely to know the official user fees for hospitalizations.

Table 4.4 Results of the ordered probit regression - behavior perceptions and awareness

\begin{tabular}{|c|c|c|c|c|c|}
\hline & $\begin{array}{c}\text { Feels } \\
\text { uncomfortable }\end{array}$ & $\begin{array}{c}\text { Recognizes } \\
\text { the hint }\end{array}$ & $\begin{array}{l}\text { Refuses } \\
\text { to pay }\end{array}$ & $\begin{array}{c}\text { Prefers to } \\
\text { use private } \\
\text { services }\end{array}$ & $\begin{array}{c}\text { Pays in case } \\
\text { of serious } \\
\text { problems }\end{array}$ \\
\hline & B (S.E.) & B (S.E. ) & B (S.E.) & B (S.E.) & B (S.E.) \\
\hline Age & $.008(.007)$ & $-.006(.006)$ & $-.001(.005)$ & $-.018^{*}(.005)$ & $-.015^{\star} \quad(.005)$ \\
\hline Gender & $.063(.166)$ & $-.090(.143)$ & $.115(.134)$ & $-.199(.136)$ & $.004(.132)$ \\
\hline Place of residence & $.078(.122)$ & $-.064(.106)$ & $.086(.099)$ & $.054(.100)$ & $-.166^{* *} \quad(.098)$ \\
\hline Level of education & $-.089(.138)$ & $.425^{*} \quad(.122)$ & $-.102(.112)$ & $.477^{*}(.115)$ & $.534^{*}(.112)$ \\
\hline Self-reported health & $.127(.160)$ & .068 (.141) & $-.207 \quad(.133)$ & $.155(.129)$ & $.358^{*}(.130)$ \\
\hline Chronically ill & $.175(.229)$ & $-.010(.204)$ & $-.215(.187)$ & $-.296(.189)$ & $.308^{* *}(.187)$ \\
\hline Family size & $.092(.068)$ & $.017(.060)$ & $-.042(.056)$ & $-.104^{* *}(.057)$ & $-.039(.056)$ \\
\hline Family income & $.035^{\star} \quad(.015)$ & $-.015(.014)$ & $-.028 * \quad(.013)$ & $.043^{*}(.016)$ & $.042^{*}(.015)$ \\
\hline Physicians visits & $-.053(.214)$ & $.695^{*}(.176)$ & $.161(.168)$ & $.499^{*} \quad(.172)$ & $.214 \quad(.165)$ \\
\hline Hospitalizations & $.612^{*} \quad(.222)$ & $.169(.213)$ & $-.330^{* *} \quad(.192)$ & $.115(.192)$ & $.632^{*}(.195)$ \\
\hline Threshold (0) & $2.563^{*}(.607)$ & $-2.229^{*} \quad(.530)$ & $-2.673(.495)$ & $-1.583^{*}(.494)$ & $-.996^{*} \quad(.481)$ \\
\hline Threshold (1) & $3.946^{*} \quad(.619)$ & $-.009 \quad .518)$ & $-891 \quad .486)$ & $-.012(.491)$ & $1.126^{*}(.481)$ \\
\hline (Pseudo-) R2 & .029 & .047 & .024 & .150 & .125 \\
\hline
\end{tabular}

${ }^{*} p<0.05 ;{ }^{* *} p<0.10$; 
Table 4.4 Results of the ordered probit regression - behavior perceptions and awareness (continued)

\begin{tabular}{|c|c|c|c|c|}
\hline & $\begin{array}{l}\text { Asked to pay } \\
\text { informally }\end{array}$ & $\begin{array}{l}\text { Knows the fee } \\
\text { size for out- } \\
\text { patient visits }\end{array}$ & $\begin{array}{c}\text { Knows the fee } \\
\text { size for } \\
\text { hospitalizations }\end{array}$ & $\begin{array}{l}\text { Knows where } \\
\text { to complain }\end{array}$ \\
\hline & B (S.E.) & B (S.E.) & B (S.E.) & B (S.E.) \\
\hline Age & $-.006(.007)$ & $.013^{*}(.005)$ & $.003(.005)$ & $-.005(.006)$ \\
\hline Gender & $-.013(.189)$ & $.407^{*}(.133)$ & $.175(.128)$ & $.102(.146)$ \\
\hline Place of residence & $.401^{*}(.140)$ & $-.247^{*}(.098)$ & $-.159^{* *} \quad(.095)$ & $-.172(.108)$ \\
\hline Level of education & $.279^{* *}(.157)$ & $.388^{*}(.113)$ & $.485^{*}(.108)$ & $.662^{*}(.124)$ \\
\hline Self-reported health & .248 (.181) & .009 (.131) & $-.206(.126)$ & $.283^{* *}(.147)$ \\
\hline Chronically ill & $.671^{*}(.253)$ & $.185(.186)$ & $.327^{* *}(.174)$ & $.353^{* *}(.204)$ \\
\hline Family size & $.121(.079)$ & $.135^{*}(.056)$ & $.015(.054)$ & $.010 \quad(.062)$ \\
\hline Family income & $-.017(.019)$ & $-.012(.013)$ & $.013(.013)$ & $.000 \quad(.015)$ \\
\hline Physicians visits & $.741^{*}(.280)$ & $1.224^{*}(.165)$ & -- & $.126(.185)$ \\
\hline Hospitalized & $.483^{*}(.246)$ & -- & $.990^{*} \quad(.185)$ & $.179(.210)$ \\
\hline $\begin{array}{l}\text { Threshold (0) } \\
\text { Threshold (1) }\end{array}$ & $3.615^{*}(.716)$ & $\begin{array}{rr}.499 & (.484) \\
2.445^{*} & (.491)\end{array}$ & $\begin{array}{rr}.017 & (.453) \\
1.971^{*} & (.459)\end{array}$ & $1.665^{\star} \quad(.537)$ \\
\hline (Pseudo-) R2 & .080 & .153 & .110 & .072 \\
\hline
\end{tabular}

${ }^{*} p<0.05 ;{ }^{* *} p<0.10$

\subsection{Discussion}

The results of our study confirm that informal payments for health care services continue to exist in Bulgaria even 10 years after the introduction of official copayments. Two earlier nationally representative surveys conducted in Bulgaria in 1996 and 1997, using a methodology comparable to ours, found a similar frequency of informal payments, ranging from $4 \%$ of respondents (including both users and non-users) in 1996 to 8\% in 1997 (Balabanova \& McKee, 2002a; Ivanov et al., 1996). Our study similarly finds that $7 \%$ of respondents have made informal payments for outpatient services during the preceding 12 months. However, the frequency of informal payments for inpatient services in our study is only about half that in previous studies (3.2\% in 2010 vs. 6-7\% of respondents in 1996 and 1997).

The results of our study also differ from findings of previous studies in other important ways. A survey carried out by the Open Society Institute in 2006 found that $49.5 \%, 36.6 \%$ and $10.8 \%$ of those who paid for GP visits, specialist visits and hospital services respectively, did so without receiving a receipt or other documents (Open Society Institute, 2008). Our study suggests a reverse pattern, with a higher 
likelihood of paying for hospital services than for outpatient care: about $13 \%$ of our respondents who paid for outpatient services do so informally, while this percentage increased to $32 \%$ for hospital services.

The discrepancies between the two studies might be due to the different methodologies used. In particular, the survey from 2006 used a broad definition to determine the size of informal payments, defining them as payments for which no document was issued. This included informal payments, but also official user charges which remained unregistered due to the tax-evasive behavior of health care providers. This broad definition is likely to be the reason for the high percentage of informal payments for outpatient visits to GPs and specialists found in the 2006 survey. These health care providers often have single practices and patients pay directly to the physician. Thus, administrative control of patient payments is lacking. In contrast, in our study we follow the patient perspective and define informal payments as those payments that are not formally regulated and should not be made by patients, omitting unregistered formal co-payments.

Furthermore, we explicitly included both informal cash payments and in kind gifts, which was not done in the 2006 study. It is therefore not surprising that our study indicates a higher percentage of respondents who paid informally for hospital care, as in kind gifts have been found to be more widespread in inpatient care (Allin et al., 2006).

Although our results suggest that most health care consumers are against the practice of informal cash payments and agree that informal payments should be eradicated, informal payments in the form of gifts in kind still seem to be accepted by a sizeable minority (27\% of respondents in our sample). The latter type of informal payments appears to be more entrenched in the perceptions and behaviors of patients and providers. One reason might be that they usually follow the treatment received, taking the form of "gratitude payments" initiated by patients themselves. This practice is associated with traditions going back to the communist period, (Gaal \& McKee, 2004; Dimova et al., 2007) and its elimination seems to be much more difficult. Indeed, a survey carried out in 2006 found that about $50 \%$ of respondents agreed with the statement that satisfied patients have to be grateful to the physician and should demonstrate this by giving gifts or money (Open Society Institute, 2008).

Another interesting finding of our study is that slightly more than half of respondents stated that they would prefer to use private services instead of paying informally for public services. We assume that this preference is due to a perceived greater transparency of prices for private services. 
Studies conducted in other CEE countries provide evidence that the general public is interested in overcoming the problem of informal payments, but often accepts these payments as a means to receive more attention, better quality and quicker access when using health services (Murauskiene et al., 2012; Danyliv et al., 2012; Golinowska \& Tambor, 2012; Baji et al., 2012).

In conclusion, our study contributes important new evidence on the persistence of informal payments in Bulgaria. It also provides new insights into consumer attitudes towards gifts in kind and informal cash payments. Perhaps most importantly, the Bulgarian experience shows that official user charges alone are insufficient to eliminate informal payments, as they complement rather than substitute for informal payments. Efforts to overcome informal payments will need to be based on comprehensive and well-sequenced reform efforts that ensure improved quality of care and increased public allocations to the health sector, including salaries of health workers. Furthermore, informal payments indicate wider failures of governance, regulation and accountability (Rechel et al., 2011). They can be due to a general distrust of the political system and state institutions, as well as broader patterns of corruption, (Cohen, 2012; Baji et al., 2011) and therefore call for improved transparency, clarity on entitlements and mechanisms for redress, and the adoption and enforcement of appropriate laws and regulations. In view of this, a broader research perspective on informal payments should be considered, focusing on the causes of corruption in all sectors of society. 
Chapter 5

PATIENT CHARGES FOR HEALTH CARE SERVICES: THE OPINIONS OF HEALTH CARE STAKEHOLDERS IN BULGARIA

Published as:

Atanasova E, Pavlova M, Moutafova E, Kostadinova T, Groot W. (2013). Patient charges for health services: the opinions of healthcare stakeholders in Bulgaria. The International Journal of Health Planning and Management DOI:10.1002/ hpm.2229 


\section{Chapter 5}

\section{Abstract}

The reforms of the Bulgarian health care sector have been widely discussed (see Chapter 2). In spite of the reforms, problems with the efficiency, equity and quality in health care provision continue to exist in Bulgaria. Among others, the reforms included the implementation of formal patient charges for the use of health care services. These were established in the country in 2000. Formal patient charges are applied to all levels of medical services with the exception of emergency care. The objective of this chapter is to describe and analyze the attitudes of Bulgarian health care stakeholders towards patient charges. The analysis is based on data collected in focus group discussions and in-depth interviews carried out in Bulgaria in May-June 2009. The question of patient payments for health care services appears a major challenge for the Bulgarian government. The legislation on patient payments in Bulgaria needs to be carefully revised and the application of these payments should be specified. The social sensitivity of these payments requires broad discussion before policy decisions are implemented. These decisions should be based on public opinions and research evidence. There is also a need of a wellthought communication strategy on the issue of patient payments by the Ministry of Health. 


\subsection{Introduction}

Patient charges for health care services are applied in many European countries (Tambor et al., 2011). Bulgaria is no exception to that. These charges are often implemented with the goal to reduce the demand for unnecessary health care services, to reallocate health care expenditures from public to private resources and/or to collect additional funds in order to improve the sustainability and quality of the health care system (Pavlova et al., 2010a). However, the implementation of patient charges for services is affected by the historical development of the health care sector, as well as by social values and believes of the population (Tambor et al., 2011).

In Bulgaria, the implementation of such charges as part of the social health insurance system (see Chapter 1, Section 1.2) ended the tradition of free of charge service delivery inherited from the health care system during the communist period. Moreover, they were introduced in a context of persistent informal (under-the-table) patient payments (Delcheva et al., 1997; Dimova et al., 2007; OSI, 2008), which continues to exist at present as discussed in Chapter 3 and 4. The new formal charges were introduced following the example of Western European countries with insurance-based health care systems, and they caused quite a lot of discussion in society. The arguments for the introduction of patient charges for health care services are related to three main factors. First, patient charges are expected to reduce unnecessary use of health care services. Second, such charges can improve physicians' motivation to provide better care since the providers are the beneficiaries of the charges. In the outpatient sector, physicians who have enough patients on their list, can receive substantial additional income from these charges. Third, patient charges provide signals to citizens that medical care has a cost and is not free of charge (Ministry of Health, 1998). The complex system of patient charges in Bulgaria has been described in Chapter 3 (see Section 3.1 Introduction).

Despite the length of the experience with formal patient charges in Bulgaria, their acceptability by health care stakeholders has not yet been sufficiently studied. However, in recent years, one of the directions of the reforms was to increase the share of the health care costs which is paid by the patient officially. Nevertheless, traditions inherited from the communist period based on the idea of free of charge universal health care provision and the deterioration in the socio-economic situation in the country (impoverishment of the population) have led to vivid discussions regarding the existence and design of these charges (National Association of General Practitioners in Bulgaria, 2013). The relevance of this issue is especially high in times of government elections. 
The aim of this chapter is to analyze the attitudes of different health care stakeholder (consumers, providers, policy-makers and insurers) towards the official patient charges introduced in 2000 and to provide new insights on this topic. Only one publication has discussed similar issues regarding user fees as well as their feasibility for Bulgaria (Pavlova, 2002). However, this study was carried out in 2000, i.e. the same year as when formal co-payments were established, and it focused on the attitudes of health care consumers only. We use data collected in 2009 among various health care stakeholders, which provides a more up-to-date picture of the attitudes towards formal patient charges.

\subsection{Data collection and analysis}

For the purpose of the study, we use a mix of qualitative and quantitative data. Qualitative data are obtained using focus group discussions and in-depth interviews carried out in Bulgaria in May-June 2009. The objective is to study the opinions and attitudes towards patient payments of different stakeholders in the health care system. Stakeholders from four basic target groups are included, namely health care consumers, health care providers, health insurance representatives and policymakers. Consumer groups include working individuals, families with children, pensioners, students, disabled and chronically sick individuals, and individuals living in rural areas. Health care providers include GPs, outpatient specialists, physicians and nurses in city hospitals, GPs practicing in rural areas and physicians in district hospitals, respectively. With regard to health insurance representatives and policy-makers, they are represented at the national and regional level.

Data among health care consumers and providers are collected via focus group discussions. Since these target groups are rather large and diverse, focus groups discussions allow including more individuals. Nevertheless, the objective has been to assure the homogeneity of each focus group in order to reach consensus during the discussion more easily. As a result, 12 focus group discussions are organized: 6 focus groups with consumers and 6 focus groups with health care providers. On average each focus group included 8 participants. The groups are composed based on the description of these two target groups presented above.

The data among policy-makers and health insurance representatives are collected via face-to-face semi-structured in-depth interviews. The choice of the datacollection method is based on the fact that these target groups are relatively small and moreover, they might feel more comfortable to express their opinion if contacted individually. In total, 5 in-depth interviews are carried out with policy-makers and 5 in-depth interviews with health insurance representatives. 
For the purpose of the focus group discussions and in-depth interviews, a list with key questions is developed based on a preliminary literature review. The same key questions are used for all target groups with slight modifications to reflect the specificity of a given target group. The key questions are used to develop guides for focus group discussions and in-depth interviews, as well as a standardized questionnaire (see Appendix D) to collect additional quantitative data on the topic right after the completion of a group discussion and interview.

The qualitative data are tape-recorded and then transcribed. The method of content analysis is applied based on the transcripts from the focus group discussions and in-depth interviews. We use meaningful units related to respondents' opinions and attitudes towards patient payments. They include:

- $\quad$ whether official patient charges for health services should exist in Bulgaria;

- for which services should user charges be applied;

- which population groups should be exempted from charges;

- what should be the primary policy objective of patient charges;

- $\quad$ who should be the beneficiary of the revenues collected.

The opinion of health care consumers, health care providers, policy-makers and health insurance representatives is analyzed using the above units of discussion.

In order to increase the validity of the results of the qualitative analysis, we compare them to the results of the quantitative data collected among the participants via the standardized questionnaire (Appendix D). The main issues discussed in the focus group discussions and interviews (incl. the abovementioned units), are repeated in the questionnaire and thus, the qualitative and quantitative data in our study are comparable. The quantitative data comprise binary variables. Kruskal Wallis H Test is used to determine whether the opinion about the units received equal support among stakeholders groups (health care consumers, health care providers and policy-makers and insurers). If we observe differences between the groups, then a Mann-Whitney U test is performed to identify which groups differ.

\subsection{Qualitative results}

\subsubsection{The opinion of health care consumers}

The attitudes of consumers towards formal patient payments are divided. Pensioners, working individuals, disabled and chronically sick people are overall against official patient payments. 
"I cannot pay the fees. For me, these are two yogurts. But, even when you give money to the doctor - the service is awful" (disabled person).

"We should not be paying extra because we pay for health insurance. We do not know what happens with patient charges" (pensioner).

Contrary to that, students and families with children support the existence of patient charges. However, this second group is against patient payments for emergency care. The first group shares the opinion that the social and economic status should be the main criterion for the exemption of patients from payment obligations, whereas the second group accepts age and health status as a basis for such exemptions, e.g. children, pregnant women, people with chronic diseases.

With regard to the policy goals of formal patient payments, a consensus exists among consumers that these payments generate additional financial resources for the health care system and discourage unnecessary use of medical care, thus, contributing to the sustainability of the health care system. A consensus also exists that it is impossible to reduce the existing informal patient payments by the introduction of official charges.

"Several generations must be changed in order to change the culture of the Bulgarians" (working individual).

\subsubsection{The opinion of health care providers}

The opinion of health care providers on formal patient payments is unanimous. Providers indicate that these payments restrict health care demand, and have an educational and financial function.

"The fees are a regulator of utilization and a source of additional income. Those fees make medical services valued by consumers" (GP, city).

According to health care providers, the current direct collection of formal patient payments by physicians is an insult to their professional status and has to change in a formal administrative collection of revenues. Some providers point out that the magnitude of patient payments should reflect the type and quality of services provided. Providers commonly suggest that the current co-payments in Bulgaria are low and need to be increased up to 2 to $4-5 \%$ of the minimum monthly salary 
for the country for outpatient and hospital care respectively. Health care providers working in the city think that formal patient payments should apply to all types of health care.

\footnotetext{
"Ministry of Health should pay fees for emergency services. More than two-thirds of patients do not need emergency care, but we are obliged to check them" (physician, city hospital).
}

At the same time, providers in rural areas and district hospitals do not accept patient payments for emergency care and services of general practitioners respectively. Health care providers are unanimous that the existence of informal patient payments is not affected by the introduction of formal ones. They point at a number of additional problems in the Bulgarian health care system, including problems with uninsured patients and the absence of an adequate system of calculating costs in the medical services.

\subsubsection{The opinion of health insurance representatives}

Health insurance representatives support the existence of official patient charges although there are occasional views against these payments. They find the magnitude of current co-payments appropriate because according to them it is affordable for patients.

"Another question is how to collect the fee. There should be no exchange of money between doctor and patient. This is humiliating" (insurer, national level).

Some insurance representatives express the opinion that patient payments should be related to the service type and to whether the patients' route is determined by a physician (referral) or by the patient's personal choice.

The view prevails that co-payments are currently the most appropriate form of patient payments in Bulgaria but there are opinions in favor of deductibles (payments of the actual service cost/price up to a given limit) and co-insurance (fees equal to a given percentage of the actual service cost/price).

"In Bulgaria there is a tradition with co-payment and this option is better" (insurer, regional level).

Health insurance representatives suggest exemptions from patient payments related to health status and demographics (children, pregnant women and 
chronically sick), as well as socio-economic status (e.g. pensioners and low-income people). Exemptions for health care providers are also proposed. Health insurance representatives agree that the policy objective of official patient charges should be the restriction of health care demand but these charges do not present a mechanism capable of reducing informal payments in Bulgaria.

\subsubsection{The opinion of policy-makers}

Policy-makers indicate that formal patient payments are in accordance with the health insurance philosophy and therefore, they should exist. However, there are concerns that the way these payments are applied in Bulgaria causes dissatisfaction for both consumers and providers. The predominant view is that the magnitude of the current patient charges is overall adequate but it is necessary to differentiate them by the patients' socio-economic status. Some policy-makers propose the application of deductibles that are updated annually, as a more suitable option than the current co-payments determined by the minimum monthly salary for the country.

There is no unanimity for which health care services patients should pay directly out-of-pocket. The opinions vary from the existence of official patient charges at all levels of health care to their total rejection. Patient payments for emergency and hospital care are especially controversial. However, the opinion prevails that children, pregnant women and disabled people should be exempted from patient payments.

\footnotetext{
"Pensioners should be exempted or should pay patient charges up to a fixed ceiling on pensions" (policy-maker, national level).
}

The reduction of unnecessary health care use, the generation of additional resources and an increase in providers' income are proposed as key policy objectives of patient payments. Policy-makers admit the fact that official patients are not capable of reducing the widespread informal payments.

\subsubsection{Comparison between the groups}

The opinions of the four groups are divided with regard to who should be the beneficiary of patient charges. Consumers most often point to the social health insurance fund at a national level and the physician who offers the service, and rarely to the health institution where the service is offered and to the state. The opinion of the health care providers is not surprising. All except the group of nurses are unanimous that physicians should benefit from the fees. In Bulgaria, patient 
payments are a source of additional income for the providers and, although they are not of crucial significance, the providers have an interest in their existence. For the policy-makers, it is the physician who offers the services who should receive these payments, while for the health insurance representatives those should be the health organizations which create the environment and the conditions for treatment.

Health care consumers and providers do not support higher patient payments for more expensive health services or for services with better quality.

If official patient payments exist and there is a limitation on these payments per patient, policy-makers and insurers may define what this limitation should be and what the maximum total fee per month/year should be. According to the consumers and health care providers this limitation on patient payments should be defined by the maximum number of services per patient per month/year.

\subsection{Quantitative results}

Table 5.1 shows the quantitative results and indicates the differences in opinions of stakeholder groups about formal patient charges. The highest acceptance for official charges (80\%) is stated among health care providers and policy-makers/insurers. There are no significant differences between these groups in their opinion about the existence of fees. However, health care consumers are less uniform in their perceptions.

Table 5.1 Quantitative results - opinion of the health care stakeholders in the study

\begin{tabular}{llcccccc}
\hline & & \multicolumn{2}{c}{$\begin{array}{c}\text { Health care } \\
\text { consumers }(\mathrm{N}=44)\end{array}$} & $\begin{array}{c}\text { Health care } \\
\text { providers }(\mathrm{N}=48)\end{array}$ & $\begin{array}{c}\text { Policy-makers } \\
\text { \& insurers (N=10) }\end{array}$ \\
\cline { 3 - 8 } & $\mathrm{N}$ & $\%$ & $\mathrm{~N}$ & $\%$ & $\mathrm{~N}$ & $\%$ \\
\hline Official patient changes for & 0 = strongly disagree & $8 \mathrm{a}, \mathrm{b}$ & 18.2 & 1 & 2.1 & 0 & 0 \\
health care services & 1 = disagree & 10 & 22.7 & 4 & 8.3 & 2 & 20 \\
should exist in Bulgaria & 2 = neutral & 5 & 11.4 & 2 & 4.2 & 0 & 0 \\
& $3=$ agree & 16 & 36.4 & 12 & 25.0 & 5 & 50 \\
& 4 = strongly agree & 5 & 11.4 & 29 & 60.4 & 3 & 30 \\
\hline
\end{tabular}

The primary policy objective of patient charges for health care services should be:

\begin{tabular}{lccccccc}
\hline - efficiency improvement & Yes & $18^{\mathrm{b}}$ & 40.9 & $28^{\mathrm{c}}$ & 58.3 & 10 & 100 \\
& No & 26 & 59.1 & 20 & 41.7 & - & - \\
- $\quad$ generation of additional resources & Yes & $21^{\mathrm{b}}$ & 47.7 & $19^{\mathrm{c}}$ & 39.6 & - & - \\
& No & 23 & 52.3 & 29 & 60.4 & 10 & 100 \\
- dealing with informal patient payments & Yes & 3 & 6.8 & 1 & 2.1 & - & - \\
& No & 41 & 93.2 & 47 & 97.9 & 10 & 100 \\
\hline
\end{tabular}


Table 5.1 Quantitative results - opinion of the health care stakeholders in the study (continued)

\begin{tabular}{|c|c|c|c|c|c|c|c|}
\hline & & \multicolumn{2}{|c|}{$\begin{array}{c}\text { Health care } \\
\text { consumers }(\mathrm{N}=44)\end{array}$} & \multicolumn{2}{|c|}{$\begin{array}{c}\text { Health care } \\
\text { providers }(\mathrm{N}=48)\end{array}$} & \multicolumn{2}{|c|}{$\begin{array}{c}\text { Policy-makers } \\
\text { \& insurers }(N=10)\end{array}$} \\
\hline & & $\mathrm{N}$ & $\%$ & $\mathrm{~N}$ & $\%$ & $\mathrm{~N}$ & $\%$ \\
\hline \multicolumn{8}{|c|}{ Patient charges for services should be applied to the following services: } \\
\hline - $\quad$ primary care (GP services) & $\begin{array}{l}\text { Yes } \\
\text { No }\end{array}$ & $\begin{array}{c}24 \text { a,b } \\
20\end{array}$ & $\begin{array}{l}54.5 \\
45.5\end{array}$ & $\begin{array}{l}36 \\
12\end{array}$ & $\begin{array}{l}75 \\
25\end{array}$ & $\begin{array}{l}9 \\
1\end{array}$ & $\begin{array}{l}90 \\
10\end{array}$ \\
\hline - services of outpatient specialist & $\begin{array}{l}\text { Yes } \\
\text { No }\end{array}$ & $\begin{array}{c}29^{a} \\
15\end{array}$ & $\begin{array}{l}65.9 \\
34.1\end{array}$ & $\begin{array}{c}41 \\
7\end{array}$ & $\begin{array}{l}85.4 \\
14.6\end{array}$ & $\begin{array}{l}8 \\
2\end{array}$ & $\begin{array}{l}80 \\
20\end{array}$ \\
\hline - $\quad$ inpatient hospital services & $\begin{array}{l}\text { Yes } \\
\text { No }\end{array}$ & $\begin{array}{c}23^{a} \\
21\end{array}$ & $\begin{array}{l}52.3 \\
47.7\end{array}$ & $\begin{array}{c}40 \\
8\end{array}$ & $\begin{array}{l}83.3 \\
16.7\end{array}$ & $\begin{array}{l}8 \\
2\end{array}$ & $\begin{array}{l}80 \\
20\end{array}$ \\
\hline - $\quad$ emergency room services & $\begin{array}{l}\text { Yes } \\
\text { No }\end{array}$ & $\begin{array}{c}5 \\
39\end{array}$ & $\begin{array}{l}11.4 \\
88.6\end{array}$ & $\begin{array}{l}10 \\
38\end{array}$ & $\begin{array}{l}20.8 \\
79.2\end{array}$ & $\begin{array}{l}- \\
10\end{array}$ & - \\
\hline
\end{tabular}

The following groups should be exempted partly or fully from patient charges for services:

\begin{tabular}{|c|c|c|c|c|c|c|c|}
\hline - children & $\begin{array}{l}\text { Yes } \\
\text { No }\end{array}$ & $\begin{array}{c}40^{a} \\
4\end{array}$ & $\begin{array}{c}90.9 \\
9.1\end{array}$ & $\begin{array}{l}31 \\
17\end{array}$ & $\begin{array}{l}64.6 \\
35.4\end{array}$ & $\begin{array}{l}8 \\
2\end{array}$ & $\begin{array}{l}80 \\
20\end{array}$ \\
\hline pensioners & $\begin{array}{l}\text { Yes } \\
\text { No }\end{array}$ & $\begin{array}{c}34^{a} \\
10\end{array}$ & $\begin{array}{l}77.3 \\
22.7\end{array}$ & $\begin{array}{l}9^{c} \\
39\end{array}$ & $\begin{array}{l}18.7 \\
81.3\end{array}$ & $\begin{array}{l}6 \\
4\end{array}$ & $\begin{array}{l}60 \\
40\end{array}$ \\
\hline people with low income & $\begin{array}{l}\text { Yes } \\
\text { No }\end{array}$ & $\begin{array}{c}28^{a} \\
16\end{array}$ & $\begin{array}{l}63.6 \\
36.4\end{array}$ & $\begin{array}{l}14 \\
34\end{array}$ & $\begin{array}{l}29.2 \\
70.8\end{array}$ & $\begin{array}{l}6 \\
4\end{array}$ & $\begin{array}{l}60 \\
40\end{array}$ \\
\hline people with chronic diseases & $\begin{array}{l}\text { Yes } \\
\text { No }\end{array}$ & $\begin{array}{c}40^{a, b} \\
4\end{array}$ & $\begin{array}{c}90.9 \\
9.1\end{array}$ & $\begin{array}{c}13^{c} \\
35\end{array}$ & $\begin{array}{l}27.1 \\
72.9\end{array}$ & $\begin{array}{l}6 \\
4\end{array}$ & $\begin{array}{l}60 \\
40\end{array}$ \\
\hline pregnant women & $\begin{array}{l}\text { Yes } \\
\text { No }\end{array}$ & $\begin{array}{c}37^{\mathrm{a}} \\
7^{2}\end{array}$ & $\begin{array}{l}84.1 \\
15.9\end{array}$ & $\begin{array}{c}18^{c} \\
30\end{array}$ & $\begin{array}{l}37.5 \\
62.5\end{array}$ & $\begin{array}{l}8 \\
2\end{array}$ & $\begin{array}{l}80 \\
20\end{array}$ \\
\hline disable person & $\begin{array}{l}\text { Yes } \\
\text { No }\end{array}$ & $\begin{array}{c}40^{a} \\
4\end{array}$ & $\begin{array}{c}90.9 \\
9.1\end{array}$ & $\begin{array}{l}27 \\
20\end{array}$ & $\begin{array}{l}57.4 \\
42.6\end{array}$ & $\begin{array}{l}9 \\
1\end{array}$ & $\begin{array}{l}90 \\
10\end{array}$ \\
\hline
\end{tabular}

The direct beneficiary of patient charges for services should be:

\begin{tabular}{lccccccc}
\hline - the physician or health care facility & Yes & $20^{\mathrm{a}, \mathrm{b}}$ & 45.5 & 46 & 95.8 & 9 & 90 \\
& No & 24 & 54.5 & 2 & 4.2 & 1 & 10 \\
& Yes & $22^{\mathrm{a}, \mathrm{b}}$ & 50.0 & 2 & 4.2 & 1 & 10 \\
- state, municipal or insurance fund & No & 22 & 50.0 & 46 & 95.8 & 9 & 90 \\
\hline
\end{tabular}

The following should apply to patient charges for services:

\begin{tabular}{llllllll}
\hline - & hes & $9^{\text {a,b }}$ & 20.5 & 23 & 47.9 & 6 & 60 \\
& No & 35 & 79.5 & 25 & 52.1 & 4 & 40 \\
- & higher charges for more costly services & 15 & 34.1 & 26 & 54.2 & 3 & 30 \\
& Yes & 29 & 65.9 & 22 & 45.8 & 7 & 70 \\
- limitation on accumulated payments per & Yes & $12^{\mathrm{b}}$ & 27.3 & $13^{\mathrm{c}}$ & 27.1 & 6 & 60 \\
$\quad$ year & No & 32 & 72.7 & 35 & 72.9 & 4 & 40 \\
- limitation on accumulated payments per & Yes & 23 & 52.3 & 25 & 52.1 & 3 & 30 \\
& No & 21 & 47.7 & 23 & 47.9 & 7 & 70 \\
\hline
\end{tabular}

${ }^{a}$ Statistically significant differences between consumers and providers, $p \leq 0.05$, Mann-Whitney U Test;

${ }^{b}$ Statistically significant differences between consumers and policy-makers/insurers, $p \leq 0.05$, MannWhitney U Test; ${ }^{c}$ Statistically significant differences between providers and policy-makers/insurers, $p \leq 0.05$, Mann-Whitney U Test. 
Significant differences in the views on patient charges for selected services are observed. Consumers less often agree that patient charges should be applied to primary care (GP services) and inpatient hospital services. More than $70 \%$ of respondents in each group are against fees for emergency room services. All groups, however, support fees for outpatient specialist.

The view on the exemption mechanisms from patient fees differs across stakeholders groups. Overall, consumers and policy-makers/insurers have a positive attitude towards the protection of vulnerable groups (children, disabled persons, people with chronic diseases). Health care providers are less in favor of this and more than $70 \%$ of them did not approve of fee reductions or full exemptions for pensioners, people with low income and chronically sick.

We observe significant differences among the groups with regard to their opinion on the primary policy objective of patient charges. The results show that efficiency improvements have full support among policy-makers and insurers. Moreover, the majority of health care providers and consumers also express considerable approval of efficiency improvements as the main policy objective. Approximately 50\% of health care consumers support the generation of additional resources as the primary goal. In contrast, health care providers as well as policy-makers and insurers do not accept patient charges as an additional source of funding. All stakeholder groups agree that the main policy objective of patient charges cannot be the elimination of informal patient payments.

Significant variations in opinions about the beneficiary of patient fees are found. Health care providers, policy-makers and insures strongly agree that the beneficiary of patient charges should be the health care providers (the physician who offers the service or the health care facility). Nevertheless, health care consumers are divided in their opinion and most often indicate the social health insurance fund as the beneficiary.

Respondents' views on the design of patient payments also present some significant differences. Approximately $80 \%$ of health care consumers and $50 \%$ of health care providers do not approve that higher charges should be applied for more expensive health services, while the policy-makers and insurers advocate these fees. The low support for higher charges for better quality services is found across all stakeholder groups. About $52 \%$ of both consumers and providers indicated that the limitation on patient charges should be based upon the maximum number of services per patient per month/year. However, this opinion is less common among policy-makers and insurers who often advocated limitations on accumulated payments per month or year. 


\subsection{Discussion}

In this chapter, we have combined qualitative and quantitative data to study the opinion of Bulgarian health care stakeholders on patient charges for health care services. The combination of methods strengthens the validity of the results. Our quantitative results support the qualitative ones and we found no controversial results. We have to acknowledge the limitations of the study due to the small sample size which limits the generalizability of the results. Nevertheless, the indepth information collected from different stakeholders of the health care system contributes to the credibility of our findings.

Overall, patient charges in Bulgaria are strongly supported by health care providers and policy-makers and insurers. The introduction of the health insurance system in 2000 was preceded and accompanied by various training courses (with the participation of international and national experts) for representatives of health care providers, health care insurers and politicians. Thus, these groups were aware of and informed about what user fees are and what their goals are. That is why the latter groups in our study recognized that efficiency improvement is one of the main objectives of the fees (preventing unnecessary use of services to reduce moral hazard).

Consumers perceive patient charges as an additional financial burden, which contributes to their attitude that fees are rather an additional source of financing. Ten years of experience with patient payments shows that they hardly increase resources for health care or contribute to quality improvement in health care, but are a source of additional income for health care providers such as GPs.

Consumers, who approve of fees, are more willing to pay if the fees contribute to the improvement of the quality of health services (see Chapter 6). However, the distrust towards obligatory fees indicated in our study, is due to the lack of information and transparency about what happens with these charges (who benefits from them, for what are charges used). This finding partly explains the co-existence of formal and informal patient payments in Bulgaria. The latter payments are widespread and consumers pay them to obtain better quality of care and quicker access to health services provided in the public health care system (Balabanova \& Mc Kee, 2002a).

The opinions among all groups are similar that patient charges should be applied at all levels of health care services, in particular for outpatient specialist services. Overall, the respondents are against fees for emergency services, but health care providers partly advocate this fee. In Bulgaria, co-payments do not apply to emergency care, which makes this part of medical services most vulnerable to overuse and turns it into the widest gate of access to the system (see Chapter 2). Emergency care serves act as a bypass in the health care system to avoid patient charges. The statutory patients' route GP - specialist - hospital is not always followed. The groups most 
at risk (the uninsured, Roma population, unemployed persons) seek physician care through the emergency room because of their inability to pay for health care services (Atanasova et al., 2011; Rechel et al., 2011). Thus, they expect free of charge services and a quicker decision on their health problems.

According to the health care legislation on patient charges, exemption mechanisms for vulnerable population groups exist in Bulgaria. However, our findings indicate that the majority of health care providers oppose the exclusion of population groups from mandatory patient charges. Consequently, they accept that some groups are exempted if the state finds a proper way for providers' reimbursement. In addition to this, it is not surprising that providers point at themselves as the direct beneficiary of the fees.

Although the views of consumers and providers coincide with regard to the limitation on fees, the motives of the different subgroups within each group of stakeholders vary. For example consumers who are more likely to seek medical care (such as pensioners, people with chronic diseases and disabled persons) are more likely to prefer a maximum total payment per patient per month/year compared to other consumer groups.

Although our results are not directly comparable to those of the 2000 nationally representative survey (Pavlova, 2002) due to the different data collection methodology used, our findings are similar. We could compare only the opinions of health care consumers. Regarding the system of exemption from charges, we do not observe changes in attitudes over the years. The results show that a high amount of consumers support the exclusion of some social groups from payment obligations, namely disabled persons, children and people with chronic diseases. Consumers are less in favor of the exclusion of pregnant woman and people with low income. Also consumers often pointed to the physician or the health care facility as the beneficiary of the fees, i.e. those who provide the health services or where the services are provided.

Similar studies conducted in other countries in CEE (Baji et al., 2011; Murauskiene et al., 2010; Gryga et al., 2010; Tambor et al., 2012) also indicate essential differences across the stakeholder groups. Moreover, the opinion of health care stakeholders is not always homogeneous across countries (Tambor et al., 2012). Lithuanian and Polish consumers are least in favor of patient fees while a large share of consumers in Ukraine express a relatively high acceptability of such fees. Overall, consumers do not trust that the additional resources generated through patient payments will be used to improve quality, but they see them as a financial burden. Moreover, the majority of stakeholders in the CEE countries believe that formal patient charges cannot eliminate the informal ones. 


\subsection{Conclusion}

Based on the main findings of this analysis, several recommendations for policies related to patient payments could be outlined. The legislation on patient payments in Bulgaria needs to be carefully revised and the application of these payments should be specified. Despite the wide range of exemptions from formal patient charges, the legislation fails to consider any limitations on the annual charges for outpatient care. Policy-makers should take into account this weak side of the exemption mechanism in Bulgaria and propose suitable solutions for to limit the formal charges.

The collection and use of patient payments should be administratively regulated by creating a pool for that purpose. Despite the fact that there exists regulation for the collection of patient payments, the absence of control on that regulation creates mistrust and discontent among health care consumers. The founding of a common pool and transparency in the process of collecting those payments may reduce the weight of this problem. For hospital care this pool may have an institutional character, as it is at present. For outpatient care, where it is not possible to create such a pool, the transition to deductibles and distribution of resources according to the services rendered could be a solution.

In general it can be concluded that consumers are in favor of greater differentiation in patient payments: based on patients' health status, socio-economic status, service type and patients' route. However, the economic rationale shows that more exemptions make the system less transparent, more difficult to manage and costly to administrate. It also increases the opportunities for fraud and corruption. Related to the latter problem, a strategy should be worked out to eradicate informal payments. Bulgarians are very sensitive to the subject of corruption in health care and the Bulgarian government considers the two concepts 'corruption' and 'health care' as mutually incompatible. Informal payments have compromised the health care sector and are a major element of corruption. The problem is highly significant and clearly underlines the wish to create an effective system for centralized and patient anticorruption control (Pashev, 2007; Institute for Social and Trade Union Studies, 2005).

The question of patient payments for health care services appears a major challenge for the Bulgarian government. The social sensitivity of the issue of patient payments requires broad discussion before policy decisions are implemented. These decisions should be based on public opinions and research evidence. There is also a need of a well-thought communication strategy on the issue of patient payments by the Ministry of Health. 
Chapter 6

\section{MODELING OUT-OF-POCKET PATIENT PAYMENTS AND WILLINGNESS TO PAY FOR PHYSICIAN AND HOSPITAL SERVICES: AN APPLICATION FOR BULGARIA}

This chapter draws upon:

Atanasova E, Pavlova M, Moutafova E, Kostadinova T, Groot W. (2012). Patient payments and the empirical analysis of consumer demand for hospital services: an application for Bulgaria. Society and Economy 34(2): 313-338. 


\section{Chapter 6}

\section{Abstract}

The implementation or amendment of patient charges in a country could benefit from a preliminary analyses of their potential effects on health care demand. This chapter focuses on physician and hospital services. Our study aims to identify strategies for the empirical analysis of demand for these services that are useful for the assessment of patient charges, and to compare these strategies using empirical data for Bulgaria. The data are collected in 2010 in a representative survey among consumers. We apply both revealed- and stated-preference approaches. Within the framework of revealed preferences, we use data on various types of patient payments (total payments, formal payments and informal payments) as dependent variables to define three types of empirical models. Within the framework of stated preferences, we use data on stated willingness to pay for a service for different sub-samples (payers, users and all respondents), which also results in three types of empirical models. We observe some similarities and differences between the models based on stated-preference data and those based on revealed-preference data. Although our findings need to be studied further to establish how rigorous the results are, they can be useful for setting up new studies on the convergent validity of the two approaches. In particular, stated-preference data could help policymakers to analyze the changes in demand when the service prices (i.e. the size of patient charges) change, before actually implementing the price changes. This is an important advantage since experiments with various price levels is usually considered unethical in the health care sector. 


\subsection{Introduction}

Economic theory predicts that the price of health care consumption imposed by patient charges, affects the demand for health care services (Folland et al. 2007; Sepehri \& Chernomas, 2001). These charges are expected to reduce unnecessary service utilization and provide incentives for a healthier life-style. Therefore, they are often recommended as a tool to combat moral hazard in the health care sector (Cutler \& Zeckhauser, 2000). Patient charges are also expected to generate revenues for the health care sector and are seen as a source of additional health care funding for maintaining health care provision and improving services quality (Robinson, 2002). There is however a major concern related to the implementation of patient charges. These charges may create barriers to health care utilization, in particular for low-income groups and especially if informal payments for health care services already exist (Sepehri \& Chernomas, 2001).

Given these theoretical considerations, the empirical analysis of the demand for health care services that require patient charges, presents a research topic relevant to policy-making. In particular, the implementation or amendment of a patient payment mechanism in a country could benefit from a preliminary analysis of its potential effects on health care demand and health care provision. Such analysis could be facilitated by the development of empirical models of consumer demand for health care services that account for the type, level and magnitude of patient payments considered by policy-makers. The presence of informal patient payments needs also to be taken into account when developing the demand models.

This chapter focuses on outpatient physician and inpatient hospital services. In particular, the aim is to identify strategies for the empirical analysis of demand for these services that are useful for the assessment of patient charges in the health care sector, and to compare these strategies using empirical data for Bulgaria.

Bulgaria presents a relevant case for our analysis given the great variety of formal and informal out-of-pocket payments in the country (see Chapter 3 and 4). The co-existence of formal and informal patient payments makes the case of Bulgaria relevant for our analysis since it allows the inclusion of both types of patient payments in the analysis.

\subsection{Background}

As shown by the results of systematic literature reviews (Skriabikova et al., 2010; Martin et al., 2007; Dawson et al., 2006), the analyses of the demand for physician 
and hospital services published in recent peer-reviewed journals, mostly have the primary objective to model the demand for these services or the use of these services, as well as to study the determinants of demand and service use. The analysis of the design of a user fee financing scheme in the health care sector is also the primary research objective in some publications. Modeling the choice of health care provider is seldom stated as a direct research aim of demand studies.

Virtually all publications apply a revealed-preference approach (i.e. based on data about past service utilization) as an analytical approach to demand modeling. The studies reported in Mooney et al. (2000) and Mataria et al. (2007) are the few exceptions that apply a stated-preference approach (i.e. based on data about hypothetical behavior stated in a survey). The extensive use of the revealedpreference approaches is not surprising. The advantage of the revealed-preference techniques is that they are based on the actual choices by consumers in market situations and reflect real consumer behavior. This assures the high predictive validity of the analyses. In contrast, stated-preference approaches are often criticized for their potentially low predictive validity (Bhatia \& Fox-Rushby, 2003; Foreit \& Foreit, 2002). Nevertheless, stated-preference approaches have one main advantage. They allow experimentation without actually being necessary to implement an intervention. Thus, stated-preference approaches can be useful for a preliminary evaluation of policy plans to implement or amend the system of patient charges in a country.

The empirical analyses of demand for physician and hospital services in recent peer-reviewed articles are mostly based on data collected among health care consumers (individuals, households or a specific population/patient group). However, patient records and data on providers' characteristics (from official statistics or administrative files) are also used as data sources. The use of readily available datasets (either cross-sectional or panel datasets) is quite common. The share of publications that report on their own data collection (e.g. based on interviews or questionnaire) is relatively low. The reason for this might be that the use of readily available datasets is comparatively inexpensive. However, when data are not collected with the specific purpose to study the relation between price and consumption, the possibilities to draw conclusions about the causes and effects might be limited. Moreover, the response rate and representativeness of the study sample obtained from the original sample is often unclear (Skriabikova et al., 2010; Lahiri \& Xing, 2004; Ellis et al., 1994).

Most of the studies use single equation methods that model a single variable (the dependent variable) as a function of one or more explanatory (independent) variables. 
Only a few publications combine more than one model. As expected, the objective of the study predetermines the type and nature of the dependent variable although the availability of data used is also a reason for opting for a certain dependent variable. Most publications take the frequency of use and the number of physician visits or hospital admissions as a dependent variable. Few publications include the choice of provider, length of stay, additions to the waiting lists and out-of-pocket expenditure as dependent variables. Various independent variables are considered, including all or some of the following groups:

- patient payments and/or indirect payments (e.g. travelling and waiting time);

- consumers' characteristics (e.g. respondent's characteristics, household features, attitude);

- providers' characteristics (e.g. treatment time and admissions);

- availability of alternative services (e.g. services at the private sector).

The demand models are mostly parameterized using regression analysis depending on the nature of the dependent variable, including various forms of logit/probit and ordinary least square regression but also count data regression (Skriabikova et al., 2010; Ho, 2006; Olivera, 2004).

The relation between the service price (i.e. the size of patient charge) and service consumption does not always appear significant. There are indications (HuntMcCool et al., 1994; Kermani et al., 2008) that the significance of this relation can vary depending on the analytical method applied (e.g. the type of regression analysis) and the specific sample studied (general population or specific population/patient group). The price elasticity of demand for health care services and the determinants that affect this elasticity are rarely reported. When the price elasticity is reported, for both physician and hospital services, its value varies across the studies from relatively highly price-elastic (higher than -1 ) to lower (-0.50) or nearly zero elasticity (less than -0.10). It should be mentioned that studies use data from countries with very different socio-economic contexts, which can explain the differences in the results on the price elasticity. Some studies report that consumers' characteristics (specifically, demographic features, income, health status, and household features) influence the demand for health care services. Non-monetary expenses (e.g. travelling and waiting time) and provider characteristics are also often indicated as significant determinants of demand (Skriabikova et al., 2010; Martin \& Smith, 2003; Jan et al., 2000).

Overall, the empirical evidence implies that patient charges have a certain potential to influence consumers' decisions whether to use services. This confirms that an adequate demand analysis is essential for the appropriate design of patient payments and the exemption mechanism that should accompany them. 
Based on the above, we outline the following considerations for the empirical application in our study.

- Objective: Our aim is to outline strategies for the analysis of the demand for physician and hospital services that are useful for the assessment of patient charges in the health care sector. Consequently, these strategies should allow studying empirically the relation between the direct price of physician and hospital services and the consumption of these services. The consideration of indirect payments (e.g. travelling and waiting time) is also relevant but in addition to direct prices.

- Approach: Stated-preference approaches allow analyzing the potential effects of alternative policy designs without actually being necessary to implement or change this policy. This indicates their usefulness in policy analysis, in particular in the assessment of patient charges before their actual implementation or increase. However, given that the predictive validity of the stated-preference approaches is still uncertain, they should be used in combination with revealedpreference approaches.

- Data: The use of data collected among health care consumers is most suitable when it comes to the assessment of patient charges. Such data allow studying variations across socio-demographic groups, which can be important for identifying vulnerable groups requiring an exemption from charges. Also, data should be collected with the specific purpose to study the relation between price and consumption to increase the possibilities to draw conclusions about causes and effects.

- Analysis: Although we recognize the need of studying various methods for the parameterization of demand models, at present regression analysis is the most widely used technique. We find three basic strategies for defining the dependent variable in the regression models: using a proxy for the service use, choice of provider or expenditure on physician and hospital services. In the first two cases, the service price is included as independent variable, while in the last case, the service price is the dependent variable.

We take the above considerations into account when developing the specific analytical models for our empirical application.

\subsection{Data and model specification}

We use data from a representative survey carried out in Bulgaria in 2010 among health care consumers on payments for health care services and consumer willingness to pay for such services. The sample selection was based on a multi- 
stage random selection procedure (see Section 1.6 Methodology and Appendix A). We analyze here the data on the use, payments and willingness to pay for physician and hospital services. For the exact wording of the questions used in this study see Appendix B (Part 8).

Given the nature of the data (see Appendix B) and the list of considerations at end of the background section, we propose the following empirical models of demand for physician and hospital services considering both revealed- and stated-preference approaches to demand analysis.

Within the framework of revealed preferences, we take the average payment for a service (i.e. physician visit or hospitalization) per respondent as a dependent variable and we analyze its relation to socio-demographic features $S$, health status $H$, household characteristics $F$ and volume of services used during the year (i.e. number of visits or hospitalizations) $Q_{\text {services }}$ :

$$
\text { Average payment per service }=f\left(S, H, F, Q_{\text {services }}\right)
$$

The relation between the average payment per service and the number of visits and hospitalizations during the year is seen as an indicator of price elasticity of demand for health care services, taking into account that the above equation can be rewritten as:

$$
Q_{\text {services }}=g(S, H, F, \text { Average payment per service })
$$

Since the average payment per service may contain a large cluster of data at zero, in particular for those who used health care services but did not pay, we use a two-part model for the parameterization of the above model. We first model the probability of paying for a given services $P_{\text {service }}$ among users and then, we model the actual average amount paid per service $E_{\text {service }}$ among those who paid.

$$
\begin{aligned}
& P_{\text {service }}=f_{1}\left(S, H, F, Q_{\text {service }}\right) \\
& E_{\text {service }}=f_{2}\left(S, H, F, Q_{\text {service }}\right)
\end{aligned}
$$

Thus, we base our analysis on the assumption that the probability of paying for a services is independent from the amount paid. The first part of the model is parameterized using probit regression, and the second part is parameterized using ordinary least square regression. 
We apply the above two-part model to various types of payments (i.e. defining different dependent variables): average total payment per service that includes both formal and informal payments, average formal payment per service and average informal payments per service. Thus, we define three two-part models for each type of services (i.e. physician services and hospitalizations) from the perspective of revealed preferences. This helps us to analyze the effect of the inclusion of informal payments in the analysis. It also allows us to make a comparison across the two types of services. In this part of the analysis, we include only respondents who used the given type of services during the previous year (i.e. current users).

Within the framework of stated preferences, we also apply a two-part model to data on willingness to pay for a physician visit and willingness to pay for a hospitalization (i.e. stated-preference data) but using different sub-samples: respondents who paid for the given type of services during the previous year (payers), respondents who used these services during the previous year (users), and total sample (including all respondents). Thus, we define three two-part models for each type of services (i.e. physician services and hospitalizations) form the perspective of stated preferences. This helps us to study the effect of the inclusion of non-users in the analysis of the willingness to pay data.

We take the respondents' stated willingness to pay per service as dependent variable and we analyze its relation to socio-demographic features $S$, health status $H$, household characteristics $F$ and volume of services used during the year (i.e. number of physician visits or hospitalizations) $Q_{\text {services }}$ :

Stated willingness to pay per service $=h\left(S, H, F, Q_{\text {services }}\right)$

For each of the three sub-samples mentioned above, we first model the probability of being willing to pay for a given service $P_{\text {WTP }}^{\text {services }}$ and then, we model the respondents' stated willingness to pay for that service $W T P_{\text {Service }}$ among those who stated a positive willingness to pay amount.

$$
\begin{aligned}
& P_{\text {service }}^{W T P}=h_{1}\left(S, H, F, Q_{\text {services }}\right) \\
& W T P_{\text {service }}=h_{2}\left(S, H, F, Q_{\text {services }}\right)
\end{aligned}
$$

Again, we base our analysis on the assumption that the probability of being willing to pay is independent from the willingness to pay amount. The first part of the models 
is parameterized using probit regression, and the second part is parameterized using ordinary least square regression.

The selection of the concrete independent variables for all models described above is based on a willingness to pay study carried out in Bulgaria about 10 year ago (Pavlova et al., 2004). We include the same set of independent variables in our stated-preference models to be able to compare our conclusions with those presented in Pavlova et al. (2004). For the sake of comparability between the revealed- and stated-preference models, we also include the same set of independent variables in the models based on past payments. This modeling strategy allows us to investigate whether the same independent variables can explain the variation in each of the six dependent variables.

Thus, we parameterize 12 two-part models - three models for physician services and three models for hospitalizations based on data on various types of past payments (total payments, formal payments and informal payments respectively), as well as three models for physician services and three models for hospitalizations based on stated willingness-to-pay data using different sub-samples (current users, users and all respondents respectively) with identical independent variables. We only compare the models qualitatively to outline directions for further research on the applicability of stated-preference techniques for policy analysis. No pretense is made that the models presented here measure the same constructs (i.e. the same preferences). We recognize that the nature of the six dependent variables is entirely different.

\subsection{Results of the empirical application}

Information on socio-demographic characteristics included in the analysis is presented in Appendix C. In total, 1003 respondents participated in the survey. The response rate is $67 \%$.

Data on physician visits and hospitalizations, as well as out-of-pocket payments and maximum willingness to pay for these services are presented in Table 6.1A and Table 6.1B. As shown in Table $6.1 \mathrm{~A}$ and Table $6.1 \mathrm{~B}$, the average probability of a physician visit is $74.2 \%$ (about 6 visits per outpatient care user per year) and the average probability of hospitalization is $16.2 \%$ (about 2 hospitalizations per inpatient care user per year). Three-quarter of the outpatient care user report outof-pocket payments (about $14 \mathrm{BGN} \approx 7$ EUR per visits). 
Table 6.1A Physician visits, out-of-pocket payments and willingness to pay - descriptive statistics

\begin{tabular}{llllll}
\hline & Value range & Frequency [\%] & Median & Mean & SD \\
\hline $\begin{array}{l}\text { Physician visits during } \\
\text { the last year }\end{array}$ & $\begin{array}{l}0=\text { not visited } \\
1=\text { visited }\end{array}$ & $\begin{array}{l}251(25.8 \%) \\
724(74.2 \%)\end{array}$ & 1.00 & 0.74 & 0.44 \\
\hline $\begin{array}{l}\text { Number of physician visits during the last } \\
\text { year (users) }\end{array}$ & From 1 to 97 & - & 3.00 & 5.69 & 7.14 \\
\hline $\begin{array}{l}\text { Payment for physician visits during the last } \\
\text { year (users) }\end{array}$ & $\begin{array}{l}0=\text { did not pay } \\
1=\text { paid }\end{array}$ & $\begin{array}{l}165(23.7 \%) \\
529(76.3 \%)\end{array}$ & 1.00 & 0.76 & 0.43 \\
\hline $\begin{array}{l}\text { Amount paid per year for physician visits } \\
\text { From 1 to 2500 BGN }\end{array}$ & - & 12.00 & 57.15 & 190.13 \\
\hline $\begin{array}{l}\text { Average out-of-pocket payment per } \\
\text { physician visit }\end{array}$ & From 1 to 333 & - & 2.50 & 13.81 & 39.44 \\
\hline $\begin{array}{l}\text { Willingness to pay for physician visits } \\
\text { 1= Yes }\end{array}$ & $\begin{array}{l}243(24.2 \%) \\
760(75.8 \%)\end{array}$ & 1.00 & 0.76 & 0.43 \\
\hline Amount willing to pay for physician visits & From 2 to 200 BGN a & 15.00 & 17.75 & 14.09 \\
\hline
\end{tabular}

${ }^{a} 1 B G N \approx 0.50$ EUR

Table 6.1B Hospitalizations, out-of-pocket payments and willingness to pay-descriptive statistics

\begin{tabular}{|c|c|c|c|c|c|}
\hline & Value range & Frequency [\%] & Median & Mean & SD \\
\hline $\begin{array}{l}\text { Hospitalized during } \\
\text { the last year }\end{array}$ & $\begin{array}{l}0=\text { not hospitalized } \\
1=\text { hospitalized }\end{array}$ & $\begin{array}{l}840(83.8 \%) \\
162(16.2 \%)\end{array}$ & 0.00 & 0.16 & 0.37 \\
\hline $\begin{array}{l}\text { Number of hospitalizations during } \\
\text { he last year (users) }\end{array}$ & From 1 to 97 & - & 1.00 & 2.31 & 7.86 \\
\hline $\begin{array}{l}\text { Payment for hospitalization during } \\
\text { the last year (users) }\end{array}$ & $\begin{array}{l}0=\text { did not pay } \\
1=\text { paid }\end{array}$ & $\begin{array}{l}50(33.5 \%) \\
100(66.5 \%)\end{array}$ & 1.00 & 0.67 & 0.47 \\
\hline Amount paid per year for hospitalizations & From 4 to $2500 \mathrm{BGN}^{\mathrm{a}}$ & - & 50.00 & 203.7 & 376.50 \\
\hline $\begin{array}{l}\text { Average out-of-pocket payment per } \\
\text { hospitalization }\end{array}$ & From 4 to $1500 \mathrm{BGN}^{\mathrm{a}}$ & - & 40.00 & 125.36 & 210.74 \\
\hline Willingness to pay for hospitalizations & $\begin{array}{l}0=\text { No } \\
1=\text { Yes }\end{array}$ & $\begin{array}{l}335(33.4 \%) \\
668(66.6 \%)\end{array}$ & 1.00 & 0.67 & 0.47 \\
\hline Amount willing to pay for hospitalization & From 30 to $800 \mathrm{BGN}^{\mathrm{a}}$ & - & 200.00 & 225.50 & 132.00 \\
\hline
\end{tabular}

${ }^{a} 1 B G N \approx 0.50$ EUR 
For inpatient care, out-of-pocket payments are reported by two-thirds of the inpatient care users (about 125 BGN $\approx 62$ EUR per hospitalization). The consumer's willingness to pay and the amount willing to pay for both physician visits and hospitalizations are very close to actual payments. Specifically, $75.8 \%$ of respondents state a willingness to pay for a physician visit (average amount willing to pay of 18 BGN per visit) and $66.6 \%$ of respondents state a willingness to pay for a hospitalization (average amount willing to pay is 225 BGN per hospitalization). Results of binary probit regression (see Table 6.2A for physician services and Table 6.3A for hospitalizations) show the importance of socio-demographic factors when comparing the probability of paying using revealed-preference data and the probability of being willing to pay using stated-preference data.

With regard to actual payments for physician visits, we observe that female respondents more often report payments (total and formal payments), while those from families with more chronically sick family members and those who use physician services more frequently, report more often informal payments. In case of total actual payments for hospitalizations by those who were hospitalized during the last year (revealed-preference data), we do not observe any statistically significant differences between the different socio-demographic groups. When we analyze the formal and informal patient payments for users separately, we find significant differences between the groups in terms of health status and age, respectively.

Regarding stated-preference data (stated willingness to pay), for both physician and hospital services, we observe an increasing number of variables that are significant with the increase of the sample analyzed (those who paid for hospitalization during the last year, those hospitalized during the last year and total sample). Household income is virtually always significant indicating that wealthier individuals are more willing to pay (in case of both physician and hospital services). Irrespective of the sample, education is significant in case of physician services (those with higher education being more willing to pay) and age is significant in case of hospitalizations (elderly being less willing to pay). Willingness to pay for hospitalization is also affected by health status, household size and presence of chronic disease. 


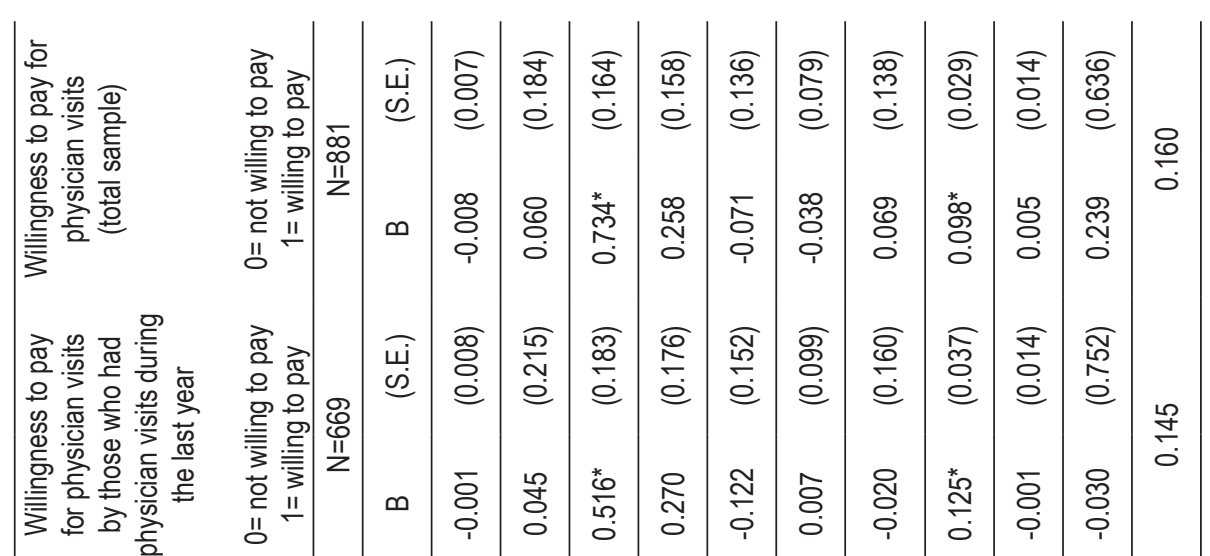

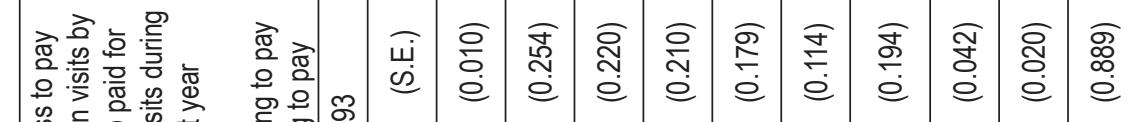

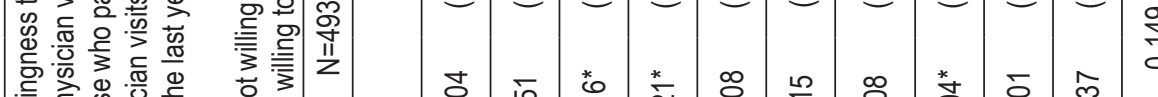
$\stackrel{\text { 守 }}{\circ}$

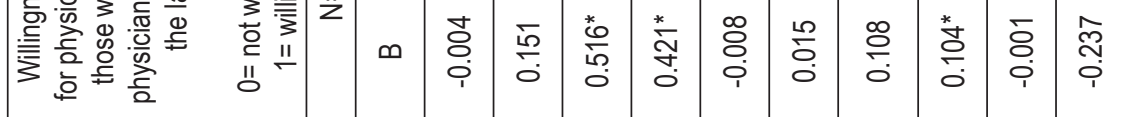

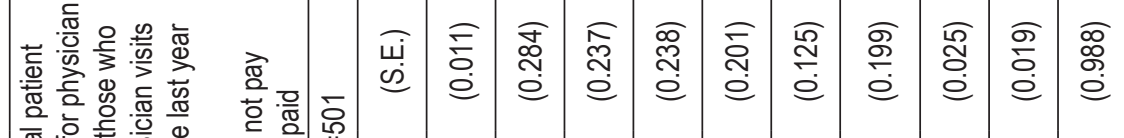

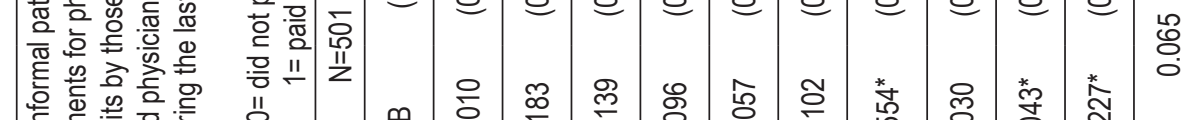

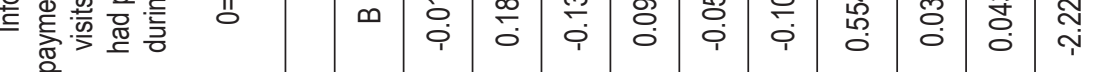
䓌

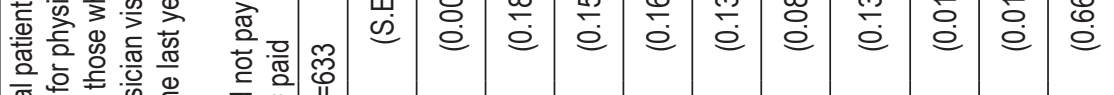

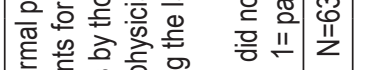

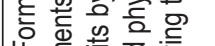

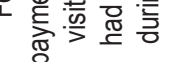

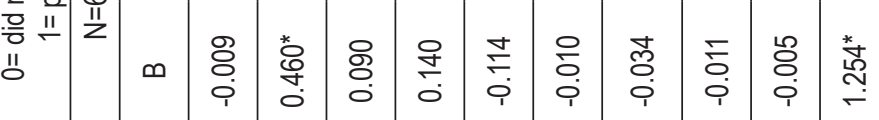

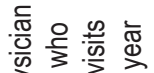

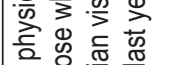

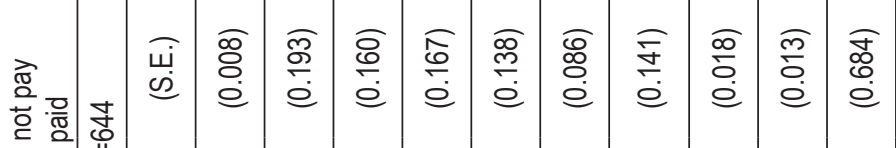
ஜํ.

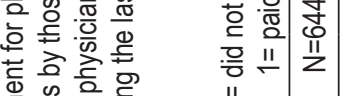
m

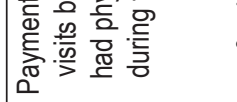




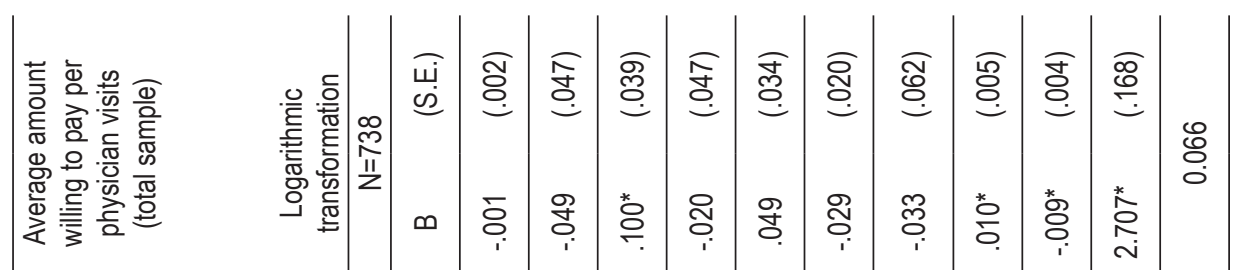

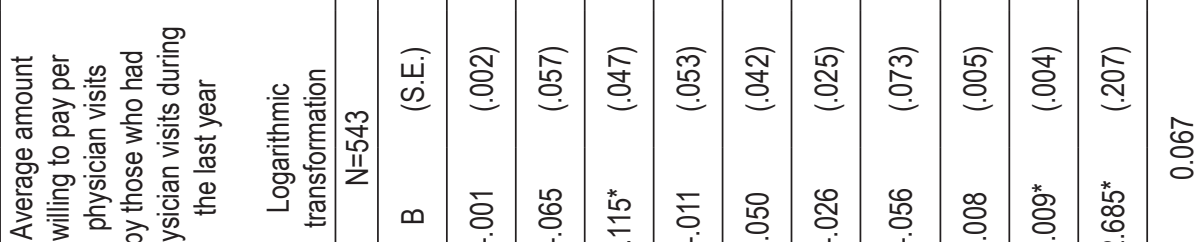

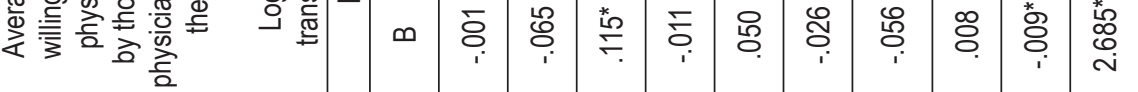

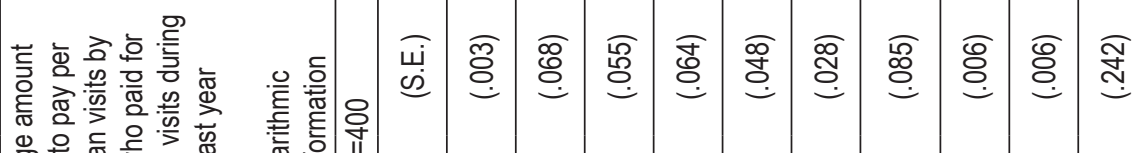

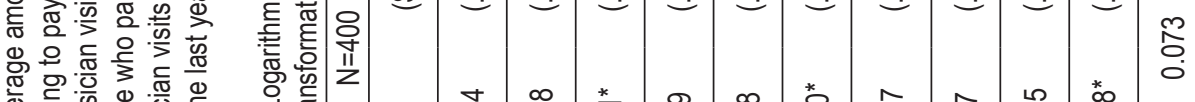

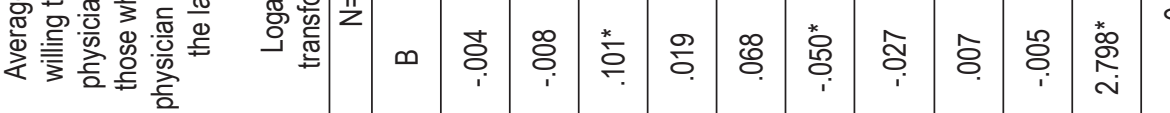

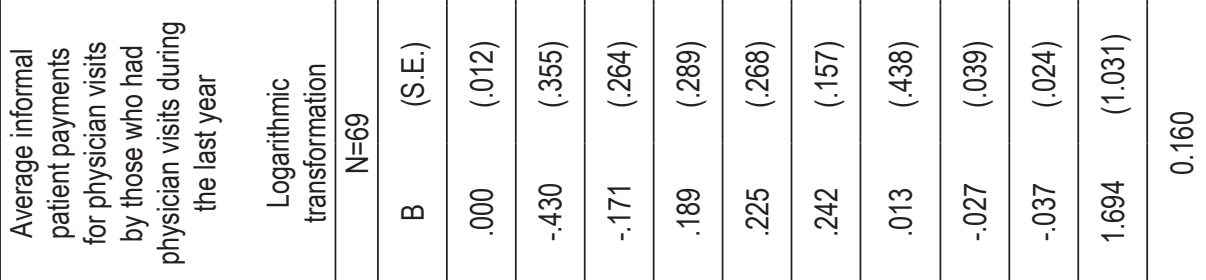

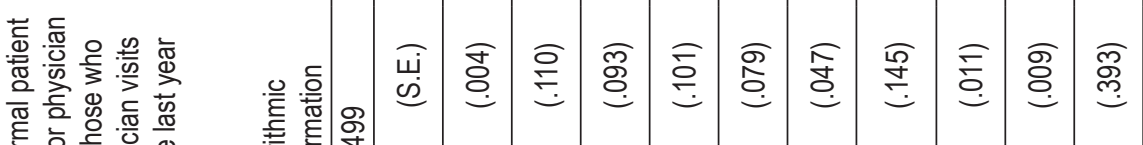

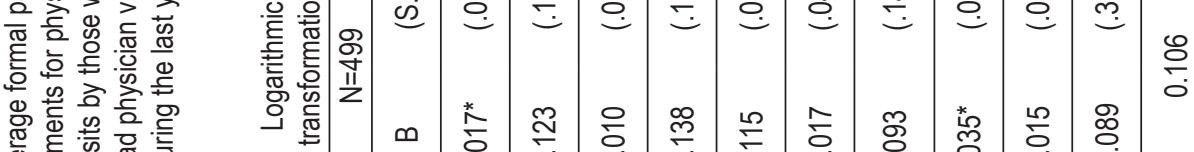

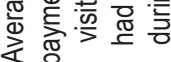

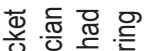

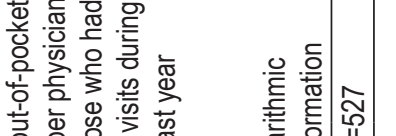

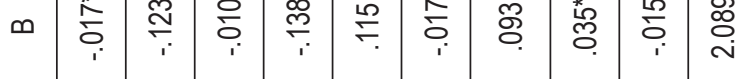

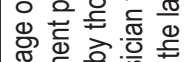
变商势言

똥

í

* 空 


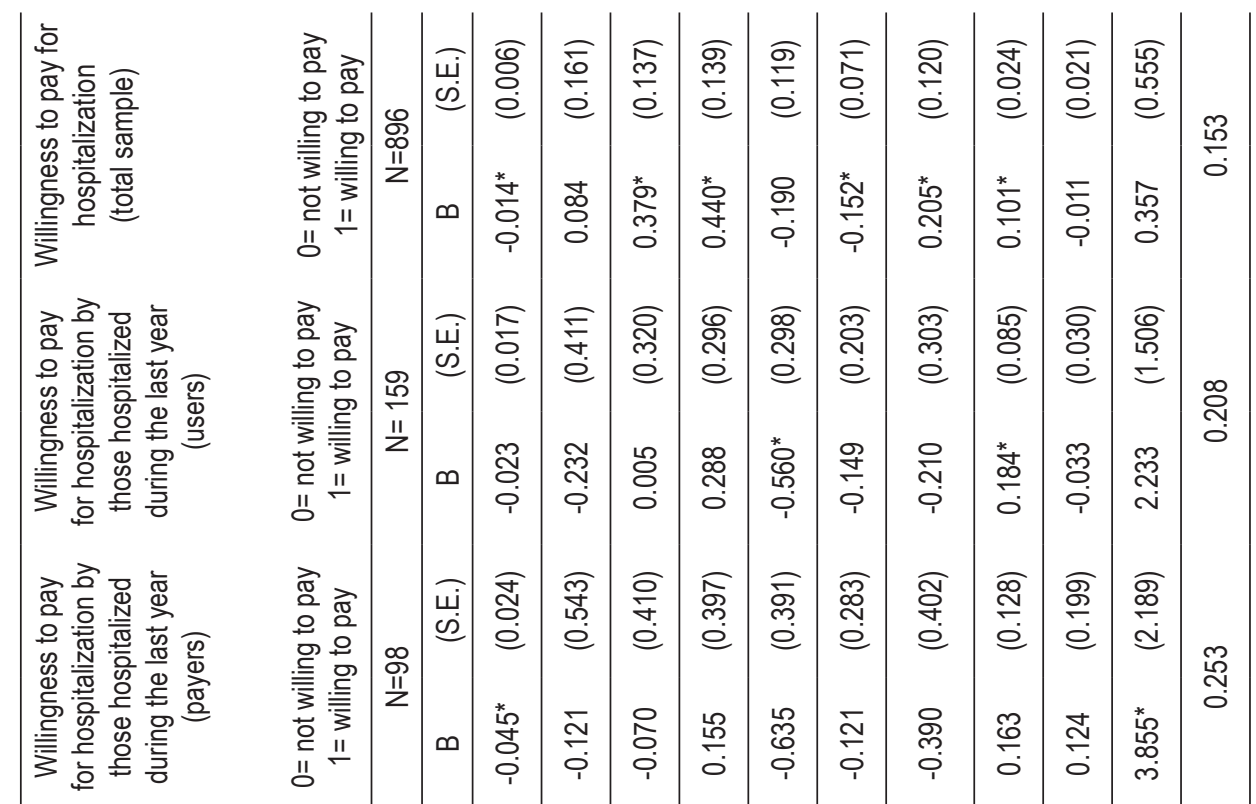

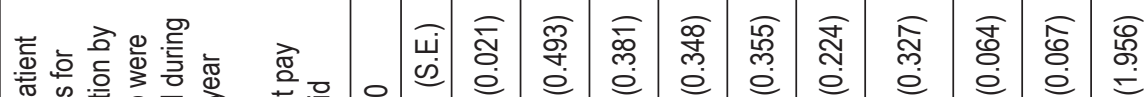

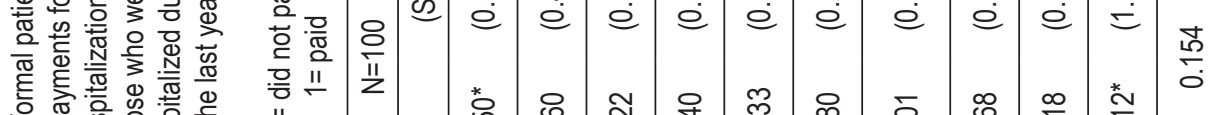

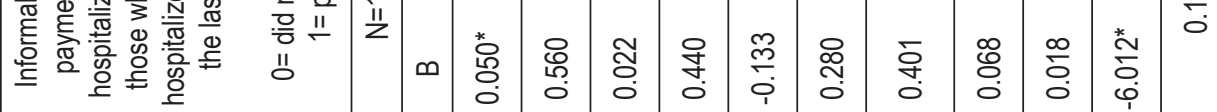

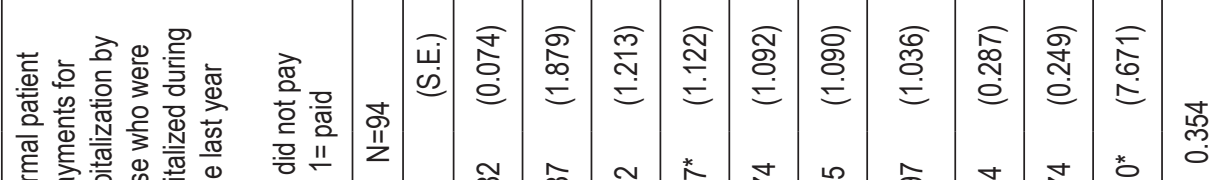

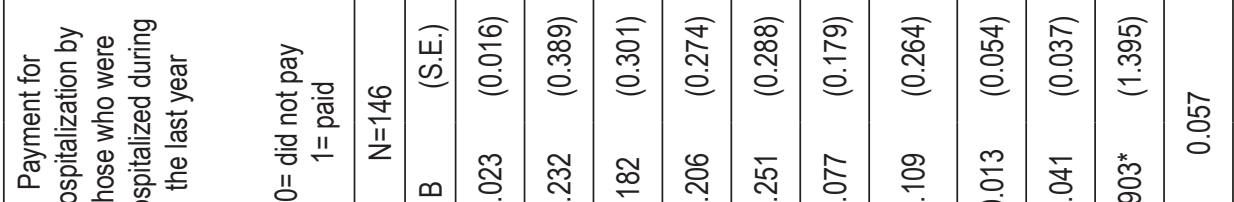

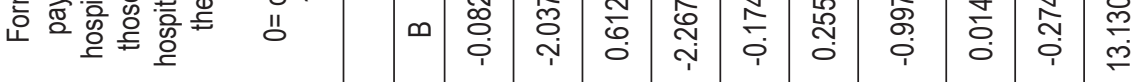

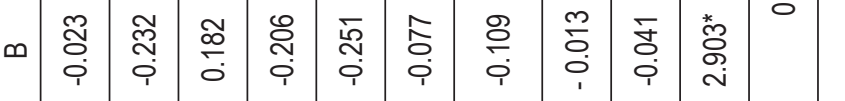

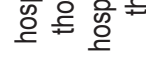
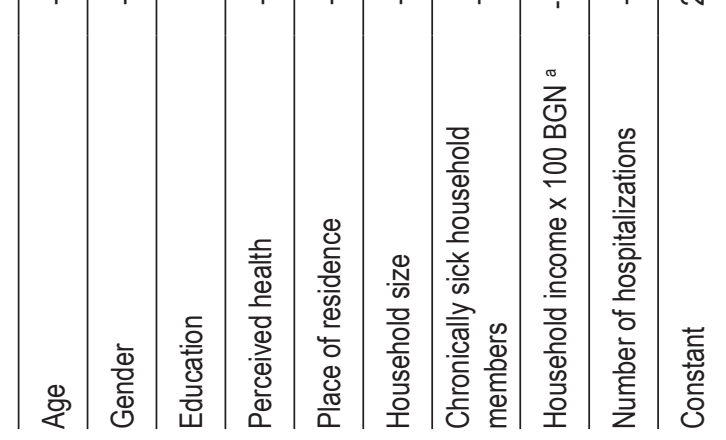


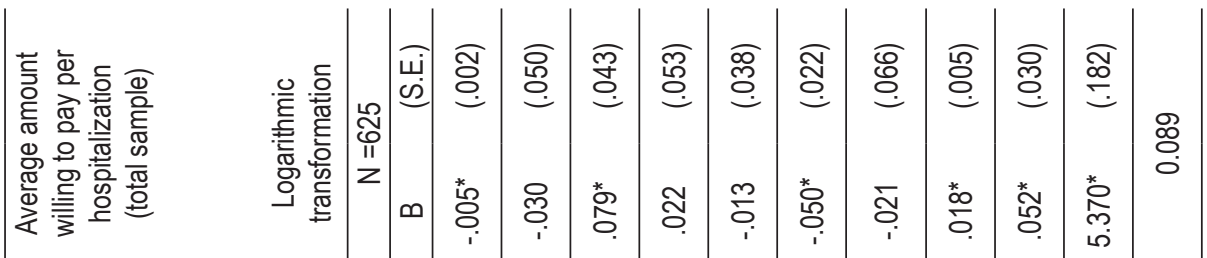

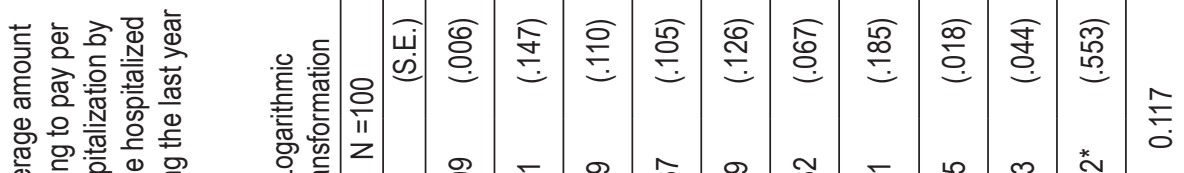

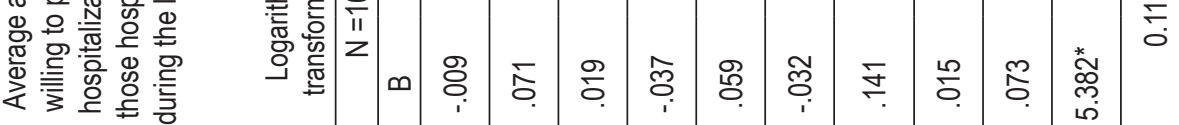

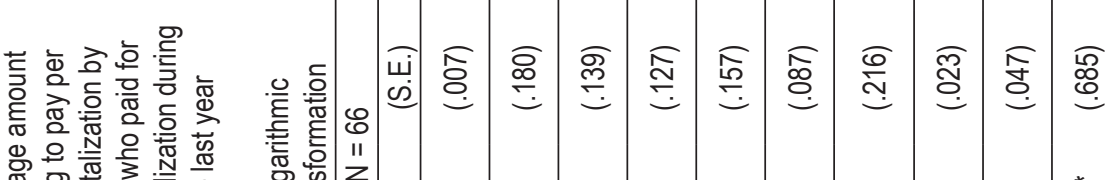

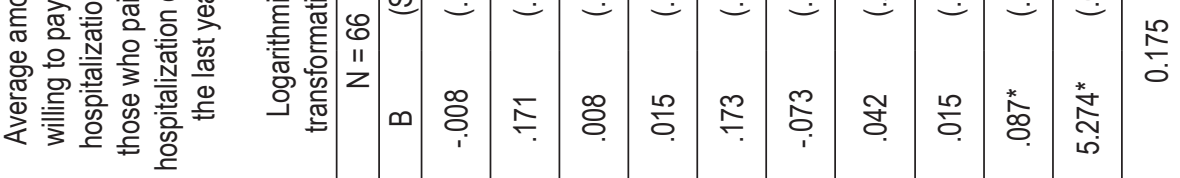

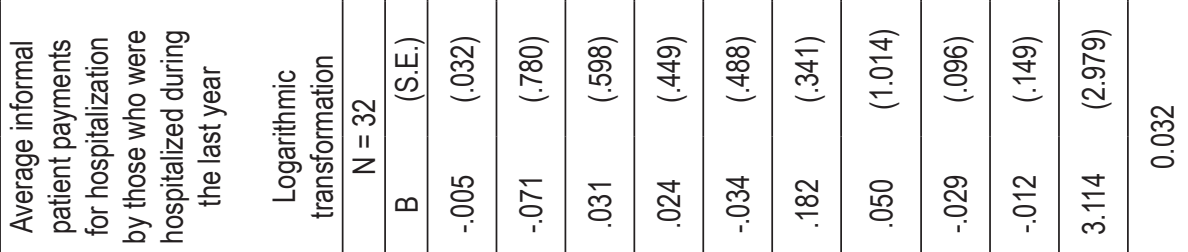

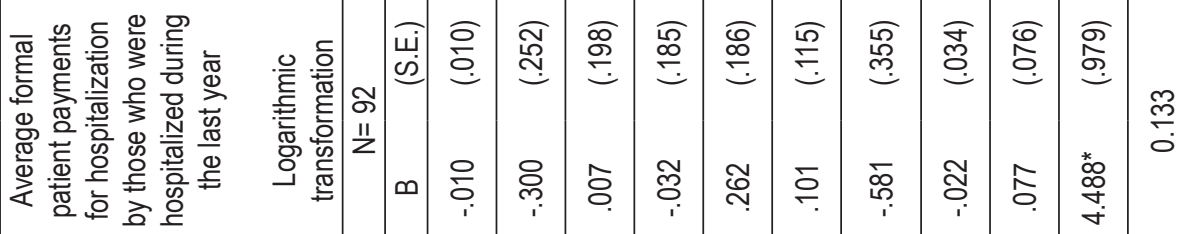

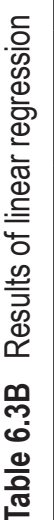

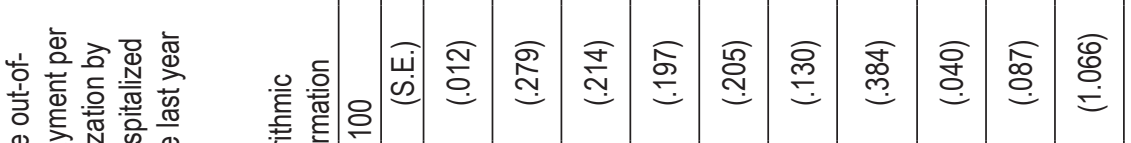

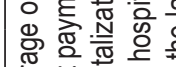

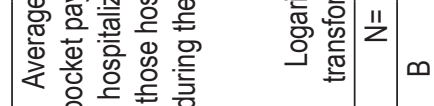
菅 荌 竞

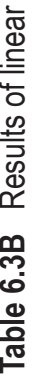


The parameters of the socio-demographic variables in the regression on the actual average out-of-pocket payment for a service (revealed-preference data) and the average amount willing to pay per service (stated-preference data, positive willingness to pay) are presented in Table 6.2B (for physician visits) and Table 6.3B (for hospitalizations). When we examine the actual out-of-pocket payments by users (incl. both formal and informal payments), we find some statistically significant associations for physician services in case of total and formal payments (in both cases younger and wealthier respondents paid higher amounts per visit). We do not find any statistically significant differences between the socio-demographic groups in case of informal payments for physician visits, as well as for total, formal and informal payments for hospitalizations.

For stated-preference data, the number of physician visits and hospitalizations is often significant in different sub-samples. Some significant differences in terms of the average amount willing to pay are observed with regard to age, education, household size and household income. The constant is significantly different than zero in all samples.

\subsection{Discussion of the empirical results}

Overall, our empirical findings correspond with the main findings from previous research presented and discussed in the background section. Specifically, we find that the nature of the relation between dependent and independent variables are similar. It should be mentioned however, that we do not always find a significant relation between actual payments and the service use (physician visits or hospitalizations). This finding does not necessarily contradict current research evidence since some other studies also report such results. Nevertheless, to be able to draw a firm conclusion about the insignificance of this relation, we need to examine the effect of the type of physician and hospital care used, which is not done in our analysis.

The relevance of our findings is found in the possibility to compare (even though only qualitatively) the results of the two approaches: revealed- and stated-preference approaches. We outline below the main conclusions based on this comparison:

- Comparison between revealed-preference models:

When we compare the revealed-preference models, we find different significant relations between the dependent variable and the independent variables (especially for formal and informal payments). This can probably be attributed to the fact that formal patient charges are regulated while informal payments are used by patients to obtain better services when this cannot be done via the official payments channels. 
This means that formal and informal payments serve different purposes and indicate different types of preferences. This confirms the importance of including informal payments in the analysis of demand for health care services but at the same time it suggests that the separate analysis of informal payments is also relevant.

- Comparison between stated-preference models:

When we compare the stated-preference models, we find that the statistically significant independent variables have the same direction across the models. However, their magnitudes differ. This means that the conclusions from the analysis of stated preferences depend on the type of the sample studied. Moreover, the inclusion of non-users in the analysis increases the number of statistically significant consumer's characteristics, which suggests that preferences among users are rather homogeneous compared to that of the total sample (especially for hospital care). If the analysis of stated preferences is used for policy decisions, such as setting patient charges, the comparison of preferences across various sub-samples will be important.

- Comparison between revealed- and stated-preference models:

The average amount paid per service (physician visits or hospitalization) and the average amount that a respondent is willing to pay for a service, are rather similar. However, we detect a larger variation in the average amount paid per service during the last year compared to the variation in the average amount that respondents are willing to pay per service. This means that the total sample is more homogeneous in the expression of the willingness to pay compared to actual payments for hospital services. The regression analysis also shows similarities and differences between the models based on stated-preference data and those based on revealed-preference data. Thus, the analysis of stated-preference data cannot substitute demand analysis based on revealed preferences although it can complement it.

- Comparison with stated-preference models in previous studies:

It is interesting to point out that our results for willingness to pay in the total sample are similar to those reported in Pavlova et al. (2004). Similarities are in terms of significant differences for willingness to pay data across consumer groups. In both studies, age, education and household income have a significant influence on the respondents' willingness to pay.

Our study does not go without limitations. The relations between prices and consumption (actual or hypothetical) examined in our analysis, are influenced by external factors such as legal and organizational context. Regulations on hospital stay and official charges in Bulgaria can be an important determinant of demand 
for hospital care in Bulgaria (similar for physician services). This means that our results cannot and should not be directly transferred to other countries. We rather recommend the application of our empirical analysis using data for other countries. The cross-country comparison can help to establish the rigorousness of our conclusions. Further research on this topic is also required to test the effect of the inclusion of other independent variables or of the same variables but as nominal categories to allow for possible non-linear effects. New analyses with different types of regression techniques can be also essential to test the effect of the analytical model as suggested by Hunt-McCool et al. (1994). The variations in the sizes of the sub-samples (some sub-samples are quite small, see regression results) can be also considered.

Clearly, our findings need to be studied further. Nevertheless, they can be useful for setting up new studies on the convergent validity of the revealed- and statedpreference approaches. Our empirical application shows that the analysis of data on actual consumer behavior, can be complemented by the analysis of data on hypothetical behavior (i.e. stated-preference data). The stated-preference data can allow analyzing the preferences of non-users (in fact potential user) of health care services. Most important however, results obtained from the stated-preference analyses could be useful for policy-makers when considering plans related to the implementation or amendment of the patient payment mechanism. Specifically, the preliminary study of hypothetical consumer behavior, before actual behavior is observed, can be an important starting point for more in-depth analyses of the level of official patient payments considered for introduction, as well as for the analysis of the adequacy of the future patient payment policy in the country.

\subsection{Conclusions and recommendations}

Despite the considerable policy relevance of consumer demand for the development of an adequate mechanism of official patient payments, applications of demand analysis with similar objectives are rarely reported in the literature (specifically for hospital services). Moreover, the studies that focus on consumer demand for health care services most often report results from a single country and a specific health care setting. Integrated econometric models of consumer demand suitable for the analysis of patient payment policies and their impact on health care utilization are lacking.

There is growing evidence that informal patient payments are also likely to influence the demand and supply of health care services (Ensor, 2004; Thompson \& Witter, 
2000). This is also suggested by our empirical findings since the distinction between formal and informal payments in the analysis leads to different conclusions. Therefore, to be useful for health policy-making, the econometric model of demand for health care services needs to take into account the potential impact of informal payments. The implementation of official patient payments in health care sectors where informal payments for health care already exist, could create a situation where patients are exposed to a double financial burden: official and informal patient payments, as it is the case of Bulgaria.

Although the stated-preference data are not frequently used for modeling the demand for health care services, they could be useful for policy making. In particular, our empirical findings suggest that stated-preference data lead to similar results as those based on revealed-preference data, especially when service users are included. Thus, stated-preference data could help policy-makers to analyze the changes in demand when the service prices (i.e. the size of patient charges) change, before actually implementing the price changes. This is an important advantage since experiments with various price levels are usually considered unethical in the health care sector. 

Chapter 7

GENERAL DISCUSSION, CONCLUDING REMARKS

AND VALORIZATION 


\subsection{Introduction}

The main goal of the dissertation has been to examine the propensity, magnitude and affordability of out-of-pocket patient payments for public health care services in Bulgaria. In addition, the attitudes of health care stakeholders towards both formal and informal payments have been analyzed to understand the stakeholders' opinions regarding these payments at present, i.e. more than 10 years after the implementation of formal patient charges. To achieve these goals, we have combined three research methods. A systematic literature review (desk research) is used in Chapter 2 to study the prior expectations and concerns about the social health insurance reforms in Bulgaria. We have particularly focused on the financial sustainability, efficiency, equity, and quality effects brought about after the implementation of social health insurance in 2000. Quantitative data analysis (based on nationally representative surveys conducted in Bulgaria in 2010 and in 2011) is applied in Chapter 3 and Chapter 4 to explore the scale of out-of-pocket payments, the current scale and types of informal payments, and whether formal charges, combined with informal payments, are affordable for the population. A qualitative study (focus groups discussions and in-depth interviews carried out in Bulgaria in 2009) has been performed in Chapter 5 . Based on these qualitative data, we elicited the opinions of different health care stakeholders towards the patient payment mechanisms for public health care services in Bulgaria. In Chapter 6, we have also compared hypothetical consumer behavior with actual behavior regarding the past payments for health care services taking into account the co-existence of formal and informal payments. This final chapter outlines and discusses the main findings presented in the dissertation. Concluding remarks are made at the end of the chapter.

\subsection{Main findings}

The main findings of this dissertation are presented in the form of six statements that extract the main results. Each statement is accompanied with recommendations for policy and suggestions for further research.

\section{Statement 1: Although some efficiency improvements in health care have been made during the 10 years of health insurance reform in Bulgaria, the overall social benefits of these reforms are less than expected.}

In chapter 2 of this dissertation, we have reviewed the evidence on the outcomes of the health insurance reforms in Bulgaria from the perspective of expectations and 
concerns at the start of the reform. Based on previous studies, we identified the positive expectations as well as concerns about negative effects that existed prior to the reforms. We examined expectations and concerns related to the financial sustainability (macro-level), efficiency (micro-level), equity, and quality of health care provision. To analyze to what extent these prior expectations and concerns were realized, we used a desk research method to identify empirical evidence on the outcomes of the health insurance reforms, as well as official macro data. The results suggest that the reforms considerably affected the foundations of the Bulgarian health care system, in particular replacing the tax-based with an insurance-based system. This led to the establishment of a contract-based provider reimbursement mechanism, compulsory participation in the social health insurance scheme for all citizens, enhancement of efficiency in health care provision as well as improvement of the social status of Bulgarian medical professionals. One of the primary objectives of the reform was to assure the financial sustainability of the system and to improve micro-level efficiency but at the same time, to preserve the guarantees for equal access to care and solidarity. The intentions of the reforms in Bulgaria were very similar to these in other CEE countries (Murauskiene et al., 2010; Gryga et al., 2010; Cerami, 2006). However, the concrete changes in Bulgaria differed from these in other countries due to the specific conditions at the start of the reforms and during their implementation. In particular, the Bulgarian health care system in transition was characterized by a difficult economic situation (deterioration of all macroeconomic indicators) and this led to the implementation of health insurance contributions that were half of what was necessary (it was set at $6 \%$ of monthly income instead of 12\%). The step-wise implementation of the reforms (focusing initially on primary care and postponing the reform in the hospital sector) led to delays and a hesitant development of the reform initiatives. Thus, the implementation of reform measures was frequently inconsistent and contradictory.

Similar to the expectations described in Chapter 2 and in line with the reform objectives outlined above, our review of the evidence confirms that the new social health insurance system in Bulgaria has brought some improvements in efficiency. Health care system funding and medical service provision were successfully split and financial resources for health care are now allocated to health care providers based on performance (contract-based). Due to the split between funding and provision, the sustainability of the system was improved. Bulgaria's total health care expenditure as a percentage of GDP increased to about $7 \%$ and is comparable to the average in Europe (WHO, 2014). It should be noted however that this increase in total health care expenditure was due to the increased reliance on out-of-pocket payments and the enlargement of the private sector. The state is practically unable 
to increase its contribution to health care, which was still around $55 \%$ of total health care expenditure in 2010 (WHO, 2014). Moreover, the state often delays paying the contributions for elderly and unemployed to the NHIF.

The contract-based relationship between insurers and providers fosters competition (quasi-competition) between health care providers and provides incentives for efficiency improvements. However, competition in health care has its limitations due to heterogeneity in health care services, information asymmetry and moral hazard, and a mercantile medical practice that increases the cost of health care. Due to these reasons, the state is responsible for the implementation of regulations that limit the negative effects of competition. Specifically, after the launch of the reforms in ambulatory care (in 2000), efficiency improvements are observed in the use of preventive and primary care services (as outlined in Chapter 2). One reason is that the NHIF has given priority to the development of care, prophylactic and treatment services for mothers, children and chronically sick patients. However, the lack of competence in setting priorities and inadequate planning of resources for prevention and health promotion turned out to be major obstacles to an effective policy in this area (Salchev, 2012). Although all health authorities in Bulgaria acknowledged during the transition that prevention and health promotion should be a priority of health policy, the share of these activities in health care expenditure has gradually decreased from $7.7 \%$ of total health care expenditure in 2010 to $5.8 \%$ in 2011 and is projected to decrease to $4.6 \%$ in 2014 (Bulgarian Academy of Sciences, 2013). This is due to the transfer of responsibilities to the NHIF as stated in the introduction.

The quasi-competition launched in the hospital sector in 2002 also forced hospitals to introduce innovations in treatment, to actively promote these innovations and to measure patient satisfaction. Although competition is not applied in its pure form (i.e. there is no perfect competition), its quasi variant has stimulated the technical and allocative efficiency of hospital care in the country (Vladimirova \& Manliev, 2013). As indicated in Chapter 2, hospital use decreased right after the introduction of health insurance indicating a more rational use of hospital care and cost reduction. Specifically, a downward trend in the number of beds in acute care in Bulgaria was observed, which reflected the efforts and political will to follow the health care trends and reforms elsewhere in Europe. Between 1998 and 2008, the number of acute care hospital beds in Europe registered an average reduction of 18\%. The decline in the number of beds in Bulgaria for the same period was about 15\% (HOPE, 2011). Despite these efforts, the number of acute hospital beds per 100 ooo population is still much higher compared to the EU12 and EU27 averages (Dimova et al, 2012a). The explanation for this is that in almost all European countries the number of acute hospital beds decreased significantly and represents at least half of the total 
number of hospital beds (HOPE, 2011). Despite the reduction in the number of beds in Bulgaria, the inpatient admission rate has increased substantially in the period 2000-2009, reflecting among others, the inefficiency and underutilization of outpatient services. According to experts at the NHIF, the reasons for the increase in hospitalization could be the concentration of highly specialized activities in certain areas leading to an imbalance in the types of services provided in the country, but also the internal migration, the method of funding of hospitals and the lack of a needs assessment of the population (Bulgarian Academy of Sciences, 2013). In many cases, the relatively low patient's trust in GPs and the free of charge emergency care are preconditions to bypass primary care. Thus, the patients go directly to specialized medical care or hospital emergency rooms, and this leads to more hospitalizations.

Inefficiency is also observed in the provision of pharmaceuticals. Although there are both regulatory and putative market-based approaches to contain pharmaceutical spending worldwide, the evidence suggests that regulatory efforts in Bulgaria (see chapter 2) and elsewhere in Europe (Towse, 2003) have not proved to be effective in containing costs or improving efficiency or access. In Bulgaria, the costs of pharmaceuticals have been growing steadily since 2000. The contributing factors include a suboptimal use of generic medicines, lack of requirement for physicians to prescribe nonproprietary names and no freedom for pharmacists to substitute generics for brand name medicines. In addition, inappropriate prescribing is common and leaves an opening for lobbying by pharmaceutical firms, bribing physicians to prescribe more and more expensive drugs than necessary. Health technology assessment studies are not used to decide on the inclusion of drugs in the NHIF reimbursement list (World Bank, 2013).

The findings from our desk research (see Chapter 2) identified that some fundamental equity principles (e.g. solidarity, equality, accessibility) were violated during the implementation of the reform. Equity became a challenge because of differences in health needs, socio-economic disparities and territorial imbalances in the system. The weak financial protection of the population and the inability to pay fees emphasize these equity problems (see Chapter 3). This is also reflected in the increasing share of out-of-pocket payments and uneven distribution of the financial burden over income groups. Individuals with lower income pay more than those with higher income because user fees are the same for everybody. Moreover, informal patient payments are still widespread (see Chapter 4) even after the introduction of official co-payments, and consumers pay them to obtain better quality of care and quicker access to services provided in the public health care system (see Chapter 5). 
The lack of political will to include the nation's health status as one of the leading national priorities, the lack of a realistic evidence-grounded health policy as well as weaknesses in the management of the health care system and failure to fight corruption in health care emerged in Chapter 2 as the main reasons for the ineffectiveness of the reforms. Overall, the results suggest that the social benefits of the health care reforms which passed through different stages are less than those initially expected. However, this finding raises questions concerning the development of a new public health policy, such as a compulsory assessment on the acceptability of health-policy decisions in terms of public needs, goals and interests.

Policy recommendations: Although major essential changes were made in the Bulgarian health care system, the system continues to suffer from substantial weaknesses. Future reforms should start by ensuring political consensus on the importance of the health care system and should provide a steady strategy for the development of the sector. This strategy needs to be accompanied by in-depth expert evaluation of what is achieved, the enactment of a National Health Map to align the health care system with the health needs of the population, and adequate professional management. Transparent debates to draw clear health policy priorities with a fixed period for their accomplishment, can improve the citizens' trust in the health care system.

Future research: This dissertation has analyzed the financial reforms in the Bulgarian public health care sector using a systematic literature review, which suggests a dependence on available data and an inability to study factors (such as changes in quality of care) that were not subject of previous research. Thus, a more extensive reform evaluation is necessary to outline the exact effects of the reforms. The assessment of the needs of the population on health care and the territorial and social imbalance as well as the evaluation of the economic and social efficiency of health care reforms should be a focus for further research. The effects of the health care reforms on the economic and social status of patients and health professionals, and the opinion of all health care stakeholders with regard to health reforms, are also relevant topics for research.

\section{Statement 2: Informal payments for health care services continue to exist in Bulgaria even 10 years after the implementation of official co- payments for publicly funded health care services.}

As outlined in Chapter 2 of this dissertation, informal payments for health care services have a long tradition in Bulgaria. However, before the political changes in 1989, almost all informal payments were gifts in kind. Informal cash payments emerged during the transition period and became rather widespread in the period 
before the social health insurance reform in 2000. After the implementation of social health insurance, informal payments continued to exist despite the formal co-payments for services under the insurance scheme. In Chapter 3 and Chapter 4, we have used data from a nationally representative survey conducted in Bulgaria in 2010, to analyze the recent experiences with informal patient payments after 10 years of official co-payments. Our results in Chapter 3 show that in 2010, around 13\% of the respondents who used outpatient services during the last 12 months, made informal payments (on average 45 EUR per year), and in 2011, around 10\% of users report informal payments (on average 23 EUR per year). In 2010, approximately one-third of the respondents who were hospitalized during the last 12 months paid informally (on average 85 EUR per year), and in 2011, 18\% of users made such payments (on average 108 EUR per year).

The results of previous studies on informal payments in Bulgaria (surveys conducted in 1996 and 1997) found a similar frequency of informal payments, ranging from 4\% of respondents (including both users and non-users) in 1996 to 8\% in 1997 (see Chapter 4). Our results in Chapter 4 suggest that $7 \%$ of respondents made informal payments for outpatient services during the preceding 12 months. However, the frequency of informal payments for inpatient services was only about half that in these earlier studies (3.2\% in 2010 vs. 6-7\% of respondents in 1996 and 1997). This could be due to legislative changes adopted during recent years, specifically the possibility given to hospitals to charge officially for extra services. The recent comparative study conducted in six countries in CEE including Bulgaria indicates the existence of informal payments in all countries. The share of users who pay informally and the size of the informal payments differ among the countries. The share is the lowest for Poland (about 8\%) and Bulgaria (about 12\%) and the highest for Ukraine (41\%) (Stepurko et al, 2013). Another study conducted in Bulgaria in 2010 (Specialized newsletter, 2010) also confirms that about $10 \%$ of respondents have paid physicians informally in cash. The above discussion suggests that the pattern of informal payments in Bulgaria has changed during the years. However, the trend of about $10-12 \%$ of the patients making informal payments has remained relatively constant.

In addition to the informal payments described above, new forms of informal patient payments have appeared. For example, although health care providers are obliged to give a receipt to patients for every co-payment received, in practice, this is often not done. Thus, formal payments are also partly transformed into informal ones (OSI, 2008). Previous studies suggest that in 2006, informal payments in Bulgaria amounted to about $3.6 \%$ of the total public health care expenditures and were a major part of total out-of-pocket payments (47.1\% in 2006). Evidence from other 
CEE countries also shows that after the implementation of official co-payments for publicly funded health care services, official and informal payments co-exist and complement each other (Baji et al., 2012).

Moreover, Chapter 2 indicates "loopholes" in the Bulgarian legislation, which lead to the abuse of patient unawareness and create disputable issues related to the legality of some types of patient payments. For example, in accordance with an ordinance issued by the Ministry of Health, which applies to hospitals only, insured individuals are entitled to additional services on request that are paid by patients out of their own pocket. Hospitals use this ordinance as a base to set up their own fees for patients who wish to freely choose the physician or hospital treatment team, for example, because a physician who is not on duty but is selected by the patient, has to perform the surgery. The fees are paid in addition to the regular co-payments for the hospital stay. Hospitals see these fees as an acceptable way to increase their funds. However, as described in Chapter 4, this practice is not always ethical. Patients are often not aware of the fact that they could avoid these fees by waving their right to make such choice. Moreover, according to the Ombudsman of Bulgaria, the option of a free choice of a physician and hospital treatment team is not an additional service. This free choice is in fact an addition to the service which is already covered by the basic package. That is why the patient should not pay additionally for it. Thus, the above mentioned fees are in effect illegal. According to the literature, these fees are defined as quasi-formal charges (officially regulated by providers but not entirely legal). In this case, the hospital is paid twice for the access to medical care. On the one hand, the NHIF reimburses the hospital via a clinical pathway and on the other hand, the insured person also contributes through the quasi-formal fee for the choice of a physician or a treatment team. Despite these weaknesses, the abovementioned ordinance has an important advantage for hospitals as it offers a formal channel for additional patient payments, and thus, diminishes the need to ask for informal payments.

In addition to the quasi-formal charges, patients are also often asked to purchase and bring pharmaceuticals and medical supplies for their hospitalization. These patient payments can be seen as quasi-informal payments because they remain unregistered at the point of service provision (Stepurko, 2013). Hence, the social health insurance system in Bulgaria has introduced co-payments but also has brought about new forms of patient payments, i.e. their quasi forms - quasi-formal and quasi-informal payments. Moreover, official co-payments were unable to replace the existing informal payments. Overall, unclear regulations (laws, ordinances etc.) and their ambiguous interpretation serve as a prerequisite for the creation of modified forms of payments (Stepurko, 2013). Therefore, it is not 
surprising that most of the people who pay informally point to corruption as the greatest problem in the Bulgarian health care system (Specialized Newsletter, 2010). The health care sector in Bulgaria is no exception of the general environment of corruption in the country. According to the international specialized survey in this field, the health care sector holds the second position after the judiciary as the most corrupted sector (Transparency International, 2013). Although, informal payments are described as 'petty corruption', their persistence contributes to the poor reputation of the health care sector.

Findings from our qualitative study presented in Chapter 5 , show that all stakeholder groups are convinced that official charges are not able to reduce the existing informal payments because of the behavioral culture of the Bulgarian society as well as legislative and institutional gaps. At the same time, official co-payments have the potential to decrease the demand for unnecessary health care services and to collect additional funds (Pavlova et al. 2010a). Studies conducted in other CEE countries (Baji et al., 2011; Murauskiene et al., 2010; Gryga et al., 2010; Tambor et al., 2012) also indicate that the majority of stakeholders in these countries believe that formal patient charges cannot eradicate the informal ones. This is, among other issues, due to distrust that the implementation of compulsory formal patient payment would benefit patients. In contrast to CEE countries, Bulgaria has retained the formal charges more than 10 years after their introduction. Nevertheless, public discussions are resumed periodically in terms of the existence, level and mechanism of formal payments. The Bulgarian health care system clearly shows that the introduction of user fees does not discontinue the practice of informal payments and both types of payments continue to co-exist.

The informal economy (not playing by the rules) is a daily routine for all major social groups in the Bulgarian society. In the transition period, it has become a compensatory mechanism. Formal rules are not always respected. In the health care system, this is being reinforced by the specificity of service delivery. Patients believe that if they want to get the best quality services from the most qualified physicians, they will have to use informal ways - to pay out-of-pocket (cash and gifts in kind) for the sake of their health or the health of their relatives. In other words, through informal payments, Bulgarian health care consumers try to ensure that they receive good service and attention, get preferential treatment on a waiting list or receive specific privileges (Bulgarian Industrial Capital Association, 2012).

Taking into account the above results we can conclude that the problem of informal payments remains relevant even 10 years after the implementation of official copayments. Although it is difficult, the Bulgarian government should take measures 
to reduce the need to pay informally and the need to ask for informal payments. This can be achieved by reducing the level of corruption, implementing adequate remuneration mechanisms that account for the performance of the individual physician, and improving the efficiency of health care provision (Stepurko, 2013). In particular, policy-makers should start with eliminating the weaknesses in the legislation, such as textual ambiguities and the lack of a transparent system for monitoring the health care provision in terms of access, quality and payments. More purposive actions on behalf of the government are needed to address the problem of informal payments.

Policy recommendations: Overall, the lack of transparency and accountability in the Bulgarian health care system has facilitated a social environment for informal payments. The Bulgarian experience shows that official user charges alone do not present a mechanism capable of reducing informal payments. Hence, a number of other measures are necessary to reduce and eliminate the informal payments. A strong regulatory framework, more attention to the development of patient rights and redress mechanisms, increased public awareness and social campaigns against informal payments can contribute to this. Incentives for voluntary health insurance under clearly defined conditions and strict control probably, are also expected to contribute to the elimination of informal payments.

Future research: High levels of corruption in the health care sector and the importance of the problem of informal payments continue to merit special attention. Studies that collect detailed information on the characteristics of informal payments in Bulgaria (e.g. type, motivation and initiator of payments) are needed. Future research may focus on these issues to provide evidence for policy-making on how informal payments take place in Bulgaria and thus, how to tackle these payments. Another interesting topic for future research (for example using focus group discussions with different stakeholders) can be the assessment of the feasibility of measures directed to overcome the problem with informal payments in Bulgaria.

\section{Statement 3: Most Bulgarian health care consumers are against informal payments in cash. However, gifts in kind are still largely accepted by the population.}

We have shown in this dissertation that informal payments still exist in the Bulgarian public health care system (see Chapter 2-4). To analyze the attitudes and perceptions towards informal payments, we have used data from a representative survey conducted in 2010. We distinguish between cash and in kind informal payments. In Chapter 4, we observe that more than $50 \%$ of the sample has negative attitudes 
towards both types of informal payments. In general, about $30 \%$ of the interviewed indicate a tolerance towards gifts in kind even though most of them disapproved of informal cash payments. The findings from a comparative study carried out simultaneously in six CEE countries including Bulgaria, suggest that the attitudes towards informal cash payments are rather negative in all countries. The attitudes towards in kind gifts are also negative but to a lesser extent (Stepurko et al., 2013).

The level of tolerance towards in kind gifts that we found is also in line with previous findings from Bulgarian studies. A survey carried out in Bulgaria in 2006 found that about $50 \%$ of respondents agreed with the statement that satisfied patients have to be grateful to the physician and should demonstrate this by giving gifts or money (OSI, 2008). According to another survey conducted in 1997, attitudes toward informal payments concur with the perception that patients have the right to show respect by giving presents, as long as they are voluntary (Balabanova \& McKee, 2002a). The negative reaction to informal payments (including in kind gifts) is stronger when they are requested by the medical staff. In general, the results of the study in 1997 indicated that according to respondents, cash or in kind informal payments in the public sector are acceptable when initiated by the patient rather than the health professional. There is also strong opposition to pressures on health care users to pay (Balabanova \& McKee, 2002a).

There are different expert opinions regarding the factors influencing the decision of patients to pay informally (Gaal \& McKee, 2004; Lewis, 2000). Taking into account the three models proposed in the literature (Tomini \& Maarse, 2011; Tambor et al., 2013) which explain the causes of informal payments by the joint effects of cultural perceptions, quality of governance and the economic situation, we have put the emphasis on the cultural model to explain the high level of tolerance towards in kind gifts that we report in this dissertation. This model considers informal payments as a particular type of behavior of care seekers who express their gratitude in the form of gifts. The value of gifts is negligible and depends on the wealth of the patient. The thankful patient gives in kind gifts without any request or hint by the medical staff and in order to be truly a gift, it should be given after the service and not before. Therefore, a true expression of gratitude does not put a sizeable burden on patients and a necessary condition should be also that it is a voluntary act. Thus, the cultural model may be used to explain the positive attitude towards gifts in kind observed in Bulgaria (Chapter 4).

In contrast to in kind gifts, informal payments in cash can have serious negative consequences. They may hinder access, create problems of the affordability to pay, may result in a refusal of treatment in the absence of payments, and lead to unnecessary medical interventions. The attention of policy-makers should be 
directed to the implementation of effective measures for their elimination, as well as the elimination of sizable in kind gifts even though initiated by patients. The latter can be used by patients to bribe the service provider with the aim to obtain services with better quality and quicker access (bypassing queues and waiting lists). In contrast to informal cash payments and sizable in kind gifts, a true gratitude payment does not violate patient's rights and dignity. The freedom of patients to give small in kind gifts does not make them vulnerable. Therefore, this type of payment is difficult to eliminate. However, there should be clear regulations on what a thankful patient can give to medical personnel after the service provision (Stepurko et al., 2013).

In Chapter 4, we have analyzed the association of socio-demographic variables, stated behavior and awareness of official user charges with the respondents' attitudes towards informal cash payments and gifts in kind. We have found that all perceived behavior statements have a significant relation with both types of attitudes. In particular, we have found that consumers who felt uncomfortable to leave the physician office without a cash payment or gift in kind, as well as those who preferred to use private services or who were asked to pay informally, more often reported making informal payments for physician visits. Those who reported that they refuse to make informal payments, less frequently reported making such payments for both types of services (physician visits and hospitalization) (see Chapter 4). A comparative study in CEE countries shows that the behavioral pattern of making informal patient payments is mostly associated with patient's perceptions rather than socio-demographic characteristics (Stepurko, 2013). According to the findings of this comparative study, the ability to refuse to pay informally when requested, was similar for Bulgarian and Ukrainian citizens about a decade ago. However, nowadays the Bulgarians feel more confident in refusing to pay informally than Ukrainians. This can be explained to some extent by the introduction of the social health insurance model in Bulgaria (in contrast to Ukraine) that requires greater patient's responsibility and the need to learn more about the patients' rights. Also, in Bulgaria, there are various institutions where citizens can submit complaints and signal illegal actions. These institutions have the right to take administrative and financial sanctions (such as fines, dismissal for breaching regulations). Therefore, the development of measures to reduce informal payments should consider not only the socio-demographic characteristics but also the individual perceptions.

In chapter 5 , we have found that the distrust towards formal charges also contributes to negativism toward the practice of informal cash payments. This is due to the lack of official information about what happens with these charges and what the real effects of their introduction are. In Bulgaria, unlike Hungary, where co-payments 
were abolished by a referendum (Baji et al, 2010), there are no published data regarding the amount of the revenues collected from co-payments. In addition, in Bulgaria compared to other CEE countries, there are no official statistics to what extent the co-payments influence the level of use of health care services. More than 10 years after the implementation of user charges, informal payments continue to exist rather than to be the exception in the relationship between patients and medical staff. This leads to an erosion of the professional image and trust.

Overall, the results presented above show that the study of patient's attitudes towards informal payments is essential. Research on this topic can help to understand individual experiences and perceptions, which can be an important ground for policy discussions. In this way, a policy that is oriented to serve the national health interests can be based on evidence. Recent trends in the development of the strategies emphasize the importance of such approach to policy (Ministry of Health, 2013).

Policy recommendations: Public attitudes towards informal payments in Bulgaria range from strongly negative to tolerant. Informal payments indicate broader failures in the health care system related to governance, regulation and accountability. Therefore, policy efforts should be directed to improve transparency and the enforcement of effective laws and regulations. Also, the role of the media in the problems of informal payments, has been described at present as "superficial" and without a beneficial effect on society and with unused potential as well (OSI, 2008). Hence, efforts should be focused on the potential of the mass-media to influence and shape public opinion. In addition, good management of health care establishments can also produce positive results in increasing patient's awareness. For example, information about the fees and how to pay them should be posted in front of all physician offices and labs. A box for signals as well as a complaint book could be placed in a visible place. Another positive step to curbing corruption in the health care sector might be the introduction of a central registration system, which requires patient payments to take place at the cashier.

Future research: Further research on the attitudes toward informal payments may examine the opinions and perceptions of other health care system stakeholders. Our study covers the patient's point of view but the problem of the persistence of informal payment has two sides. Therefore, the focus of future studies might be on the behavior of health care providers. The different positions of the physicians in health care markets (simultaneously agent and seller) may lead to conflicting interests which may be detrimental to the "physician-patient" relationship. Also, the changes in the scale of informal payments both the cash and the in kind informal payments, should be monitored. 


\section{Statement 4: The burden of out-of-pocket patient payments is considerable in Bulgaria and moreover, these payments are unevenly distributed among socio-demographic groups.}

In Bulgaria, the share of out-of-pocket payments has increased substantially, which reflects a common trend in Europe. Recent reports indicate that out-of-pocket payments in Bulgaria accounted for $44.2 \%$ of total expenditure on health in 2010. This share is one of the highest in Europe (WHO, 2013; Bulgarian Academy of Sciences, 2013). Thus, out-of-pocket payments constitute a major source of health financing in Bulgaria. However, up-to-date evidence on the distribution of these payments across socio-demographic groups is lacking.

We have studied whether user fees, combined with informal payments are affordable for the population. For this purpose, we have analyzed two indicators of inability to pay: the need to borrow money to pay for health care and the need to forego health care services due to high payment requirements. In Chapter 3 , we have found that in 2010 and 2011, 60\% of users paid out-of-pocket payments for both physician services and hospitalizations. Of those who paid, about $6 \%$ borrowed money to pay for physician services in both years and more than $10 \%$ of users borrowed money to pay for hospitalization. In addition to this, $32 \%$ of the sample forewent physician visits due to the patients' inability to pay and about $6 \%$ of the sample reported foregoing hospital services. Both coping strategies (borrowing money or foregoing services) can have negative consequences. Borrowing money might secure timely treatment but can push the household into poverty, whereas not seeking health care services can have negative consequences for the individual's health status as well as for society.

The results from a comparative study, which took place in 2010 in six CEE countries including Bulgaria simultaneously, also suggest that foregoing health care services is more often observed for outpatient care than for hospitalizations, whereas the opposite is true for borrowing money (Tambor et al, 2013). When considering the average number of foregone services, Bulgaria takes the middle position (2.8 visits to physicians and 1.6 hospitalizations) between Romania (highest number of foregone services) and Poland and Hungary (lowest number of foregone services). Borrowing money to cover payments is less common in Bulgaria compared with Ukraine and Romania (Tambor et al, 2013).

The findings in Chapter 3 of this dissertation also provide insights in the burden of out-of-pocket payments for different socio-demographic groups in Bulgaria. In case of outpatient care, the probability of borrowing money increases with a poorer health status, lower income and the presence of a chronic illness. Foregoing 
physician services is more likely among the latter three groups and also among women, young people and those with no social health insurance. At the same time, individuals in large cities more often report borrowing money to pay for hospital care. Foregoing hospitalization is significantly more likely among chronically sick, those with poor health status and lower income. These findings are in line with the results for other CEE countries (Tambor et al, 2013). Thus, irrespective of the coping strategy (borrowing money or foregoing services) used by the patients to deal with their inability to pay, our results show that population groups with insufficient household resources (low income) and in frequent need of health care (poor health and chronic conditions) are the most vulnerable groups. These groups should be the primary target of the exemption mechanism in Bulgaria.

It should be pointed out that an adequate exemption mechanism can only partly solve the problem of the inability to pay of vulnerable groups. This is because of the existence of informal payments in Bulgaria (as shown in Chapter 3 and Chapter 4), which fall outside government regulations. Although Bulgarian patients mostly pay small formal charges some patients also pay informally. The mean and median values of annual informal payments tend to exceed the mean and median values of annual out-of-pocket payments. Specifically for inpatient care, the total amount of money paid for a hospitalization (nearly twice higher than for physician services), more frequently includes informal payments compared with payments for physician services. Also, total patient payments for a hospitalization have increased during the last years. A previous study conducted in Bulgaria in 2006 presented an average level of total patient payments (formal and informal) for outpatient services similar to our findings (OSI, 2008). In contrast, however, we find much higher average amounts of out-of-pocket payments for hospital care in 2010. On the one hand, we explain this difference by the existence of quasi-formal charges in case a patient wishes to choose the hospital team (see statement 1 and statement 2), which allows to some extent the opportunity for supplier-induced demand. On the other hand, this difference could be partly attributed to the informal payments in hospital care (Chapter 3 and Chapter 4). Patients need to pay informally either because they want to secure attention and quality of care, or because they are requested by the staff to pay informally (Stepurko, 2013).

Our results in Chapter 3 also contribute to the understanding of patient's awareness of the levels of user charges. More than $50 \%$ of the respondents with regard to physician services and more than $75 \%$ with regard to hospital care reported that they did not always know the exact fee size before service provision. Although these fees have been broadly applied since 2000, consumers are still poorly informed about them. 
An important change in terms of the fee size was the reduction of official patient charges for pensioners. In July 2008, patient charges for persons above the age of 60 were reduced to $1 \mathrm{BGN}$ (about $0.50 \mathrm{EUR}$ ) per outpatient visit with the remainder of the co-payment covered by the state. The motivation for this change was the overall low income of the Bulgarian pensioners. However, this discounted rate did not last long, and in January 2011 the co-payment for this population group was restored to its original level. Two years later, the issue is back on the agenda and pensioners will have to pay a reduced fee of 1 BGN. Pensioners need be well informed about these changes. Otherwise they might still end up paying a full charge if a provider decides not to apply the new lower fee for pensioners. The inability to pay among pensioners could become a major barrier to accessing health care services.

Policy recommendations: Based on the results discussed above, it can be concluded that there is evidence on the existence of a high financial burden of outof-pocket payments for patients in Bulgaria. Financial barriers are an important factor limiting access to health care and can have a negative effect on patients' health. From an economic perspective, the deterioration of an individual's health (death and morbidity) leads to a loss of national product (WHO, 2009). Therefore, the efforts of policy-makers should be directed to reduce the incidence of inability to pay for health care. This can be done through the adjustment of an exemption mechanism that excludes vulnerable population groups from patient charges.

Future research: As indicated by our results, Bulgarian patients suffer from a high burden of payments. However, the total out-of-pocket payments level is much higher than the level indicated in this dissertation because one of the main items of expenditure (out-of-pocket payments for pharmaceuticals) is not included in our study. As explained in Chapter 1, we focus on out-of-pocket payments for physician services. Thus, future research that encompasses out-of-pocket payments for pharmaceuticals can provide further details about the burden of these payments for patients. We also need further evidence on the effect of exemptions on access to health care services and the affordability of payments.

\section{Statement 5: In order to sustain equitable additional financing of the health care system, Bulgarian policy-makers need to retain and possibly reconsider the exemption mechanism that accompanies formal co- payments and to address the informal payments.}

As was pointed out in Chapter 3 of the dissertation, the Bulgarian legislation stipulates a broad exemption mechanism involving exclusion on various grounds. The exclusions on an economic basis refers to persons without income placed in 
institutions for children or other social institutions, persons under arrest and prisoners, unemployed members of the family registered in the employment bureau, regardless of whether they receive compensation, as well as people with low income who receive social assistance (National Health Insurance Fund, 2014). This aspect of the exemption mechanism is of great importance in Bulgaria, where the unemployment rate is rather high (12\% in 2012) and social security benefits are rather low due to the unstable economic development in the country (NSI, 2011). Moreover, the Bulgarian legislation on formal co-payments also constitutes exemptions based on age and occupation. These are the exemptions for children under certain age, minors, people involved in the defense of the country, war veterans and war invalids. In addition, exemptions based on health status are applied as well. The list with the medical conditions according to which the patients are exempted from co-payment, is defined in the National Framework Contract. There are also exclusions for persons with more than $71 \%$ diminished working capacity according to the Ordinance for medical specialists' report (National Health Insurance Fund, 2014).

Despite the wide range of exceptions, there is no distinction between people in the cities and people in the rural areas who are confronted with high transportation costs. The rural population groups who live far from the health care facilities have to meet the same co-payment obligations as the urban population. There are both, economic and health-status reasons, for at least lowering the co-payment obligations for those in the rural areas. High unemployment and low incomes in most village regions can be seen as a barrier to access to health care services. Furthermore the mortality and morbidity rates are higher among the rural population compared with the urban population due to a more intensive process of aging of the rural population (National Statistic Institute, 2013). Therefore, the patient charges differentiation for rural and urban population should be in the focus when exemptions are discussed.

In Chapter 5, we have analyzed the opinions of different health care stakeholders towards the official patient charges, in particular for which services should these charges be applied, which population groups should be exempted partly or fully from fees as well as whether there should be limitations on fees. With respect to the services, we find that all stakeholder groups advocate patient charges for outpatient specialist services. As described in Chapter 2 and Chapter 5, the emergency services in Bulgaria are free of charge for the entire population. However, we find that a fifth of the health care providers are in favor that user fees should be applied for these services as well. Only policy-makers and insurers are unanimous that charges should not be applied to emergency care. Owing to the lack of payment obligations for emergency care, this type of medical services has become the preferred gateway to the health care system (see Chapter 2). Thus, currently, emergency services are 
most discussed due to the numerous problems and overcrowding related to the absence of formal charges.

Findings from our quantitative results in Chapter 5 also show that regarding the full or partial exemptions, the stakeholders' viewpoints on the exemption mechanism differ considerably. All stakeholder groups are least in favor of the exemption of pensioners and people with low income. At the same time, all stakeholder groups have positive attitudes toward the exemption of other vulnerable individuals, such as children, disabled persons and pregnant women. Hence, the statutory exemption mechanism in Bulgaria is sufficiently wide compared with the public attitudes toward it. In addition, our results in Chapter 5 also suggest that the limitation on accumulated payments can have a different basis. Consumers and providers more often prefer the maximum number of services per patient per month/year as a basis for limitation, whereas policy-makers/insurers are in favor of limitations on accumulated payments per month/year. The Bulgarian legislation, however, fails to consider any limitations on the patient charges, except for inpatient care (see Chapter 3 and Chapter 5). That is why policy-makers should take into account this omission when planning changes associated with the exemption mechanism. The change in the Bulgarian co-payments arrangements is often in the focus of policy debates during the election periods. Policy-makers usually end up changing the size of the user fee (reduced fee size) for one specific consumer group, namely the pensioners, however, the last change is related by fixed co-payments for users.

It is also necessary to ensure that the exemption mechanism is applied properly. As suggested by the literature (Arsenijevic et al., 2013 ), there are many factors that can lead to the inaccurate application of the exemption mechanism especially if health care providers are not compensated for the reduced patient charges that they collect as a result of the exemptions. Health care providers should be obliged to place the exemption list at a visible place in front of the physician office. Exempted groups should be given the possibilities to file an official complaint if the service provider asks them to pay the formal fee, or tries to induce an informal payment as a compensation for the exemption. It should also be pointed out that patients, who are exempted from patient charges, might initiate informal payments themselves to secure the attention of the health care provider and quality of care provided to them. As suggested by the literature, health care providers might provide substandard care to patients from exempted groups when an additional patient co-payment is absent (Arsenijevic et al., 2013). A close monitoring of health care services provided to exempted groups is necessary. 
In addition to the revision of the exemption mechanism related to formal charges, to reduce the burden of out-of-pocket payments in Bulgaria, there is also a need to deal with informal patient payments. Although the introduction of patient charges is often association with the expectation that informal contributions can be eliminated, our results show that this has not happened in Bulgaria (see statement 2). As mentioned earlier, our findings in Chapter 3 and Chapter 4 indicate a low awareness about the exact size of fees which leads to a higher burden for the patient due to simultaneously making of formal and informal payment (see statement 4). Consequently, the information regarding the level changes of the user charges and their purposes need to be periodically published in order to reduce the risk of unexpected costs and to increase the patient awareness.

Policy recommendations: There is no universal point of view on the exemption mechanism. In all European countries, there is some form of exemptions or fee reduction irrespective of what type of patient charges is applied (Paris et al, 2010; Tambor et al, 2010). The key exemption groups are young and elderly people, people with certain chronic diseases and low-income households (Robinson, 2002). In view of this, we can suggest that the exemption mechanism that accompanies formal patient charges in Bulgaria, is in a way optimal since it considers various exemptions based on different criteria. However, as shown in this dissertation, the mix of formal and informal charges can present an excessive financial burden for individuals. These concerns should be taken into account when considering changes in the exemption mechanism. In order to sustain equitable additional financing, Bulgarian policy-makers need not only to maintain the current exemption mechanism but also to further discuss the limitations for outpatient services, especially if informal payments continue to exist. Moreover adjustments related to the list of exemption groups, for example also including the rural population, and members of big families, can be a subject of re-examination. Even if these groups are not viewed as poor, the accumulated patient payments or the combination of user fees and travelling costs can pose a financial barrier for using health care services.

Future research: Future research should focus on the out-of-pocket payments by exempted groups in Bulgaria to examine whether formal charges are paid by these groups irrespective of the exemption. Furthermore, the additional financing of the health care establishments due to the patient charges can be explored in order to obtain more insights on how these resources are allocated and used, and whether exempted groups are requested to pay informally as a compensation for the exemption. 


\section{Statement 6: Preferences among Bulgarians to pay for services with good quality and quick access have not changed much during the past 10 years.}

Preferences among Bulgarian consumers to pay formally for health care services are in the focus of this dissertation (see Chapter 6). Despite the burden of out-of-pocket payments that we have found based on revealed-preference data (see Chapter 3) and despite the informal payments (Chapter 4), our findings also indicate a high willingness to pay for services with good quality and quick access based on statedpreference data. The probability that the respondents are willing to pay formally for health care services, is more than $70 \%$ for a physician visits and more than $65 \%$ for a hospitalization. However, when we take into account the socio-demographic characteristics, it becomes apparent that the prevalence of the willingness to pay is not equally distributed across the different groups of respondents. Similar to other CEE countries (Golinowska \& Tambor, 2012; Danyliv et al, 2013), we also find that a higher willingness to pay for health care services is most often observed among young people and those with higher incomes. A comparative study in CEE countries including Bulgaria shows that the proportion of those willing to pay for physician services is overall rather substantial (Danyliv et al, 2013). The findings of this comparative study place Bulgaria in the middle of the range of stated willingness to pay. Furthermore, the study shows that in these countries, including Bulgaria, the cost of services is rather close to the socially acceptable willingness to pay levels.

In Chapter 6, we have compared the average actual past payments for outpatient and inpatient services given the co-existence of formal and informal payments, with the stated willingness to pay for both services. We find that three-fourths of the outpatient care users state average out-of-pocket payments of about 14 BGN (7 EUR), whereas the average amount willing to pay is about 18 BGN (9 EUR) per visit. At the same time, two-thirds of the hospitalized users report average total payment of about 125 BGN (about 60 EUR), while $66.6 \%$ of respondents state an average amount willing to pay of 225 BGN (about 112 EUR) per hospitalization. Thus, our empirical findings show similar results obtained from two approaches (revealedand stated-preference approaches). Although the stated-preference approaches are criticized for their low predictive validity, our findings provide positive evidence that estimates based on stated preferences can be very close to real consumer behavior. In contrast to most CEE countries where formal charges for public health care services are not implemented, the Bulgarian case can be seen as a good ground for the comparison of two approaches because of the established and working formal patient payment mechanism. 
To check the steadiness of the preferences among Bulgarian consumers to pay formal fees, we compare our results to those from a study carried out in Bulgaria about 10 years ago (Pavlova et al, 2004). This study took place before the actual insurance implementation, i.e. when the public health care services were still free of charge. We used the same set of independent variables in our stated-preference models (see Chapter 6) for the comparison. The findings in both studies show similarities with regard to differences in the willingness to pay among consumer groups. Age, education and household income are the most frequent significant variables that have an influence on the respondent's decision for a hypothetical payment. For young individuals who are not frequent health care users, as well as for those who have better jobs and higher incomes, the acceptance of fees is higher (see Chapter 5) and they also state a higher willingness to pay (Chapter 6). The group of respondents with a higher level of education probably realizes the objectives of patient charges and accepts the willingness to pay in order to obtain a given benefit. It is not surprising that household income is almost always significant indicating that well-off individuals have a greater propensity for payment (in case of both outpatient and inpatient services). Given the comparability of our findings with the findings from the Bulgarian study in 2000 (Pavlova et al, 2004), it can be concluded that preferences among consumers to pay for improved physician and hospital services has not changed much during the past 10 years.

The analyses in this dissertation suggest that over the last decade (marked by difficult economic conditions), Bulgarians have not considerably changed their preferences to pay if they can obtain public health care services with high quality and quick access. Taking into account the official fee size (stipulated in the insurance law) and consumer willingness to pay (outlined in this dissertation), we suggest that the current patient payment mechanism is not detrimental for the average Bulgarian consumers. However, it should not be forgotten that about one-third of the respondents report to be unwilling to pay, mostly due to their inability to pay. Consequently, the part of the population that faces financial restrictions should be the focus of policy attention. In order to protect vulnerable groups, there is a need to implement limits on the payment obligation for outpatient services (see Statement 5).

Policy recommendations: Although, the majority of Bulgarian consumers declare to be willing to pay for public health services, the willingness to pay amounts should not be taken and understood as a fee size that the government should implement. Bulgarian policy-makers should be aware of the presence of informal payments. Thus, in the presence of informal payments, the ability of the average Bulgarian consumer to pay formal charges is much lower than the stated willingness to pay. Also, in order to avoid wrong signals, we should underline that the results 
on willingness to pay reported in this dissertation, should be interpreted in view of consumer preferences for public health care services with good quality and quick access rather than possible fee amounts. In particular, the high willingness to pay reported in this dissertation can only be expected if public health care services in Bulgaria are actually provided with good quality and quick access. As suggested in Chapter 2, this is not yet the case in Bulgaria. The Bulgarian government should invest in the improvement of the public health care sector and should eliminate the need of making informal payments, before considering an increase in formal patient charges.

Future research: Given the consumer's willingness to pay, we have drawn conclusions about the comparison between the two approaches applied (revealedand stated-preferences approaches). However, further research is needed to confirm the credibility and convergent validity of our first attempt for a comparison of both approaches based on data from Bulgaria. We also need further evidence (qualitative data) for the reasons for the unwillingness to pay official fees as well as whether those who unwilling to pay have experienced informal payments.

\subsection{Concluding remarks and valorization}

The findings of this dissertation reflect the parallel existence of formal and informal payments in Bulgaria that together lead to higher out-of-pocket payments. However, if consumers can obtain health care services with good quality and quick access, they state a high level of willingness to pay. The evidence on formal and informal patient payments outlined in this dissertation, may facilitate decisions of Bulgarian policymakers related to the health care system funding and out-of-pocket payments in particular.

As was pointed out in the introduction of this dissertation, the Bulgarian health care system is based on an insurance model consisting of compulsory social health insurance and voluntary health insurance. However, the voluntary health insurance is still limited and covers only a relatively small share of the population. Although respondents with social health insurance have better access to medical services, the empirical results in this dissertation show that they also often need to borrow money to be able to use public health care services. Also, despite the mandatory nature of the social health insurance, there is a large part of the population without insurance coverage (the largest part of them with low or no income). Therefore, the Bulgarian government is confronted with the challenge to review the current health insurance model. Policy-makers have to take the responsibility and to propose a reorganization. 
They have to create favorable economic incentives for both population and insurance companies to participate in the second pillar of health insurance, i.e. voluntary health insurance. This can help to shift part of the financial burden from the state to the private insurance sector, which can leave extra funds for providing adequate services to disadvantageous groups, who cannot afford voluntary health insurance. The underestimation and underdevelopment of the voluntary health insurance has also limited competition among insurers and providers, as well as free choice for consumers. However, if this pillar becomes a priority it should not duplicate the basic benefits package as it is at present (Bulgarian Academy of Sciences, 2013). Furthermore, the development of the voluntary health insurance in Bulgaria can allow individuals who are willing to pay, to obtain extra services without the need of cash informal payments.

This dissertation provides empirical evidence (both qualitative and quantitative) on the support rather than the opposition to official patient payments in Bulgaria. Given previous research in Bulgaria that explored whether formal patient charges are feasible and acceptable to the population at the start of the insurance reform, and given the findings reported in this dissertation about 10 years after the reform implementation, we can conclude that more patient payment in the public health care sector is appropriate and affordable to the average Bulgarian consumer. But there are disadvantaged population groups, who are unable to pay formal patient charges. Although the Bulgarian patient payment mechanism includes an extensive exemption mechanism involving exclusions on various bases (a strength that should not be denied), the exemption of additional population groups, such as rural dwellers and large families, should be also considered. All disadvantaged groups need to be effectively exempted from formal payment obligations. There is also a need to eliminate the existence of informal patient payments, which leads to additional payment obligations for health care users. These payments are used by patients and health care providers as a means to overcome the poor service quality, to compensate the low remuneration of health care personnel and to receive proper attention. However, the fight against these payments requires a set of different measures, persistency and strict control, and regular government investments in the improvement of service quality.

It should be noted that except for the extensive system of exemptions, the copayment mechanism in the Bulgarian public health care sector shows additional strengths. The decision of the government to tie the size of formal patient payments to the minimum monthly salary in the country, makes the Bulgarian co-payment mechanism rather unique compared to other countries. This co-payment design reduces the political risk of public disaffection when patient payments are 
increased. Also, the patient payment arrangements in Bulgaria and the policy motivations for their implementation show a political attempt to provide consumers with economic incentives for a cost-effective health care utilization. However, special attention should be also paid to the use of formal payments as a tool for improving the quality of health care provision. Although these payments cannot generate considerable financial resources for the health care system, they can help to mobilize enough additional financial support at a facility level to improve health care provision. As suggested by this dissertation, the provision of public health care services with good quality and quick access is highly valued by Bulgarian consumers (in terms of stated willingness to pay for such services). Related to this, the present situation leaves much to be desired as was also confirmed by the dissertation. To align the public health care provision to consumer preference, the Bulgarian government needs to put priority to the improvement of public health care provision.

High levels of out-of pocket payments are the result of the health care reforms in Bulgaria. According to Komitov and Genev (2009) the health care reform will be finished "when each Bulgarian citizen is admitted in hospital without worry about how much extra money will be asked." 


\section{REFERENCES}

Aarva P, Ilchenko I, Gorobets P, Rogacheva A. (2009). Formal and informal payments in health care facilities in two Russian cities, Tyumen and Lipetsk. Health Policy and Planning, 24:395-405.

Allender S, Scarborough P, Peto V, Rayner M, Leal J, Luengo-Fernandez R, Gray A. (2008). European cardiovascular disease statistics. Brussels. The European Heart Network.

Allin S, Davaki K, Mossialos E. (2006). Paying for 'free' health care: the conundrum of informal payments in post-communist Europe. In: Kotalik J, Rodriguez D, editors. Global Corruption Report 2006. London. Pluto Press, 63-71.

Arsenijevic J, Pavlova M, Groot W. (2013). Out-of-pocket payments for public health care services by exempted groups in Serbia during the period of postwar health care reforms. International Journal of Health Planning and Management, forthcoming.

Atanasova E, Moutafova E, Kostadinova T, Pavlova M. (2010). Patient payments and the problems in medical services provision in Bulgaria. Journal of Health Care, Health and Management / Zeszytu Naukowe Ochrony Zdrowia. Zdrowie Publiczne i Zarządzanie, VIII(1):48-53.

Atanasova E, Pavlova M, Velickovski R, Nikov B, Moutafova E, Groot W. (2011). What have 10 years of health insurance reforms brought about in Bulgaria? Re-appraising the Health Insurance Act of 1998. Health Policy, 102 (2-3): $263-269$.

Atanasova E, Pavlova M, Moutafova E, Kostadinova T, Groot W. (2012). Patient payments and the empirical analysis of consumer demand for hospital services: an application for Bulgaria. Society and Economy, 34(2): 313-338.

Atanasova E, Pavlova M, Moutafova E, Rechel B, Groot W. (2013). Out-of-pocket payments for health care services in Bulgaria: financial burden and barrier to access. European Journal of Public Health, 23(6): 916-922

Avdeeva O. (2007). Health System in Transition. HiT profiel in brief - Bulgaria. Berlin. European Observatory on Health System and Policies.

Avdeeva O, Georgieva L. (2008). Promoting the quality of health services in Bulgaria. Eurohealth, 13(2):19-20. 
Baji P, Boncz I, Jenei G, Gulácsi L . (2010). The short story of co-payments for health care services in Hungary - lessons for neighbouring countries. Journal of Health Care, Health and Management / Zeszytu Naukowe Ochrony Zdrowia. Zdrowie Publiczne i Zarzadzanie, VIII(1): 37-47.

Baji P, Pavlova M, Gulácsi L, Groot W. (2011). User fees for public health care services in Hungary: Expectations, experience, and acceptability from the perspectives of different stakeholders. Health Policy, 102(2-3):255-262.

Baji P, Pavlova M, Gulacsi L, Homolyáné Cseta Zs, W.Groot. (2012). Informal payments for health care services and short-term effects of the introduction of visit fees on these payments in Hungary. International Journal of Health Planning and Management, 27(1): 63-79.

Balabanova D, McKee M. (2002a). Understanding informal payments for health care: The example of Bulgaria. Health Policy, 62: 243-273.

Balabanova D, McKee M. (2002b). Access to health care in a system transition: the case of Bulgaria. International Journal of Health Planning and Management, 17:377-395.

Balabanova D, McKee M. (2004). Reforming health care financing in Bulgaria: the population perspective. Social Science \& Medicine, 58: 753-765.

Balabanova D, McKee M, Pomerleau J, Rose R, Haerpfer C. (2004). Health service utilization in the Former Soviet Union: evidence from eight countries. Health Services Research, 39:1927-1950.

Bhatia M. R, Fox-Rushby J. A. (2003). Validity of Willingness to Pay: Hypothetical Versus Actual Payments. Applied Economic Letters, 10(12): 737-740.

Bonilla-Chacin M, Murrugarra E, Temourov M.(2005). Health care during transition and health system reform: evidence from the poorest CIS countries. Social Policy and Administration, 39:381-408.

Borisov V, Rathwell T. (1996). Health care reform in Bulgaria: an initial appraisal. Social Science and Medicine, 42(11):1501-1510.

Bulgarian Academy of Sciences. Economic Research Institute. (2013). Economic development and policies in Bulgaria: evaluations and expectations. Annual Report. Goreks Press. Sofia (in Bulgarian).

Bulgarian Industrial Capital Association. (2012). The Informal Economy in the Bulgarian health care regarding some characteristics. Available at: http:// www.factor-news.net/img/Neformalnata_ikonomika_v zdraveopazvaneto. pdf (in Bulgarian). 
Bulgarian Medical Association. (2011). Plan for health care reforms. Available at: http://www.forummedicus.com/archives/all-publications/1906 (Accessed on 15 December 2011) (in Bulgarian).

Cerami A. (2006). The Reform Challenges to the Central and Eastern European Welfare Regime. International Conference "Transformation of Social Policy in Europe: Patterns, Issues and Challenges for the EU-25 and Candidate Countries".

Cichon M, Normand C. (1994). Between Beveridge and Bismark - options for health care financing in Central and Eastern Europe. World Health Forum, $15: 323-328$.

Cohen N. (2012). Informal payments for health care - the phenomenon and its context. Health Economics, Policy and Law, 7(3):285-308.

Colombini M, Rechel B, Mayhew S. (2011). Access of Roma to sexual and reproductive health services: findings from Albania, Bulgaria and Macedonia. Global Public Health.

Cutler D, Zeckhauser R. (2000). The Anatomy of Health Insurance. In: Culyer, A.J. - Newhouse, J.P. (eds): Handbook of Health Economics. Amsterdam: Elsevier Science B.V.

Danyliv A, Stepurko T, Gryga I, Pavlova M, Groot W. (2012). Is there a place for the patient in the Ukrainian health care system? Patient payment policies and investment priorities in health care in Ukraine. Society and Economy, 34(2): 273-291.

Danyliv A, Pavlova M, Gryga I, Groot W. (2013). Willingness and ability to pay for physician services in six Central and Eastern European countries, (forthcoming)

Danyliv A. (2014). Willingness to pay for physician services in Central and Eastern European countries: application of stated preferences techniques to the assessment of patient charges. PhD Thesis.

Datzova B. (2003). Heath care reform and inequity of access to health care in Bulgaria. Geneva. United Nations Research Institute for Social Development.

Datzova B. (2006). The difficult transition to national health insurance in Bulgaria. Journal of International Development, 18(3):425-434.

Dawson D, Jacobs R, Martin S, Smith P. (2006). The impact of patient choice and waiting time on the demand for health care: results from the London Patient Choice project. Applied Economics, 38: 1363-1370. 
Delcheva E, Balabanova D, McKee M. (1997). Under-the-counter payments for health care: evidence from Bulgaria. Health Policy, 42(2):89-100.

Delcheva E. (1999). What do customers pay for Bulgarian health care? Zdravna Ikonomika, 4:18-35 (in Bulgarian).

Delcheva E. (2006a). Overall access to quality health care. In: Angelov I et al, editors. Economics in Bulgaria and EU: Running economic development: Strategies and reality. Sofia: EI of BAN, p.76-97. (in Bulgarian).

Delcheva E. (2006b). Universal access to health care. In: Angelov I, editor. Catching up economic development of Bulgaria - strategy and realities. Sofia. Institute of Economics of the Bulgarian Academy of Sciences and Friedrich Ebert Foundation.

Delcheva E. (2011). Imbalances in health care expenditures in Bulgaria. Scripta Scientifica Medica, 43(7): 121-123 (in Bulgarian).

D'Intignano B. (1992). Health care finance in Europe. EUR/RC42/Tech.Disc./1 0519K. Copenhagen. WHO/Regional Office for Europe.

Dimova A, Atanasova E, Mutafova E. (2002). $2^{\text {nd }}$ of July - the day " $X$ " or Where the expectations of Bulgarian physicians and patient meet. Proceedings of the conference with international participation "Economy and Development of Society“. Varna. Economic University, p.192-198. (in Bulgarian).

Dimova A, Popov M, Rohova M. (2007). The health care reform in Bulgaria: analysis. Sofia. Open Society Institute.

Dimova A, Rohova M, Moutafova E, Atanasova E, Koeva S, Panteli D, van Ginneken E. (2012a). Bulgaria: Health System Review. Health Systems in Transition, 2012, 14(3):1-186.

Dimova A, Rohova M, Popov M, Rechel B. (2012b). Health Reform in Bulgaria. In: Bartlett W, Bozikov J, Rechel B, editors. Health Reforms in South-East Europe. Houndmills, New York: Palgrave Macmillan, 49-63.

Donaldson C, Shackley P. (2003). Willingness to Pay for Health Care. In: Scott, A. et al. (eds): Advances in Health Economics. New York: John Wiley \& Sons, Ltd.

Ellis R, McInnes D, Stephenson E. (1994). Inpatient and outpatient health care demand in Cairo, Egypt. Health Economics, 3: 183- 200.

Ensor T. (2004). Informal payments for health care in transition economies. Social Science \& Medicine, 58(2):237-46. 
Exadaktylos N. (2005). Organisation and financing of the health care systems of Bulgaria and Greece - what are the parallels?. BMC Health Services Research, $5: 5: 41$.

Folland S, Goodman A, Stano M. (2007). The Economics of Health and Health Care. Upper Saddle River, NJ. Pearson Prentice Hall.

Foreit J. R, Foreit K. G. F. (2002) The Reliability and the Validity of Willingness to Pay Surveys for Reproductive Health Pricing Decisions in Devolving Countries. Health Policy, 63(1): 37-47.

Gaal P, McKee M. (2004). Informal payment for health care and the theory of' INXIT'. International Journal of Health Planning and Management, 19(2):163-78.

Gaal P, Evetovits T, McKee M. (2006a). Informal payment for health care: evidence from Hungary. Health Policy, 77:86-102.

Gaal P, Belli P, McKee M, Szocska M. (2006b). Informal payment for health care: Definitions, distinctions, and dilemmas. Journal of Health Politics, Policy and Law, 31(2):251-91.

Gaziano C. (2005). Comparative analysis of within-household respondent selection techniques. Public Opin Quart, 69(1):124-57.

Genev E, Kalaikov D. (2003). Child health care and the health reform. Paediatria, 38-39. (in Bulgarian).

Georgieva L, Salchev P, Dimitrova S, Dimova A, Avdeeva O. (2007). Bulgaria: Health system review. Health Systems in Transition, 2007, 9(1):1-156.

Gladilov S, Delcheva E. (2000). Health Economics. Sofia.Princeps. (in Bulgarian).

Golinowska S, Tambor M. (2012). Out-of-pocket payments on health in Poland: size, tendency and willingness to pay. Society and Economy in Central and Eastern Europe, 34(2): 253-271.

Gotsadze G, Bennett S, Ranson K, Gzirishvili D. (2005). Health care seeking behaviour and out-of-pocket payments in Tbilisi, Georgia. Health Policy and Planning, 20:222-242.

Griga I, Stepurko T, Danyliv A, Gryga M, Lynnyk O, Pavlova M, Groot W. (2010). Attitudes towards patient payments in Ukraine: is there a place for official patient charges? Journal of Health Care, Health and Management / Zeszytu Naukowe Ochrony Zdrowia. Zdrowie Publiczne i Zarządzanie, VIII(1):6978. 
Habibov N. (2011). The inequity in out-of-pocket expenditures for health care in Tajikistan: evidence and implications from a nationally representative survey. International Journal of Public Health, 56:397-406.

Habicht T, Aaviksoo A, Koppel A. (2007). Hospital reform in Bulgaria and Estonia: What is rational and what not?. Tallinn. Poliitikauuringute Keskus Praxis.

Hadjiev VD, Toneva ZD, Short SD. (2007). On the inequitable impact of universal health insurance: the experience of Bulgaria in transition. Health Sociology Review, 16(2): 130-145.

Haralampieva G. (1999). Insurance burden of implementing the health insurance on the employed people. Social Medicine, 7(4):35-37. (in Bulgarian).

Ho K. (2006). The welfare of restricted hospital choice in the US medical care market. Journal of Applied Econometrics, 21: 1039-1079.

HOPE. (2011). Hospital in Europe: Healthcare data. Report.

Hunt-McCool J, Kiker B, Ng Y. (1994). Estimates of the Demand for Medical Care under Different Functional Forms. Journal of Applied Econometrics, 9(2): 201-218.

Institute for Social and Trade Union Studies. (2005). Reforms and privatization of health care - social and economic consequences. Global Policy Network $-G P N$, Sofia.

Ivanov L, Glutnokova Z, Kalinov K. (1996). Adequacy and quality of primary health care (consumers' and doctors' opinion). Sofia: The National Center of Public Health. Ministry of Health. Report from a sociological survey, Bulletin 1.

Jan S, Mooney S, Ryan M, Bruggemann K, Alexander K. (2000). The use of conjoint analysis to elicit community preferences in public health research: a case study of hospital services in South Australia. Australian and New Zealand Journal of Public Health, 24(1): 64-70.

Kanavos P, McKee M. (1998). The context for health reform. In: Saltman RB, Figueras J, Sakellarides C, editors. Critical challenges for health care reform in Europe. Buckingham: Open University Press, p.23-52.

Kermani M, Ghaderi H, Yousefi A. (2008). Demand for Medical Care in the Urban Areas of Iran: An Empirical Investigation. Health Economics, 17(7): 849862.

Komitov G, Genev S. (2006). Ensuring the access of the health insured to the outpatient medical care. Healthcare Management, 6(6):68-74. (in Bulgarian). 
Komitov G, Genev S. (2009). Management of resources - a priority of health reform. Sofia. Goreks Pres. (in Bulgarian).

Koulaksazov S, Todorova S, Tragakes E, Hristova S. (2003). Bulgaria: Health system review. Health Systems in Transition, 2003, 5(2):1-92.

Lahiri K, Xing G. (2004). An econometric analysis of veterans' health care utilization using two-part models. Empirical Economics, 29: 431-449.

Lewis M. (2000). Who is paying for health care in Eastern Europe and Central Asia? In World Bank. Europe and Central Asia Region. Washington D.C.USA.

Lewis M. (2007). Informal payments and the financing of health care in developing and transition countries. Health Affairs, 26:984-97.

Liaropoulos L, Siskou O, Kaitelidou D, Theodorou M, Katostaras T. (2008). Informal payments in public hospitals in Greece. Health Policy, 87:72-81.

Markova N. (2006). How does the introduction of health insurance change the equity of health care provision in Bulgaria? Washington, DC: IMF Institute.

Martin S, Smith P. (2003). Using panel methods to model waiting times for National Health Service surgery. Journal of The Royal Statistical Society Series A, 3: 369-387.

Martin S, Rice N, Jacobs R, Smith P. (2007). The market for elective surgery: Joint estimation of supply and demand. Journal of Health Economics, 26: 263285 .

Mataria A, Luchini S, Daoud Y, Moatti J. (2007). Demand Assessment and PriceElasticity Estimation of Quality-Improved Primary Health Care in Palestine: A Contribution from the Contingent Valuation Method. Health Economics, 16: 1051-1068.

Ministry of Health. (1998). National Conference on Health Reform in Bulgaria. Verbatim report, Sofia. (in Bulgarian).

Ministry of Health. (2000). Better health for better feature. Sofia. MoH. (in Bulgarian).

Ministry of Health. (2008). National Health Strategy 2008-2013. Sofia. Ministry of Health.

Ministry of Health. (2013). National health strategy 2014-2020. Draft.

Moutafova E, Atanasova E, Kostadinova T. (2011). Ethical aspects of patient payments in Bulgaria. Health economics and management, 2 (in Bulgarian). 
Murauskiene L, Veniute M, Pavlova M. (2010). The opinions of the key health care stakeholders towards patient payments in Lithuania. Journal of Health Care, Health and Management / Zeszytu Naukowe Ochrony Zdrowia. Zdrowie Publiczne i Zarządzanie, VIII (1):62-68.

Murauskiene L, Pavlova M, Veniute M, Groot W. (2012). Towards a more comprehensive view on patient payments in Lithuania: new findings from a population survey. Society and Economy, 34(2): 241-251

National Association of General Practitioners in Bulgaria. (2013). User fee again exchange value for politicians. Available at: (http://www.nsoplb. org/novini/2011/06/potrebitelskata-taksa-otnovo-razmenna-moneta-zapoliticite, accessed 26 June 2013).

National Centre of Health Information. (2007). Health care. Statistics reference book of 2000-2006. Sofia. NCHI. (in Bulgarian).

National Centre of Health Informatics. (2010). Public Health Statistics 2010. Sofia. NCHI.

National Health Insurance Fund. (2003). Annual report of NHIF in Bulgaria. Sofia. NHIF. (in Bulgarian.

National Health Insurance Fund. (2004). Annual report of NHIF in Bulgaria. Sofia. NHIF. (in Bulgarian).

National Health Insurance Fund. (2005a). Annual report of NHIF in Bulgaria. Sofia. NHIF. (in Bulgarian).

National Health Insurance Fund. (2005b). Information bulletin, number 3-4 Sofia. NHIF. (in Bulgarian).

National Health Insurance Fund. (2006). Annual report of NHIF in Bulgaria. Sofia. NHIF. (in Bulgarian).

National Health Insurance Fund. (2007). Annual report of NHIF in Bulgaria Sofia. NHIF. (in Bulgarian).

National Health Insurance Fund. (2008a). Annual report of NHIF in Bulgaria. Sofia. NHIF. (in Bulgarian).

National Health Insurance Fund. (2008b). Compulsory health insurance contributions. Sofia. NHIF. (in Bulgarian).

National Health Insurance Fund. (2010). Rights and obligations of the insured patients in 2010. Sofia. NHIF. (in Bulgarian). 
National Health Insurance Fund. (2014) Available at: http://www.nhif.bg/web/ guest/25. (Accessed 10 January 2014).

National Statistical Institute. (2000). Health Care. Sofia. NSI. (in Bulgarian).

National Statistic Institute. (2005a). Health Care. Sofia. NSI. (in Bulgarian).

National Statistical Institute. (2005b). Research among people living with disease in Bulgaria. Sofia. NSI. (in Bulgarian).

National Statistical Institute. (2010). Health Care. Sofia. NSI. (in Bulgarian).

National Statistical Institute. (2011). Statistical Panorama - Bulgaria 2011. Sofia. NSI. (in Bulgarian).

National Statistic Institute. (2013). Health Services 2012. Sofia. NSI. (in Bulgarian).

National Social Security Institute. (2010). Statistic data. Sofia. NSSI. (in Bulgarian).

O’Brien B, Viramontes J. (1994). Willingness to Pay: A Valid and Reliable Measure of Health State Preferences?. Medical Decision Making, 14(3): 289-297.

OECD. (2012). Health at a Glance: Europe 2012. OECD Publishing. http://dx.doi. org/10.1787/9789264183896-en.

Oldendick R, Bishop G, Sorenson S, Tuchfarber A. (1988). A comparison of the Kish and last-birthday methods of respondent selection in telephone surveys. $J$ Official Statistics, 4:307-18.

Oliveira M. (2004). Modelling demand and supply influences on utilization: A flow demand model to predict hospital utilization at the small area level. Applied Economics, 36: 2237-225.

Open Society Institute. (2008). Informal payments in the health care system (report). Sofia. OSI. (in Bulgarian).

Open Society Institute. (2009). Health-uninsured individuals and health insurance in Bulgaria. Sofia. OSI. (in Bulgarian).

Official Gazette. (2006). Regulation on the right of access to medical care. No 45/ 2.06.2006.

Pashev K. (2006). Health care reforms in Bulgaria: towards diagnosis and prescription. Munich. Personal RePEc Archive.

Pashev K. (2007). Corruption in the health care sector in Bulgaria. Sofia. Center for the Study of Democracy. 
Paris V, Devaux M, Wei L. (2010). Health Systems Institutional Characteristics: A Survey of 29 OECD Countries. OECD Health Working Papers, No. 50, OECD Publishing. http://dx.doi.org/10.1787/5kmfxfq9qbnr-en.

Pavlova M, Groot W, van Merode F. (2000). Appraising the financial reform in Bulgarian public health care sector: The health insurance act of 1998. Health Policy, 53:185-199.

Pavlova M. 2002. Patient payments in the Bulgarian public health care sector. Are they feasible? Thesis.

Pavlova M, Groot W, van Merode F. (2002). Public attitudes towards patient payments in Bulgarian public health care sector: Results of a household survey. Health Policy, 59: 1-24.

Pavlova M, Groot W, van Merode F. (2003). The importance of quality, access and price to health care consumers in Bulgaria: a self-explicated approach. International Journal of Health Planning and Management, 18: 343-61.

Pavlova M, Groot W, van Merode G. (2004). Willingness and ability of Bulgarian consumer to pay improved public health care services. Applied Economics, 36(10):1117-1130.

Pavlova M, Tambor M, van Merode G, Groot W. (2010a). Are patient charges an effective policy tool? Review of theoretical and empirical evidence. Journal of Health Care, Health and Management / Zeszytu Naukowe Ochrony Zdrowia. Zdrowie Publiczne i Zarządzanie, VIII (1): 29-36.

Pavlova M, Stepurko T, Gordeev V, Tomini S, Gryga I, Groot W. (2010b). Informal patient payments for health care services: Policy challenges and strategies for solutions. Zeszytu Naukowe Ochrony Zdrowia Zdrowie Publiczne i Zarządzanie, VIII (1):5-11.

Pavlova M, Groot W, van Merode G. (2011). Is There a Place for an Increased Reliance on Patient Charges in Central and Eastern European Countries?. Scripta Scientifica Medica, 43(7):137-141.

Pavlova M, Arsenijevic J, Groot W, van Merode F. (2012). Projection of health service consumption and patient payment revenues in CEE countries using system dynamics modeling. Society and Economy in Central and Eastern Europe, 34(2):359-78.

Petkov V. (2004). Satisfaction with the quality of the health care in Bulgaria after the introduction of mandatory health care in Bulgaria. Healthcare Management, 4(4):28-30. (in Bulgarian). 
Petkov V. (2007). Prospects of voluntary health insurance. Sofia: Filfest. (in Bulgarian).

Preker A, Jakab M, Schneider M. (2002). Health financing reform in Central and Eastern Europe and the former Soviet Union. Berlin: European Observatory on Health Care System.

Rangelova R, Sariiski G. (2007). Health expenditure scenarios in the new member states. Country report on Bulgaria. Enepri research report no. 44. Brussels. ENEPRI.

Rechel B, McKee M. (2009). Health reform in central and eastern Europe and the former Soviet Union. Lancet, 374:1186-1195.

Rechel B, Blackburn C, Spencer N, Rechel B. (2009a). Access to health care for Roma children in Central and Eastern Europe: findings from a qualitative study in Bulgaria. International Journal for Equity in Health, 8:24.

Rechel B, Spencer N, Blackburn C, Holland R, Rechel B. (2009b). Impact of health reforms on child health services in Europe: the case of Bulgaria. European Journal of Public Health, 19(3):326-330.

Rechel B, Blackburn C, Spencer N, Rechel B. (2011). Regulatory barriers to equity in a health system in transition: a qualitative study in Bulgaria. BMC Health Services Research, 11: 219.

Robinson R. (2002). User Charges for Health Care. In: Mossialos et al. (eds). Funding Health Care: Options for Europe. Buckingham: Open University Press.

Ruger J, Kim Hak-Ju. (2007). Out-of-pocket health care spending by the poor and chronically ill in the Republic of Korea. American Journal of Public Health, 97(5): 804-811.

Salchev P. (2012). Health policy in the field of prevention. Politiki, 2. Sofia. OSI. (in Bulgarian).

Sari N, Langenbrunner J, Lewis M. (2000). Affording out-of-pocket payments for health services: evidence from Kazakhstan. Eurohealth, 16:37-39.

Schneider P. (2007). Issues affecting the sustainability of health financing in several countries in of south east Europe. Washington, DC: The World Bank.

Sepehri A, Chernomas R. (2001). Are User Charges Efficiency- and EquityEnhancing? A Critical Review of Economic Literature with Particular Reference to Experience from Developing Countries. Journal of International Development, 13(2): 183-209. 
Skriabikova O, Pavlova M, Groot W. (2010). Empirical Models of Demand for OutPatient Physician Services and Their Relevance to the Assessment of Patient Payment Policies: A Critical Review of the Literature. International Journal of Environmental Research and Public Health, 7(6): 2708-2725.

Skarbinski J, Walker H, Baker L, Kobaladze A, Kirtava Z, Raffin T. (2002). The burden of out-of-pocket payments for health care in Tbilisi, Republic of Georgia. JAMA, 287(8): 1043-9.

Specialized newsletter. (2010). Available at: http://www.bphu.eu/uploads/files/ MEDIA.NEXT/February.10/Press.room.16.02.10.doc (in Bulgarian).

Stepurko T, Pavlova M, Gryga I, Groot W. (2010). Empirical studies on informal patient payments for health care services: A systematic and critical review of research methods and instruments. BMC Health Services Research, 10:273.

Stepurko T. (2013) Informal Patient Payments in Central and Eastern European Countries. PhD Thesis.

Stepurko T, Pavlova M, Gryga I, Groot W. (2013). Informal payments for health care services - corruption or gratitude? A study on public attitudes, perceptions and opinions in six Central and Eastern European countries. Communist and Post-Communist Studies, 46(4):419-431.

Szalay T, Pažitný P, Szalayová A, Frisová S, Morvay K, Petrovič M, van Ginneken E. (2011). Slovakia: Health system review. Health Systems in Transition, 2011, 13(2):1-200.

Tambor M, Pavlova M, Woch P, Groot W. (2011). Diversity and dynamics of patient cost-sharing for physicians' and hospital services in the 27 European Union countries. European Journal of Public Health, 21(5): 585-590.

Tambor M, Pavlova M, Golinowska S, Sowada C, Groot W. (2012). Towards a stakeholders' consensus on patient payment policy : the views of health-care consumers, providers, insurers and policy makers in six Central and Eastern European countries. Health Expectations, DOI: 10.1111/hex.12035.

Tambor M, Pavlova M, Golinowska S, Sowada C, Rechel B, Groot W. (2013). The formal-informal patient payment mix in European countries. Governance, economics, culture or all of these? Health Policy, 113(3): 284-295.

The 38th National Assembly. (1998). Health Insurance Act. State Newspaper 1998; №70. (in Bulgarian). 
Thompson R, Witter S. (2000). Informal Payments in Transitional Economies: Implications for Health Sector Reform. International Journal of Health Planning and Management, 15(3): 169-187.

Tomini S, Maarse H. (2011). How do patient characteristics influence informal payments for inpatient and outpatient health care in Albania: Results of logit and OLS models using Albanian LSMS 2005. BMC Public Health, 11:375 doi:10.1186/1471-2458-11-375.

Towse A. (2003). The efficient use of pharmaceuticals: does Europe have any lessons for a Medicare drug benefit? Health Affairs, 22 (3):42-45.

Transparency International. (2013). Corruption by Country/Territory. Available at: http://www.transparency.org/country\#BGR.

van Doorslaer E, Wagstaff A, van der Burg, $\mathrm{H}$ et al. (1999). The redistributive effect of health care finance in twelve OECD countries. Journal of Health Economics, 18(3): 291-313.

Velkov V. (2011). Thirty percent pay under the table. Now, they can select their team. Available at: http://www.24chasa.bg/Article.asp?ArticleId $=955064$ (Accessed on 5 December 2011) (in Bulgarian).

Vekov T. (2008). The medical professionals' opinions regarding the health care reform in Bulgaria. Healthcare Management, 8(5):65-75. (in Bulgarian).

Vekov T. (2009a). Health care reform in Bulgaria:1999-2009. Outcomes, opinions and recommendations. Sofia. Ciela (in Bulgarian).

Vekov T. (2009b). Health reform in Bulgaria 1999 -2009: results, opinions, recommendations. Sofia. Ciela (in Bulgarian).

Vekov T. (2009c). Health insurance in Bulgaria during the period 1999-2009: results, models, opinions. Sofia. Ciela (in Bulgarian).

Vekov T, Grigorov M, Djambazov S. (2009). The misuse of clinical paths as an instrument for funding inpatient care in Bulgaria. World Hospitals and Health Services, 45(3):10-12.

Vienonen MA, Wlodarczyk WC. (1993). Health care reform on the European scene: evolution, revolution or seesaw? World Health Statistics Quarterly, 46:166169. 
Vladimirova M, Manliev G. (2013). The quasi-competition for health services on regulated market: the case of Bulgaria. International Conference of Public Policy "Comparative Health Reforms in Central and Eastern Europe: Europeanization versus Subsidiarity”.

Vodenitcharov T, Borissov V. (1995). The health system and policy in Bulgaria: problems and trends. Cahiers Sociol Demographic Medicales, 32(2-3):177190.

Walters S, Suhrcke M. (2005). Socioeconomic inequalities in health and health care access in central and eastern Europe and CIS: a review of the recent literature. WHO European Office for Investment for Health and Development. Working paper 2005/1.

World Bank. (2013). Health Sector Reform Policy Note Bulgaria 2012. Washington, DC, World Bank.

World Health Organization. (2005). HFA Data. Geneva. WHO.

World Health Organization. (2009). WHO guide to identifying the economic consequences of disease and injury. World Health Organization.

World Health Organization. (2010). World Health Statistics 2010. Geneva. WHO.

World Health Organization. Regional Office for Europe. (2012). European Health for All database, January 2012 edition. WHO Regional Office for Europe. Copenhagen. Available at: http://www.euro.who.int/hfadb (Accessed on 19 July 2012).

World Health Organization. (2013). European Health for all Database. Copenhagen. WHO Regional Office for Europe. Copenhagen. Available at: http://www. euro.who.int/hfadb (Accessed 15 September 2013).

World Health Organization. Regional Office for Europe. (2014). European Health for All database (HFA-DB). WHO Regional Office for Europe, Copenhagen. Available at: http://www.euro.who.int/hfadb (Accessed 15 January 2014).

Zlatanova T, Petrova-Gotova T, Komitov G, Genev S, Zlatanova-Velikova R. (2008). The problem with referrals to medical specialists from the patients' point of view. Healthcare Management, 8(4):9-14 (in Bulgarian). 
Appendix A

DESCRIPTION OF THE QUANTITATIVE DATA COLLECTION 


\section{Data collection}

In Chapter 3, 4 and 6, we use data from household surveys carried out in July 2010 and in July 2011, in Bulgaria as a part of an international research project. The data collection was sub-contracted to Gallup International. The sub-contractor was responsible for the preparation of the data collection, the data-collection and the creation of the database. The sub-contractor used the survey questionnaire developed by the project team. The English wording of the questionnaire can be found in Appendix B.

The objective of the survey was to provide quantitative data on past utilization of and payments for health care services, data on attitude towards informal payments and willingness to pay for health care improvements. The survey was conducted based on face-to-face individual interviews at the respondents' home. The aim was to have 1000 and 800 effective interviews within the first and second wave of data collection respectively that present samples representative for the country. The sampling methodology was based on a multi-staged random probability method:

Stage 1: Distribution of sampling points. The sampling points were distributed proportionally to regional, urban/rural and ethnic characteristics of the population. Within each region, the cities and towns belonging to the same group were put in an alphabetical order. The cities and towns included in the survey, were selected at random from that list. The number of sampling points in the rural areas was calculated based on the ratio urban/rural population in a country.

Stage 2: Selection of addresses / households. The objective was to identify 8-10 (6-8 within the second wave) respondents per sampling point. To select addresses/ households of potential respondents, the random route method was used. For each sampling point, a starting point and direction were determined. The household selected for the survey, was every fourth address on the left-hand side of the street in urban areas, turning left at intersections and, after reaching a dead end, going back to the last crossing and further proceeding at random. In a block-of-flats of up to four floors, every fifth apartment household was selected, counting from the first apartment on the left of the ground floor. In cases of unsuitable household, the interviewers approached the apartment next door and continued doing this until reaching a suitable household. At that point, the interviews resume the standard step of every fifth apartment. In a block-of-flats of 5 floors and more, the selection is every tenth apartment. In rural areas, every fourth inhabitable house on both sides of the interviewer's route was selected. In compounds of several houses behind a common fence, the interviewer had to select the fourth one from the left (counting 
from the gate), or if there were less than four houses behind a common fence, then the interviewer went out of the common yard, counting the houses as if they were along the street.

Stage 3: Selection of the respondent within the household selected. The selection of the respondent within the selected household was done using the "last birthday" principle. In this procedure, the interviewer asked to speak to the adult member of the household who had the last birthday. The last-birthday method is based on the assumption that the assignment of birthdates is a random process and also every household member has an equal chance of being selected. Only one individual per household was interviewed.

Stage 4: Replacement of the respondent/household. If the respondent determined on stage 3 refused or was unavailable to participate after two call backs recorded in the fieldwork report, a replacing respondent was identified following the second and third stage. The interviews were carried out face-to-face by qualified and experienced interviewers who attended a training prior to the survey to clarify the fieldwork standards and the specificities of the questionnaire. A high number of interviewers (108 in 2010 and 91 in 2011) were involved in the survey to avoid the interviewer bias that might occur when one interviewer carries out many interviews.

The sampling procedure described above, is known as an efficient method for selecting a sample representative for the population of a particular country. It is proven by practice that the sample produced by this method does not differ significantly from the official statistical data on age, gender and other demographic parameters.

In 2010, 1034 respondents were successfully contacted and out-of them 508 refused or were unable to participate in the survey. This resulted in a response rate (calculated as interviewed/successfully contacted respondents) of $67 \%$. The final sample for Bulgaria contains data for 1003 respondents (out of the 1034 interviews completed, in 31 cases, the interviews were discarded due to various deficiencies in data collected), 63-290 interviews per region in 129 sampling points. In 2011, 824 respondents were successfully contacted, out-of them 518 refused or were unable to participate in the survey. The final sample for Bulgaria contains data for 817 respondents, 64-240 interviews per region in 103 sampling points. After the data collection, about $10 \%$ of all respondents interviewed were re-contacted either by telephone or in person to verify that the interview had been carried out. The verification procedure did not indicate problems. 



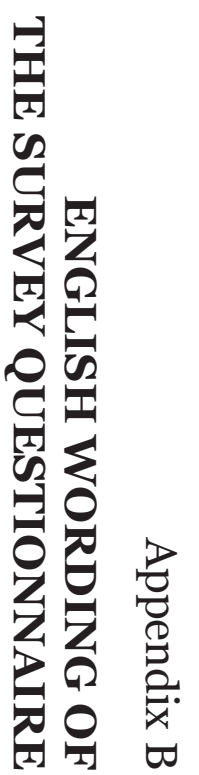




$\begin{array}{ll}\text { PROJECT: } & \text { ASSPRO CEE 2007 } \\ \text { SURVEY: } & \text { WILLINGNESS AND ABILITY OF PATIENTS TO PAY } \\ & \text { FOR MEDICL SERVIICES } \\ & \text { QUESTIONNAIRE - ROUND 1 / JUNE-JULY 2010 / BULGARIA } \\ \text { FIELDWORK CARRIED OUT BY: } \quad \text { BBSS Gallup International } \\ \text { FIELDWORK MANAGED BY: } & \text { BBSS Gallup International }\end{array}$

THE QUESTIONNAIRE SHOULD BE FILLED IN ONLY FOR RESPONDENTS WHO ARE 18 YEARS OLD OR OLDER.

\section{FILL IN THE FOLLOWING INFORMATION:}

SAMPLING POINT

REGION

RESPONDENT ID NUMBER

DATE OF THE INTERVIEW

(DD/MM/YYYY)

START TIME

(USE 24 HOURS CLOCK)

INTERVIEWER ID NUMBER

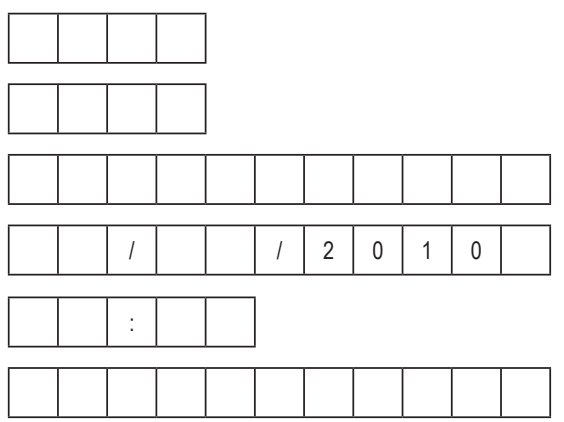

๑ ASSPRO CEE 2007 / project no. 217431 / funded by the European Commission under FP7 Theme 8 SSH

No parts of this questionnaire may be used, translated, stored, published, copied or transmitted in any form and by any means(electronic, mechanical, copying, recording and etc.) without the written permission issued by the coordinators of project ASSPRO CEE 2007 (project no. 217431). For project details: www. assprocee2007.com

Partner in Bulgaria: Medical University-Varna; Department of Health Economics and Management, $E$. Moutafova, T. Kostadinova, E. Atanasova; E-mail: dep_hcm@abv.bg; Тел:+359 52634279

Project coordinator: Dr. M.Pavlova; Scientific coordinators: Prof.Dr. Wim Groot and Prof.Dr.Frits van Merode. Department BEOZ; Faculty HMLS; Maastricht University; PO BOX 616, Maastricht 6200 MD, The Netherlands.

E-mail: M.Pavlova@BEOZ.unimaas.nl; Tel: +31-43-3881705
INFORMED CONSENT PROCEDURE

BEFORE YOU START, READ THE FOLLOWING TO THE RESPONDENT:

- The aim of this survey is to collect data on citizens' opinion about the quality, access and price of medical services they use.

- The survey is not commissioned by the government or a health insurer.

- This survey is part of an international research project funded by the European Commission. The same survey is carried out in several European countries.

- The data collected during the survey will be used for research purposes, namely for statistic analyses and reports.

- Your answers will not be related to your personal details (address, etc.) and will be completely confidential.

- Answers to all questions are highly important to the project, so we hope that you will share your opinions and thoughts by answering all questions in the questionnaire.

Do you agree to participate in this survey?

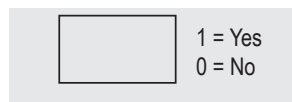

CONTINUE THE INTERVIEW ONLY IF THE RESPONDENT AGREES TO PARTICIPATE.

\section{ASK THE QUESTIONS FOLLOWING THEIR ORDER IN THE QUESTIONNAIRE.}

READ THE EXACT WORDING OF THE QUESTIONS, AND AFTERWARDS, IF NECESSARY, MAKE CLARIFICATIONS.

\section{USE LOCAL CURRENCY FOR ALL RELEVANT QUESTIONS (XXX) NOTE: 1EUR ₹2BGN.}

PLEASE TRY TO AVOID "DON'T KNOW" (DK) ANSWERS AND REFUSALS.

IF THE RESPONDENT REFUSES TO ANSWER, KEEP THE ANSWER BOX BLANK 


\section{PART 1: USE AND PAYMENTS FOR PHYSICIAN SERVICES USED BY THE RESPONDENT}

The first set of questions concerns medical services that YOU used during the last 12 months (June 2009 - May 2010), and the money that you paid out-of-pocket (or your family members paid on your behalf) for YOU receiving these services.

Out-of-pocket payments include OFFICIAL payments, for which one may usually receive a receipt or other document, INFORMAL cash payments (such as gratitude cash payments or under-the-table cash payments), or gifts in kind for receiving medical services.

Out-of-pocket payments EXCLUDE monthly payments for health insurance (or voluntary health accounts), as well as payments that the patient receives back from the state or a health insurer.

Instruction: Questions Q.1A/Q.3A define next sections. Please try to avoid "Don't know".

\begin{tabular}{|c|c|c|}
\hline \multirow[t]{2}{*}{ Q.1A } & \multirow{2}{*}{$\begin{array}{l}\text { During the last } 12 \text { months, how many times did YOU } \\
\text { PERSONALLY visit a physician or a physician visited you } \\
\text { personally at your home, including any physician in both the } \\
\text { public and private system? (Homeopaths and traditional healers } \\
\text { who are not physicians, and also dentists are excluded.) }\end{array}$} & $\begin{array}{l}\text { TIMES } \\
0=\text { None } \\
99=\text { DK }\end{array}$ \\
\hline & & IF NONE, GO TO Q.2C \\
\hline \multirow[t]{2}{*}{ Q.1B } & \multirow{2}{*}{$\begin{array}{l}\text { Considering all types of official and informal cash payments, } \\
\text { and gifts in kind, how much IN TOTAL did you spend (out-of- } \\
\text { pocket) on these visits EXCLUDING payments for travelling, } \\
\text { transportation by ambulance and pharmaceuticals? }\end{array}$} & $\left\{\begin{array}{l}X X X \\
0=\text { None } \\
99=\mathrm{DK}\end{array}\right.$ \\
\hline & & IF NONE, GO TO Q.2A \\
\hline Q.1C & $\begin{array}{l}\text { How much of this amount approximately was for INFORMAL } \\
\text { cash payments and gifts in kind? }\end{array}$ & $\begin{array}{l}X X X \\
0=\text { None } \\
99=\text { DK }\end{array}$ \\
\hline \multirow[t]{2}{*}{ Q.1D } & $\begin{array}{l}\text { Was it necessary to TAKE OR BORROW cash from family, } \\
\text { friends, bank, via credit card or sell assets to cover these formal } \\
\text { and informal payments for PHYSICIAN services that you used? }\end{array}$ & $\begin{array}{l}1=\text { YES } \\
0=\text { NO } \\
99=\text { DK }\end{array}$ \\
\hline & & IF NO/ DK, GO TO Q.2A \\
\hline Q.1E & How much IN TOTAL was it necessary to take or borrow? & $\begin{array}{l}X X X \\
99=D K\end{array}$ \\
\hline Q.2A & $\begin{array}{l}\text { Are you overall satisfied with the QUALITY of physician } \\
\text { services that you used during the last } 12 \text { months - yes, no, } \\
\text { somewhat? }\end{array}$ & $\begin{array}{l}2=\text { YES } \\
1=\text { SOMEWHAT } \\
0=\text { NO } \\
99=\text { DK }\end{array}$ \\
\hline Q.2B & $\begin{array}{l}\text { Are you overall satisfied with the ACCESS to physician services } \\
\text { that you used during the last } 12 \text { months - yes, no, somewhat? }\end{array}$ & $\begin{array}{l}2=\text { YES } \\
1=\text { SOMEWHAT } \\
0=\text { NO } \\
99=\text { DK }\end{array}$ \\
\hline Q.2C & $\begin{array}{l}\text { During the last } 12 \text { months, how many times have you been ill } \\
\text { but DID NOT VISIT AT ALL a physician because you could not } \\
\text { afford to pay either for the visit or for the transportation/travel? }\end{array}$ & $\begin{array}{l}\text { TIMES } \\
99=\mathrm{DK}\end{array}$ \\
\hline
\end{tabular}

PART 2: USE AND PAYMENTS FOR PHYSICIAN SERVICES USED BY THE RESPONDENT

Q.3A During the last 12 months, how many times were YOU hospitalised (placed in a hospital), including day surgeries or day treatments?

(Re-hospitalisation, i.e. repeated hospitalisation for the same health problem, should be counted separately as a different hospitalisation.)

TIMES
$0=$ None
$99=$ DK

IF NONE, GO TO Q.4C

Q.3B Considering all types of official and informal cash payments, and gifts in kind, how much IN TOTAL did you spend (out-of-pocket) on these hospitalisations EXCLUDING payments for travelling, transportation by ambulance and pharmaceuticals?

How much of this amount approximately was for INFORMAL cash payments and gifts in kind?

Q.3D Was it necessary to TAKE OR BORROW cash from family, friends, bank, via credit card or sell assets to cover these formal and informal payments for HOSPITAL services that you used?

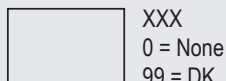

IF NONE, GO TO Q.4A

XXX
$0=$ None
$99=\mathrm{DK}$

$1=\mathrm{YES}$
$0=\mathrm{NO}$
$99=\mathrm{DK}$
$0=\mathrm{NO}$
$99=\mathrm{DK}$

IF NO/ DK, GO TO Q.4A

Q.3E How much IN TOTAL was it necessary to take or borrow?

Q.4A Are you overall satisfied with the QUALITY of hospital services that you used during the last 12 months

- yes, no, somewhat? $99=D K$

Q.4B Are you overall satisfied with the ACCESS to hospital services that you used during the last 12 months - yes, no, somewhat?

$2=$ YES

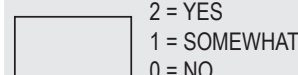
$0=\mathrm{NO}$ $99=\mathrm{DK}$

\begin{tabular}{|l}
$2=$ YES \\
$1=$ SOMEWHAT \\
$0=$ NO \\
$99=$ DK
\end{tabular}

Q.4C During the last 12 months, how many times have you been referred to a hospital but NOT GONE AT ALL because you could not afford to pay either for the hospital service or for the transportation/travel?

Q.4D Have YOU been ever hospitalised (placed in a hospital), including day surgeries or day treatments? TIMES

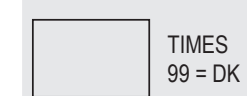
$99=\mathrm{DK}$

$1=$ YES $0=\mathrm{NO}$ $99=\mathrm{DK}$ 
The following questions concern your attitude towards INFORMAL cash payments and gifts in kind to

physicians, medical staff or other personnel in health care facilities. Your personal opinion is very important, no matter whether you used or not medical services. There are no wrong or right answers.

\begin{tabular}{|c|c|c|}
\hline Q.5A & $\begin{array}{l}\text { What is your attitude towards INFORMAL CASH PAYMENTS } \\
\text { to physicians, medical staff or other personnel in health care } \\
\text { facilities - positive, negative or indifferent? }\end{array}$ & $\begin{array}{l}2=\text { POSITIVE } \\
1=\text { INDIFFERENT } \\
0=\text { NEGATIVE } \\
99=\text { DK }\end{array}$ \\
\hline Q.5B & $\begin{array}{l}\text { What is your attitude towards GIVING GIFTS IN KIND to } \\
\text { physicians, medical staff or other personnel in health care } \\
\text { facilities - positive, negative or indifferent? }\end{array}$ & $\begin{array}{l}2=\text { POSITIVE } \\
1=\text { INDIFFERENT } \\
0=\text { NEGATIVE } \\
99=\text { DK }\end{array}$ \\
\hline $\mathrm{Q} .6 \mathrm{~A}$ & $\begin{array}{l}\text { Have you been ever PERSONALLY ASKED by physicians, } \\
\text { medical staff or other personnel in health care facilities to pay } \\
\text { informally in cash or to give a gift in kind? }\end{array}$ & $\begin{array}{l}1=\text { YES } \\
0=N O \\
99=D K\end{array}$ \\
\hline Q.7A & $\begin{array}{l}\text { Have you ever personally paid INFORMALLY IN CASH to } \\
\text { physicians, medical staff or other personnel in health care } \\
\text { facilities? }\end{array}$ & $\begin{array}{l}1=Y E S \\
0=N O \\
99=D K\end{array}$ \\
\hline Q.7B & $\begin{array}{l}\text { Have you ever personally given any GIFT IN KIND to } \\
\text { physicians, medical staff or other personnel in health care } \\
\text { facilities? }\end{array}$ & $\begin{array}{l}1=\text { YES } \\
0=N O \\
99=\text { DK }\end{array}$ \\
\hline Q.8A & $\begin{array}{l}\text { Do the following statements apply to YOU PERSONALLY? } \\
\text { I will feel UNCOMFORTABLE if I leave the physician's office } \\
\text { without a gratitude cash payment or gift in kind. }\end{array}$ & $\begin{array}{l}2=\text { YES } \\
1=\text { SOMEWHAT } \\
0=\text { NO } \\
99=\text { DK }\end{array}$ \\
\hline Q.8B & $\begin{array}{l}\text { I would RECOGNISE the hint of physicians or medical staff } \\
\text { for an informal cash payment or a gift in kind. }\end{array}$ & $\begin{array}{l}2=\text { YES } \\
1=\text { SOMEWHAT } \\
0=\text { NO } \\
99=\text { DK }\end{array}$ \\
\hline Q.8C & $\begin{array}{l}\text { I will REFUSE to pay if a physician or medical staff ask me to } \\
\text { pay informally for a medical service. }\end{array}$ & $\begin{array}{l}2=\text { YES } \\
1=\text { SOMEWHAT } \\
0=\text { NO } \\
99=\text { DK }\end{array}$ \\
\hline Q.8D & $\begin{array}{l}\text { I will PREFER to use private medical services if I have to pay } \\
\text { informally for public medical services. }\end{array}$ & $\begin{array}{l}2=\text { YES } \\
1=\text { SOMEWHAT } \\
0=\text { NO } \\
99=\text { DK }\end{array}$ \\
\hline Q.8E & $\begin{array}{l}\text { If I have SERIOUS PROBLEMS with my health, I will be } \\
\text { ready to pay as much as I have in order to get better medical } \\
\text { services. }\end{array}$ & $\begin{array}{l}2=\text { YES } \\
1=\text { SOMEWHAT } \\
0=\text { NO } \\
99=\text { DK }\end{array}$ \\
\hline
\end{tabular}

Q.9A Do you AGREE with the following statements?

Informal CASH payments to physicians and medical staff are similar to corruption.

Q.9B Gifts IN KIND to physicians and medical staff are similar to corruption.

Q.9C Informal CASH payments to physicians and medical staff are an

expression of gratitude.

Q.9D Gifts IN KIND to physicians and medical staff are an expression of gratitude.

Q.9E Informal cash payments and gifts in kind to physicians and medical staff are INEVITABLE because of the low funding of the health care sector.

Q.9F Cash or gifts in kind, given informally to physicians and medica staff, should be ERADICATED.

Q.10A Do you know the size of the official fees for medical services of PHYSICIANS (including any kind of specialists) BEFORE you use such services - always, sometimes, never?

Q.10B Do you know the size of the official fees for HOSPITAL services related to hospital admissions (staying in hospital) BEFORE you use such services - always, sometimes, never?

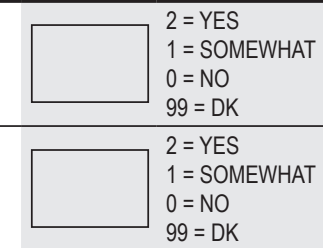

$99=\mathrm{DK}$ $2=$ YES $1=$ SOMEWHAT $0=\mathrm{NO}$ $99=\mathrm{DK}$ $2=$ YES $1=$ SOMEWHAT $0=\mathrm{NO}$ $99=\mathrm{DK}$ $2=$ YES $2=$ YES
$1=$ SOMEWHAT $0=\mathrm{NO}$ $99=\mathrm{DK}$ $2=$ YES $1=$ SOMEWHAT $0=\mathrm{NO}$ $99=\mathrm{DK}$ $2=$ ALWAYS $1=$ SOMETIMES $0=$ NEVER $99=\mathrm{DK}$ 2 = ALWAYS $1=$ SOMETIMES $0=$ NEVER $99=\mathrm{DK}$

Q.10C Do you know where to COMPLAIN if physicians, medical staff or other personnel in health care facilities ask you to pay informally for a medical service? 


\section{PART 4: PREFERENCES FOR PHYSICIAN'S SERVICES}

This part of the questionnaire concerns YOUR PREFERENCES regarding physician's services. There are no right or wrong answers. The questions ask about your personal opinion.

\section{SHOW CARD 1.}

The card presents a list of seven characteristics of physician's services. By physician, we mean here any kind of medical specialist.

Please, arrange these characteristics according to their importance TO YOU in case you need to select a physician for a medical consultation due to a MAJOR HEALTH PROBLEM - this means unfamiliar symptoms that cause discomfort or pain, and prevent you from usual activities.

Please rank with 1 the MOST IMPORTANT characteristics to you, with 2 the second most important and so on till 7, where 7 means least important. Please, do not repeat numbers.

\section{Q.11A MEDICAL EQUIPMENT AT THE PHYSICIAN'S OFFICE} (MODERN / OUTDATED)

Q.11B REPUTATION AND SKILLS OF THE PHYSICIAN (KNOWN TO BE GOOD / UNKNOWN)

Q.11C CONDITION OF THE PHYSICIAN'S OFFICE (GOOD CONDITION - RENOVATED / BAD CONDITIONS

Q.11D ATTITUDE OF THE STAFF (INCL. THE PHYSICIAN) (POLITE / IMPOLITE)

Q.11E TRAVEL TIME TO THE PHYSICIAN'S OFFICE (FROM PATIENT'S HOME TO THE OFFICE)

Q.11F WAITING TIME IN FRONT OF THE PHYSICIAN'S OFFICE (IN THE WAITING ROOM OR IN THE CORRIDOR)

FILL IN THE RANKS FROM 1 TO 7 STATED BY THE RESPONDENT. RANKS SHOULD NOT REPEAT.

AMOUNT OF MONEY PAID BY THE PATIENT (SIZE OF THE VISIT FEE)

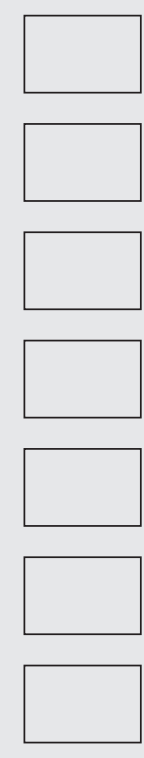

PART 5: CHOICE OF PHYSICIAN

\section{SHOW CARD 2A.}

The characteristics of physician's services that you just ranked are used here to describe two physician's profiles. As before, by medical physician, we mean here any kind of medical specialist.

Let us assume that these are the ONLY physician's characteristics that you know. Let us also assume that you experience a major health problem which makes you concerned. Because of this problem, you HAVE DECIDED to visit a physician but you can/may choose only between these two physicians based on the information on the card.

Which of these two physicians would you choose?

REPEAT THE LAST QUESTION SHOWING CARD 2B TO CARD 2H (ONE CARD AT A TIME).

\begin{tabular}{|c|c|c|c|c|c|c|}
\hline \multirow{8}{*}{ Q.12A } & & PHYSICIANA & & TYSICIAN B & \multirow{8}{*}{ CARD 2A } & \multirow{8}{*}{$\begin{array}{l}0=A \\
1=B\end{array}$} \\
\hline & MEDICAL EQUIPMENT & MODERN & \multicolumn{2}{|c|}{ OUTDATED } & & \\
\hline & \begin{tabular}{|l} 
PHYSICIAN'S REPUTATION AND SKILLS \\
\end{tabular} & UNKNOWN & \multicolumn{2}{|c|}{ KNOWN TO BE GOOD } & & \\
\hline & CONDITION OF THE OFFICE & RENOVATED & \multicolumn{2}{|c|}{ RENOVATED } & & \\
\hline & ATTITUDE OF THE STAFF & IMPOLITE & \multicolumn{2}{|r|}{ IMPOLITE } & & \\
\hline & TRAVEL TIME TO THE OFFICE & $60 \mathrm{MIN}$ & \multicolumn{2}{|r|}{$15 \mathrm{MIN}$} & & \\
\hline & WAITING IN FRONT OF THE OFFICE & $10 \mathrm{MIN}$ & \multicolumn{2}{|r|}{$45 \mathrm{MIN}$} & & \\
\hline & PATIENT VISIT FEE & 5.- EURO & \multicolumn{2}{|r|}{ 5.- EURO } & & \\
\hline \multirow{8}{*}{ Q.12B } & & \multicolumn{2}{|c|}{ PHYSICIAN C } & PHYSICIAN D & \multirow{8}{*}{ CARD 2B } & \multirow{8}{*}{$\begin{array}{l}0=C \\
1=D\end{array}$} \\
\hline & MEDICAL EQUIPMENT & \multicolumn{2}{|c|}{ OUTDATED } & MODERN & & \\
\hline & PHYSICIAN'S REPUTATION AND SKILLS & \multirow{2}{*}{\multicolumn{2}{|c|}{$\frac{\text { KNOWN TO BE GOOD }}{\text { BAD CONDITIONS }}$}} & UNKNOWN & & \\
\hline & CONDITION OF THE OFFICE & & & RENOVATED & & \\
\hline & ATTITUDE OF THE STAFF & \multicolumn{2}{|l|}{ POLITE } & IMPOLITE & & \\
\hline & TRAVEL TIME TO THE OFFICE & \multirow{2}{*}{\multicolumn{2}{|c|}{15 MIN }} & $60 \mathrm{MIN}$ & & \\
\hline & WAITING IN FRONT OF THE OFFICE & & & $10 \mathrm{MIN}$ & & \\
\hline & PATIENT VISIT FEE & \multicolumn{2}{|c|}{ 10.- EURO } & 5.- EURO & & \\
\hline \multirow{8}{*}{ Q.12C } & & PHYSICIANA & & IYSICIAN B & \multirow{6}{*}{ CARD 2C } & \multirow{8}{*}{$\begin{array}{l}0=A \\
1=B\end{array}$} \\
\hline & MEDICAL EQUIPMENT & MODERN & & MODERN & & \\
\hline & PHYSICIAN'S REPUTATION AND SKILLS & UNKNOWN & & KNOWN & & \\
\hline & CONDITION OF THE OFFICE & RENOVATED & BAD & CONDITIONS & & \\
\hline & ATTITUDE OF THE STAFF & IMPOLITE & & MPOLITE & & \\
\hline & TRAVEL TIME TO THE OFFICE & $60 \mathrm{MIN}$ & & $15 \mathrm{MIN}$ & & \\
\hline & WAITING IN FRONT OF THE OFFICE & $10 \mathrm{MIN}$ & & $10 \mathrm{MIN}$ & & \\
\hline & PATIENT VISIT FEE & 5.- EURO & & 5.- EURO & & \\
\hline
\end{tabular}




\begin{tabular}{|l|c|c|}
\hline & PHYSICIAN C & PHYSICIAN D \\
\hline MEDICAL EQUIPMENT & MODERN & MODERN \\
\hline PHYSICIAN'S REPUTATION AND SKILLS & KNOWN TO BE GOOD & UNKNOWN \\
\hline CONDITION OF THE OFFICE & BAD CONDITIONS & RENOVATED \\
\hline ATTITUDE OF THE STAFF & POLITE & IMPOLITE \\
\hline TRAVEL TIME TO THE OFFICE & 60 MIN & 60 MIN \\
\hline WAITING IN FRONT OF THE OFFICE & 45 MIN & 10 MIN \\
\hline PATIENT VISIT FEE & 5 -- EURO & 5 -- EURO \\
\hline
\end{tabular}

CARD 2D

Q.12D \begin{tabular}{|l|c|c|}
\hline PATIENT VISIT FEE & 5.- EURO & 5.- EURO \\
\hline
\end{tabular}

\begin{tabular}{|c|c|c|c|c|c|}
\hline \multirow{8}{*}{ Q.12E } & & PHYSICIANA & PHYSICIAN B & \multirow{8}{*}{ CARD 2E } & \multirow{8}{*}{$\begin{array}{l}0=A \\
1=B\end{array}$} \\
\hline & MEDICAL EQUIPMENT & MODERN & MODERN & & \\
\hline & PHYSICIAN'S REPUTATION AND SKILLS & UNKNOWN & KNOWN TO BE GOOD & & \\
\hline & CONDITION OF THE OFFICE & RENOVATED & RENOVATED & & \\
\hline & \begin{tabular}{|l|l|} 
ATTITUDE OF THE STAFF \\
\end{tabular} & IMPOLITE & IMPOLITE & & \\
\hline & TRAVEL TIME TO THE OFFICE & $60 \mathrm{MIN}$ & $60 \mathrm{MIN}$ & & \\
\hline & WAITING IN FRONT OF THE OFFICE & $10 \mathrm{MIN}$ & $10 \mathrm{MIN}$ & & \\
\hline & \begin{tabular}{|l} 
PATIENT VISIT FEE \\
\end{tabular} & 5.- EURO & 10.- EURO & & \\
\hline \multirow{8}{*}{ Q.12F } & & PHYSICIAN C & PHYSICIAN D & \multirow{8}{*}{ CARD $2 F$} & \multirow{8}{*}{$\begin{array}{l}0=C \\
1=D\end{array}$} \\
\hline & \begin{tabular}{|l|} 
MEDICAL EQUIPMENT \\
\end{tabular} & MODERN & MODERN & & \\
\hline & PHYSICIAN'S REPUTATION AND SKILLS & UNKNOWN & UNKNOWN & & \\
\hline & CONDITION OF THE OFFICE & RENOVATED & RENOVATED & & \\
\hline & ATTITUDE OF THE STAFF & POLITE & IMPOLITE & & \\
\hline & TRAVEL TIME TO THE OFFICE & $15 \mathrm{MIN}$ & $60 \mathrm{MIN}$ & & \\
\hline & WAITING IN FRONT OF THE OFFICE & $45 \mathrm{MIN}$ & $10 \mathrm{MIN}$ & & \\
\hline & \begin{tabular}{|l|} 
PATIENT VISIT FEE \\
\end{tabular} & 10.- EURO & 5.- EURO & & \\
\hline \multirow{8}{*}{ Q.12G } & & PHYSICIANA & PHYSICIAN B & \multirow{8}{*}{ CARD $2 G$} & \multirow{8}{*}{$\begin{array}{l}0=A \\
1=B\end{array}$} \\
\hline & \begin{tabular}{|l|} 
MEDICAL EQUIPMENT \\
\end{tabular} & MODERN & OUTDATED & & \\
\hline & PHYSICIAN'S REPUTATION AND SKILLS & UNKNOWN & UNKNOWN & & \\
\hline & CONDITION OF THE OFFICE & RENOVATED & RENOVATED & & \\
\hline & ATTITUDE OF THE STAFF & IMPOLITE & POLITE & & \\
\hline & TRAVEL TIME TO THE OFFICE & $60 \mathrm{MIN}$ & $60 \mathrm{MIN}$ & & \\
\hline & WAITING IN FRONT OF THE OFFICE & $10 \mathrm{MIN}$ & $10 \mathrm{MIN}$ & & \\
\hline & PATIENT VISIT FEE & 5.- EURO & 5.- EURO & & \\
\hline \multirow{8}{*}{ Q.12H } & & PHYSICIAN C & PHYSICIAN D & \multirow{8}{*}{ CARD 2H } & \multirow{8}{*}{$\begin{array}{l}0=C \\
1=D\end{array}$} \\
\hline & MEDICAL EQUIPMENT & OUTDATED & MODERN & & \\
\hline & PHYSICIAN'S REPUTATION AND SKILLS & UNKNOWN & UNKNOWN & & \\
\hline & CONDITION OF THE OFFICE & BAD CONDITIONS & RENOVATED & & \\
\hline & \begin{tabular}{|l|} 
ATTITUDE OF THE STAFF \\
\end{tabular} & IMPOLITE & IMPOLITE & & \\
\hline & TRAVEL TIME TO THE OFFICE & $60 \mathrm{MIN}$ & 60 MIN & & \\
\hline & WAITING IN FRONT OF THE OFFICE & $45 \mathrm{MIN}$ & $10 \mathrm{MIN}$ & & \\
\hline & PATIENT VISIT FEE & 10.- EURO & 5.- EURO & & \\
\hline
\end{tabular}

PART 6: PREFERENCES FOR HOSPITAL SERVICES

This part of the questionnaire concerns YOUR PREFERENCES regarding hospital services. There are no right or wrong answers. The questions ask about your personal opinion.

\section{SHOW CARD 3.}

The card presents a list of seven characteristics of hospital services.

Please, arrange these characteristics according to their importance TO YOU in case you need to select a hospital for yourself for a PLANNED SURGERY, which will require a 5-days hospitalisation and the illness is not life-threatening

Please rank with 1 the MOST IMPORTANT characteristics to you, with 2 the second most important and so on till 7, where 7 means least important. Please, do not repeat numbers.

Q.13A MEDICAL EQUIPMENT AT THE HOSPITAL (MODERN / OUTDATED)

Q.13B REPUTATION AND SKILLS OF THE SURGEON (KNOWN TO BE GOOD / UNKNOWN)

Q.13C CONDITION OF THE HOSPITAL INTERIOR (GOOD CONDITION - RENOVATED / BAD CONDITIONS)

Q.13D ATTITUDE OF THE STAFF (INCL. THE PHYSICIAN) (POLITE / IMPOLITE)

Q.13E TRAVEL TIME TO THE HOSPITAL (FROM PATIENT'S HOME TO THE HOSPITAL)

Q.13F WAITING TIME FOR THE OPERATION

FILL IN THE RANKS FROM 1 TO 7 STATED BY THE RESPONDENT. RANKS SHOULD NOT REPEAT.
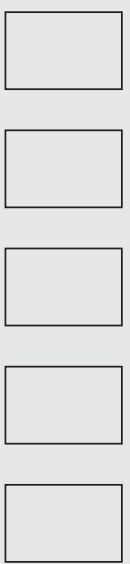
TYPES OF FEES CHARGED BY THE HOSPITAL)
Q.13G AMOUNT OF MONEY PAID BY THE PATIENT
(SIZE OF THE TOTAL HOSPITAL FEE INCLUDING ALL

\section{(FROM THE REFERRAL TO THE ADMISSION)}




\section{PART 7: CHOICE OF HOSPITAL}

\section{SHOW CARD 4A.}

The characteristics of hospital services that you just ranked are used here to describe two hospital profiles. Let us assume that these are the ONLY hospital characteristics that you know. Let us also assume that you MUST UNDERGO a planned surgery in a hospital, which will require a 5-days hospitalisation and the illness is not life-threatening. You can/may choose only between these two hospitals based on the information on the card.

The patient hospitalisation fee includes all types of fees charged by the hospital (for example, lab test, diagnostics, medical consumables, pharmaceuticals, TV, separate room). Fees are not necessarily dependent on the medical service costs since a part of the costs is covered by public funds.

Which of these two hospitals would you choose?

REPEAT THE LAST QUESTION SHOWING CARD 4B TO CARD 4H (ONE CARD AT A TIME).

Q14A

\begin{tabular}{|l|c|c|}
\hline & HOSPITALA & HOSPITAL B \\
\hline MEDICAL EQUIPMENT & MODERN & OUTDATED \\
\hline PHYSICIAN'S REPUTATION AND SKILLS & UNKNOWN & KNOWN TO BE GOOD \\
\hline CONDITION OF THE OFFICE & RENOVATED & RENOVATED \\
\hline ATTITUDE OF THE STAFF & IMPOLITE & IMPOLITE \\
\hline TRAVEL TIME TO THE OFFICE & 3 HOURS & 1 HOUR \\
\hline WAITING IN FRONT OF THE OFFICE & 1 MONTH & 4 MONTHS \\
\hline PATIENT VISIT FEE & 100 - EURO & 100. - EURO \\
\hline
\end{tabular}

\section{CARD 4A}

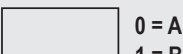

$1=B$

PATIENT VISIT FEE

\begin{tabular}{|c|c|c|}
\hline HOSPITAL C & HOSPITAL D \\
\hline OUTDATED & MODERN \\
\hline & KNOWN TO BE GOOD & UNKNOWN \\
\hline BAD CONDITIONS & RENOVATED \\
\hline POLITE & IMPOLITE \\
\hline 1 HOUR & 3 HOURS \\
\hline 1 MONTH & 1 MONTH \\
\hline & $200 .-$ EURO & $100 .-$ EURO \\
\hline
\end{tabular}

MEDICAL EQUIPMENT

PHYSICIAN'S REPUTATION AND SKILLS

Q.14B

CONDITION OF THE OFFICE

ATTITUDE OF THE STAFF

TRAVEL TIME TO THE OFFICE

WAITING IN FRONT OF THE OFFICE

PATIENT VISIT FEE

CARD 4B

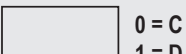

$1=\mathrm{D}$

\begin{tabular}{|l}
\hline \\
\hline
\end{tabular}

PHYSICIAN'S REPUTATION AND SKILLS

Q.14C

CONDITION OF THE OFFICE

ATTITUDE OF THE STAFF

TRAVEL TIME TO THE OFFICE

WAITING IN FRONT OF THE OFFICE

\begin{tabular}{|c|c|}
\hline HOSPITALA & HOSPITAL B \\
\hline MODERN & MODERN \\
\hline UNKNOWN & UNKNOWN \\
\hline RENOVATED & BAD CONDITIONS \\
\hline IMPOLITE & IMPOLITE \\
\hline 3 HOURS & 1 HOUR \\
\hline 1 MONTH & 1 MONTH \\
\hline $100 .-$ EURO & $100 .-$ EURO \\
\hline
\end{tabular}

CARD 4C

$0=\mathrm{A}$

$1=B$
Q.14D

CONDITION OF THE OF

ATTITUDE OF THE STAFF

TRAVEL TIME TO THE OFFICE

WAITING IN FRONT OF THE OFFICE

PATIENT VISIT FEE

\begin{tabular}{|l|l|l} 
& HOSPITALA & HOSPITAL B \\
\hline
\end{tabular}

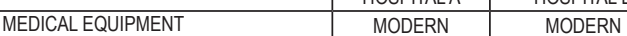

\begin{tabular}{|l|l|l|}
\hline PHYSICIAN'S REPUTATIONAND SKILLS & UNKNOWN & KNOWN TO BE GOOD \\
\hline
\end{tabular}

CONDITION OF THE OFFICE

Q.14E

\begin{tabular}{|l|c|c}
\hline ATTITUDE OF THE STAFF & RENOVATED & RENOVATED \\
\hline
\end{tabular}

\begin{tabular}{|l|r|r}
\hline TRAVEL TIME TO THE OFFICE & IMPOLITE & IMPOLITE \\
\hline
\end{tabular}

WAITING IN FRONT OF THE OFFICE

3 HOURS

100.- EURO

3 HOURS

$1 \mathrm{MONTH}$

PATIENT VISIT FEE

200.- EURO

CARD 4E

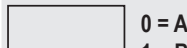

MEDICAL EQUIPMENT

\begin{tabular}{|l|l|l} 
& HOSPTALC & HOSPTTAL \\
\hline
\end{tabular}

\begin{tabular}{c|c}
\hline MODERN & MODERN \\
\hline UNKNOWN & UNKNOWN
\end{tabular}

ATTITUDE OF THE STAFF

TRAVEL TIME TO THE OFFICE

WAITING IN FRONT OF THE OFFICE

RENOVATED $\quad$ RENOVATED

POLITE

1 HOUR

4 MONTHS

200.- EURO

IMPOLITE

3 HOURS

CARD 4F

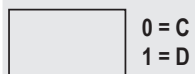

\begin{tabular}{|l|l|l|}
\hline & HOSPITALA & HOSPITAL B \\
\hline
\end{tabular}

\begin{tabular}{|l|c|c}
\hline MEDICAL EQUIPMENT & MODERN & OUTDATED \\
\hline
\end{tabular}

\begin{tabular}{|l|l|l}
\hline PHYSICIAN'S REPUTATION AND SKILLS & UNKNOWN & UNKNOWN \\
\hline
\end{tabular}

CONDITION OF THE OFFICE

Q.14G

ATTITUDE OF THE STAFF

TRAVEL TIME TO THE OFFICE

WAITING IN FRONT OF THE OFFICE

\begin{tabular}{l|c} 
RENOVATED & RENOVATED \\
\hline
\end{tabular}

CARD 4G PATIENT VISIT FEE

\begin{tabular}{|c|c|}
\hline IMPOLITE & POLITE \\
\hline 3 HOURS & 3 HOURS \\
\hline
\end{tabular}

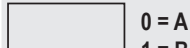

\begin{tabular}{c|c}
1 MONTH & 1 MONTH \\
\hline
\end{tabular}

\begin{tabular}{|l|c|c|}
\hline & HOSPITAL C & HOSPITAL D \\
\hline
\end{tabular}

PHYSICIAN'S REPUTATION AND SKILLS

CONDITION OF THE OFFICE

Q.14H

ATTITUDE OF THE STAFF

TRAVEL TIME TO THE OFFICE

WAITING IN FRONT OF THE OFFICE

OUTDATED

OUTDATED $\quad$ MODERN

\begin{tabular}{l|r}
\hline BAD CONDITIONS & RENOVATED \\
\hline
\end{tabular}

CARD 4H

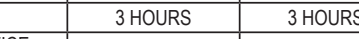

\begin{tabular}{|l|c|c|}
\hline PATIENT VISIT FEE & 4 MONTHS & 1 MONTH \\
\hline
\end{tabular}

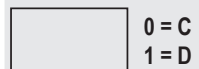




\section{PART 8: WILLINGNESS TO PAY FOR MEDICAL SERVICES}

Next questions concern your WILLINGNESS and ABILITY to pay for medical services provided by the state or included in the social health insurance package.

Imagine that you could obtain these services with GOOD QUALITY and QUICK ACCESS if you pay an

OFFICIAL FEE to the health care facility (e.g. polyclinic, clinic or hospital).

\section{SHOW CARD 5 .}

This card presents the meaning of good quality and quick access.

Good quality would mean:

- Modern medical equipment

- Renovated health care facility

- Polite staff with good reputation and skills

Quick access would mean:

- Max 30 min travelling to the health care facility

- Max 10 min waiting in front of the physician office

- Max 1 month waiting for a planned surgery

At the bottom of the card, you can also see possible fees intervals regarding physician's and hospital services. Higher fee would mean better quality and quicker access. Fees are fixed prices and are not necessarily dependent on the service costs, since a part of the costs are covered by public funds.

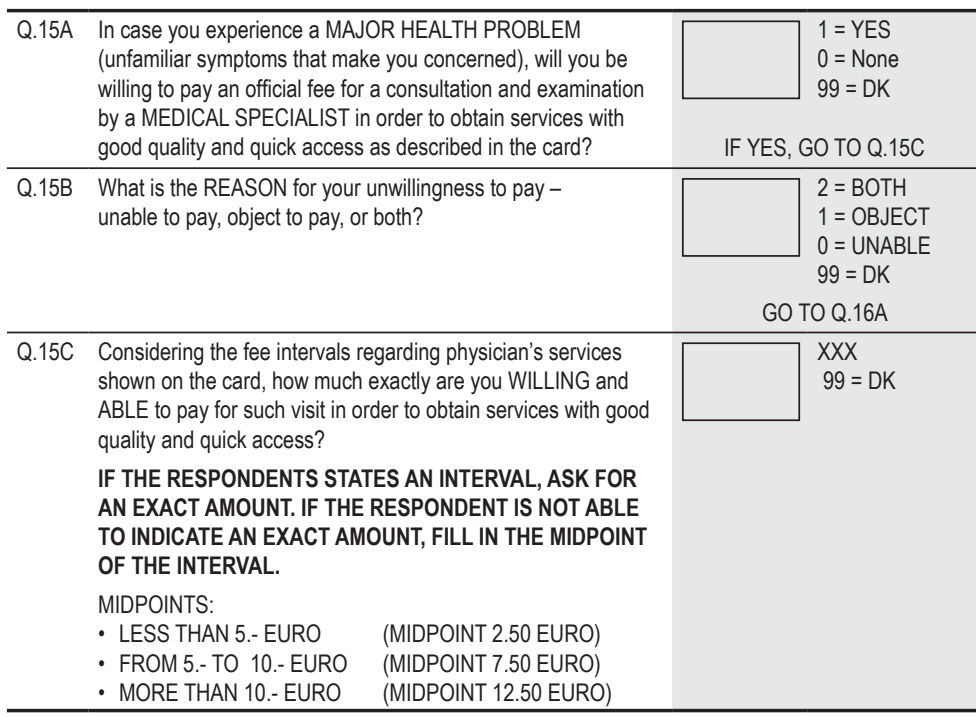

Q.16A In case you have to undergo a PLANNED SURGERY (for example, a 5-day hospitalisation and no life-threatening illness), will you be willing to pay an official fee for this HOSPITALISATION in order to obtain services with good quality and quick access as described in the card?

$1=$ YES
$0=$ None
$99=\mathrm{DK}$

IF YES, GO TO Q.16C

Q.16B What is the REASON for your unwillingness to pay - unable to pay, object to pay, or both?

\section{$2=\mathrm{BOTH}$}

$1=$ OBJECT

$99=\mathrm{DK}$

GO TO PART 9

Q.16C Considering the fee intervals regarding hospital services shown on the card, how much exactly are you WILLING and ABLE to pay for such hospitalisation (including all types of fees charged by the hospital) in order to obtain services with good quality and quick access?

IF THE RESPONDENT STATES AN INTERVAL, ASK FOR AN EXACT AMOUNT. IF THE RESPONDENT IS NOT ABLE TO INDICATE AN EXACT AMOUNT, FILL IN THE MIDPOINT OF THE INTERVAL.

MIDPOINTS

- LESS THAN 100 - EURO

- FROM 100 - TO 200.-EURO (MIDPOINT 150 EURO)

- MORE THAN 200.- EURO 


\section{PART 9: SOCIO-DEMOGRAPHIC CHARACTERISTICS}

Next questions concern your social and demographic characteristics. The information that is required will not be related to your identity. The data are only necessary in order to analyse the results of this survey in a statistical way.

\begin{tabular}{|c|c|c|c|c|}
\hline Q.17A & In which YEAR were you born? & 1 & 9 & \\
\hline Q.17B & $\begin{array}{l}\text { FILL IN THE RESPONDENT'S } \\
\text { GENDER. }\end{array}$ & & & $\begin{array}{l}1=\text { FEMALE } \\
0=\text { MALE }\end{array}$ \\
\hline Q.17C & $\begin{array}{l}\text { FILL IN THE TYPE OF } \\
\text { RESPONDENT'S RESIDENCE } \\
\text { PLACE. }\end{array}$ & & & $\begin{aligned} 4= & \text { THE CAPITAL } \\
3= & \text { CITY (MORE THAN 500,000 } \\
& \text { INHABITANTS) } \\
2= & \text { CITY }(200,000-500,000 \\
& \text { INHABITANTS) } \\
1= & \text { TOWN (UP TO 200,000 } \\
& \text { INHABITANTS) } \\
0= & \text { VILLAGE }\end{aligned}$ \\
\hline Q.17D & $\begin{array}{l}\text { SHOW CARD } 6 \text {. } \\
\text { What is the level of your current } \\
\text { EDUCATION or current study? }\end{array}$ & & & $\begin{aligned} 5= & \text { TERTIARY EDUCATION (ISCED 5+6) } \\
4= & \text { POST-SECONDARY NON-TERTIARY } \\
& \text { EDUCATION (ISCED 4) } \\
3= & \text { UPPER SECONDARY EDUCATION } \\
& (\text { ISCED } 3) \\
2= & \text { LOWER SECONDARY OR SECOND } \\
& \text { STAGE OF BASIC EDUCATION } \\
& (\text { ISCED } 2) \\
1= & \text { PRIMARY OR FIRST STAGE OF } \\
& \text { BASIC EDUCATION (ISCED 1) } \\
0= & \text { NOT COMPLETED PRIMARY } \\
& \text { EDUCATION (ISCED 0) }\end{aligned}$ \\
\hline Q.17E & $\begin{array}{l}\text { SHOW CARD } 7 . \\
\text { What is your primary OCCUPATION } \\
\text { (activities) at present? }\end{array}$ & & & $\begin{aligned} 8= & \text { STUDENT }(\text { IN EDUCATION) } \\
7= & \text { EMPLOYEE (IN PAID JOB) } \\
6= & \text { OWN/FAMILY PRIVATE BUSINESS } \\
& \text { (INCLUDING SELF-EMPLOYED) } \\
5= & \text { UNEMPLOYED (JOB-SEEKING) } \\
4= & \text { NOT EMPLOYED (NOT SEEKING } \\
& \text { FOR A JOB, INCL. HOUSEWIFE) } \\
3= & \text { PENSIONER (BECAUSE OF AGE) } \\
2= & \text { PENSIONER (BECAUSE OF } \\
& \text { ILLNESS) } \\
1= & \text { FARMER/AGRICULTURER } \\
0= & \text { SOLDIER }\end{aligned}$ \\
\hline
\end{tabular}

\section{Q.17F SHOW CARD 8.}

What is your MARITAL status at present?

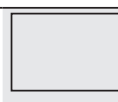

5 = NEVER MARRIED AND SINGLE

4 = LIVING WITH A PARTNER

WITHOUT MARRIAGE

$3=$ MARRIED (LIVING TOGETHER)

$2=$ MARRIED (LIVING SEPARATELY)

1 = DIVORCED AND SINGLE

AT PRESENT

$0=$ WIDOW/ERAND SINGLE

AT PRESENT

\section{Q.18A SHOW CARD 9.}

How do you perceive your present HEALTH status?

5 = PERFECT HEALTH

$4=$ VERY GOOD HEALTH

$3=$ GOOD HEALTH

$2=$ FAIR HEALTH

$1=$ BAD HEALTH

$0=$ VERY BAD HEALTH

During the last 12 months, did you need to

use medical services FREQUENTLY due to
chronic disease or a major health problem?

Have a physician told you that you have any of

the following health PROBLEMS?

Q.18C Diabetes (increased sugar in the blood)

Q.18D Chronic heart disease or high arterial blood pressure

Q.18E Chronic lung, liver or kidney disease

Q.18F Stroke

Q.18G Infarct

\section{$1=Y E S$}

$0=\mathrm{NO}$

Q.18H Other chronic or major health problems

Do you have COMPULSORY social health insurance paid either by you or others?

Q.19B Do you have supplementary VOLUNTARY health insurance (or voluntary health account) paid either by you or others?

\begin{tabular}{l}
\begin{tabular}{|l|l}
\hline 1 & $=$ YES \\
0 & $=$ NO \\
1 & $=$ YES \\
0 & $=$ NO \\
1 & $=$ YES \\
0 & $=$ NO \\
1 & $=$ YES \\
0 & $=$ NO \\
1 & $=$ YES \\
0 & $=$ NO \\
1 & $=$ YES \\
0 & $=$ NO \\
\hline 1 & $=$ YES \\
0 & $=$ NO \\
\hline 1 & $=$ YES \\
0 & $=$ NO \\
\hline &
\end{tabular} \\
\hline$\quad$
\end{tabular}




\section{Part 10: HOUSEHOLD CHARACTERISTICS AND HOUSEHOLD INCOME}

The last set of questions concerns your household. Household is one person or a group of persons sharing a flat/house and having a common budget or common expenditure.

FAMILY MEMBERS LIVING TOGETHER ARE ONE HOUSEHOLD ONLY IF THEY ALSO HAVE A COMMON BUDGET OR COMMON EXPENDITURE. FAMILY MEMBERS WHO DO NOT LIVE TOGETHER ARE NOT ONE HOUSEHOLD.

\begin{tabular}{|c|c|c|}
\hline$Q .20 \mathrm{~A}$ & $\begin{array}{l}\text { How many PERSONS are there in your } \\
\text { household (incl. you)? }\end{array}$ & PERSONS \\
\hline Q.20B & $\begin{array}{l}\text { How many CHILDREN under the age of } 18 \\
\text { are there in your household? }\end{array}$ & CHILDREN \\
\hline Q.20C & $\begin{array}{l}\text { At present, how many persons in your } \\
\text { household (incl. you) have a PAID WORK } \\
\text { or RECEIVE money (for example different } \\
\text { kinds of social support, money from renting } \\
\text { properties, etc)? }\end{array}$ & PERSONS \\
\hline Q.20D & $\begin{array}{l}\text { At present, how many persons in your } \\
\text { household (incl. you) have CHRONIC } \\
\text { DISEASES or major health problems? }\end{array}$ & PERSONS \\
\hline $\mathrm{Q} .21 \mathrm{~A}$ & $\begin{array}{l}\text { SHOW CARD } 10 . \\
\text { Please take a look at this card. } \\
\text { Could you tell me which of the following } \\
\text { categories corresponds to the NET } \\
\text { AVERAGE HOUSEHOLD INCOME per } \\
\text { month (i.e. after tax income) - considering } \\
\text { all household members and all sources } \\
\text { - wages, social welfare, pensions, rents, } \\
\text { fees, etc? }\end{array}$ & 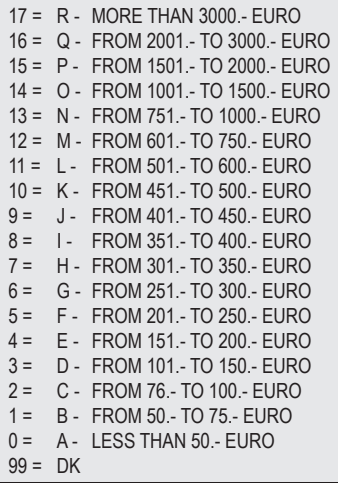 \\
\hline$Q .21 B$ & $\begin{array}{l}\text { SHOW CARD } 11 . \\
\text { Which of the following is TRUE regarding } \\
\text { your current household income? }\end{array}$ & $\begin{aligned} 4= & \text { ALLOWS TO BUILD SAVINGS } \\
3= & \text { ALLOWS TO SAVE JUST A LITTLE } \\
2= & \text { ONLY JUST MEETS THE EXPENSES } \\
1 & =\text { NOT SUFFICIENT } / \text { NEED TO USE } \\
& \text { SAVINGS } \\
0= & \text { NOT REALLY SUFFICIENT } / \\
& \text { NEED TO BORROW } \\
99= & \text { DK }\end{aligned}$ \\
\hline
\end{tabular}

The last question concerns your PERCEPTIONS about the net monthly household income that would allow managing appropriately your current day-to-day household needs.

\section{SHOW CARD 12.}

Which net monthly household income (i.e. after tax income) would you in YOUR CIRCUMSTANCES say to be: Very good? Good? Sufficient? Insufficient? Bad? Very bad?

INSTRUCTION: PLEASE TRY TO AVOID "DON'T KNOW".

\begin{tabular}{|c|c|c|}
\hline & & $\begin{array}{l}\text { FILL IN BELOW THE INCOME LEVELS STATED } \\
\text { BY THE RESPONDENT: }\end{array}$ \\
\hline Q.22A & $\begin{array}{l}\text { VERY GOOD } \\
\text { MONTHLY HOUSEHOLD INCOME }\end{array}$ & \begin{tabular}{|l|l}
$\mathrm{XXX}$ \\
$99=\mathrm{DK}$
\end{tabular} \\
\hline Q.22B & $\begin{array}{l}\text { GOOD } \\
\text { MONTHLY HOUSEHOLD INCOME }\end{array}$ & $\begin{array}{l}X X X \\
99=D K\end{array}$ \\
\hline Q.22C & $\begin{array}{l}\text { SUFFICIENT } \\
\text { MONTHLY HOUSEHOLD INCOME }\end{array}$ & $\begin{array}{l}X X X \\
99=D K\end{array}$ \\
\hline Q.22D & $\begin{array}{l}\text { INSUFFICIENT } \\
\text { MONTHLY HOUSEHOLD INCOME }\end{array}$ & $\begin{array}{l}X X X \\
99=D K\end{array}$ \\
\hline Q.22E & $\begin{array}{l}\text { BAD } \\
\text { MONTHLY HOUSEHOLD INCOME }\end{array}$ & $\begin{array}{l}X X X \\
99=D K\end{array}$ \\
\hline Q.22F & $\begin{array}{l}\text { VERY BAD } \\
\text { MONTHLY HOUSEHOLD INCOME }\end{array}$ & $\begin{array}{l}X X X \\
99=D K\end{array}$ \\
\hline
\end{tabular}

This is the end of the questionnaire.

Thank you for your participation

END TIME

(USE 24 HOURS CLOCK) 
Appendix C SOCIO-DEMOGRAPHIC CHARACTERISTICS OF THE SAMPLES 


\section{SOCIO-DEMOGRAPHIC CHARACTERISTICS OF THE SAMPLES}

\begin{tabular}{|c|c|c|c|c|}
\hline & & & 2010 & 2011 \\
\hline Age & Years & $\begin{array}{l}\text { Median } \\
\text { Mean } \\
(\text { SD) } \\
\text { Valid N }\end{array}$ & $\begin{array}{l}47.0 \\
47.6 \\
17.6 \\
1003\end{array}$ & $\begin{array}{l}51.0 \\
50.2 \\
16.9 \\
817\end{array}$ \\
\hline Gender & $\begin{array}{l}0=\text { male } \\
1=\text { female }\end{array}$ & $\begin{array}{l}\mathrm{N}(\%) \\
\mathrm{N}(\%)\end{array}$ & $\begin{array}{l}479(47.8 \%) \\
524(52.2 \%)\end{array}$ & $\begin{array}{l}350(42.8 \%) \\
467(57.2 \%)\end{array}$ \\
\hline Education & $\begin{array}{l}0=\text { basic } \\
1=\text { secondary } \\
2=\text { university }\end{array}$ & $\begin{array}{l}\mathrm{N}(\%) \\
\mathrm{N}(\%) \\
\mathrm{N}(\%)\end{array}$ & $\begin{array}{l}225(22.5 \%) \\
545(54.4 \%) \\
232(23.1 \%)\end{array}$ & $\begin{array}{l}207(25.3 \%) \\
434(53.1 \%) \\
176(21.6 \%)\end{array}$ \\
\hline Residence place & $\begin{array}{l}0=\text { village } \\
1=\text { town (up to } 200000) \\
2=\text { city }(200000 \text { or more) }\end{array}$ & $\begin{array}{l}\mathrm{N}(\%) \\
\mathrm{N}(\%) \\
\mathrm{N}(\%)\end{array}$ & $\begin{array}{l}287(28.6 \%) \\
451(45.0 \%) \\
265(26.4 \%)\end{array}$ & $\begin{array}{l}238(29.1 \%) \\
364(44.6 \%) \\
215(26.3 \%)\end{array}$ \\
\hline Self-reported health status & $\begin{array}{l}0=\text { bad health } \\
1=\text { fair health } \\
2=\text { good health }\end{array}$ & $\begin{array}{l}\mathrm{N}(\%) \\
\mathrm{N}(\%) \\
\mathrm{N}(\%)\end{array}$ & $\begin{array}{l}122(12.3 \%) \\
245(24.5 \%) \\
632(63.2 \%)\end{array}$ & $\begin{array}{l}102(12.5 \%) \\
218(26.7 \%) \\
496(60.8 \%)\end{array}$ \\
\hline Compulsory health insurance & $\begin{array}{l}0=\text { No } \\
1=\text { Yes }\end{array}$ & $\begin{array}{l}\mathrm{N}(\%) \\
\mathrm{N}(\%)\end{array}$ & $\begin{array}{l}126(12.6 \%) \\
875(87.4)\end{array}$ & $\begin{array}{c}76(9.3 \%) \\
741(90.7 \%)\end{array}$ \\
\hline Voluntary health insurance & $\begin{array}{l}0=\text { No } \\
1=\text { Yes }\end{array}$ & $\begin{array}{l}\mathrm{N}(\%) \\
\mathrm{N}(\%)\end{array}$ & $\begin{array}{l}854(86.2 \%) \\
137(13.8 \%)\end{array}$ & $\begin{array}{c}744(91.1 \%) \\
73(8.9 \%)\end{array}$ \\
\hline Persons in the household & Number of persons & $\begin{array}{l}\text { Median } \\
\text { Mean } \\
(\mathrm{SD})\end{array}$ & $\begin{array}{l}3.0 \\
3.0 \\
1.4\end{array}$ & $\begin{array}{l}3.0 \\
2.9 \\
1.4\end{array}$ \\
\hline $\begin{array}{l}\text { Chronically sick household } \\
\text { members }\end{array}$ & Number of persons & $\begin{array}{l}\text { Median } \\
\text { Mean } \\
(\mathrm{SD})\end{array}$ & $\begin{array}{l}1.0 \\
0.7 \\
0.8\end{array}$ & $\begin{array}{l}1.0 \\
0.8 \\
0.8\end{array}$ \\
\hline $\begin{array}{l}\text { Net monthly household income } \\
\text { per household member (BGN) } \\
1 \mathrm{BGN} \approx 0.5 \text { EUR }\end{array}$ & & & 325 & 325 \\
\hline
\end{tabular}


Appendix D

ENGLISH WORDING OF THE STAKEHOLDER QUESTIONNAIRE 


\section{STAKEHOLDER QUESTIONNAIRE}

Next questions concern your opinion about the current or future design of official patient payments in Bulgaria. There are no right or wrong answers. We are interested in your opinion.

\begin{tabular}{|c|c|c|}
\hline Q.1 & $\begin{array}{l}\text { If official patient payments exist, in your opinion, what should be the primary } p \\
\text { payments? Please, mark only one option. } \\
\text { - Discouraging unnecessary use of health care services } \\
\text { - Generating additional resources for the health care system } \\
\text { - Allowing hospitals/clinics to generate additional resources } \\
\text { - Increasing the income of individual health care providers } \\
\text { - Controlling the overall health care expenditure } \\
\text { - Dealing with informal patient payments } \\
\text { Other, please specify:.................................... }\end{array}$ & ctive of patient \\
\hline Q.2 & $\begin{array}{l}\text { If official patient payments exist, do you think that these payments should be } \\
\text { applied to the following services? } \\
\text { - primary care (GP services) } \\
\text { - services of outpatient specialist } \\
\text { - inpatient hospital services } \\
\text { - emergency room services }\end{array}$ & $\begin{array}{l}\text { Yes No } \\
\text { Yes No } \\
\text { Yes No } \\
\text { Yes No }\end{array}$ \\
\hline Q.3 & $\begin{array}{l}\text { If official patient payments exist, do you think that these payments should be } \\
\text { higher for more expensive health care services? }\end{array}$ & Yes No \\
\hline Q.4 & $\begin{array}{l}\text { If official patient payments exist, do you think that these payments should be } \\
\text { higher for health care services with better quality? }\end{array}$ & Yes No \\
\hline Q.6 & $\begin{array}{l}\text { If official patient payments exist and there is a limitation on patient payments } \\
\text { all patients, in your opinion, how should be this limitation defined? Please, ma } \\
\text { - Maximum total patient payments per patient per month/year } \\
\text { - Maximum number of services per patient per month/year, for which patient } p\end{array}$ & $\begin{array}{l}\text { th, which applies to } \\
\text { ne option. } \\
\text { are paid }\end{array}$ \\
\hline
\end{tabular}

Q.8 If official patient payments exist and there are exemptions or reduced fees for some population groups, in your opinion, which of the following groups should be exempted fully from patient payments or should pay only reduced fees?

- children

Yes No

- pensioners

Yes No

- people with low income

Yes No

- people with chronic diseases

Yes No

- pregnant women

Yes No

- disabled person

Yes No

Other, please specify:..

Q.9 If official patient payments exist, in your opinion, who should be the beneficiary of patient payments?

Please, mark only one option.

- The physician, who offers the service

- The health institution, where the service is offered

- The local authorities (the municipality)

- Local health insurance fund

- The state at a national level

- Social health insurance fund at a national level

Q.10 Do you agree with the following statement?

"Official patient payments should exist in Bulgaria"

Strongly agree

Agree

Neither agree nor disagree

Disagree

Strongly disagree 


\section{SUMMARY}




\section{Formal and informal patient payments for public health care service in Bulgaria}

\section{Summary}

During the past two decades of transition from a state-planned to a market economy, the Bulgarian health care sector experienced radical reforms. In particular, the development of a private health care sector was accompanied by the introduction of social health insurance in 2000, which brought about important changes in the organization and funding of the Bulgarian health care system. Among other issues, the reform included the introduction of formal patient charges for public health care services. These charges take the form of co-payments and apply to all levels of medical services, except emergency care. The official fee for each outpatient visit to a general practitioner (GP) and medical specialist (after a referral) is equal to $1 \%$ of the minimum monthly salary for the country. For hospitalization that fee amounts to $2 \%$ of the minimum monthly salary per day for the first 10 days of the hospital stay and it is paid once a year. Since these fees are defined as a percentage of the minimum monthly salary, their amount increases with the rise of the minimum monthly salary in the country. The formal co-payments are collected and retained by the providers and their official objective is to improve efficiency in public health care provision. However, these charges were implemented in a situation of informal patient payments (which continue to exist irrespective of the formal charges). Thus, the dissertation is focusing on the financial burden of formal and informal patient payments in the Bulgarian public health care sector.

The study is also inspired by previous research on out-of-pocket patient payments in Bulgaria conducted before and after the introduction of social health insurance (and the introduction of formal co-payments related to it). However, previous research appears limited in scope since it primarily analyses different aspects of informal payments in Bulgaria. Only in some exceptional cases, the potential of formal co-payments and their acceptability to the population are examined. None of the previous studies however, addresses the co-existence of formal and informal patient payments. Thus, in contrast to previous research, this dissertation offers an integrated analysis of both formal and informal patient payments, as well as of the attitudes of health care stakeholders towards these payments. Besides, the dissertation provides up-to-date evidence on out-of-pocket health care expenditures in Bulgaria, which gives an opportunity to make a comparison to earlier studies and to outline overall trends in formal and informal patient payments in Bulgaria. 
The dissertation also focuses on the stated willingness to pay for public health care services and on its comparison to actual out-of-pocket payments. The latter problem has not been addressed in previous studies in Bulgaria, and has received little attention in international research on the analysis of patient payment policies. Although stated-preference methods are broadly applied within the framework of cost-benefit analysis, they are relatively new (as opposed to revealed-preference methods, i.e. actual payment behavior) and their predictive validity is still uncertain. This diminishes their application in policy analysis. The comparison of stated-preference data with revealed-preference data offered in this dissertation is expected to contribute to the establishment of their validity.

Chapter 1 of this dissertation outlines the above research motivation as well as the scope of the study, its central aim and methodology. As specified in the chapter, the aim of this dissertation is to analyze the propensity, magnitude and affordability of formal and informal patient payments for public health care services in Bulgaria, as well as the attitudes of health care stakeholders towards these payments. Given the central aim, the following research questions are addressed: (1) what have been the main outcomes of the financial reforms in the Bulgarian public health care sector?; (2) what is the scale of out-of-pocket payments for public health care services in Bulgaria and to what extent are these payments affordable for Bulgarian patients?; (3) how widespread are informal patient payments in the Bulgarian public health care system and what are the public attitudes towards these payments?; (4) what are the views of health care stakeholders about the existence of official patient charges for public health care services?; (5) to what extent are Bulgarian consumers willing to pay official charges for public health care services and how does stated willingness to pay compare to actual payments?.

The study applies a complex methodology combining three research methods: systematic literature review (desk research), quantitative data analysis (survey method) and qualitative study (focus-groups discussions and semi-structured interviews). The first method (systematic literature review) is applied when addressing research question 1 to review the main directions of the financial reforms in Bulgaria, the trends in health care expenditure and evidence on the outcomes of the health insurance reform. The results of the application of this method provide a basis to analyze prior expectations and concerns in terms of the implementation of social health insurance reform.

The second method (quantitative data analysis) is used to address research questions 2, 3 and 5. The method uses data from representative national surveys of 1003 respondents who participated in 2010 and 817 respondents in 2011. The data 
are collected in face-to-face interviews at respondents' homes using a standardized questionnaire (with identical questions on health care use and expenditure in both years). The questionnaire is validated in discussions with external experts and pretested to decide on the amount of questions and to improve the wording of the questions. To draw the sample, a multi-stage random probability method was used: selecting the residence area (based on official statistics to assure representativeness), then selecting the household (random route method), and finally, selecting the individual respondents (last-birthday principle). The data collected in the survey allow for analyzing the propensity, magnitude and affordability of formal and informal patient payments for public health care services in Bulgaria, as well as consumer willingness to pay for public health care services. The attitudes of Bulgarian health care consumers towards informal patient payments are also studied using these survey data.

Related to research question 4, a qualitative study is carried out in Bulgaria in MayJune 2009. The qualitative study includes 12 focus group discussions: 6 groups with consumers and 6 groups with health care providers. These focus groups are supplemented with 10 in-depth interviews: 5 with policy-makers and 5 with health insurance representatives. The data collected in the focus-groups discussions and semi-structured interviews are analyzed to compare the opinion and attitudes of the different health care stakeholders toward formal patient payments.

Chapter 2 presents the results of the systematic literature review. The analysis suggests that the implementation of the social health insurance mechanism in Bulgaria helped to improve the transparency in the funding of the public health care sector through the introduction of earmarked social health insurance contributions. However, this did not help to achieve a more important objective, namely to generate additional financial resources for the public health care sector. Even though total health care expenditure has reached 7\% of GDP as a result of increased out-of-pocket payments in both the public and private health care sector, public expenditure on health care has remained one of the lowest in the EU in both relative and absolute terms (varying between $3.0 \%$ and $4.8 \%$ of GDP during the last years). Thus, no matter how funds are collected, if there is no economic growth in the country, the public health care budget cannot be increased significantly. Moreover, to establish the new health insurance body, a huge amount of financial resources was spent and high administrative costs were persuasive in the next year. At the same time, the basic social insurance package was continuously being reduced due to insufficient insurance funds. Also, there is a lack of efficient health care financing corresponding to patient preferences, and an effective system for collecting and managing the scare health care resources. Quality of health care provision and patient satisfaction 
with health care services are not well monitored. Most importantly however, the equity-related problems (such as geographical disparities) that characterized the health care provision in the past, have remained and numerous problems related to patient inability to pay have emerged.

In view of this, Chapter 3 presents empirical evidence on the scale of out-of-pocket payments for public health care services in Bulgaria as well as evidence on the affordability of these payments for Bulgarian patients. As suggested by the analysis, about $76 \%$ (2010) and $84.0 \%$ (2011) of outpatient service users report to have paid out-of-pocket, with $12.6 \%$ (2010) and 9.7\% (2011) of users reporting informal payments. Of those who used inpatient services, 66.5\% (2010) and 63.1\% (2011) report to have made out-of-pocket payments, with $32 \%$ (2010) and $18 \%$ (2011) reporting to have paid informally. Out-of-pocket payments differed considerably across socio-demographic groups. The results suggest a large inability to pay which is indicated by the need to borrow money and/or to forego services. In total, $32 \%$ of the sample report in 2010 foregoing physician visits due to high out-of-pocket payments. In 2011, this share is a bit lower (26\%) but still substantial. Regarding hospitalizations, about $6 \%$ of the sample in 2010 and $4 \%$ of the sample in 2011 reported foregoing such services. Also, in both years, about $6 \%$ of users borrowed money to pay for physician services and more than $10 \%$ of users borrowed money to pay for hospitalizations. Regression analysis shows that the inability to pay is especially pronounced among those with poor health status and chronic diseases, and those on low household income. Lack of transparency of the formal charges is also observed. Older people, women, those with higher levels of education, chronic illnesses, and poor self-reported health are better informed about the size of official user fees than other groups.

Chapter 4 presents empirical evidence on the scale of informal patient payments, as well as on public attitudes and perceived behavior related to these payments. The results confirm the existence of informal payments in the Bulgarian health care sector. In 2010, the average amount paid informally per year for outpatient visits is $92 \mathrm{BGN}$ (about $46 \mathrm{EUR}$ ). The average amount paid informally for inpatient services is nearly twice higher (198 BGN, about 100 EUR). Overall, gifts in kind appear to be more common and more tolerated by health care consumers than cash informal payments. Respondents who have ever paid informally in cash in health care facilities represented $19 \%$ of the sample in contrast to $44.4 \%$ of the sample who have ever personally given any gift in kind. In addition to this, more than $50 \%$ of the sample has negative attitudes towards both informal cash payments and gifts in kind but these attitudes are more negative in case of cash informal payments than in case of gifts in kind. In general, about $30 \%$ of the interviewed indicate a 
tolerance towards gifts in kind. Nevertheless, $78 \%$ of the sample state that they would not feel uncomfortable if they leave the physician's office without gratitude cash payment or gift in kind. About $54 \%$ of the respondents would refuse paying informally if a physician or medical staff asked them to make such payments and $52 \%$ would prefer to use private services to avoid paying informally. However, a group of respondents who express negative attitudes towards informal patient payments, reported making such payments (i.e. being pushed to pay informally). Informal payments exist despite the formal service charges, which questions the adequacy of patient payment policy in Bulgaria.

In Chapter 5, qualitative data on the opinions and attitudes of Bulgarian health care stakeholders (health care consumers, providers, insurers and policy makers) toward formal patient charges are analyzed. The analysis suggests that overall, health care providers, health insurance representatives and policy makers support the existence of official patient charges. The attitudes of consumers towards the existence of formal patient payments for health care services are divided. In particular, the groups of pensioners, working individuals, disable and chronically sick people are overall against formal patient payments. With regard to the primary policy objective of patient charges for health care services, the stakeholders' opinions suggest that these payments can contribute to both efficiency improvements in the health care sector and generation of additional financial resources for public health care provision. All stakeholder groups unanimously agree that official payments are not capable of replacing, even reducing, informal payments. Also, an overall consensus exists among the stakeholder groups that patient charges are most suitable in case of services of outpatient medical specialists and such charges should not be applied for emergency care. There is no unanimity among the groups with regard to who should be exempted partly or fully from patient charges. The opinions of the four groups are also divided with regard to who should be the beneficiary of patient charges. The group of health care providers indicates problems with the administration of formal services charges. There is a need of revising the current legislation on patient payments in Bulgaria and specifying its application in a more explicit manner.

To facilitate the development of an adequate patient payment policy in Bulgaria, Chapter 6 presents empirical evidence on the willingness of Bulgarian consumers to pay official charges for public health care services (stated-preference data). The stated willingness to pay is compared to actual out-of-pocket payment for health care. Three fourths of the outpatient care user report out-of-pocket payments (about $14 \mathrm{BGN} \approx 7$ EUR per visits). For inpatient care, out-of-pocket payments are reported by two-thirds of the inpatient care users (about 125 BGN $\approx 62$ EUR per 
hospitalization). Results on the consumer willingness to pay and the amount willing to pay for both physician visits and hospitalizations are very close to actual payments, especially when service users are included. Specifically, $75.8 \%$ of respondents state willingness to pay for a physician visits (average amount willing to pay of 18 BGN per visit) and $66.6 \%$ of respondents state willingness to pay a formal fee for a hospitalization (average amount willing to pay of 225 BGN per hospitalization). Results of binary regression show the importance of socio-demographic factors when comparing the probability of paying based on revealed-preference data and probability of being willing to pay using stated-preference data. The results on willingness to pay are however obtained based on the scenario that public health care services are provided with good quality and quick access (e.g. adequate availability of equipment and materials, provider's skills, facility maintenance and service delivery). Thus, improvements in health care provision in Bulgaria are required before the willingness to pay levels can be expected in reality.

The general discussion of the key findings of the dissertation is presented in Chapter 7. As the chapter outlines, social health insurance in Bulgaria brought about certain efficiency improvements in the public health care sector, but the system is still rather inefficient. Overall, the social benefit of the reform is less than expected. The main reasons for this are related to the ineffective organization of the Bulgarian public health care sector, as well as to the overall lack of financial resources for health care in the country. Our analysis raises a major concern about the deterioration of equity in the public health care sector after the introduction of social health insurance. Some fundamental equity principles (e.g. solidarity, equality, accessibility) are violated as a result of the insurance implementation. As shown by the empirical evidence in this dissertation, Bulgarian patients experience a high burden of out-of-pocket payments for health care. More than 30\% of those in need of health care services either borrow money or forego services due to payments. There are considerable inequities in accessing health care services especially for poorer part of the population. It is essential to revise the current system of exemptions taking into account the household income and health status of patients. Poor people and frequent health care users should be exempted from formal patient charges or should meet reduce charges. It is also essential to eradicate informal patient payments since these payments are outside any formal regulation. The results in this dissertation confirm the existence of substantial informal patient payments in Bulgaria even after 10 years of formal co-payments. This means that co-payments are unable to replace informal payments. The forms of payments co-exist at present increasing the financial burden to the patients. 
The eradication of informal patient payments will be a challenging policy task. As shown by this dissertation, Bulgarian consumers are in general negative towards informal cash payments and the majority agrees that informal payments should be eradicated. However, informal gifts in kind are still accepted by the public. Also, some patients pay informally despite their negative attitude toward such payments. Thus, apart from consumer attitudes, factors related to insufficient and inefficient funding of public health care services, as well as to weak governance in the Bulgarian health care sector should be also addressed when developing a strategy for dealing with informal patient payments. Although, Bulgarian consumer are willing to pay formal chargers if services are provided with good quality and quick access, the ability of these charges to eliminate informal payments is questionable. Moreover, there is a lack of consensus among Bulgarian health care stakeholders on what is an adequate patient payment mechanism. However, the stakeholders agree that a reform in this direction is needed.

The dissertation provides clear evidence on the affordability problems in the Bulgarian public health care sector. The burden of out-of-pocket payments experienced by the poor who are less likely to seek health care when needed and are more likely to report inability to pay as the reason for not obtaining treatment, should raise concern among policy makers. Financial barriers are the most important limiting factor in health care accessibility. The impact of out-of-pocket payments on access to health care is underlined by the high percentage of people who avoid visits or hospitalizations namely because of inability to pay. Moreover, patients are still weakly informed about the formal user charges for hospitals. Some of the suggested measures in this regard could be improving and updating the available information about official user fees and free-of-charge services as well as their accessibility to patients. A stronger regulatory framework, higher and regular salaries for health workers, more developed patient rights are also incentives for the improvement of the relations between health care stakeholders.

The legislation on patient payments in Bulgaria needs to be carefully revised. In order to sustain equitable additional financing, Bulgarian policy-makers need not only to maintain the current exemption mechanism but also to further discuss the limitations of outpatient services, especially if informal payments continue to exist. Stated-preference data used in this survey could be an appropriate instruments for policy-makers to help them to analyze the changes in demand when the service prices (i.e. the size of patient charges) change, before actually implementing the price changes. 
Bulgarians are very sensitive about the subject of corruption in health care and the Bulgarian government considers the two concepts of "corruption" and "health care" as mutually incompatible. Informal payments have compromised the health care sector and it is placed in the leading triad of corruption occurrence. Future strategies against informal payments should ensure creation of a simple and easily accessible system for filing complaints by patients that are asked to pay informally for health care services. This calls for strengthening control and accountability in the health care sector and creating a system of penalties against those who receive/ request informal payments.

The results presented in this dissertation can be of interest for other countries as well. In particular, Bulgaria is no exception from the overall trends in Europe related to the continuously growing rates of private expenditure on health care. These facts are confirmed by our study and strengthen the relevance of the research results presented in this dissertation. Moreover, the inability to pay for health care, reported in this dissertation could be a warning for policy makers in other European countries to analyze in advance the potential effect of patient charges before their introduction or amendment. Moreover, the Bulgarian experience shows that even 10 years after the introduction the official payments, informal payments can continue to exist if no additional policy measure are taken. 


\section{Формални и неформални потребителски плащания за публични здравни услуги в България}

\section{Резюме}

През последните двадесет години на преход от централизирана планова към пазарна икономика българската здравна система претърпява съществени реформи. Едновременно с развитието на частния сектор в здравеопазването се въвежда и система на социално здравно осигуряване, която води до значителни промени в организацията и финансирането на българската здравна система. Освен всичко друго, реформата включва и въвеждане на официални потребителски такси за публичните здравни услуги. Тези такси приемат формата на съвместни плащания и се прилагат на всички нива за медицинските услуги с изключение на спешната помощ. Потребителските такси се събират и оползотворяват от доставчиците на здравни услуги и се въвеждат с цел подобряване на ефективността в предоставянето на публични здравни услуги. Те обаче са въведени успоредно със съществуващите неформални плащания. Във връзка с това дисертацията се фокусира върху финасовата тежест на формалните и неформалните потребителски плащания в публичния здравен сектор на България.

Настоящото изследване също така е предпоставено от проучвания върху директните плащания от пациента, проведени преди и след въвеждането на социалното здравно осигуряване в България. Тези проучвания обаче са ограничени в своя обхват, тъй като преди всичко анализират отделни аспекти на неформалните плащания. Само в някои случаи се изследва потенциалът на съвместните плащания и това, дали те са приемливи за населението. Нито едно от по-ранните проучвания не разглежда съвместното съществуване на формални и неформални потребителски плащания. За разлика от съществуващите изследвания настоящата дисертация предлага интегриран анализ на двата вида плащания, както и анализ на нагласите на различните участници в здравната система към тези плащания. Освен това дисертацията предоставя нови данни за разходите за директни плащания от пациента, което дава възможност да се правят сравнения с по-ранни проучвания и да се очертаят тенденциите при двата вида плащания.

Дисертацията също изследва заявената готовност за плащане от потребителите за публични здравни услуги, като я сравнява с действително направените от тях директни плащания. Последният проблем не е обхванат 
в предходни изследвания в България и не е получил достатъчно внимание в чуждестранните литературни източници. Въпреки че методите за заявените предпочитания (stated-preference methods) ce прилагат широко в рамките на анализа "разход-полза", те са относително нови за разлика от методите на изявените предпочитания (revealed-preference methods), т.e. реалното потребителско поведение, но тяхната прогностична валидност все още е неясна. Това намалява тяхното приложение в политическите анализи. Можем да предположим, че сравнението на данните от заявените предпочитания с данните от изявените предпочитания, представени в тази дисертация, ще допринесе за установяване на тяхната валидност.

Глава 1 от дисертацията представя мотивацията за изследването, както и обхвата на проучването, неговата цел и методология. Целта на дисертацията е да се анализират склонността към плащане, размерът и достъпността на формалните и неформалните плащания за пациентите, както и нагласите на различните участници в здравната система към тези плащания. С оглед на основната цел са поставени следните изследователски въпроси: (1) какви са основните резултати на финансовите реформи в българското обществено здравеопазване; (2) какъв е размерът на директните плащания за публични здравни услуги в България и до каква степен тези плащания са достъпни за българския пациент; (3) колко широко разпространени са неформалните плащания на пациентите в системата на българското обществено здравеопазване и какви са обществените нагласи към тези плащания; (4) какви са мненията на различните участници в здравеопазването относно съществуването на официални потребителски такси за публични здравни услуги; (5) до каква степен българските потребители са готови да плащат потребителски такси за публични здравни услуги и как заявеното желание за плащане е сравнимо с действителните плащания.

Проучването използва комплексна методология, като комбинира три изследователски метода: систематичен обзор на литературата, количествен анализ на данни и качествено изследване (дискусии във фокусни групи и полуструктурирани интервюта). Първият метод (систематичният литературен обзор) е приложен към първия изследователски въпрос, при прегледа на основните резултати от реформата във финансирането на здравеопазването, тенденциите в разходите за здравеопазване и доказателствата за резултатите от проведената реформа. Резултатите от прилагането на този метод дават основание да се анализират предварителните очаквания и опасения относно изпълнението на здравноосигурителната реформа. 
Вторият метод (количественият анализ на данни) е използван за адресиране на втори, трети и пети изследователски въпрос. Използвани са данни от представително национално проучване сред 1003 респонденти, участвали през 2010 г., и 817 респонденти, участвали през 2011 г. Данните са събрани чрез персонално интервю в дома на респондента, като е използван стандартизиран въпросник (идентични въпроси за използваемостта на здравните услуги и разходите за тях в двете години). Въпросникът е утвърден в дискусия с външни експерти и предварително тестван, за да се определи количеството на въпросите и тяхната по-добра формулировка. За определяне на извадката е приложен многоетапен метод: избиране на населено място (на базата на официални статистически данни, за да се гарантира представителност), след това избиране на домакинство (случаен метод) и накрая избиране на респондент (принцип на последния рожден ден).

Качествено изследване, проведено в България през май-юни 2009 г., предоставя данни за четвъртия изследователски въпрос. Проучването включва 12 фокусни групи: 6 групи с потребители и 6 групи с доставчици на здравни услуги. Тези групи са допълнени с 10 дълбочинни интервюта: 5 с политици и 5 с представители на здравното осигуряване. Данните, събрани чрез дискусии във фокусни групи и полуструктурирани интервюта, са анализирани, за да се сравнят мненията и нагласите на различните участници в здравната система по отношение на формалните потребителски такси.

Глава 2 представя резултати от систематичния литературен обзор. Анализът показва, че прилагането на социално здравноосигурителния механизъм в България спомага за подобряване на прозрачността във финансирането на сектора на общественото здравеопазване чрез въвеждане на целеви здравноосигурителни вноски. Това обаче не допринася за постигане на поважната цел, а именно - генериране на допълнителни финансови ресурси за публичния здравен сектор. Въпреки че в резултат на нарасналите директни плащания както в публичния, така и в частния сектор общите разходи за здравеопазване достигат 7\% от БВП, публичните разходи за здравеопазване остават едни от най-ниските в ЕС (варират между 3.0\% и 4.8\% от БВП през последните години). Следователно, без оглед на източника, при липса на икономически растеж в страната бюджетьт на публичното здравеопазване не може да нарасне значително. В допълнение, създаването на новата здравно осигурителна организация е свързано със значителни финансови средства, като административните разходи остават високи и в последващите години. В същото време основният осигурителен пакет непрекъснато се редуцира поради недостатъчни средства. Липсва и ефективно финансиране на здравеопазване- 
то, съответстващо на потребителските предпочитания, както и ефективна система за събиране и управление на ограничените ресурси в здравеопазването. Качеството на предоставеното здравно обслужване и удовлетвореността на пациентите от здравни услуги не са добре наблюдавани. Най-важното обаче е, че успоредно със съществуващите проблеми, касаещи справедливостта (като географски различия), характеризирали предоставянето на здравни услуги в миналото, се появяват и редица нови проблеми, свързани с неспособността на пациента да плаща.

С оглед на това, глава 3 представя емпирични доказателства за размера на директните плащания за публични здравни услуги в България, както и доказателства за достъпността на тези плащания за българските пациенти. Анализът показва, че около 76\% (2010 г.) и 84.0\% (2011 г.) от потребителите на извънболнична помощ заявяват, че са правили директни плащания, като 12.6\% (2010 г.) и 9.7\% (2011 г.) от използвалите услугите са плащали неформално. От тези, които са използвали болнични услуги, 66.5\% (2010 г.) и 63.1\% (2011 г.) заявяват, че са правили директни плащания, като 32\% (2010 г.) и 18\% (2011 г.) са плащали неформално. Директните плащания се различават значително в различните социално-демографски групи. Резултатите показват голяма неспособност за плащане, която налага вземане на пари на заем и/или въздържане от услуга. Като цяло 32\% от извадката през 2010 г. отбелязват въздържане от посещение на лекар поради високите директни плащания. През 2011 г., този дял е малко по-нисък (26\%), но все още значителен. По отношение на хоспитализациите около 6\% от извадката през 2010 г. и 4\% от извадката през 2011 г. посочват въздържане от този вид услуга. През двете години около 6\% от ползвалите услугите вземат пари на заем, за да платят на лекар от извънболничната помощ, и повече от 10\% от потребителите вземат пари на заем, за да платят за хоспитализация. Регресионният анализ показва, че неспособността за плащане е особено изразена сред потребителите с лош здравен статус и хронични заболявания, както и сред тези с ниски доходи. Наблюдава се и липса на прозрачност относно формалните плащания. Възрастните хора, жените, лицата с по-високо ниво на образование, хронично болните и лицата, които определят здравословното си състояние като лошо, са по-добре информирани за размера на официалните потребителски такси в сравнение с останалите групи.

Глава 4 представя емпирични доказателства за размера на неформалните плащания на пациентите, както и за обществените нагласи и заявеното очаквано поведение относно тези плащания. Резултатите потвърждават съществуването на неформални плащания в българския здравен сектор. 
През 2010 г. средната сума, платена неформално на година за посещения в извънболничната помощ, е 92 лв. (около 46 евро). В същото време средната сума, платена неформално за болнични услуги, е почти два пъти по-висока (198 лв., около 100 евро). Като цяло, подаръци в натура се правят по-често и са по-толерирани от потребителите, отколкото неформалните плащания в брой. Респондентите, които някога са плащали неформално в брой в лечебни заведения, представляват 19\% от извадката, за разлика от 44.4\% от извадката, които някога лично са давали подарък в натура. В допълнение на това повече от 50\% от извадката имат негативни нагласи към двата вида неформални плащания (в брой и в натура), но тези нагласи са по-негативни в случай на неформални плащания в брой, отколкото в случай на подаръци в натура. Около 30\% от интервюираните изразяват толерантно отношение към подаръците в натура. Въпреки това, 78\% от извадката заявяват, че те не биха се чувствали неудобно, ако напуснат лекарския кабинет, без да плащат в брой от благодарност или да дадат подарък. Около 54\% от респондентите биха отказали да платят неформално, ако лекар или медицински персонал ги накара да направят такива плащания, и $52 \%$ биха предпочели да използват частни услуги, за да избегнат неформални плащания. Обаче група от респонденти, които изразяват негативни нагласи към неформалните плащания, посочват, че са правили такива плащания (били са принудени да платят неформално). Неформалните плащания съществуват въпреки формалните потребителски такси, което поставя под въпрос адекватността на политиката за плащанията на пациентите в България.

В глава 5 са анализирани данни от качествено проучване относно мненията и нагласите на българските участници в здравната система (потребители, доставчици на здравни услуги, осигурители и политици) към формалните потребителски такси. Анализът показва, че доставчиците на здравни услуги, представителите на здравното осигуряване и политиците подкрепят съществуването на формални потребителски такси. Нагласите на потребителите обаче са разделени. По-специално групите на пенсионерите, работещите лица, инвалидите и хронично болните са като цяло против формалните такси. По отношение на основната политическа цел при въвеждане на потребителските такси за здравни услуги становищата на заинтересованите страни показват, че тези плащания могат да допринесат както за подобряване на ефективността в здравния сектор, така и за генериране на допълнителни финансови ресурси за предоставяне на здравни услуги. Всички участници в здравната система са единодушни, че формалните потребителски такси не са в състояние да заменят и дори да намалят неформалните плащания. Също 
така съществува консенсус, че потребителските такси са по-подходящи за услуги от извънболничната специализирана помощ и не следва да се прилагат за спешната помощ. Не съществува единодушие сред групите за това кой би трябвало да бъде частично или напълно освободен от потребителска такса. Мненията на четирите групи също са разделени по отношение на това кой следва да се възползва от таксите. Групата на доставчиците на здравни услуги посочва като проблем администрирането на формалните такси. Налице е необходимост от преразглеждане на действащото законодателство, касаещо потребителските такси в България, и установяване на прилагането му по един по-ясен начин.

За подпомагане развитието на адекватна политика за плащанията на пациентите в България глава 6 представя емпирични доказателства за готовността на потребителите да плащат официални такси за публични здравни услуги. Заявената готовност за плащане е сравнена с действително направените директни плащания за здравни услуги. Три четвърти от ползвалите извънболнични услуги посочват направени директни плащания около 14 лв. Директните плащания за болнични услуги, посочени от две трети от ползвалите тези услуги, са около 125 лв. Резултатите за готовността на потребителите да плащат и сумата, която са готови да платят за лекарските посещения и хоспитализациите, са много близки до действително направените плащания, особено когато са включени ползвателите на услугата. Поконкретно 75.8\% от респондентите заявяват готовност да плащат за посещение при лекар (средна сума около 18 лв. за посещение) и 66.6\% от респондентите заявяват готовност да плащат формални такси за хоспитализация (средна сума 225 лв. за хоспитализация). Резултатите от регресионния анализ показват значението на социално-демографските фактори при сравняване на вероятността за плащане на базата на данни от разкритите предпочитания и вероятността за готовност за плащане на базата на данни от заявените предпочитания. Резултатите за готовността за плащане обаче са получени въз основа на сценарий, че публичните здравни услуги са предоставени с добро качество и бърз достъп (т. е. достатъчна наличност на оборудване и материали, квалифицирани доставчици, поддържани съоръжения и навременни услуги). Следователно, необходимо е подобряване на предоставяните здравни услуги в България, преди да се изяви действителната готовност за плащане.

Глава 7 съдържа обща дискусия на основните резултати от дисертацията. Обръща се внимание на това, че социалното здравно осигуряване в България е довело до известни подобрения в ефективността в публичния здравен сектор, но системата все още е доста неефективна. Като цяло, социалната 
полза от реформата е по-малка от очакваната. Основните причини за това са свързани с неефективната организация на българския публичен здравен сектор, както и липсата на финансови ресурси за здравеопазването в страната. Анализът показва значително влошаване на справедливостта в публичния здравен сектор след въвеждането на социалното здравно осигуряване, което е сериозен проблем. Някои фундаментални принципи (т.е. солидарност, равенство, достьпност) са нарушени като резултат от въвеждането на осигуряването. Както показват представените в дисертацията емпирични резултати, българският пациент понася тежко бреме от директни плащания за здравни услуги. Повече от 30\% от тези, които имат нужда от здравни услуги, вземат пари на заем или пропускат услуги поради неспособност да плащат. Има значителни неравенства в достъпа до здравни услуги, особено за по-бедната част от населението. От съществено значение е да се преразгледа настоящата система на освободените от такси лица, като се вземат предвид доходът на домакинствата и здравният статус на пациентите. Бедните лица и тези, които често ползват здравни услуги, би трябвало да бъдат освободени от формални потребителски такси или таксите за тях трябва да бъдат намалени. Премахването на неформалните плащания също е от съществено значение, тъй като тези плащания са извън всякаква регулация. Резултатите от настоящата дисертация потвърждават наличието на неформални плащания дори десет години след въвеждането на формални съвместни плащания. Това означава, че съвместните плащания не са в състояние да заменят неформалните плащания. Понастоящем формалните и неформалните плащания съществуват едновременно и увеличават финансовото бреме за пациента.

Премахването на неформалните плащания е предизвикателство за политиците. Както показва настоящата дисертация, българските потребители са с негативни нагласи към неформалните плащания в брой и повечето са съгласни, че тези плащания трябва да бъдат изкоренени. Въпреки това, неформални подаръци в натура продължават да се приемат от обществеността. Някои пациенти плащат неформално въпреки негативните си нагласи към подобни плащания. При разработването на стратегия по отношение на неформалните плащания, освен потребителските нагласи, трябва да се вземат под внимание и факторите, свързани с недостатъчното и неефективно финансиране на публичните здравни услуги, както и незадоволителното управление на българското здравеопазване. Въпреки че българските потребители са готови да платят формални такси, ако услугите са предоставени с добро качество и бърз достъп, способността на тези такси да елиминират неформалните плащания е под въпрос. Нещо повече - сред различните участници в здравната система 
няма консенсус за това, какъв е адекватният механизъм за плащанията на пациентите. Всички участници обаче са съгласни, че е необходима реформа в тази посока.

Настоящата десертация предоставя ясни доказателства за съществуващи проблеми с достъпността до публичния здравен сектор. Тежестта на директните плащания, понасяна от бедните, които по-рядко търсят здравни услуги при нужда и по-често посочват неспособността за плащане като причина за пропускане на лечение, трябва да породи безпокойство у политиците. Финансовите бариери са най-важният фактор при ограничаване на достъпността до здравеопазването. Влиянието на директните плащания върху достъпа до здравни услуги е подчертано от високия процент на хората, които се въздържат от посещение при лекар или хоспитализация именно поради неспособност за плащане. Освен това пациентите са все още слабо информирани за формалните потребителски такси при постъпване в болница. Някои от предложените мерки в това отношение могат да бъдат подобряване и актуализиране на наличната информация за официалните потребителски такси и услугите, освободени от такси, както и осигуряване на достъпност на информацията за пациентите. По-строга регулаторна рамка, по-високи и редовни заплати за здравните работници, по-развити права на пациентите са също стимули за подобряване на отношенията между заинтересованите страни в здравеопазването.

Законодателството за плащанията на пациентите в България трябва да бъде внимателно преразгледано. За да се запази справедливото допълнително финансиране, е нужно не само да се поддържа съществуващият механизъм на освободени от такси лица, но също така да се обсъдят ограничения за извънболничните услуги, особено ако неформалните плащания продължават да съществуват. Данните от заявените предпочитания, използвани в това проучване, могат да бъдат подходящ инструмент за политиците, който да им помогне при анализиране на изменения в търсенето при промяна на цените на услугите, преди действителното им въвеждане.

Българските граждани са много чувствителни към темата за корупцията в здравеопазването и за българското правителство понятия - “корупция” и “здравеопазване” - са взаимно несъвместими. Неформалните плащания компрометират здравния сектор и го поставят във водещата тройка на секторите с разпространение на корупция. Бъдещите стратегии срещу неформалните плащания следва да осигурят създаването на проста и лесно достъпна система за подаване на жалби от пациенти, от които е неофициално 
поискано да платят за здравни услуги. Това налага засилване на контрола и отчетността в сектора на здравеопазването и създаване на система от санкции срещу тези, които получават/искат неформални плащания.

Резултатите, представени в настоящата дисертация, могат да бъдат от интерес и за други страни. България не е изключение от общите тенденции в Европа на постоянно нарастващи частни разходи за здраве. Това се потвърждава и от нашето проучване, което засилва актуалността на получените резултати. Неспособността за плащане за здравни услуги, която се отчита и изследва в настоящата дисертация, може да бъде предупреждение за политиците в други европейски страни да анализират предварително потенциалните ефекти от потребителските такси преди тяхното въвеждане или изменение. Българският опит показва, че дори десет години след въвеждането на формални потребителски плащания неформалните плащания могат да продължат да съществуват, ако не се вземат допълнителни политически мерки. 


\section{THANK YOU WORDS}

I am not superstitious but I definitely believe in destiny. I graduated from a modern and perspective specialty Healthcare Management created and developed in collaboration with Maastricht University. The beginning was difficult for all - the university, lecturers and students. However, I am among the lucky ones because right after my graduation, I got the opportunity to work at Medical University of Varna as Assistant Professor and to be involved in training courses and projects. In one of these projects, a joint project between Maastricht University and Medical University of Varna, I met my future supervisors - Prof. Dr. Wim Groot and Dr. Milena Pavlova. During one of meetings, Wim wrote an exemplary plan of the $\mathrm{PhD}$ thesis but the topic was completely different. The topic eventually changed but the satisfaction of carrying out a PhD study at Maastricht University remained.

At present, I wish to express my enormous gratitude to Wim and Milena for believing in me and giving me the chance to be part of the research team in the ASSPRO CEE 2007 project. Dear Wim, I am impressed with your biography and experience that strengthen my respect and admiration. The meetings with you brought about relief that we are on the right track. In moments of hesitation you asked questions that helped to guide the process. Working with you is a pleasure and honor. Thank you for your beneficial advices and comments. Dear Milena, as our fantastic and excellent project coordinator, I would like to thank you for the additional opportunity given in the project, in particular training the junior researchers with possibility to obtain doctoral degree. I am very grateful for your tireless and dedicated work, for your immeasurable help, friendship and guidance. Your supervision was a guarantee for deeper analyses and successful publication of the articles.

I would like to thank my co-supervisor Associate Professor Emanuela Moutafova for a fair and transparent manner in which I joined the project ASSSPRO CEE 2007 and became $\mathrm{PhD}$ candidate. Dear Emanuela, I truly appreciate your support and efforts not only during the research but also in the various challenges that I met in my work and life. Owing to you, I became familiar with research and organizational tasks, and I certainly benefited from this opportunity. I am also very grateful to Prof. Dr. Todorka Kostadinova, Vice Rector of Medical University of Varna and my co-author in joint research. Dear Dora, thank you for your support and assistance, and for helping me with the focus group discussions and in-depth interviews during the ASSPRO CEE 2007 project. I appreciate your involvement as my fourth supervisor. 
Dear supervisors, it was a privilege to write this dissertation under your perfect guidance. Thank you for the new knowledge and expertise you provided me with.

The positive externalities of preparing this dissertation are the meetings and friendships with people from different countries. I would like to thank all colleagues from the ASSPRO CEE 2007 project team. My special thanks go to all junior researchers: Jelena, Tania, Marzena, Petra, Andriy, Vladimir, Sonila and Reza, and also Param, Anil and Florian. Dear friends, without you, the life and work in Maastricht would not have been such enjoyable, dynamic and careless. Each of you has contributed to the enrichment of my world.

I would also like to thank all my colleagues from the Department of Health Economics and Managment. It is a great honor for me working with you in one of the best teams in the university. I am grateful to you for involving me in other research projects and for the calm atmosphere in which I could do my research. I am thankful for the great support of Prof. Dr. Stefka Koeva who always follows my progress.

I cannot miss the opportunity to thank my co-author Dr. Bernd Rechel. Dear Bernd, I am thankful for your excellent and precise collaboration. I cannot forget your immediate replies with constructive and useful comments!

I would like to thank the assessment committee for reviewing this dissertation and for their positive evaluation. Further, I would like to acknowledge the European Commission for the funding. Without their financial support this PhD study would not have been possible. I am also grateful to the administration at both universities for facilitating the project. Suus Koene, Brigitte Caenen and Arnold van Alphen thank you for your kind help, I really appreciate it.

My deepest gratitude also goes to my parents, my husband, my brother and my friends who always looked after me in the most difficult period in my career. I love you very much! 


\section{CURRICULUM VITAE}

Elka Atanasova was born on 11 May 1974 in Lovech, Bulgaria. After graduating from High School in Humanities in 1992 in Varna, she started in 1993 her studies in health care management at the Medical University of Varna. After defending her master thesis, in 1998, she obtained a Master's degree. In January 1999, she was employed as manager of postgraduate education for physicians at Medical University of Varna. In May 1999, she passed successfully a state exam in economics and started to work as Assistant Professor in Economics and Health Economics at the Department of Health Care Management at the same university. Her teaching includes microeconomics, health economics, economics, organization and financing of healthcare establishments, pharmacoeconomics. Since 2003, she also holds the diploma Acknowledged Specialty in Health Economics from the Medical University of Varna. Currently, she is Chief Assistant Professor of Economics and Health Economics at the Department of Health Economics and Management, Medical University of Varna.

In 2008, Elka joined the project ASSPRO CEE 2007, funded by the European Commission under the Seventh Framework program, and coordinated by the Maastricht University. Within the frame of that project, she worked as $\mathrm{PhD}$ researcher and prepared her $\mathrm{PhD}$ thesis on out-of-pocket payments in Bulgaria at the Department of Health Services Research, Maastricht University.

She has published over 30 research and policy papers, and participated in several international projects, research seminars and conferences. She is co-author of the latest country profile "Bulgaria: health system review" published by the World Health Organization 2012, on behalf of the European Observatory on Health Systems and Policies. In 2013, she was rapporteur for Bulgaria for the Study on Corruption in the Healthcare sector, commissioned by the European Commission. 


\section{LIST OF PUBLICATIONS}

\section{Articles in English (peer-reviewed journals)}

Atanasova E, Pavlova M, Moutafova E, Kostadinova T, Groot W. (2013). Patient charges for health services: the opinions of healthcare stakeholders in Bulgaria. The International Journal of Health Planning and Management DOI:10.1002/ hpm.2229

Atanasova E, Pavlova M, Moutafova E, Rechel B, Groot W. (2013). Informal payments for health services: the experience of Bulgaria after 10 years of formal copayments. European Journal of Public Health DOI:10.1093/eurpub/ckt165

Atanasova E, Pavlova M, Moutafova E, Rechel B, Groot W. (2013). Out-of-pocket payments for health care services in Bulgaria: financial burden and barrier to access. European Journal of Public Health, 23(6): 916-922

Atanasova E, Pavlova M, Moutafova E, Kostadinova T, Groot W. (2012). Patient payments and the empirical analysis of consumer demand for hospital services: an application for Bulgaria. Society and Economy 34(2): 313-338.

Atanasova E, Pavlova M, Velickovski R, Nikov B, Moutafova E, Groot W. (2011). What have 10 years of health insurance reforms brought about in Bulgaria? Reappraising the Health Insurance Act of 1998. Health Policy, 102 (2-3): 263- 269. 

